\title{
A Grounded Theory of Preneurial Agency in Information Technology Creation
}

\author{
By
}

Anthony Mark Thistoll

A thesis submitted to Victoria University of Wellington in fulfilment of the requirements for the degree of

Doctor of Philosophy in Information Systems

Victoria University of Wellington

2011 


\begin{abstract}
The purpose of this study was to examine how entrepreneurs act to bring an Information Technology-based innovation into being. Successful realisation of such innovations requires collective effort, involving resources and actors both internal and external to the entrepreneur's own venture (Van de Ven, 1993a, 2005; Lavie, 2006). The study is qualitative in nature and uses the Glaserian variant of the grounded theory method to collect and analyse data obtained from interviewing entrepreneurs, intrapreneurs, and collective agents involved in creating IT innovation. Through undertaking open, selective, and theoretical coding and the process of constant comparative analysis, the research produces a substantive theory for explaining: A Grounded Theory of Preneurial Agency in IT Creation.
\end{abstract}

The Grounded Theory of Preneurial Agency in IT Creation accounts for the actions of both entrepreneurs and intrapreneurs who are jointly called "preneurs" within this study, and their interaction with collective agents to create IT innovation. The process of preneurial agency, the actions the preneur undertakes to create the innovative idea and make it a tangible reality, is shown as a triality involving the combined agency of the preneur and collective agents interacting within social structures established by the preneur. To support this abstracted view of entrepreneurship, the study develops and defines a family of terms to describe the process of preneurship, the preneur, preneurial agency, and the preneurial $b a$ within which the actors interact to create IT-based innovation.

The value of the research lies in its view of the preneur's process of transition from entrepreneur to intrapreneur and to institutional actor; and how the actions of both the entrepreneur and intrapreneur to create IT innovation can be shown in an abstracted process of preneurial agency. It is expected that through the application of a specific set of actions, presented in The Grounded Theory of Preneurial Agency in IT Creation as six theoretical propositions, practitioners will be better able to inform their practice, and enhance the self management of their preneurial agency and interaction with collective agents. 


\section{ACKNOWLEDGEMENTS}

I dedicate this thesis to the memory of my late father, Raymond George Thistoll. He was encouraging from the start, but sadly he is not here at the end.

Like the story told within the thesis, the creation of this $\mathrm{PhD}$ thesis is the work of collective agency. While it was my journey, there were a number of people I interacted with along the way and without their assistance I would not have been able to create this thesis. I would like to thank those people and organisations who have provided me with the support, guidance and assistance needed to complete this journey.

- The Victoria University of Wellington for awarding me a PhD Scholarship and providing funding for my research. It is a privilege only a few get to enjoy and it made it possible for me to fulfil one of my life's ambitions.

- My guides who supported me and showed me the way, my chief supervisor Dr Val Hooper who was always able to see the gaps in my logic and my co-supervisor Professor Pak Yoong who ensured I stayed true to the method.

- To Associate Professor David Pauleen, who gave me the encouragement and opportunity to begin my $\mathrm{PhD}$.

- Special thanks to my wife Sonia for her support and understanding and for sharing the inevitable sacrifices and challenges.

- To Laura for editing my work and Jo for assisting with transcribing interviews.

- Finally, to my interviewees as it is their story that is told here, and without their openness and honesty the findings of this research would not be what they are. 


\section{Table of Contents}

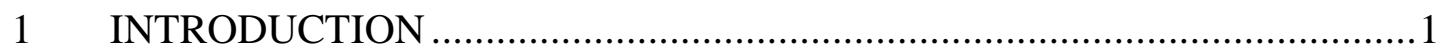

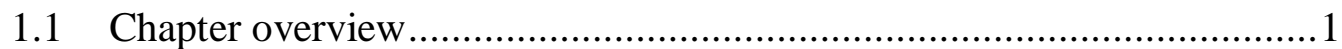

1.2 Research problem and motivation ...............................................2

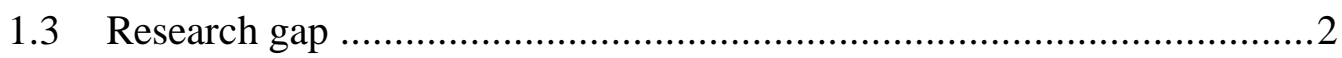

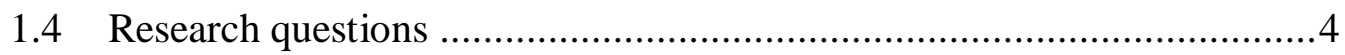

1.5 Research strategy and methodology .............................................6

1.6 The researcher's role and interest in the area of study ...........................6

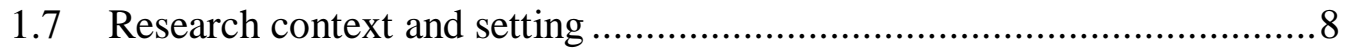

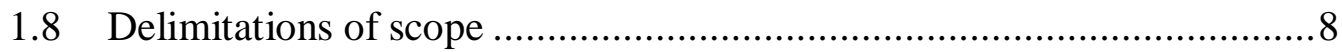

1.9 Value and importance of the research................................................ 8

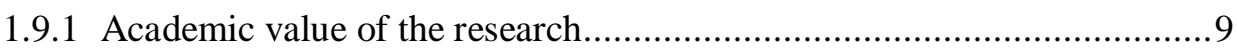

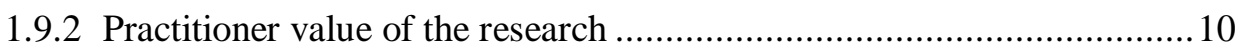

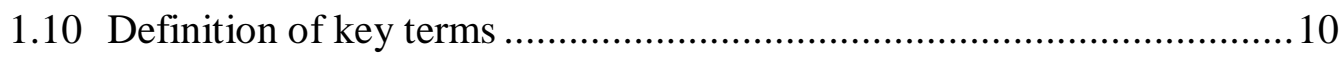

1.10.1 Key terms (as developed and used within the context of the

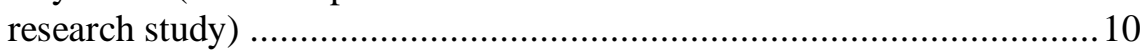

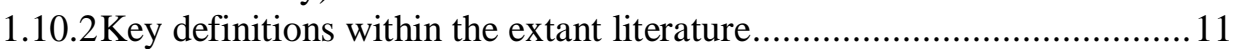

1.11 Structure of this thesis.................................................................... 12

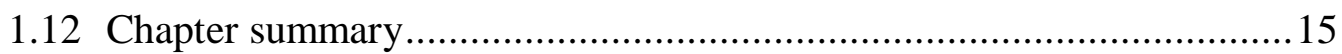

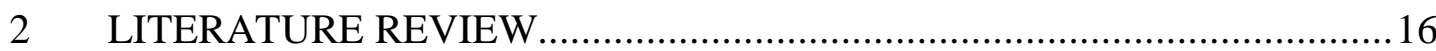

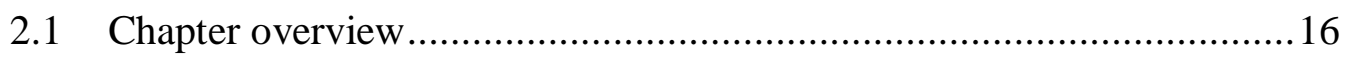

2.2 Information Technology Innovation .............................................. 17

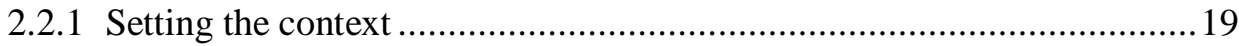

2.2.2 Institutional entrepreneurship and technology innovation .....................20

2.2.3 Beyond the dominant paradigms in IT innovation research ..................23

2.2.4 In summary: information technology innovation ................................25

2.3 Entrepreneurship - an historical overview ......................................25

2.3.1 Treatment of entrepreneurship within the Austrian School of

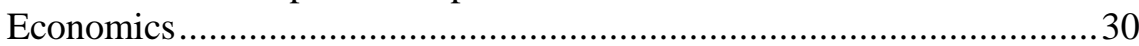

2.3.2 In summary: historical and economic overview .....................................33

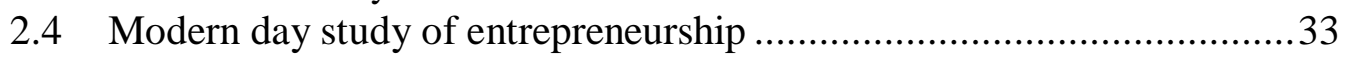

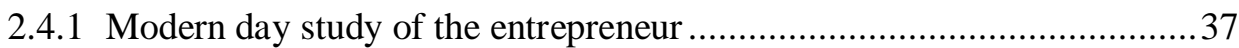

2.4.2 In summary: modern day study of entrepreneurship and the

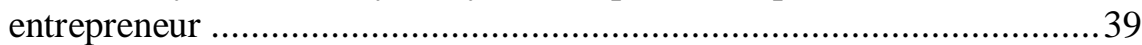

2.5 Corporate entrepreneurship, intrapreneurship, and the intrapreneur .......39

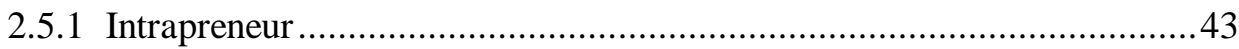

2.5.2 In summary: corporate entrepreneurship, intrapreneurship, and the intrapreneur. 
2.6 Organisational Knowledge Creation Theory

2.6.1 Innovation, entrepreneurship and Organisational Knowledge Creation Theory

2.6.2 Organisational Knowledge Creation Theory an historical overview.......48

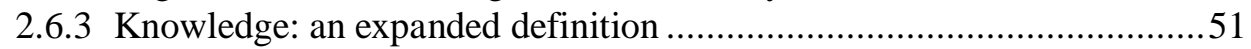

2.6.4 Explicit and tacit knowledge continuum............................................51

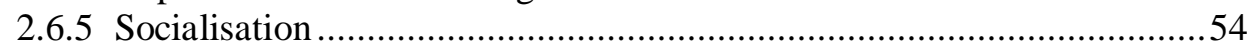

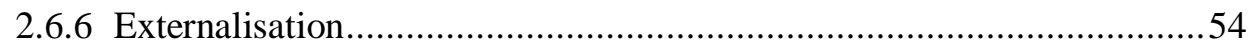

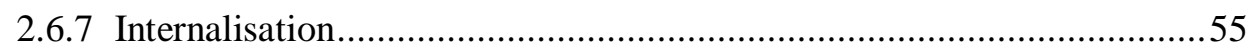

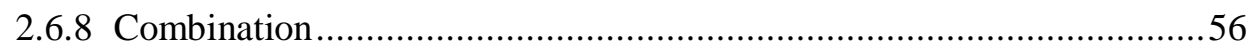

2.6.9 Unified Model of Dynamic Knowledge Creation .....................................57

2.6.10The concept of $b a$....................................................................................59

2.6.11 In summary: Organisational Knowledge Creation Theory as it

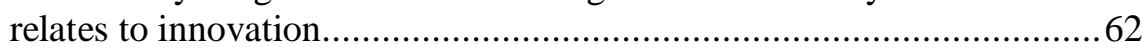

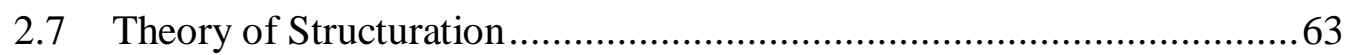

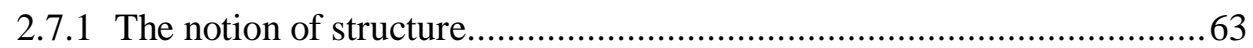

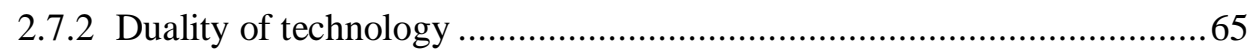

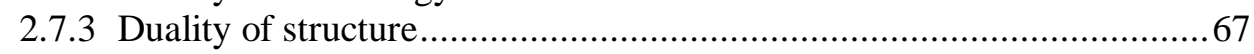

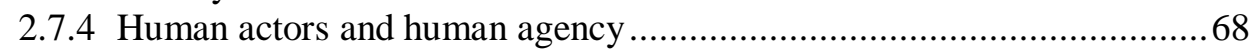

2.7.5 Human agency and social sciences based perspectives ........................69

2.7.6 Economic based perspectives of structuration and human agency ..........73

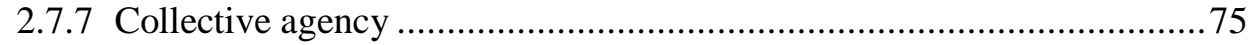

2.7.8 In Summary: structuration, human agency, and collective agency ..........76

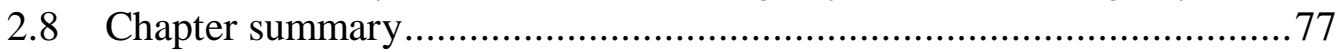

3 RESEARCH STRATEGY AND METHODOLOGY ….............................78

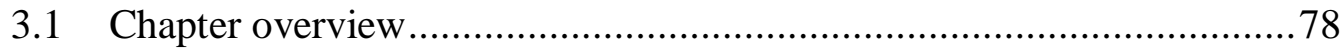

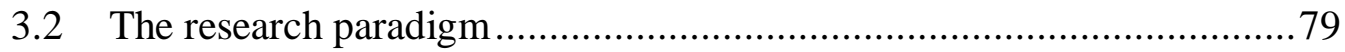

3.3 The research strategy and methodology .......................................... 80

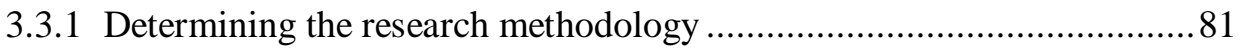

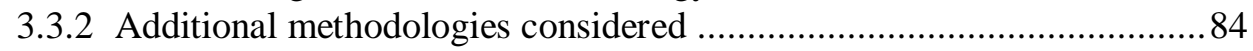

3.4 Research method: Grounded Theory ............................................... 85

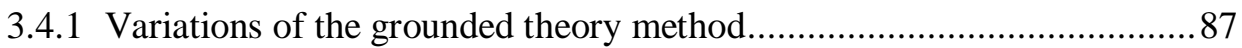

3.4.2 Grounded theory in IS research...................................................... 90

3.4.3 Approach adopted: Glaserian as interpreted for use in IS studies ...........92

3.4.4 Reading for Theoretical Sensitivity ..................................................98

3.4.5 Use of qualitative software analysis programs ....................................99

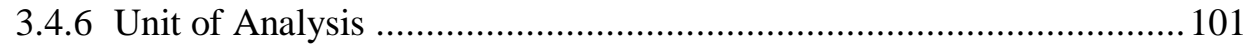

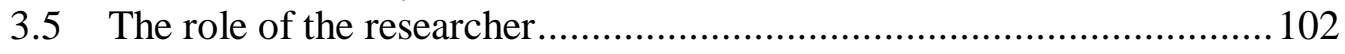

3.6 Issues of rigour, credibility and validity in grounded theory

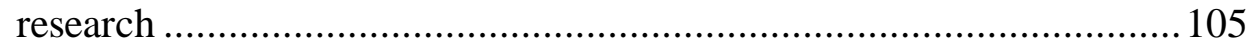

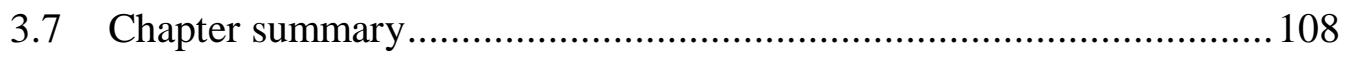

4 DATA COLLECTION AND ANALYSIS ............................................. 109

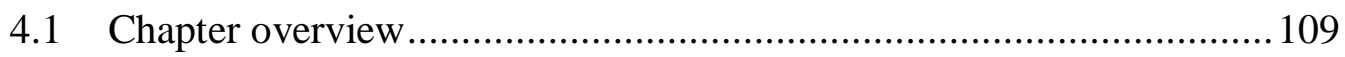




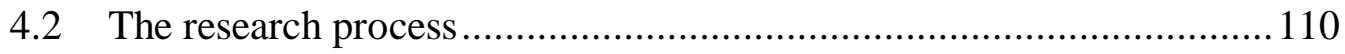

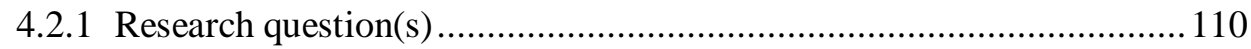

4.2.2 Research location and setting ........................................................111

4.2.3 Research protocol ………………………………………………....112

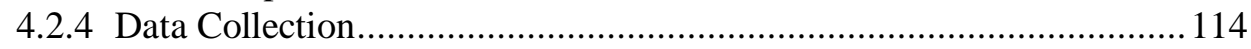

4.3 Reading for coding sensitivity........................................................... 123

4.4 Entering the field in the general topic area ......................................... 126

4.4.1 Open coding - constant comparison of incidents to incidents ................ 128

4.4.2 A change away from using Nvivo ………………………………....... 132

4.5 Iterative conceptualisation ................................................................ 134

4.5.1 The category of entrepreneurial vision ................................................136

4.5.2 Reading for theoretical sensitivity ...................................................... 138

4.5.3 Theoretical coding: Emergence of initial BSP Entrepreneurial Agency ………………………………………………...... 139

4.5.4 Summary of the activities leading to the first level of abstraction ......... 143

4.6 Theoretical sampling (associated with interview groups one to

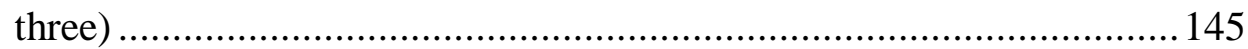

4.7 Scaling up and theoretical integration ................................................ 147

4.7.1 Disconnect within the research data ....................................................... 149

4.8 Progressing beyond the Basic Social Process of entrepreneurial

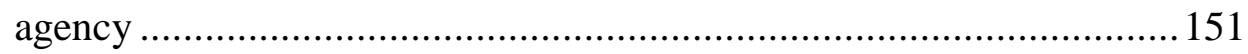

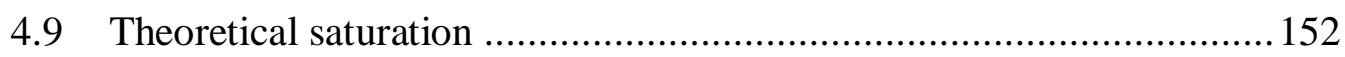

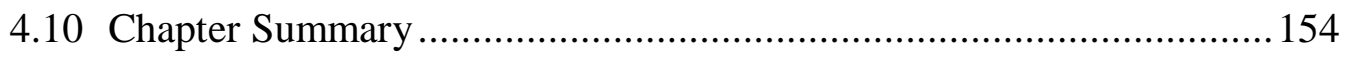

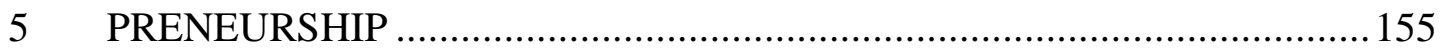

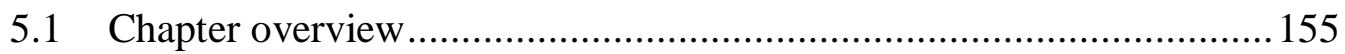

5.2 Reading for enhanced theoretical sensitivity to preneurship and IT

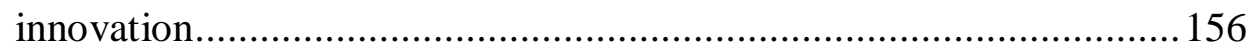

5.3 Theoretical sampling: to explore issues of intrapreneurship................... 157

5.4 Selective coding: accounting for issues of intrapreneurship .................. 160

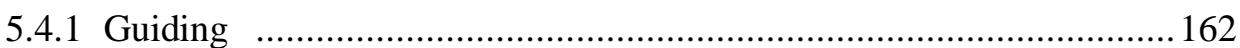

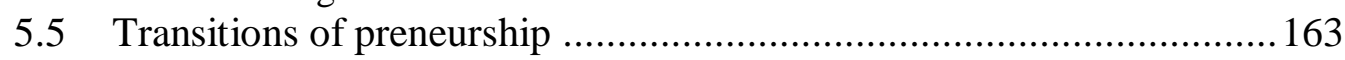

5.5.1 Reanalysing the first group of interviews ................................................. 164

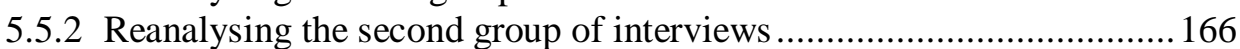

5.5.3 Reanalysing the third group of interviews ................................................. 167

5.5.4 Establishing the "preneurial ba".......................................................... 170

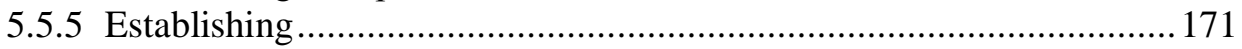

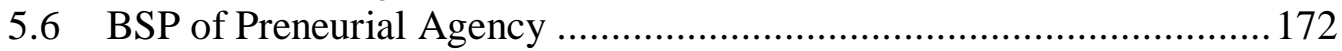

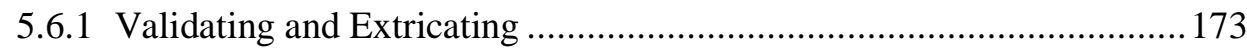

5.6.2 Emergence of the BSP of Preneurial Agency ...................................... 174 
5.7 Preneurial Agency: alignment to traditional notions, and study, of entrepreneurship

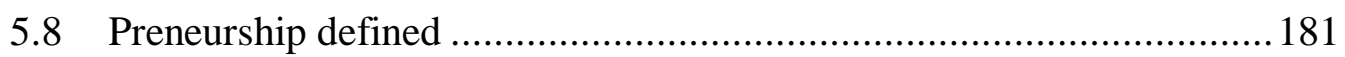

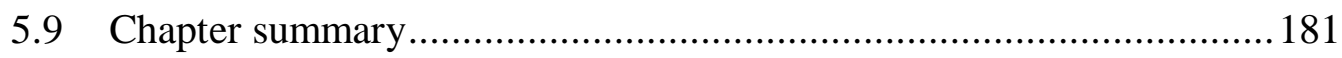

$6 \quad$ PRENEURIAL AGENCY IN IT CREATION .......................................... 183

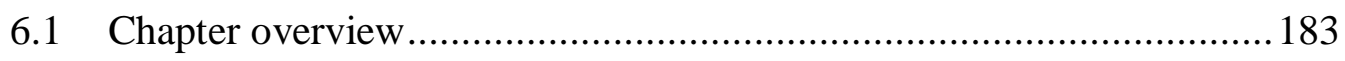

6.2 A Grounded Theory of Preneurial Agency in IT Creation .................. 185

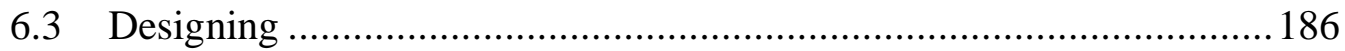

6.3.1 Architecting the road map............................................................. 187

6.3.2 Leveraging - prior knowledge and network relationships ................... 192

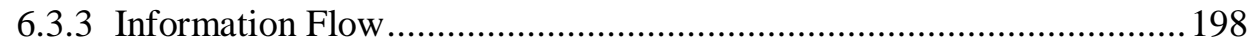

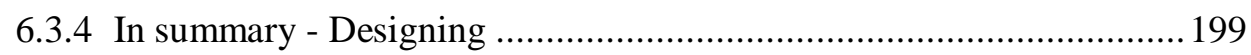

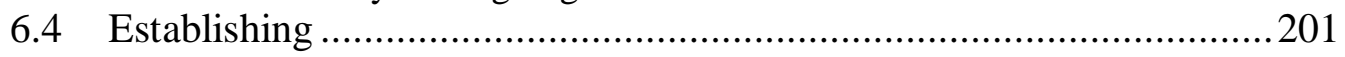

6.4.1 Establishing the Preneurial ba ............................................................201

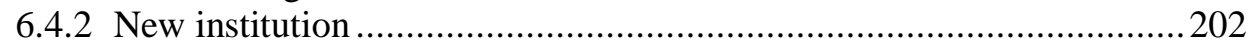

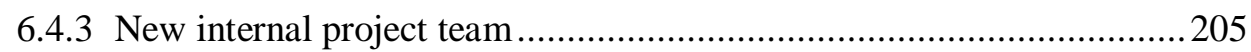

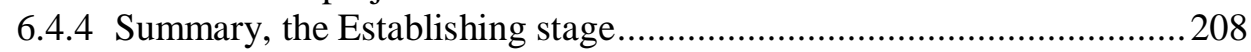

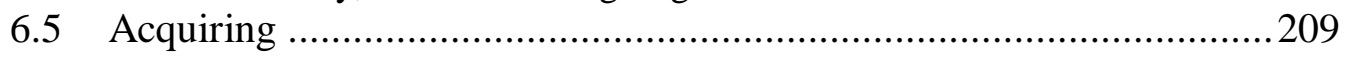

6.5.1 Addressing skill gap - software development expertise ......................211

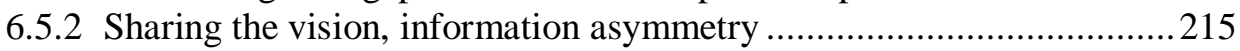

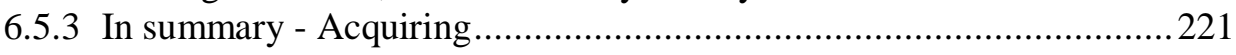

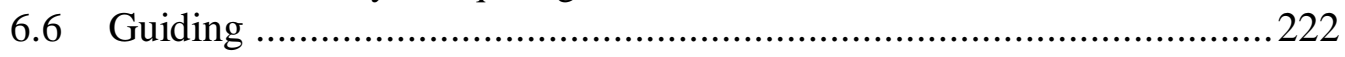

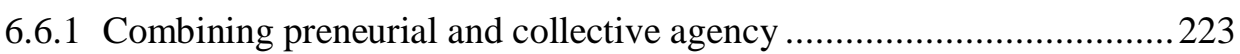

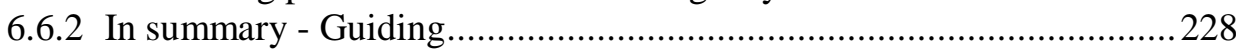

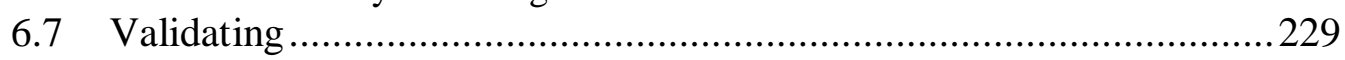

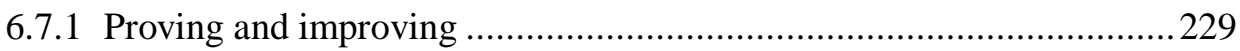

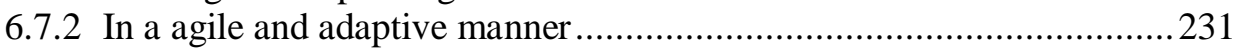

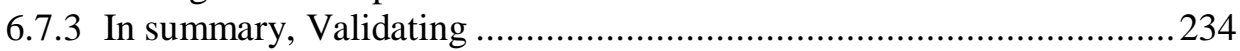

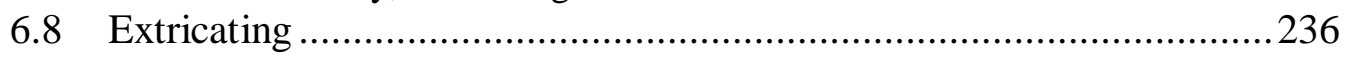

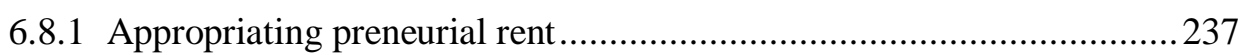

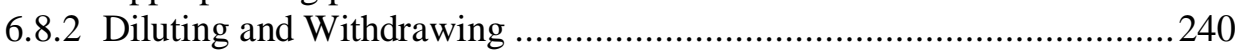

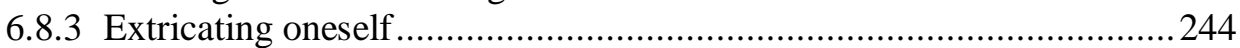

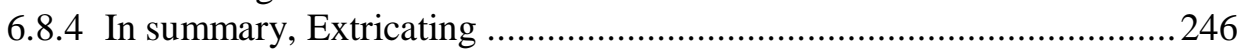

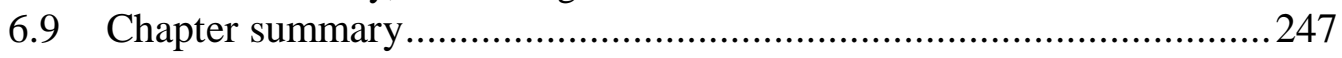

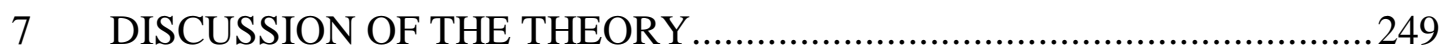

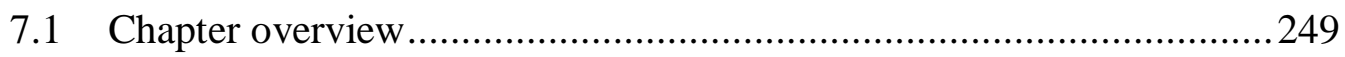

7.2 Within the context of Information Systems research ........................250

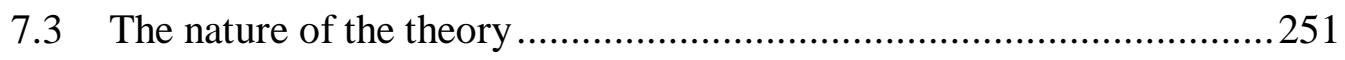

7.4 Relationship to existing theory of IT innovation ..............................255 
7.5 Relationship to existing theory of Organisational Knowledge

Creation

7.6 Relationship to existing theory of Structuration...............................258

7.7 Relationship to existing theory of Entrepreneurship ........................260

7.8 Relationship to existing Resource Based Theory ..............................262

7.9 Relationship to existing theory of IT Adoption.................................263

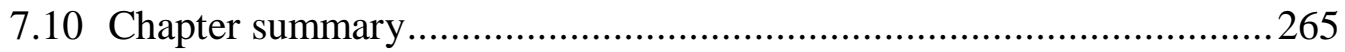

8 RELECTIONS, IMPLICATIONS, AND CONCLUSIONS .......................2266

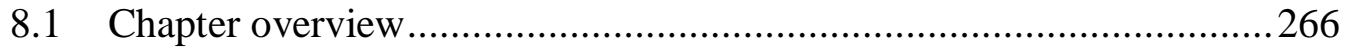

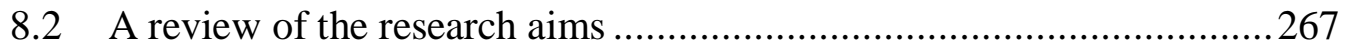

8.3 Reflections on the research method ................................................ 268

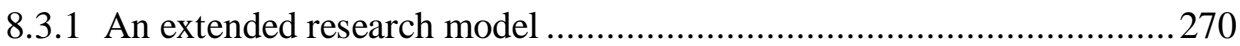

8.3.2 Undertaking a Grounded Preliminary Literature Review ....................272

8.3.3 Reading for Theoretical Sensitivity .................................................... 273

8.3.4 Reflections and assessment against guidelines and criteria specified by Fernandez et al. (2002); Fernandez (2003) ....................................2 273

8.4 Issues of credibility, originality, resonance and usefulness ................278

8.4.1 Assessment against Charmaz's (2006) criteria for grounded theory

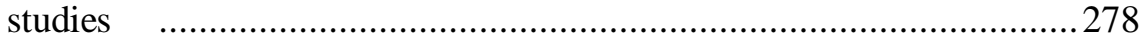

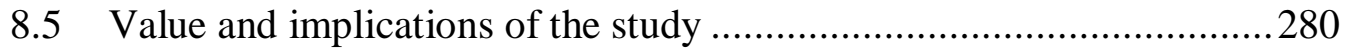

8.5.1 Value and implications of the research to study...............................280

8.5.2 Value and implications of the research to practitioners .........................283

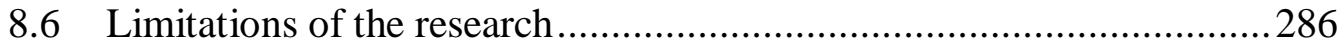

8.7 Directions for future research.................................................... 287

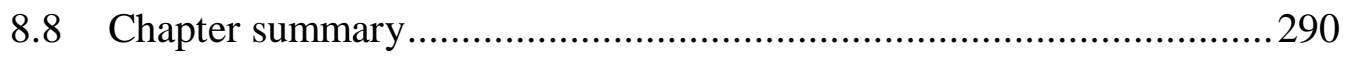

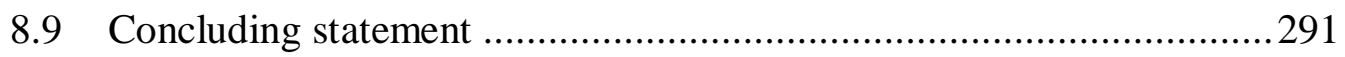

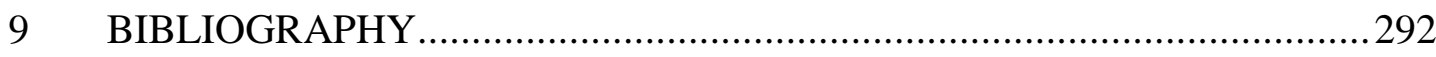

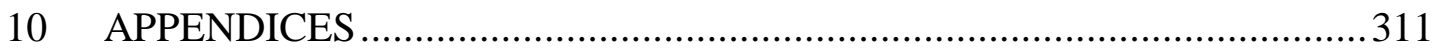




\section{Table of Figures}

Figure 1: Event-driven explanations (Aldrich, 2001) .....................................24

Figure 2: Modes of knowledge creation ........................................................58

Figure 3: Key properties and dimensions of the four modes of knowledge

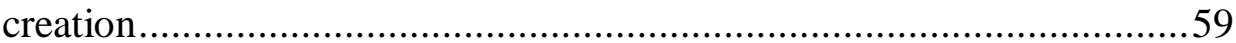

Figure 4: Different Kinds of Agency in Interaction (Dey, 1999, p. 198) ...............74

Figure 5: The inductive-deductive cycle of the grounded theory method ..............87

Figure 6: A Research Model: steps and processes in the grounded theory process (Fernandez et al., 2002; Fernandez, 2003; Lehmann, 2001) ......93

Figure 7: Model of inductive theory generation: initial open and conceptual

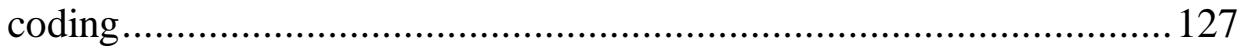

Figure 8: Edited NVivo screen capture of comparing incident to incident .......... 130

Figure 9: Conceptual substance of the general area under study ......................... 132

Figure 10: Interplay between Intangible-Tacit and Tangible-Explicit in the IT creation process ....................................................................... 138

Figure 11: Emergence of the label "Designing" from the data .............................. 142

Figure 12: Model of inductive theory generation: first level of abstraction ........... 144

Figure 13: Boundary based view of entrepreneurs, intrapreneurs and the

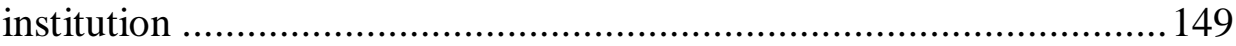

Figure 14: Model of inductive theory generation: application of the grounded theory method to point of theoretical integration and saturation .......... 153

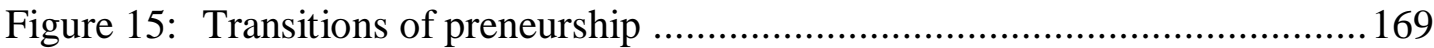

Figure 16: Transitioning to the BSP of Preneurial Agency ................................. 173

Figure 17: Emergence of the BSP of Preneurial Agency ..................................... 175

Figure 18: A boundary based view of Preneurship ............................................. 180

Figure 19: Information flow between the preneur and collective agent in the Designing stage of the PA process

Figure 20: Asymmetric flow of information between the preneurial actor and collective agent

Figure 21: Examples of knowledge conversion within a preneurial $b a$ established by interviewee (I-15) .................................................222

Figure 22: A framework for analysing grounded theory studies ........................ 252

Figure 23: Assessment: Grounded Theory of Preneurial Agency in IT Creation ... 254

Figure 24: Structuration Model of Technology..................................................258

Figure 25: Structurational Model of IT Creation .................................................259

Figure 26 : Reasoned Action Model of Preneurship ........................................... 265

Figure 27: Extended research model: steps and processes in the grounded

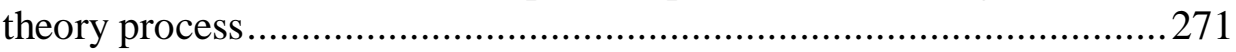

Figure 28: Structurational Model of Preneurship in IT Creation .......................... 288 


\section{Table of Tables}

Table 1: Antoncic and Hisrich's (2003) dimensions of intrapreneurship 42

Table 2: $\quad$ Summary of differences between entrepreneurs and intrapreneurs as discussed by Luchsinger and Bagby (1987)

Table 3: $\quad$ Types of $B a$

Table 4: Different Kinds of Agency in Interaction (Dey, 1999, p. 198) ..............69

Table 5: Criteria for improving grounded theory studies ................................. 107

Table 6: First group of six - interviewee description and initial

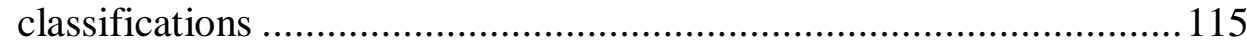

Table 7: Second group of six - interviewee description and initial

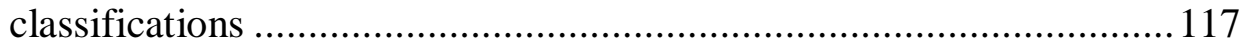

Table 8: Third group of six - interviewee description and initial

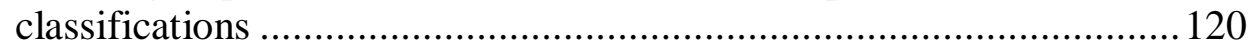

Table 9: Fourth group of six - interviewee description and initial classifications ...................................................................... 121

Table 10: Examples of conceptual codes identified from the extant literature

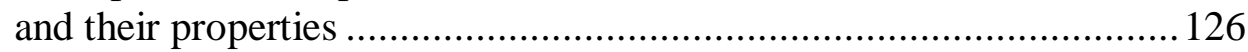

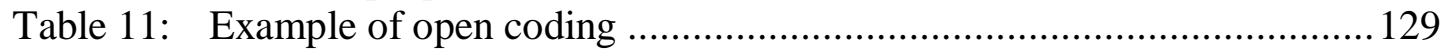

Table 12: Example of conceptual codes and properties .................................... 131

Table 13: Category of entrepreneurial vision, dimensions, and properties ........... 137

Table 14: Transition BSP of Entrepreneurial Agency.......................................... 141

Table 15: Theoretical sampling interviewee groups one to three ........................ 146

Table 16: Alignment to Luchsinger and Bagby's (1987) characteristics of an

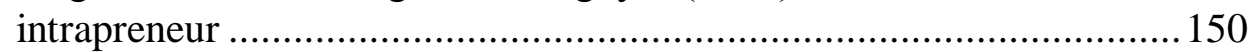

Table 17: Theoretical sampling interviewee group three to four.......................... 158

Table 18: Transitions of preneurship within the fourth group of interviews......... 164

Table 19: Transitions of preneurship within the first group of interviews ............. 165

Table 20: Transitions of preneurship within the second group of interviews ....... 166

Table 21: Transitions of preneurship within the third group of interviews ........... 167

Table 22: Occurrences of transitions associated with preneurship ....................... 168

Table 23: Shared space associated with each preneur...................................... 170

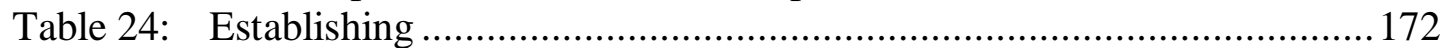

Table 25: Summary of approaches for describing entrepreneurship ................... 178

Table 26: Grounded Theory of Preneurial Agency in IT Creation ........................ 184

Table 27: Concepts and properties related to the stage of Designing .................... 186

Table 28: Innovation Design and Development Requirement............................. 190

Table 29: Concepts and properties related to the Establishing stage ....................201

Table 30: Concepts and properties related to the stage of Acquiring ..................209

Table 31: Assessment of preneurs' software development skill level and primary source of software development expertise ............................2212

Table 32: Concepts and properties related to the stage of Guiding ......................222

Table 33: Concepts and properties related to the stage of Validating..................229

Table 34: Interviewee comments related to acting in an agile way .....................2231

Table 35: Concepts and properties related to the stage of Extricating ..................236

Table 36: Functional roles of the preneurs .....................................................245

Table 37: Support and contradictions to theories of Entrepreneurship ................. 261

Table 38: Support and contradictions to theories of IT Adoption .........................264 
Table of Appendices

Appendix A - SIM Human Ethics Committee Application ................................... 312

Appendix B - SIM Human Ethics Committee Approval ......................................... 319

Appendix C - Doctoral Research Information Sheet (entering the field) ................320

Appendix D - Doctoral Research Information Sheet (Substantive Topic) ............... 322

Appendix E - Doctoral Research Consent \& Signoff Form.................................. 324

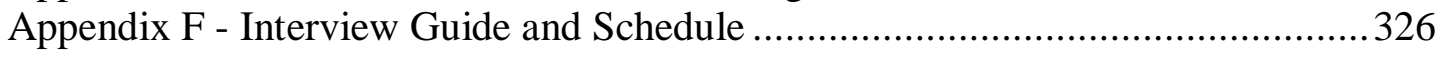

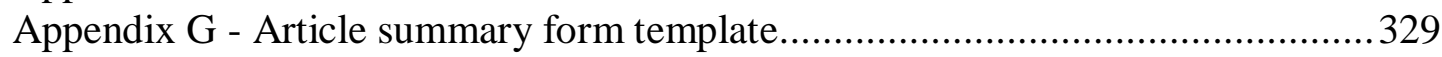

Appendix H - Abridged articles summary example ........................................... 330

Appendix I - Conceptual codes from reading for coding sensitivity ....................... 332

Appendix J- Example of memos made during coding ......................................... 333 


\section{INTRODUCTION}

\subsection{Chapter overview}

This chapter introduces the topic of the dissertation that originally motivated this research. It explains how, as the research progressed, a refined research topic emerged from the data, in accordance with the research method used. The cross disciplinary nature of the research - which seeks to address research gaps within network theory, Information Technology innovation, and entrepreneurship based research domains - is described. The research method is outlined, with specific mention of my role as a "hybrid" researcher. The value and importance of the research findings are summarised, and a list of the key definitions used and developed in this study is provided. Finally, a brief outline of the chapters within in this thesis is provided.

\section{Chapter Contents}

1.2 Research problem and motivation

1.3 Research gap

1.4 Research questions

1.5 Research strategy and methodology

1.6 The researcher's role and interest in the area of study

1.7 Research context and setting

1.8 Delimitations of scope

1.9 Value and importance of the research

1.10 Definition of key terms

1.11 Structure of this thesis

1.12 Chapter summary 


\subsection{Research problem and motivation}

The research problem emanates from a key characteristic of the practitioner community; that is, entrepreneurs are typically resource poor when they set out to create their IT innovation. They must seek out and use resources that they do not have so that their new venture survives and they are able to create their innovation. They do this by leveraging their own social networks and those of other people who they seek out, to obtain resources that are initially outside their reach. Consequently a single entrepreneur acting alone cannot bring a technologybased innovation into being and widespread use. Successful realisation of such innovations requires collective effort, involving resources and actors both internal and external to the entrepreneur's own venture (Van de Ven, 1993a, 2005; Lavie, 2006).

Often the external resource acquiring relationships needed to commercialise innovation are mediated by third parties, known as brokers. How the entrepreneur manages his/her relationship with these network brokers and extracts maximum value from it can be crucial to the outcome of his/her innovation efforts (Burt 1992:2005).

Therefore, it was originally intended that this research would identify enablers, drivers and inhibitors impacting on these relationships as experienced by both entrepreneurial actors and network brokers. I hoped that by providing a better understanding of such micro mechanisms at play within the relationship, this research would contribute to the success of future IT-based innovation efforts by allowing practitioners to become more skilled, efficient, and effective in the management of these relationships.

\subsection{Research gap}

I sought to address perceived gaps within three areas: (1) social networks, (2) IT innovation, and (3) entrepreneurship-based research domains. 
Network-based studies have traditionally been focused on issues of network structure as opposed to issues related to individual agency. Leading authors within the network-based research domain - such as Granovetter $(1973 ; 2005)$, Gulati (1998; 2007), and Burt (1992; 2007) - seek to explain network relationships through focusing on network structures and patterns of dyadic ties, rather than aspects of individual agency. Even in his early work, Burt (1983) acknowledges this aspect by conceding that network analysts such as himself are concerned less with the relationships between pairs of actors than with the complexity of the structure of relations among many actors as a system. In some of his most recent work (see Burt, 2007), he has begun to call for a shift in focus to aspects of individual agency.

Similarly, Fichman (2004) and Van de Ven and Engleman (2004) advocate for a shift in the focus of innovation-related research. Within the IT innovation-related research domain, Fichman (2004) calls for more innovative approaches to the study of innovation itself. He maintains that research based in the dominant paradigm of adoption and diffusion has reached a point of diminishing returns and is increasingly unlikely to provide frameworks for supporting ground-breaking research.

Within the entrepreneurship-based domain, Van de Ven and Engleman (2004) lament the fact that, although many researchers cite the need to develop better understanding of entrepreneurship processes, there is little event-driven process research in entrepreneurship. In a comparable stance to Fichman (2004), Van de Ven and Engleman regard the dominant paradigm in entrepreneurship-based research and teaching as being focused on variance theories and cross-sectional methods with less attention to process theory and event-driven or longitudinal method. Consequently, they believe that it is time to encourage process-based approaches that draw upon the social sciences to complement traditional variance approaches. Such approaches, they argue, have potential to unlock a different, more fundamental level of understanding temporal processes. 
The perceived gaps within the network and IT innovation-based domains informed my initial research directions as I entered the field in the general topic area. It was when my research had progressed to a point where the substantive topic area and theoretical code associated with Basic Social Processes were identified, that the third research gap around the need for event-driven, process orientated theory began to influence the research direction.

Partly in response to Fichman's requirement to adopt a more innovative approach to studying IT innovation, the grounded theory method was adopted for the research study. A central requirement of the method is that the substantive topic must emerge from the data and that while an initial research question may guide the study, the research must be free to allow the core category to emerge from the data. As Glaser (2005, p. 3) asserts, the grounded theory procedure seeks to "stop preconceived forcing based on discipline, supervisors, pet codes, a "grande" perspective and to unwarranted hunches".

\section{$1.4 \quad$ Research questions}

This research addressed the question:

How do entrepreneurs and intrapreneurs act, and interact with other people in order to secure and combine the resources required to make their entrepreneurial vision a tangible reality?

In keeping with the grounded theory method, a broad research question was set to initially guide the initial enquiry.

1) What are the drivers, enablers, and inhibitors of resource acquiring relationships between entrepreneurial actors within information technology firms and their network brokers? 
Two sub-questions, designed to obtain information to assist entrepreneurial actors and network brokers to better understand the nuances in managing resource acquiring network relationships, were also posed:

2) How do these driving, enabling, and inhibiting factors influence or moderate how the parties obtain benefit from the relationship?

3) What similarities, differences, and complementarities exist between the parties in regard to the identified drivers, enablers, and inhibitors?

As the research progressed and a core category emerged from the data, a shift occurred in the research focus. Focusing singularly on the entrepreneur did not allow all the variation in the data to be explained, as IT innovation is also created by intrapreneurs. In addition, focusing solely on the entrepreneur or intrapreneur's interaction with network brokers was also found to be too restrictive, as they actually interact with a range of participants to make their innovative idea a tangible reality. Brokers were replaced with the more inclusive notion of collective agents.

Both the research problem and motivation for this study originated from prior research associated with my Masters project in which I investigated issues of network participation when commercialising high-technology innovation internationally (see Thistoll and Pauleen, 2010). That research had identified the important role that network brokers play in the innovation process, especially in issues associated with adoption and diffusion.

Consequently, this study was initially framed with a narrow and restrictive focus on (a) the entrepreneur; and (b) network brokers. As the core category began to emerge from the data, the research shifted in focus. The shift was in line with the original problem statement that entrepreneurs are typically resource poor when starting out to create their innovation and must leverage their own and other people social networks to obtain resources initially outside their reach. Innovation is a collective effort involving resources and actors both internal and external to 
the entrepreneur, and in accordance with the requirements of the grounded theory method. The new focus was expanded to include the intrapreneur and to take a more inclusive view of "collective agents", as opposed to just brokers, who aid the entrepreneur and intrapreneur to create IT innovation.

\subsection{Research strategy and methodology}

In this study, I undertook the role of an interpretive researcher. Interpretive researchers are translators of other persons' words and actions and they act as the go-between for the participant and the audience the researcher wants to reach (Corbin and Strauss, 2008). The interpretive stance equipped me with a perspective that enabled phenomena to be understood through the meanings that people assigned to them and as I interpreted the responses.

Through translating the words of the entrepreneurial actors and the people they interacted with, I sought to understand how they acted to acquire the resources they needed to create IT innovation. In addition to this objective, I also sought to derive a theory as this research was being carried out to fulfil the requirements of the degree of Doctor of Philosophy in Information Systems. It is expected that such research leads to a new and defensible theory (School of Information Management, 2009).

Given these objectives, I adopted the grounded theory method and in particular the Glaserian variant. The Glaserian approach advocates theory development as a method of discovery, where categories emerge from the data (Charmaz, 2006). This approach was further refined through adopting the Glaserian variant as interpreted and recommended for use in IS-based studies. The research strategy and methodology are outlined and justified in Chapter 3.

\subsection{The researcher's role and interest in the area of study}

The motivation to undertake research that sought to understand how the entrepreneurial actor creates IT innovation lay in my prior experience and 
knowledge gained as a practitioner. In part, I sought to inform my own practice through academic scholarship and research.

In my career, I have acted both as intrapreneur and collective actor in the creation of IT innovation. I have worked in medium to large corporate environments and have acted to initiate and create innovation. I have also worked with entrepreneurs, aiding them in creating their innovative ideas. In one instance, I worked within a start-up company and lead the activities to coordinate the institutional activities associated with the adoption and diffusion of the IT-based innovation.

Consequently, I did not fit with either of Walsham's (1995) two descriptions of the interpretive researcher: (a) the outside observer, or (b) the involved participant. At the time of conducting the research, I was not involved in IT based innovation and therefore was not a participant researcher; yet I was also not an outside observer who maintained distance from the respondents. To inform my research, I was able to utilise personal relationships and past experiences to acquire both participants and insights for my research; therefore, I undertook the role of a "hybrid" researcher.

The hybrid researcher undertakes research into the practice of other practitioners and has familiarity with the research topic (Reed and Procter, 1995). Such a position is accommodated within the grounded theory method, as researchers using the method must be knowledgeable enough to truly understand what respondents are saying and able to assign meaning to what is said (Lings and Lundell, 2005). The method does not presuppose an empty head, but rather an open mind (Dey, 1999). In Chapter 3, section 3.5, I discuss my role as a knowledgeable researcher and how I adopted the process of reflectivity to manage potential biases arising from this approach. 


\subsection{Research context and setting}

All participants in the study were chosen for their ability to inform the emergent theory. They had all played a role in creating IT-based innovation, either as (a) entrepreneur, (b) intrapreneur, or (c) collective agent.

The participants were all New Zealand citizens, with all but one living within the greater Wellington region at the time of the interviews. This person was interviewed while in the region visiting family. Enough respondents were found within the Wellington region to develop the emergent theory to a point of saturation and the research did not need to extend beyond this geographic area.

\subsection{Delimitations of scope}

The research was tied to the IT artefact, specifically how IT innovation is created. Consequently, the emergent theory is specific to IT creation and does not seek to explain the creation of innovation associated with other industries.

The research was focused on the actions of the entrepreneur and the intrapreneur and does not seek to explain their motivation, the environment they operate within, their personal characteristics, or even the characteristics of their innovation.

In addition, the research was focused on the actions that the entrepreneur and intrapreneur undertake to create the first tangible version of the innovation, the prototype. It does not seek to explain more traditional issues, such as use and diffusion, which assume that the innovation exists and has already been created. Delimitations are identified and discussed in Chapter 4.

\subsection{Value and importance of the research}

This study seeks to provide a number of noteworthy contributions to both the academic and practitioner communities involved with IT innovation. In addition, 
the study seeks to make a contribution to research within the wider field of entrepreneurship and provide academics with an abstracted view of the preneurial process. A full list of the contributions of this research is provided and discussed in Chapter 8, section 8.5; with the main contributions introduced here.

\subsubsection{Academic value of the research}

For academic researchers within the field of IT innovation, this research extends the field of study beyond the dominant paradigm to include the process where the IT innovation is created through the actions of human actors. In addition, academics are provides with a triality based view of technology creation, where technology is created through and informed by the agency of the preneur, collective agents and the shared space they interact within.

For academics within the wider entrepreneurship and innovation related research domains, an abstracted view of entrepreneurship is provided where the actor is seen to transition between roles and institutional boundaries.

For scholars within both IT innovation and entrepreneurship based research domains an event-driven, process orientated Grounded Theory of Preneurial Agency in IT Creation is provided.

For researchers using the grounded theory method, the steps and process of the grounded theory method as modelled by Fernandez, Lehmann, and Underwood (2002); Fernandez (2003); and Lehmann (2001a) is extended to incorporate a Grounded Literature Review. The Grounded Literature Review takes the rigours and systematic steps of the grounded theory method and applies it to the literature review process. 


\subsubsection{Practitioner value of the research}

For practitioners, the research provides a view of the entrepreneur as someone who becomes an intrapreneur and institutional actor. Conversely, the intrapreneur is firstly an institutional actor who becomes an intrapreneur and may move on to be an entrepreneur. Both the entrepreneur and intrapreneur are institutional actors at some point, and they share commonalities as to how they go about creating IT innovation.

This study suggests that over time the entrepreneur should be increasingly seen as someone who becomes an intrapreneur and institutional actor, and that the title entrepreneur may become less suitable to describe their function as time progresses. The term "preneur" is found to better account for how entrepreneurs and intrapreneurs transition between roles and organisational boundaries over time.

The preneur undertakes a specific set of actions which is able to be expressed as six theoretical propositions. By understanding the propositions, the preneur may be better able to inform their practice and enhance the self management of his/her preneurial agency and interactions with collective agents.

\subsection{Definition of key terms}

This study introduces a new family of terms related to the abstracted phenomenon of preneurship, which are defined and discussed in Chapter 5, section 5.8 and introduced here. In addition, the study adopts specific meaning associated with a number of common terms as listed within this section to orientate the reader

\subsubsection{Key terms (as developed and used within the context of the research study)}

Collective agents: human agents who, through their collective actions, assist in the creation of innovation (see Chapter 4, section 4.2.1). 
Preneur: an actor who may be external (entre) and/or internal (intra) to an existing institution and who is involved in the creation process and undertakes actions to create their innovative idea and make it a tangible reality (see Chapter 5 , section 5.8).

Preneurship: The creation process a preneur undertakes to make their innovative idea a tangible reality (see Chapter 5, section 5.8).

Preneurial Agency: the actions the preneur undertakes to create their innovative idea and make it a tangible reality (see Chapter 5, section 5.8).

Preneurial ba: is a shared space within which the preneur and collective agents interact and undertake actions to make an innovative idea a tangible reality (see Chapter 5, section 5.5.4).

\subsubsection{Key definitions within the extant literature}

Action: a lived experience that is guided by a plan or project arising from the subject's spontaneous activity and is distinguished from all other lived experiences by a peculiar act of attention (Schutz, 1967).

Actor: the human actor - includes inherent aspects of what a person does as well as his/her capacity to understand what they do while they do it (Giddens, 1984).

Agent: the actor as part of a group or collective; everybody is inescapably an agent in some of their doings (Archer, 1995).

Agency: a term used to describe human action (Giddens, 1984); and the ability to coordinate one's actions with others and against others; to persuade, coerce, or monitor one's own activities or the activities of others (Sewell, 1994).

ba: a shared context in which knowledge is shared, created, and utilised (Nonaka and Toyama, 2003). 
Collective Agency: the collective efforts of people working together to achieve a common result (Bandura, 1996b).

Innovation: the output of a creative application of knowledge, induced through entrepreneurial action, to increase the set of techniques and products commercially available in the economy (Courvisanos, 2007).

Information Systems Innovation: the organisational application of digital computer and communication technologies -now commonly known as Information Technology, or IT (Swanson, 1994).

Prototype: a tangible form of the concept achieved by combining existing concepts, products, components, and procedures with a new concept - in other words, combining new explicit knowledge with existing explicit knowledge (Ichijo and Nonaka, 2007).

Information Technology (IT): any artefact of which underlying technological base is comprised of computer or communications hardware and software (Cooper and Zmud, 1990).

\subsection{Structure of this thesis}

This thesis is structured into 8 chapters: Chapter 1 - Introduction; Chapter 2 Literature Review; Chapter 3 - Research strategy and methodology; Chapter 4 Data collection and analysis; Chapter 5 - Preneurship; Chapter 6: Preneurial Agency; Chapter 7 - Discussion of the Theory; and Chapter 8 - Reflections, implications and conclusions. A brief indication of the contents of each of the remaining chapters is provided:

\section{Chapter 2: Literature Review}

A cross disciplinary approach is adopted when reviewing the extant literature in the fields of technology innovation, entrepreneurship, and intrapreneurship. The 
literature is reviewed from both historical early $20^{\text {th }}$ century and modern day perspectives, and from economic and sociological based perspectives. The literature review also covers Organisational Knowledge Creation Theory and Structuration Theory as these theories inform the emergent theory developed in this study.

\section{Chapter 3: Research Strategy and Methodology}

In this Chapter, I discuss the research paradigm and research strategy chosen for use in the study, with specific reference to the Glaserian variant of the grounded theory method.

\section{Chapter 4: Data Collection and Analysis}

This chapter focuses on how I applied the grounded theory method in my study. I discuss my research protocol, and describe and classify the participants in the study according to their role as entrepreneur, intrapreneur or collective agent. A model of inductive theory generation is introduced and used as an illustrative tool to explain what stages of the grounded theory process were utilised at certain points of the analysis and how the abstraction progressed beyond the identification of the initial core category to a further, higher, level of abstraction.

\section{Chapter 5: Preneurship}

The first half of this chapter focuses on how the core category of Preneurial Agency emerged from the data obtained from a last round of interviews to explore issues associated with intrapreneurship in greater depth. The analysis associated with the last group of interviews is described, as is the reanalysis of all the interview data and how the analysis produced the Grounded Theory of Preneurial Agency in IT Creation. The second half of the chapter substantiates and situates the core category within the extant literature associated with entrepreneurship, and explains and defines key terms arising from the study. 


\section{Chapter 6: Preneurial Agency}

Through the use of a narrative style, the Grounded Theory of Preneurial Agency in IT Creation is described in detail with interviewee comments and quotes interwoven to tell the story of how preneurs act to create IT innovation. In addition to the participant's comments, scholarly comment and extant literature is also woven into the narrative to further explain and substantiate the process. The chapter is structured into six main sections: (a) Designing, (b) Establishing, (c) Acquiring, (d) Guiding, (e) Validating, and (f) Extricating, each of which explains a stage in the Preneurial Agency (PA) process.

\section{Chapter 7: Discussion of the Theory}

In this chapter the nature of the Grounded Theory of Preneurial Agency in IT Creation is discussed and related to existing theory in the fields of: IT innovation, Organisational Knowledge Creation; Structuration; Entrepreneurship; Resource Based Theory; and IT Adoption. I also discuss the role of theory development in IS research and state that this study develops a substantive theory for explaining. The chapter also produces a Reasoned Action Model of Preneurship.

\section{Chapter 8: $\quad$ Reflections, implications and conclusions}

In this, the final chapter, I review the research aims and answer the initial questions guiding the study, as well as reflecting on the research method. The value and importance of the research findings to both academics and practitioners is identified. Then the limitations of the research are noted and direction is given for possible areas of future research. The chapter provides two additional contributions of the study: (a) an extended research model for grounded theory based studies; and (b) a structurational model of preneurship in IT creation which explains and demonstrates the triality of structuration and agency in the PA process. Finally a concluding statement is made. 


\subsection{Chapter summary}

This chapter introduces the original general topic area and explains how, as the analysis progressed, a refined yet more inclusive research question was developed which led to the substantive topic area emerging from the data. The research method is identified, with specific mention of the variation used. My role as a hybrid researcher with prior experience within the general topic area is explained. Key definitions as used and developed in the study are listed, summaries of the potential value of the research are presented, and chapter overviews are provided. 


\section{LITERATURE REVIEW}

\subsection{Chapter overview}

This chapter reviews the literature associated with the substantive topic areas of technology innovation, entrepreneurship, and intrapreneurship. The review then covers literature associated with Organisational Knowledge Creation Theory and Structuration Theory. These two theories inform the emergent theory developed in later chapters.

The literature crosses a number of research domains; consequently the discussion encompasses economic and sociological based perspectives. Reference is made to historical and modern, mid to late $20^{\text {th }}$ century to current, perspectives, as many of today's concepts and theories within the wider topic area are grounded in well established research domains. Relationships to the research domain of technology innovation and Information Systems are identified and justified where important.

\section{Chapter Contents}

2.2 Information technology innovation

2.3 Entrepreneurship - a historical perspective

2.4 Modern day study of entrepreneurship

2.5 Corporate entrepreneurship, intrapreneurship, and intrapreneur

2.6 Organisational Knowledge Creation Theory

2.7 Theory of Structuration

2.8 Chapter summary 


\subsection{Information Technology Innovation}

Within this section, I begin by reviewing literature associated with technology innovation and more specifically IT innovation as within the IS discipline issues of entrepreneurship and innovation are typically associated with IT innovation. IT innovation is distinct from other forms of innovation in that it comprises both computer hardware and software. Research on Information Technology (IT) Innovation is primarily concerned with identifying factors that facilitate or hinder the adoption of new IT-based processes or products (Fichman, 2004). The majority of such research is done within what Fichman (2004) calls "the dominant paradigm" which seeks to explain innovation through the use of economicrationalistic models where organisations with a greater ability to innovate are expected to exhibit a greater quantity of innovations. The economic-rationalistic approach, which is covered in detail in section 2.3.1, focuses on factors that affect the economic returns from innovation and the rational way that managers make decisions when adopting and using innovation.

Paradigms are analytic strategies for integrating structure with process (Corbin and Strauss, 2008) but researcher reliance on the dominant paradigm within IT innovation research is, as Fichman (2004) argues, showing diminishing returns and hampering the progression of new ground-breaking research. Hence, Fichman urges researchers within the field to undertake more innovative approaches to the study of IT innovation itself.

An early definition and view of technology innovation is provided by Daft (1978) who sees innovation as a process consisting of four essential steps: (a) conception of an idea; (b) proposing of the idea; (c) the decision to adopt the idea; and (d) the implementation of the idea. These ideas originate from institutional members who span the boundary between organisations and technology, and who are expert in a particular task domain and have use for the innovation.

Consequently, Daft (1978) defines a technical innovation as an idea for a new product or service which is usually related to technology; as opposed to an 
administrative innovation. Administrative innovations pertain to the policies of recruitment, allocation of resources, structuring of tasks, authority, and rewards which are related to the social structure of the organisation.

Using the organisational department as the unit of analysis, Daft's (1978) dualcore model of organisational innovation provides a categorisation of vested interest with its splitting out the technical core from the administrative core (Zmud, 1982). The technical core is responsible for producing the products and services that justify the unit's existence. The administrative core is responsible for planning, controlling and coordinating the units function both within the team and the wider organisational hierarchy.

Using this framework, Zmud (1982) focuses on innovation within a software development group and concludes, in part, that it may be beneficial to the organisation to manage the diffusion process differently for the software development team and for those managers that are directed at improving the management of the process. Diffusion of innovation refers to the pattern of its adoption by an organisational population over time (Swanson, 1994).

Continuing the focus on the diffusion of innovation, Zmud in a later collaboration found that that while rational decision making models may be useful in explaining information technology adoption, political and learning models may be more useful in examining diffusion; where increased organisational effectiveness is obtained by using the IT innovation (Cooper and Zmud, 1990).

Cooper and Zmud (1990) define the term "Information Technology" in a broad sense as referring "to any artefact whose underlying technological base is comprised of computer or communications hardware and software" (p.123). They also provide a definition of technology implementation as viewed through a technology diffusion perspective: "an organizational effort directed towards diffusing appropriate information technology within a user community" (p.124). 
Continuing the stream of research focusing on diffusion and adoption Swanson (1994) builds on Daft's (1978) dual-core model and extends Zmud's (1982) focus on the Information Systems (IS) department who focus business related issues associated with Information Technology to develop a tri-core model to account for IS innovation across the wider organisation. IS innovations are posited to be of three types: (a) Type I innovations confined to the IS task; (b) Type II innovations supporting administrations of the business; and (c) Type III innovations embedded in the core technology of the business. Swanson defines IS innovation as "the organizational application of digital computer and communication technologies (now commonly known as Information Technology, or IT)" (1994, p. 1072).

Exploring the differences in innovative behaviour, Swanson and Ramiller (2004) introduce the notion of mindful innovation with IT; where a mindful firm attends to innovation with reasoning grounded within its own organisational facts and specifics. This perspective builds on an earlier collaboration between these authors (see Swanson and Ramiller, 1997) who revisit the institutional view of how IS innovation comes to be used and conclude that a diverse interorganisational community creates and employs an organising vision which facilitates the interpretation and legitimisation of the vision. This allows for the organisation and mobilisation of organisational resources to implement and diffuse the innovation. As Swanson and Ramiller (1997) state "an organizing vision is a focal community idea for the application of information technology in organizations" (p. 406).

\subsubsection{Setting the context}

Issues of adoption, diffusion, and implementation are outside the scope of this research and consequently the literature associated with these phenomena is only lightly explored. For detailed reviews of how these phenomena are treated within the Information Technology innovation associated literature the reader is referred to the work of: (a) Lucas, Swanson, and Zmud (2007) who review implementation, innovation, and related themes in information systems research; 
(b) Melville and Ramirez (2008) who focus on IT innovation diffusion; (c) Wastell and McMaster (2008) who seek to diversify the research agenda through focusing on organisational dynamic issues; (d) Williams, Dwivedi, Lal, and Schwarz (2009) and their review of contemporary trends and issue in IT adoption and diffusion research; and (e) Wang (2009) and his exploration of new dimensions in information technology innovation concepts.

This research study seeks to diverge from the dominant paradigm as advocated by Fichman (2004) and takes a more innovative approach to the study of IT innovation. This divergence is to focus on the creation of the IT artefact and consequently focus on the actions of the external entrepreneur and internal intrapreneur who undertake innovation. Issues of entrepreneurship have, in part, been explored within the IT Innovation field through studying the phenomenon known as institutional entrepreneurship.

\subsubsection{Institutional entrepreneurship and technology innovation}

Arguments associated with Institutional Theory which looks at the relationship between structure and behaviour date back to the middle of the nineteenth century. Early articulations stressed the role of habit and history in constraining choice within social systems, with more recent arguments emphasising the importance of symbolic systems and mental maps that provide guidelines for behaviour (Scott, 2008).

In recent decades most Institutional Theory-based research studies have focused on higher level entities such as the organisation and have been strongly influenced by Structuration Theory, with institutional scholars mainly concentrating on issues of institutional change and examining modes of reinforcement, diffusion, and renewal (Scott, 2010).

Institutional Theory in organisational analysis has a limited theory action as it generally focuses on how meanings are taken for granted within the social structures that make up organisations and institutions (Fligstein, 1997). Seeking 
to extend the focus of Institutional Theory-based research studies, Fligstein (1997) incorporates the role of entrepreneurial actors and proposes a Theory of Institutional Entrepreneurship. Within the Theory of Institutional Entrepreneurship action is viewed as the outcome of social skills that institutional entrepreneurs possess and how that skill translates into institutional arrangements.

With its primary focus on skills, the Institutional Theory in organisational analysis neglects questions of agency, interest, and change in its quest to explain the broader factors that induce organisations to be the same (DiMaggio, 1988; Fligstein, 1997). As DiMaggio (1988) explains, and in the process giving rise to the term institutional entrepreneur, "new institutions arise when organized actors with sufficient resources (institutional entrepreneurs) see in them an opportunity to realize interests that they value highly" (p. 14).

Through sudden and unpredictable changes institutional actors may be thrust into action, becoming institutional entrepreneurs who, by being both strategic and opportunistic, take advantage of the uncertainty to effect change. Even though institutional entrepreneurs cannot construct the institutional order, they can influence its ultimate design through participation in the negotiation process that occurs during the period of change. Their participation and influence is manifested in the rules, norms, and beliefs that describe reality for the organisation (Hoffman, 1999).

Where Hoffman (1999) focuses on the institutional entrepreneur's influence, Garud, Hardy, and Maguire (2007) view institutional entrepreneurs as skilled actors who can draw upon existing cultural and linguistic materials to narrate and theorise changes in ways that give other social groups reason to cooperate. In short, as Garud et al., (2007) state, institutional entrepreneurship is "a concept that reintroduces agency, interest and power into institutional analyses of organizations" (2007, p. 957). 
The additional skill of leveraging is emphasised by Maguire, Hardy, and Lawrence (2004) who see the institutional entrepreneur as someone who has the ability to leverage resources to create new institutions or to transform existing ones. Where Maguire et al., (2004) and researchers such as Garud et al., (2007), and Hoffman (1999) emphasise the skills of the human actor, researchers like Lounsbury and Crumley (2007) and Van de Ven (1993a; 1993b; 2005) emphasise the skills of the institution e.g. institutions undertaking collaborations to innovate and individuals influencing the process.

Extending beyond the notion of human agency, Lounsbury and Crumley (2007) see the study of institutional entrepreneurship encompassing powerful actors such as the state or professions that are able to reshape the social organisation of fields and aid in the establishment of new dominant practices.

Dominant practices are seen by Lounsbury and Crumley (2007) as a kind of institution. They define practices as "sets of material activities that are fundamentally interpenetrated and shaped by broader cultural frameworks such as categories, frames, and other kinds of ordered belief systems" (p. 996).

An example of an institution within the IS industry, is Java and the powerful actor sponsoring the practice is Sun Microsystems. Technology standards such as Java, represent the interface specification or rules of engagement that dictate how different components of technological systems work together to provide utility to users. Through shaping common standards, institutions (where the institution is a powerful actor) can build attributes of their technologies directly into emerging institutional structures (Garud, Jain, and Kumaraswamy, 2002)

Central to the institutional based view is the notion that no one actor has sufficient resources and competencies to create change by him/her self. The entrepreneurial firm is but one actor, able to perform only a limited set of roles, and is dependent upon many other actors to accomplish all the functions needed for an industry to emerge and prosper (Van de Ven, 1993a). 
Van de Ven (2005) sees technology innovation as consisting fundamentally of a collective process of building an infrastructure that reduces the time, costs, and risks for each participating actor; each actor-firm is advised to build on their own distinctive competencies and become nodes in value chain networks. While actors (firms) are urged to cooperate, Van de Ven sees them as partisan "in the sense that they participate from their own frames of reference and often have different and conflicting interests" (2005, p. 370).

Exploring how the entrepreneurship process develops over time, Van de Ven and Engleman (2004) seek to understand how innovation happens and they reinforce a call by Aldrich (2001) to encourage entrepreneurship scholars to devote more research to the "how" question. How questions are concerned with describing and explaining the temporal sequence of events that unfold in the development of entrepreneurial ventures which seek to develop an innovation. Van de Ven and Engleman also call for researchers to answer how-related research questions using a semi-narrative style.

\subsubsection{Beyond the dominant paradigms in IT innovation research}

Entrepreneurship research tends to focus on two general questions: (a) what are the antecedents or consequences of entrepreneurship; and (b) how does the entrepreneurship process unfold over time? The vast majority of entrepreneurship research focuses on the first question, with relatively few researchers attempting to address the second question. Those that do attempt to answer the second question tend to adopt the wrong methodology as they employ variance theory methods to study questions best studied using narrative process methods (Van de Ven and Engleman, 2004).

Consequently, Van de Ven and Engleman (2004) recommend that theorists use process theories and methods to explore "how" questions and isolate meaningful elements that lead to the outcome and then derive a narrative process story that ties elements into a coherent whole. 
Event-driven explanations are built forward from observed or recorded events to outcomes. Through adopting such a perspective researchers are able to think forward, not backwards, and build event-driven explanations (Aldrich, 2001). This is depicted in Figure 1, which shows how an event leads to outcomes which in turn lead to other outcomes.

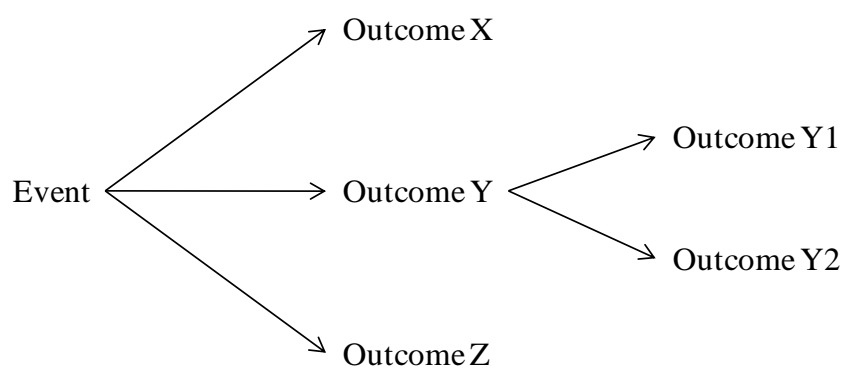

Figure 1: $\quad$ Event-driven explanations (Aldrich, 2001)

Explaining event driven outcomes can be achieved through the use of stories, a narrative that explains the relationship between events in the process (Pentland, 1999).

Recognising the value of the narrative story, Van de Ven and Engleman (2004) advocate researchers using event-driven explanations to employ Pentland's (1999) features of narrative text: (a) sequence in time - narratives should include a clear beginning, middle, and end; (b) focal actor or actors - narratives are always about someone or something that ties the events in a narrative together; (c) identifiable narrative voice - a narrative is something that someone tells in an identifiable voice that reflects an identifiable point of view; (d) canonical or evaluative frame of reference - narratives carry meaning and cultural value and embody a sense of what is right or wrong, appropriate or inappropriate, and so on; and (e) other indicators of contents and context - narrative texts typically explain more than just bare events as they contain a variety of textual devices that are used to indicate, time, place, attributes of the characters, and context so that information that is central to the interpretation of events can be provided (Pentland, 1999, pp. 712713). 


\subsubsection{In summary: information technology innovation}

The dominant research paradigm within IT research focuses on issues of diffusion, adoption, and use. Fichman (2004) calls for future research to extend beyond the dominant paradigm and for researchers to adopt more innovative approaches to the study of innovation itself.

A specialist stream of research within the technology innovation domain focuses on Institutional Theory and the institutional entrepreneur, exploring issues associated with institutional agency, as opposed to human agency.

Seeking to move beyond the dominance of "what" based research within the technology innovation and entrepreneurship domain, Van de Ven and Engleman (2004) call for "how" based event-driven research that derives narrative process stories.

IT innovation related research is a product of the mid to late $20^{\text {th }}$ century. The wider field of study related to innovation and entrepreneurship goes back to mid $17^{\text {th }}$ century.

\subsection{Entrepreneurship - an historical overview}

Ever since the pioneering work of Richard Cantillion in 1755, the phenomenon commonly referred to as "entrepreneurship" has been the focus of a growing body of literature exploring the functions and attributes of the entrepreneur. Entrepreneur is derived from the French word "entreprendre" meaning "to undertake" (Matlay, 2005); "ability to take charge" (Etemad, 2004); and when used by Cantillion indicated the general undertaking of a business (Pender, 2009). Cantillion, the first person to explore the entrepreneurial function in economics (Kalantaridis, 2004), was an Irish economist of French descent who introduced the term "entrepreneur" into economic theory to describe a person who is a specialist in taking risks (Casson, Yeung, Basu and Wadeson, 2006). 
Cantillion used the term "entrepreneur" to describe a person who "insures" workers by buying their output for resale before consumers have indicated how much they are willing to pay for it; and it is that person, the entrepreneur, who bears the risk of price fluctuations within the market place (Casson et al. 2006). By entering into contracts with suppliers at known prices in order to produce goods that could be sold later at uncertain prices, the entrepreneur received a residual profit (Ricketts, 2006).

As a concept, entrepreneurship began to be popularised through the influential work of Jean-Batiste Say who focused on entrepreneurship as a special kind of labour responsible for combining the factors of production (Pender, 2009). Say, in the early 1800's emphasised the entrepreneur's ability to "marshal" and command resources in order to respond to unfilled opportunities (Etemad, 2004).

Say is acknowledged as the first person to explicitly distinguish between the function of the entrepreneur and that of the capitalist. Say understood that the entrepreneur does not have to be rich as they are able to access and use borrowed capital (Kalantaridis, 2004). Kalantaridis (2004) goes on to state that Say also realised the role of uncertainty in the entrepreneurs' decision making process; the entrepreneur had to estimate fairly accurately the importance of a product and the probable likely demand for it.

Adding to the emergent view of the entrepreneur, Hawley (1927) introduces the issues of ownership rights. He believes that ownership rights allow the entrepreneur to make decisions about the coordination of resources to gain entrepreneurial profits in return for absorbing the uncertainty of owning those resources (Wright and Burrows, 2006).

As Hawley (1913) explains' economic activities are prompted by individualistic purposes and when combined in economic action, result in each individual voluntarily entering into productive combinations. With prearrangement these combinations are divisible and certain ownership percentages can be allocated to 
each contributor. This combination is effected by the entrepreneur; the factors of production only become economic when their results are combined by the entrepreneur to serve his/her purposes (Hawley, 1927).

Hawley argues that the enterprise of the entrepreneur was the crucial missing element in economics; even though enterprise was not a factor of production like land, labour and capital (Kalantaridis, 2004). Kalantaridis (2004) concludes that Hawley's contribution to the field of entrepreneurship was limited; while he acknowledged the role of the entrepreneurial enterprise in motivating production and dealing with uncertainty, he remained agnostic about either the cognitive or motivational influences of such people.

The notion of risk was refined by US economist Frank Knight (1921) who distinguished between risk which is insurable and uncertainty which is not (Casson et al. 2006). Knight (1921) saw risk as the objective correlative of the subjective uncertainty. Knight places emphasis on the entrepreneur's ownership (proprietorship) of the resources of production and responsibility for decision taking and the pursuant risks associated with the decision (Hunter, 2005; Hunter and Wilson, 2007).

Knight (1921) viewed the entrepreneur as "the owner of all real wealth and ownership involves risk; the coordinator "makes decisions," but it is the entrepreneur who "accepts the consequences of decisions."” (p. 33). The entrepreneur, by making decisions based on uncertainty and accepting risk, obtains the opportunity to make profit. The notions of risk and uncertainty and the ambiguities therein are at the foundation of Knight's core theories.

Knightian uncertainty (Knight, 1921) has been described as longitudinal uncertainty because of its time-dependent characteristics. No agent in the system can possess accurate knowledge of the future, owing to the fact that much knowledge relevant to the prediction of the future has not yet been created by any economic agent (Dew, Velamuri, and Venkataraman, 2004). Over time, an 
entrepreneur's Knightian uncertainty regarding an idea gradually diminishes and moves towards the category of Knightian risk (Velamuri and Venkataraman, 2005). Once the decision is made, risk becomes the key issue.

Where Knight associated risk with the entrepreneur, Joseph Alois Schumpeter saw risk as the function of the capitalist who lent money to the entrepreneur. Schumpeter saw the entrepreneur as the innovator, the individual who introduces new combinations of production factors (Kalantaridis, 2004). Foundation theory associated with entrepreneurial opportunity and product innovation is associated with Schumpeter's work and his analysis of the purely economic features of capitalistic society during the period 1907 - 1909. This analysis was first published in his native language of German in 1911, from which an English translation was made in 1934. While Schumpeter was an economist and associated with the Austrian School of Economics, his contribution cannot be classified as strictu sensu i.e. belonging to a specific school of thought (Cassis and Minoglou, 2005).

Schumpeter rejected the prevalent view at the time, that economic change is induced exogenously and that entrepreneurial activity is a response to exogenous force. He constructed an alternative perspective, the endogenous growth theory, which sees the entrepreneur as the source of all dynamic change in the economy (Cassis and Minoglou, 2005).

Schumpeter maintains that the function of the entrepreneur is to innovate, or to carry out new combinations (Casson, 1982). Schumpeter (1934) distinguishes between five types of innovation: (a) the introduction (or improvement) of new goods, (b) introduction of new methods of production, (c) opening of new markets, (d) the conquest of new sources of supply of raw-materials or halfmanufactured goods, and (e) the creation of a new type of industrial organisation.

Not only did Schumpeter see the entrepreneur as the innovator, he also saw them as the person who foresaw the entrepreneurial opportunity through their ability to 
see things differently. For entrepreneurship to occur, Schumpeter (1934) maintains that resource owners should not share the same resource conjectures (inference or judgment based on inconclusive or incomplete evidence) and that if all potential entrepreneurs shared the same entrepreneurial conjecture they would compete to capture the same entrepreneurial profit. Should this occur, the conjecture would be divided to a point where the incentive to pursue the opportunity was eliminated (Shane and Venkataraman, 2000). Or as Shane and Cable (2002) posit, if other entrepreneurs possessed the same beliefs and information, competition between entrepreneurs would eliminate the entrepreneurial opportunity.

Shane and Cable (2002) also emphasise Schumpeter's belief that the exploitation of an entrepreneurial opportunity requires the entrepreneur to believe that the expected value of the entrepreneurial profit will be large enough to compensate for the opportunity cost of other alternatives.

Schumpeter believes that the existence of entrepreneurial opportunities could be explained by new information; he maintains that changes in technology, political forces, regulation, economic environment, and social trends create new information that entrepreneurs can use in order to figure out how to recombine resources into more valuable forms (Shane, 2003).

Schumpeter's notion of entrepreneurship has been associated with the "high level" kind that has historically led to the creation of railways, development of chemical industries, and the growth of integrated oil companies. The much more common "low level" entrepreneurship carried out by the ordinary firm or individual was to be explained, as the Austrian School of Economics evolved, through the work of Hayek (1937) and, later, Kirzner (1973) (Casson et al. 2006). 


\subsubsection{Treatment of entrepreneurship within the Austrian School of Economics}

The Austrian School is credited with providing one of the most coherent and theoretical frameworks to understand entrepreneurship (Kalantaridis, 2004). The Austrian School of Economics was influential in the late 19th and early 20th century and was profoundly pro-free market, anti-socialism and anti-fascism (Kiessling, 2004). As Kiessling (2004) summarises, the Austrian School of Economics was founded in the work of Austrian economist Carl Menger and supporters of his work such as Eugen von Bohm-Bawerk and Friedrich von Wise, both of whom were teachers of Schumpeter, one of its most famous champions. At the heart of this school of thought is the notion that the key process in economic change is the introduction of innovations, with the central innovators being the entrepreneurs, as they are the initiators of the change process.

In the Austrian models of market process, the entrepreneur initiates change in the market by identifying and introducing new trading opportunities. Such change is dependent on the drive and ability of entrepreneurs to discover and exploit opportunities that are unknown to other agents until they are initiated by the entrepreneur (Carter, 2006). Carter (2006) explains the market process, as espoused by 20th century economists within this school of thought such as Hayek (1937; 1945) and Mises (1949), as one of dynamic competition between agents.

With, Hayek focusing on how knowledge is disseminated amongst market participants and Mises stressing the role of profit-seeking by entrepreneurs driving the process.

According to Hayek (1945) knowledge never exists in concentrated or integrated forms. It exists as dispersed bits of incomplete and frequently contradictory knowledge which are held by separate individuals; hence the economic problem is how to acquire and use knowledge when it is not held in totality by any one person. 
Hayek's view of the world is one where there is a continuous process of minor discoveries brought about by individuals attending to their wants at any particular time of need. Hayek (1937) contends that the part of economic theory which is concerned with causes, effects, and conclusions and is capable in principle of verification is made up of propositions about the acquisition of knowledge How an individual perceives that knowledge and shapes it is influenced by the individual's prior experiences. Therefore, Hayek sees entrepreneurs as key economic agents who gather together partial and localised information and knowledge in order to generate hypotheses that are subsequently tested, confirmed, or refuted (Kalantaridis, 2004).

Mises' view of the entrepreneur within economic theory is of the acting man who reacts to changes occurring in the data of the market and, through such action, earns profit or suffers loss (Mises, 1949).

For every acting man, as Mises (1949) refers to the phenomenon, success or failure depends on how they deal with the uncertain conditions of the future and the correctness of their anticipation of uncertain events. As Mises sees it, this action, human action, is one of the fundamental elements of cosmic activity that brings about change and therefore is a legitimate object of scientific investigation. Specifically:

HUMAN action is purposeful behavior. Or we may say: Action is will put into operation and transformed into an agency, is aiming at ends and goals, is the ego's meaningful response to stimuli and to the conditions of its environment, is a person's conscious adjustment to the state of the universe that determines his life (Mises, 1949, p. 11).

Mises (1949) uses the term entrepreneur-promoter to describe those humans who have more initiative, are more venturesome, have a quicker eye than the crowd, push and promote economic improvement. The promoter concept refers to a 
general characteristic of human nature that is present in all market transactions. Consequently, Mises views the entrepreneur-promoter through their restlessness and eagerness to make large profits as the prime driving force in the market.

Mises and Hayek, from the 1930's onwards, steered the Austrian tradition in a direction sharply different to that of the mainstream micro-economic theory of the time and renewed interest in the Austrian tradition and its ability to understand and explain competitive market processes (Kirzner, 1997).

Israel Kirzner was also recognised as a leading scholar within the neo-Austrian School and he extended the tradition through adding a focus on alertness to currently unexploited opportunities for trade (Ricketts, 2006). As Ricketts further comments, Kirzner saw pure profit as not so much a return for bearing uncertainty but more a reward for pure alertness

Kirzner (1973) takes and extends the Misesian notion of human action and sees it both as a task that identifies a relevant means-ends framework and as efficiency seeking behaviour where the entrepreneur undertakes an integrated set of human activities. For instance, once the entrepreneur has completed some entrepreneurial decision making process and acquired the resources necessary to produce the commodity, they establish a firm to aid in the ownership and combination of the resources so they may maximise the profit potential. At this point the entrepreneur may be seen as no longer a "pure entrepreneur" in that thereafter they may receive quasi-rents to be derived from the ownership of the already acquired resources.

Through the continuing operation of the firm the entrepreneur-owner may go on to exploit opportunities for deploying the already acquired resources of the firm in profitable new ventures. Thus, as Kirzner (1973) maintains, the entrepreneur may once again be seen as a pure entrepreneur as they purchase the firm's internal resources at a low market rate and turn them into a profit through ventures that other firms have not realised as being attractive. 
Kirzner's $(1973 ; 1997)$ view of entrepreneurship differs to that of Schumpeter's (1934) perspective in that Kirzner argues that the existence of opportunities requires only differential access to existing information, whereas Schumpeter believes that new information is important in explaining the existence of entrepreneurial opportunities (Sane, 2003). As Shane (2003) further explains Schumpeter argues that changes in such things as technology, political forces and social trends create new information that entrepreneurs can use to figure out how to recombine resources into new more valuable forms.

From Kirzner's perspective, the profits that accrue to the entrepreneur cannot be related to the value of any resource, but are instead the reward for alertness and for making the right conjectures as the alert entrepreneur spots opportunities and carries out the steps to eliminate the inconsistencies they imply (Metcalfe, 2006).

\subsubsection{In summary: historical and economic overview}

The study of entrepreneurship originates from the mid 1700's through economic based theories and associated literature. The entrepreneur is seen as someone that undertakes change and combines the resources of productions to create new combinations. Issues of differences, uncertainty, and newness are seen to be at the heart of the entrepreneurial function.

\subsection{Modern day study of entrepreneurship}

Modern day perspectives on entrepreneurship are, in many respects, a synthesis and extension of the views of entrepreneurship developed at the turn of the 20th century (Casson, 1982). Casson (1982) concludes that, while there are a number of differences, on the whole the similarities of modern day theories with those of the early $20^{\text {th }}$ century are more significant than their differences. 
In a similar vein, Cassis and Minoglou (2005) maintain that there is no definitive theory of entrepreneurship but a coexistence of alternative interpretations entwined with historical theory. Consequently to understand entrepreneurship one must first begin with an appreciation of the core concepts.

At its core, entrepreneurship can be construed in terms of arbitrage, innovation, and risk taking, and the entrepreneur as a specialist in taking difficult and complex decisions which other people do not want to take responsibility for (Casson et al., 2006). Entrepreneurship is also a self-directed activity that does not occur spontaneously due to the presence of technology or industrial change, but requires the actions of individuals who identify and pursue opportunities which, themselves, lack agency (Shane, 2003).

The entrepreneur is seen as a specialist in finding and leveraging resources (Morris, 2002), and in prying resources away from existing users (Rao, 1998). They carry out these activities in order to pursue entrepreneurial opportunities and bring their product and/or service innovation into being, in disregard of the resources they control or have at their disposal (Stevenson and Jarillo, 1990). The entrepreneur goes about these tasks by balancing variables such as risk taking, innovativeness, and proactiveness (Miller, 1983).

The work of Miller (1983) consolidates much of the early work and perspectives specific to entrepreneurship to offer a multidimensional concept of entrepreneurship encompassing the firm's actions related to product-marketing and technology innovation. Miller defined the entrepreneurial firm as "one that engages in product-market innovation, undertakes somewhat risky ventures and is first to come up with "proactive" innovations, beating competitors to the punch" (1983, p. 771). Miller concluded that entrepreneurship is a composite weighting of these three variables: risk taking, innovation, and proactiveness.

While Miller (1983) advocates a multidimensional perspective, it was still grounded at the individual and/or the entrepreneurial firm level. The work of 
Burgelman (1983), published at the same time as that of Miller, introduced the concept of internal entrepreneurship as opposed to external entrepreneurship.

Burgelman sees external entrepreneurship as a first order phenomenon consisting of "the individual entrepreneur's process of combining resources dispersed in the environment with his or her own very unique resources to create a new combination that is basically independent of all other resource" (1983, p.1354). Through focusing on where resources are located, Burgelman is able to differentiate between external and internal entrepreneurship.

Where the external entrepreneur combined resources located within the wider environment, the internal entrepreneur mainly used resources nested within the institution. This additional perspective saw internal entrepreneurship as involving "new resource combinations which remain, to some extent, nested in the larger resource combination constituted by the firm, and thus also retain at least a potential degree of dependence on it" (p.1354).

Burgelman's definition of entrepreneurship is important as he extends the focus to the internal participants, while also stressing the process of resource combining between the focal firm and external parties. Both Miller's and Burgelman's perspective were extended by later researchers.

Morris and Paul (1987) use Miller's multidimensional concept as the foundation for their exploration of approaches to strategic decision making. The propensity of a company's top management to take calculated risks and their proactiveness in making strategic decision where seen by Morris and Paul (1987) as critical factors in determining a firms entrepreneurial orientation.

This early view of entrepreneurial orientation was extended by Morris and Lewis (1995) to include attitudinal and behavioural components in order to encompass the willingness of the individual or organisation to embrace opportunities. 
In line with Burgelman's perspective, Caruana, Morris, and Vella (1998) define entrepreneurship "as the process of creating value by bringing together a unique package of resources to exploit an opportunity" (p. 16). Similarly, Stevenson and Jarillo (1990) maintain that "The essence of entrepreneurship is the willingness to pursue opportunity, regardless of the resources under control... We are seeing the entrepreneurial phenomenon whenever opportunity requires resources beyond those controlled is being pursued" (p. 23).

A slightly different perspective is offered by Venkataraman (2002), whereby entrepreneurship is concerned with how the opportunity to create "value" in society is discovered and acted upon by some individuals. Value is deemed to be embodied in products and services. Higher levels of entrepreneurship are seen to be directly associated with increases in Gross Domestic Product (GDP), societal wealth, and quality of life (Morris, 2001). As Morris (2001) states, "the more entrepreneurship there is, the more economic development occurs" (p. v).

Miller's (1983) focus on the entrepreneur, entrepreneurial firm, and variables of risk taking, innovation, and proactiveness as well as the process and economic based perspectives of Schumpeter (1934) and Knight (1921) and their respective concepts of entrepreneurial opportunity and Knightian uncertainty, are the foundation for understanding and leveraging the entrepreneurial concept.

But as Stevenson and Jarillo (1990) counsel: (a) it is individuals who carry out entrepreneurial activities, no matter how they are defined; and (b) their characteristics personality, background and skills matter. 


\subsubsection{Modern day study of the entrepreneur}

In small centralized firms, entrepreneurship is predominantly influenced by the leader: his personality, his power, and his information. He is in a position sufficiently powerful to override structural and environmental obstacles to entrepreneurship. (Miller 1983, p. 773)

The entrepreneur is the company founder and innovator within their own firm (Miller, 1983). A functional definition of the entrepreneur associating them with their management of risk is offered by Casson (1982) where the: "entrepreneur is someone who specialises in taking judgemental decisions and the coordination of scarce resources" (p. 23). Alternatively, Casson and Godley (2005) provide what they term an "indicative based definition" and define entrepreneurs as "those who exercise entrepreneurial judgement" (p. 31). Entrepreneurial judgement refers to an entrepreneur possessing the quality of judgement required to improvise a decision successfully when no agreed decision is available (p. 30).

Where the functional perspective simply states that an "entrepreneur is what an entrepreneur does", the indicative based perspective provides a description of the entrepreneur through how they may be recognised (Casson 1982, p. 22). Casson (1982) places emphasis on the skilled actions that an entrepreneur carries out and how they successfully exploit their superior judgement. The entrepreneur has to routinely call upon a variety of different skills, such as: (a) negotiating tactics; (b) ability to innovate; and (c) skills in the less glamorous aspect of business management such as inventory management and quality control.

Rather than focusing on risk, Venkataraman (2002) places the focus squarely on resource combining, defining an entrepreneur "as one who realizes or conjectures (either through genuine insight and knowledge, or through mere luck) that some resources are underutilized in their current occupation and recombines them into a potentially more useful and fruitful combination" (p. 51). 
Studies by Shane (2000), Shane and Venkataraman, (2000), and Shane (2002) found that who becomes an entrepreneur depends more on information and opportunities than on the psychological attributes. Consequently, Venkataraman and Shane (2000) caution against the use of narrowly defined and person centric definitions of entrepreneurs which do not account for how the entrepreneur recognises entrepreneurial opportunities. As they conclude, to have entrepreneurship, you must first have entrepreneurial opportunities; the entrepreneur must not only discover an opportunity they must also exploit it.

Because people do not always need legal entities when they organise, the exploitation of an opportunity does not have to involve the entrepreneur creating a new legal entity (Shane, 2003). By way of explanation Shane (2003) gives the examples of a group of traders that gather together to smuggle goods into a country, or an entrepreneur who provides a licence to others allowing them to exploit the opportunity. But Shane then explains at length that, in order to exploit an opportunity for which they have gathered resources, the entrepreneur must also engage in organising activity that involves the creation of routines and structures.

Aligning with a more economic based perspective, Kalantaridis (2004) sees the entrepreneur as an economic agent and as someone who puts together the factors of production, as well as contracts with other entrepreneurs and economic actors in a network of product and distribution. Within this perspective, the entrepreneur is differentiated from the salaried manager in that they are able to make judgemental decisions about the process in its entirety. Kalantaridis paints the picture of the entrepreneur as "a multidimensional economic agent who is active and unified in specific contexts" (2004, p. 87). In support of this perspective, Kalantaridis (2004) refers to Granovetter (1985) and his concept of contextualised human behaviour, where human actors operate within social contexts and, consequently, their purposive actions are embedded in concrete, ongoing systems of social relations. 


\subsubsection{In summary: modern day study of entrepreneurship and the entrepreneur}

Entrepreneurship must be enacted, through the actions of entrepreneurial individuals who are skilled in making judgemental decisions. Research moves beyond economic based environmental considerations to include attitudinal, motivational, and skill based characteristics associated with the entrepreneur. The phenomenon of entrepreneurship is increasingly perceived as involving both internal and external elements.

\subsection{Corporate entrepreneurship, intrapreneurship, and the intrapreneur}

Over time, the field of entrepreneurship-based research began to account for entrepreneurial activity found within corporate environments. Burgelman (1983), a pioneering researcher in this field, saw corporate entrepreneurship as a process where firms engage in diversification through internal developments that are typically the result of interlocking entrepreneurial activities of multiple participants. Within this context, the role of entrepreneurial activity is to provide the required diversity.

Where Burgelman favoured the term "corporate entrepreneurship", Pinchot (1985) made popular the term "intrapreneuring" and resulting variants such as "intrapreneur", which Pinchot describes as his shorthand for "intracorporate entrepreneur". In the broadest sense, "intrapreneurship" is entrepreneurship within an existing organisation (Antoncic and Hisrich, 2001).

An equally broad definition of corporate entrepreneurship is provided by Sathe (2003) who describes it as new business creation in a corporate division. Sathe (2003) notes, however, that some regard the term "corporate entrepreneurship" as an oxymoron because a popular image of corporate executives in the 1950s and 1960s was of conservative, bureaucratic, grey suit wearing people, which in the 1980s and 1990s gave way to short-term thinkers unwilling to take risk. Further to this, in the post-Enron era, images of greed and wealth transfer at the expense of shareholder are commonly associated with corporate entrepreneurs. 
Antoncic and Hisrich (2001) extend their broad definition of corporate entrepreneurship as entrepreneurship within an organisation to include "a process that goes on inside an existing form, regardless of its size, and leads not only to new business ventures but also to other innovative activities and orientations" ( $p$. 498).

Extending Burgelman's (1983) base perspective and favouring the corporate entrepreneurship terminology, Stevenson and Jarillo (1990) add a Schumpeterian orientation and see corporate entrepreneurship as a process, where individuals within the organisation spot and pursue opportunities which require resources beyond those they control.

Reviewing literature associated with the wider field of entrepreneurship, Stevenson and Jarillo (1990) conclude that the focus of entrepreneurship based research can be divided into three categories: (a) what happens when entrepreneurs act; (b) why they act; and (c) how they act.

How the corporate entrepreneur acts is the focus of Stevenson and Jarillo's (1990) research which sought to analyse characteristics of entrepreneurial management and how entrepreneurs were able to achieve their aims. It did not seek to understand issues of personal motivation and was oblivious to environmental inducements and effects of such action. The authors comment that "how" orientated research may extend to covering how entrepreneurs use and manage networks to access and control resources.

Adding the aspect of innovation, alongside opportunities and resources, Ireland, Kuratko, and Morris (2006) define corporate entrepreneurship as "a process through which individuals in an established firm pursue entrepreneurial opportunities to innovate without regard to the level and nature of currently available resources" (p. 10). Rather than seeing innovation as the output of the process, Ireland et al. (2006) place emphasis on how established firms use innovation to pursue entrepreneurial opportunities. When corporate entrepreneurs 
adopt what the authors refer to as an entrepreneurial mindset, actors within established firms are able to increase their ability to sense opportunities and mobilise resources and the knowledge required to exploit them under conditions of uncertainty and environmental change.

Corporate entrepreneurship is also seen as a means by which organisations renew themselves; it revitalises, reinvigorates, and reinvents and is the spark and catalyst that places firms on the path to competitive superiority (Covin and Morgan, 1999). It is both a source of organisational renewal (Sathe, 1985) and a means of new business creation undertaken by existing businesses (Sathe, 2003). A firm's external environment, corporate strategy, and internal organisational factors may influence the intensity of corporate entrepreneurship activities undertaken within the firm (Zahra, 1991).

Reviewing literature associated with corporate entrepreneurship/intrapreneurship, Antoncic and Hisrich (2001) conclude that previous views of entrepreneurship can be classified into four dimensions: (a) new business venturing; (b) innovativeness; (c) self-renewal; and (d) proactiveness (see Table 1 for further explanation).

In a later collaboration, Antoncic and Hisrich (2003) provide a refined construct of intrapreneurship and add four new factors to their original dimensions: (a) risk taking; (b) competitive aggressiveness, and split out; (c) new business venturing into new ventures and new businesses; and (d) innovativeness into product/service innovativeness and process innovativeness. Accordingly, they provide an updated and refined definition of intrapreneurship as "an essentially activity-based or activity-orientated concept that operates at the organizational boundary and stretches current organizational products and services, technology, norms, orientations, structures or operations into new dimensions" (p. 20). 
In addition to the dimensions of intrapreneurship, Antoncic and Hisrich (2001) identify two main sets of antecedents: (a) intra-organisational environments, and (b) the firm's external environment. Antoncic and Hisrich's (2003) eight dimensions of intrapreneurship are adopted by Monnavarian and Ashena (2009) who focus on the organisational side of intrapreneurship in order to understand the role social capital plays in intrapreneurship. Researching a number of managers within a single organisation and using construct analysis, Monnavarian and Ashena (2009) detected and validated four of Antoncic and Hisrich (2003) dimensions: (a) innovation, (b) competitive aggressiveness, (c) proactiveness in business, and (d) risk taking.

The eight dimensions of intrapreneurship - as espoused by Antoncic and Hisrich (2003) and as validated in part by Monnavarian and Ashena (2009) are summarised in Table 1.

Table 1: $\quad$ Antoncic and Hisrich's (2003) dimensions of intrapreneurship

\begin{tabular}{|l|l|}
\hline $\begin{array}{l}\text { Dimension of } \\
\text { intrapreneurship }\end{array}$ & $\begin{array}{l}\text { Definition as per Antoncic and Hisrich } \\
\mathbf{( 2 0 0 3 )}\end{array}$ \\
\hline New Ventures & $\begin{array}{l}\text { Creation of new autonomous or semi } \\
\text { autonomous units or firms }\end{array}$ \\
\hline New Business & $\begin{array}{l}\text { Pursuit of and entering into new businesses } \\
\text { related to current products or markets }\end{array}$ \\
\hline $\begin{array}{l}\text { Product/Service } \\
\text { Innovativeness }\end{array}$ & Creation of new products and services \\
\hline $\begin{array}{l}\text { Process } \\
\text { Innovations }\end{array}$ & $\begin{array}{l}\text { Innovations in production procedures and } \\
\text { processes }\end{array}$ \\
\hline Self-renewal & $\begin{array}{l}\text { Strategy reformulation, reorganisation, and } \\
\text { organisational change }\end{array}$ \\
\hline Risk Taking & $\begin{array}{l}\text { Possibility of loss due to quickness in taking } \\
\text { bold actions and committing resources in the } \\
\text { pursuit of new opportunities }\end{array}$ \\
\hline Proactiveness & $\begin{array}{l}\text { Top management orientation for pioneering } \\
\text { and initiative taking }\end{array}$ \\
\hline $\begin{array}{l}\text { Competitive } \\
\text { Aggressiveness }\end{array}$ & \begin{tabular}{l} 
Aggressive posturing towards competitors \\
\hline
\end{tabular}
\end{tabular}


The dimensions of intrapreneurship as developed by Antoncic and Hisrich (2003) are primarily organisation focused, but as previously discussed, Stevenson and Jarillo (1990) emphasise that it is individuals within organisations that spot and pursue opportunities. Organisations are inanimate and cannot therefore engage in discovery; that is the domain of people employed within the organisation (Shane, 2003).

\subsubsection{Intrapreneur}

The term "intrapreneur" entered popular usage through the work of Gifford Pinchot III and the publication of his (1985) bestselling book, titled "Intrapreneuring". For Pinchot (1985), the intrapreneur is someone who may be the creator or inventor, but is always the dreamer who takes hands-on responsibility and figures out how to turn an idea into a profitable reality within an organisation. Conversely, the entrepreneur is someone that fills the role of the intrapreneur outside the organisation. The corporate intrapreneur is very much like the entrepreneur in that both take personal risks to make new ideas happen, but they work within large organisations, as opposed to being outside them.

Inherent in Pinchot's (1985) view of intrapreneurship is the notion that the intrapreneurs must have the freedom to innovate and that the climate of the organisation must encourage and reward such behaviour (Kolchin and Hyclak, 1987). Kolchin and Hyclak, (1987) also comment that Pinchot sees the intrapreneur as someone that thrives on learning how to manipulate and work within systems in order to accomplish his or her vision; someone who is adept in getting others to agree to their personal vision.

Seeking to compare and contrast the behaviours of entrepreneurs and intrapreneurs, Luchsinger and Bagby (1987) provide a consensus view as to the meaning of the word entrepreneur. They took the French root of the word entrepreneur, "enterprise", and matched it with the German equivalent "unternehmen" meaning to "undertake". Thus, they define entrepreneur to mean "a person who undertakes risks to begin or maintain a productive operation, 
usually in an independent capacity" (p. 10). Reviewing available literature at the time, Luchsinger and Bagby (1987), discuss the main differences between entrepreneurs and intrapreneurs - as summarised in Table 2.

Table 2: $\quad$ Summary of differences between entrepreneurs and intrapreneurs as discussed by Luchsinger and Bagby (1987)

\begin{tabular}{|l|l|}
\hline Contrast -Entrepreneurs & Contrast - Intrapreneur \\
\hline Provider of his or her own setting & $\begin{array}{l}\text { Operates within the setting of an established } \\
\text { organisation with structural and procedural } \\
\text { constraints }\end{array}$ \\
\hline $\begin{array}{l}\text { Have more control over their environments, } \\
\text { especially the internal }\end{array}$ & Have low control over their environments \\
\hline Bears their own financial risk & $\begin{array}{l}\text { Financial risk is borne by the intrapreneur's } \\
\text { company }\end{array}$ \\
\hline Failure means bankruptcy & Can return to the parent organisation \\
\hline $\begin{array}{l}\text { Have to obtain their own administrative and } \\
\text { operational support }\end{array}$ & $\begin{array}{l}\text { The innovative company can provide a source of } \\
\text { administrative and operational support. }\end{array}$ \\
\hline Are typically the boss & $\begin{array}{l}\text { Likely to report to a superior and must seek internal } \\
\text { sponsorship especially in the face of internal } \\
\text { criticism or resistance. }\end{array}$ \\
\hline
\end{tabular}

Luchsinger and Bagby (1987) also provide some limited comment on the similarities between entrepreneurs and intrapreneurs, Both the entrepreneur and intrapreneur relies heavily on teamwork and group innovation and both have the potential to mobilise innovation and resources on behalf of worthy projects.

Additional differences are identified by Chisholm (1987), especially around the role of rewards. Chisholm (1987) sees the intrapreneurs as those who are mainly inspired by challenge and who succeed in the face of obstacles. They typically do not aspire to huge economic rewards from their endeavours as the ultimate purpose of intrapreneurship is the advancement of the corporation. It is the corporation that captures the economic benefit and it is for the organisation to decide if it will share any of the economic benefit with the intrapreneur.

Conversely, entrepreneurs are commonly seen to be motivated, at least in part, by economic gain and wealth creation and it is up to them how they share that benefit as they progress through their ventures. The entrepreneur may be seen to have a sense of equanimity which enables them to accept that at some stage they will get 
it wrong; whereas bureaucratic organisations are often seen as intolerant of failure and, as a result, the intrapreneur may lose employment in the organisation (Chisholm, 1987).

While in the mid to late 1980s there was an initial burst of articles focusing on the role intrapreneurs play within organisations and the behaviours that are associated with their actions, there has been a dearth of literature since then with researchers and authors favouring investigations into entrepreneurship and innovation by corporations and the diffusion and adoption process associated with new technologies.

In one of the few recent studies that take a person-centric view of intrapreneurship, Brunåker and Kurvinen (2006) see the intrapreneur acting "not as a change agent for someone else's intentions but as a self appointed actor who initiates and drives the process of creating unequivocal interpretations of equivocal events" (p. 118).

These authors researched operational managers and engineers in a multinational pulp and paper company and found that the intrapreneur was someone from inside the organisation who had a thorough knowledge of the local operation and its strength and weaknesses. That person typically set out to deal with problems they faced in an unconventional way and by using resources that could be generated. They acted on their own initiative and were not invited to act by anyone else Brunåker and Kurvinen (2006). This implies anyone could become an intrapreneur.

\subsubsection{In summary: corporate entrepreneurship, intrapreneurship, and the intrapreneur}

The corporate intrapreneur, as differentiated from the external entrepreneur, is someone that acts in the interest of the organisation and uses organisational resources to carry out their activities within internal organisational boundaries. Corporate intrapreneurs are often self appointed actors that identify potential 
improvements within their specialist functional domains and undertake the necessary actions to bring about innovations.

An example of corporate intrapreneurship is provided by Nonaka (1994) in his discussion of the activities of new product development team at Matsushita's Home Bakery. Nonaka does not recognise the activity of Tanaka and colleagues as intrapreneurial, as he was using their activities to describe his theory of Organisational Knowledge Creation, yet intrapreneurial they were. As Brunåker and Kurvinen (2006) state, intrapreneurs are typically people that set out to deal with problems they face in an unconventional ways. A software engineer working with a master baker to solve a problem on how to knead bread in a home bread making machine is an example of intrapreneurship within organisation. 


\subsection{Organisational Knowledge Creation Theory}

Within this section, Organisational Knowledge Creation Theory is described and discussed as it informs the theory developed in this study. Focus is placed on how knowledge creation relates to innovation and how knowledge that is intangible is made tangible through the process of knowledge conversion.

\subsubsection{Innovation, entrepreneurship and Organisational Knowledge Creation Theory}

Organisational Knowledge Creation Theory has been associated with product innovation from its conception, through Nonaka's (1994) using the development of a new automatic home bread making machine by a product development team to illustrate his theory. Nonaka and von Krogh (2009) go as far as declaring that Organisational Knowledge Creation Theory aims to explain creativity, change, and innovation within an organisation.

Innovation is seen from a knowledge creation viewpoint as the process where an organisation creates and defines problems and then actively develops new knowledge to solve them (Nonaka, 1994). With specific reference to product development, Ichijo and Nonaka (2007) describe it as an innovation independent of an existing business's daily operation. It brings together representatives from a number of different functional areas to interact and create new knowledge in the form of new products.

Innovation is not just linked to new products but also with renewal. As Ichijo and Nonaka (2007) maintain, the "essence" of innovation is that an organisation seeks to recreate the world according to a particular ideal or vision; it is a highly individual process of personal and organisational self renewal. Ichijo and Nonaka stress that the personal commitment of the individual and their identification with the company and its mission becomes indispensable to the innovation process. 
While innovation is intrinsically linked with Organisational Knowledge Creation Theory, there has been little discussion on the linkage between entrepreneurship and knowledge creation. As Nonaka et al. (2006) comment, there has been limited use of entrepreneurship research within Organisational Knowledge Creation Theory and in particular the origins of knowledge and the origins of the firm.

One of the few times when Nonaka makes a direct reference to entrepreneurship is in relation to leadership, and even then it is to point out the different perspectives. Nonaka and Toyama (2007) pose the question as to what might drive a firm to create knowledge continuously. They considered Schumpeter's argument that innovations are brought about by entrepreneurial leaders who are part of society's elite. But this perspective did not fit with Nonaka and Toyama's view of leadership within the organisational context, as leadership in the knowledge creating firm is based on flexible distributed leadership rather than leadership as a fixed control mechanism; that is, leadership is not just the domain of a few elite members.

\subsubsection{Organisational Knowledge Creation Theory an historical overview}

In the early 1990s Ikujiro Nonaka and his colleagues laid the foundation for what was to become a formal Theory of Organisational Knowledge Creation. This theory seeks to explain performance differences among firms which are attributable to the result of goals and strategies, as opposed to issues of market failure and economic based theories (Nonaka and Toyama, 2007). The theory places emphasis on capturing and amplifying knowledge created by individuals within an organisational context and connecting it to the organisation's knowledge systems (Nonaka and von Krogh, 2009). 
The historical roots of this theory are traced back to the early 1980s when a software developer, Ikuko Tanaka, worked alongside a master baker in order to study dough kneading techniques. At the time, Tanaka was part of a new product development team seeking to make a fully automatic home bread making machine, but the bread produced from the first prototype was of poor quality and taste.

Trying to understand why the machine could not produce good quality bread, Tanaka suggested that, to see how bread is made and to study the kneading technique which is a critical part of the process, they should train with a head baker who had a reputation for making the best bread. Whilst working alongside this baker, Tanaka learned how to make bread and developed her kneading skills through observation, imitation, and practice, but both she and the baker were unable to articulate to the engineers working on the new product development project how the kneading was done. Ultimately, Tanaka came up with the descriptive phrase "twist stretch" to provide a rough image of the kneading process both she and the master baker used. This description helped the engineers to design a propeller that mimicked the strength and speed of the kneading process, which was important to activate the yeast and sugars in the dough in order to make nice tasting bread (Nonaka and Takeuchi, 1995).

For Nonaka and Takeuchi (1995) this new product development initiative provided an excellent illustrative case study by which to develop and demonstrate their theory of organisational knowledge creation. As the machine embodied the skills of a master baker in a device that can be operated by people with no knowledge of bread making, the product development team had captured the skills of a master baker in such a way that they were able to mimic them in an electricalmechanical dough-kneading process; effectively they had taken the master baker's tacit knowledge and made it explicit.

The bread baking machine example captured the basic principles of what Nonaka (1994) initially called a Dynamic Theory of Organisational Knowledge Creation, 
which looked at four patterns of interaction between tacit and explicit knowledge. This framework was to become known as the Spiral of Knowledge, more commonly known as the SECI model. SECI stands for Socialisation, Externalisation, Combination and Internalisation Model and is discussed in depth in the later part of this section. This theory and its associated four stage model of knowledge conversion, the SECI model, sought to explain what individuals come to know in their work lives and how that knowledge benefits their colleagues and, ultimately, the larger organisation (Nonaka, von Krogh, and Voelpel, 2006).

In the organisational knowledge creation process individuals interact with other individuals, both internal and external to the firm, in order to transcend their own boundaries and "as a result, change themselves, others, the organisation, and the environment" (Nonaka and Toyama, 2007, p. 16); consequently it may be viewed as a dialectical process, in which contradictions are synthesised through the dynamic interactions among individuals, organisations, and the environment (Nonaka and Toyama, 2003). Organisational knowledge creation, as opposed to individual knowledge creation, takes place when all four modes of knowledge creation are "organizationally" managed to form a continual cycle (Nonaka, 1994).

The Theory of Organisational Knowledge Creation has attracted little systematic criticism Gourlay (2006). For Gourlay (2006) knowledge creation theory is better seen as a theory of managerial decision making rather than one of knowledge creation theory and knowledge conversion. Also as Hildreth and Kimble (2002) point out if we accept Polanyi's view of tacit (implicit) knowledge as being inexpressible, it cannot be converted into explicit knowledge because it can never be externalised and written down in an explicit form as knowledge in not only tacit it is inherently tacit. Rather than seeing these points as flaws in the Theory of Organisational Knowledge Creation, Nonaka and von Krogh (2009) maintain they are explained within the theory as tacit / explicit distinction along a knowledge continuum allows the conceptual basis for knowledge conversion to be more fully understood. 
Over time, Nonaka and colleagues have refined and expanded the Organisational Knowledge Creation Theory to the point where it now consists of three key elements: (a) the SECI knowledge conversion process, where knowledge is created through the conversion of tacit and explicit knowledge; (b) " $b a$ ", the shared context for knowledge creation; and (c) knowledge assets, which are the inputs, outputs, and moderators of the process (Nonaka, Toyama, and Konno, 2000). These three elements are discussed in detail in the next sections, along with a detailed discussion of knowledge as viewed within the knowledge creation context and the concept of knowledge conversion which explains how tacit and explicit knowledge interact along a continuum (Nonaka and von Krogh, 2009).

\subsubsection{Knowledge: an expanded definition}

Extending Nonaka's (1994) original definition of knowledge as a "justified true belief', Nonaka and von Krogh (2009) take the opportunity to provide an expanded definition of knowledge as used within Knowledge Creation Theory. They see knowledge as comprising three complementary properties: (a) individuals justify their beliefs based on their interactions with the world; (b) knowledge is the actuality of skilful action that allows individuals to define, prepare, shape, and learn to solve a task or problem; and (c) knowledge is explicit and tacit along a continuum.

In relation to the third property of knowledge as a continuum, Nonaka and von Krogh (2009) clarify that within Organisational Knowledge Creation Theory tacit and explicit knowledge should not be seen as separate entities but rather as complementary and based on the same continuum.

\subsubsection{Explicit and tacit knowledge continuum}

Nonaka (1994) draws on the work of Michael Polanyi (1966) as the initial source for his exploration of the two key types of knowledge, "tacit knowledge" and “explicit knowledge". As Nonaka (1994) summarises, Polanyi classified human knowledge into two categories: (a) "explicit" or codified knowledge, referring to 
knowledge that is transmittable in formal, systematic language; and (b) "tacit" knowledge, which refers to knowledge that has a personal quality, which makes it hard to formalise and communicate and is deeply rooted in action, commitment, and involvement in a specific context.

Explicit knowledge can be expressed in words and numbers and is easily communicated and shared in the form of hard data, specific formulas, codified procedures or universal principles (Ichijo and Nonaka, 2007). In order for explicit knowledge to become one's own it has to be actualised through action in such things as product concepts or manufacturing procedures (Nonaka and Toyama, 2003).

Tacit knowledge is personal knowledge embedded in individual experience; it is not easily visible and expressible, hence it is hard to articulate and communicate. Tacit knowledge is subjective; the individual may experience insights, intuition, and hunches based on personal factors such as beliefs, perspectives, and value systems (Ichijo and Nonaka, 2007).

Ichijo and Nonaka (2007) segment tacit knowledge into two dimensions: (a) the technical dimension, which encompasses things like craft skills and is associated with the term "know-how"; and (b) a cognitive dimension, which is normally taken for granted as it is so ingrained within the individual. This dimension encompasses such things as beliefs, perceptions, and mental models.

Tacit knowledge is the key cornerstone of Organisational Knowledge Creation Theory incorporating "knowledge that is unarticulated and tied to the senses, movement skills, physical experiences, intuition or rules of thumb" (Nonaka and von Krogh, 2009, p. 635). Nonaka and von Krogh maintain that within an organisational context tacit knowledge has come to serve two main purposes: (a) as a foundation for social practices, and (b) as a foundation for innovation. 
Social processes and practices drive the transfer and transformation of knowledge (Massey and Montoya-Weiss, 2006). In order to define the concept of social practice, Nonaka and von Krogh (2009) defer to the work of Tsoukas (2003), who builds on the work of MacIntyre (1984). A social practice is any coherent, complex, coordinated form of human activity through which goods internal to that form of activity are realised. Social practices within a firm are seen to consist of three dimensions: (a) role-related social expectations, (b) dispositions, and (c) interactive situations (Tsoukas, 1996).

Intertwined with social structures is human agency; firms as social structures do not exist independently of human agency (Nonaka and Toyama, 2003). Nonaka and Toyama see new knowledge being created through the interactions between social structures and human agency, as the environment influences agents and, in turn, agents are continually recreating their environments through social interaction.

Through social interaction and dialoguing with other individuals, the agent is able to create his/her image of reality and vision for the future (Nonaka and Toyama, 2007). Through this interaction new structures are created and it is this interconnection between agents and structure which makes the knowledge creation process occur as a dynamic and inter-linked interaction from an individual-to-societal level (Nonaka and Toyama, 2003).

Consequently the knowledge creation process "is driven by the dualistic nature between the agents and structure as well as between tacit and explicit knowledge" (Nonaka and Toyama, 2003, p. 09). Thus, socialisation between human agents is the start of the knowledge creation process. It is first stage of the knowledge creation spiral - SECI model, and it is the process of converting new tacit knowledge gained through shared experiences in day-to-day social interactions (Nonaka and Toyama, 2003). 


\subsubsection{Socialisation}

Individuals can acquire tacit knowledge without language Nonaka (1994). To demonstrate this, Nonaka (1994) provides the example of an apprentice working with a mentor and learning through observation, imitation, and practice. In a business context this can be facilitated through on-the-job training. This sharing of tacit knowledge between individuals, without language, is what Nonaka refers to as Socialisation.

Socialisation can occur in a variety of contexts such as informal social meetings where tacit knowledge such as world views, mental models, and mutual trust can be created and shared - or by the interaction of a business person with customers or suppliers (Nonaka, Toyama and Kono, 2000).

Product development activity within an organisation typically starts with socialisation, as new knowledge required to start the process is gained through individuals in organisations interacting with customers. This new knowledge is then articulated as a product concept through the process of externalisation (Nonaka and Toyama, 2007).

\subsubsection{Externalisation}

Tacit and explicit knowledge are complementary and can expand over time through a process of mutual interaction. Within the SECI model this interaction involves two different operations, externalisation and internalisation: externalisation refers to the process of tacit knowledge being converted into explicit knowledge, while internalisation refers to the conversion of explicit knowledge into tacit knowledge (Nonaka, 1994).

Externalisation requires the expression of tacit knowledge and its translation into forms that can be understood by others through using techniques such as expressing one's ideas or images as words, concepts, figurative language such as metaphors, analogies, or narratives and visuals (Nonaka and Konno, 1998). 
When tacit knowledge is made explicit, knowledge is crystallised, allowing it to be shared by others, and to become the basis of new knowledge (Nonaka, Toyama and Kono 2000). Nonaka et al. (2000) identify the new product development and quality control circles which allow workers on the shop floor to articulate their accumulated tacit knowledge, as an example of where new knowledge is created within an organisational context through externalisation.

The new product development process and quality circles provide the workers with a context within which they can relate and share their tacit knowledge. The active exposure to such a context allows the worker and/or individual to detach themselves from routines and see inherent contradictions (Nonaka and Toyama, 2003).

\subsubsection{Internalisation}

The second conversion process within the SECI model is internalisation. Nonaka (1994) sees this process as the closest to the traditional notion of "learning" and where learning is reinforced by action. Internalisation involves converting explicit knowledge into tacit knowledge in order to create new knowledge (Nonaka and Konno, 1998). When explicit knowledge has been internalised by the individual, it extends their tacit knowledge base in the form of shared mental models or technical know-how and may become an asset of value (Nonaka, Toyama and Kono 2000).

The individual is exposed to explicit knowledge through their daily interactions within the wider environment. Thus, knowledge creation can be viewed as a synthesising, dialectical process through the dynamic interactions among individuals and specifically between the organisation and the environment (Nonaka and Toyama, 2003). This perspective introduces the concept of human agency and its interaction with and impacts on organisation structures and the environment, as knowledge is created through the interactions between human agency and social structures. Specifically, "Internalized knowledge affects the human agency and the structure, as it changes the action of human agency and 
how it views the structure" (Nonaka and Toyama, 2003, p. 6). Nonaka and Toyama do not supply a definition of human agency, but do refer to Giddens's (1984) Structuration Theory.

\subsubsection{Combination}

Combination is the process of converting explicit knowledge into more complex and systematic sets of explicit knowledge (Nonaka, Toyama and Kono 2000). It involves the use of social processes such as meetings and phone calls to combine different bodies of explicit knowledge held by individuals (Nonaka, 1994). Explicit knowledge is combined into more complex sets of explicit knowledge and normally relies on three processes: (a) capturing and integrating new explicit knowledge; (b) the dissemination of explicit knowledge through such aids as presentations or meetings; and (c) editing or processing explicit knowledge to make it more usable, for example producing business plans, reports, and market data. Such collation activities aid the organisational decision and help justify decisions (Nonaka and Konno, 1998).

Conversely, Nonaka, Toyama, and Kono (2000) report that the combination process can also include the breaking down of concepts, such as a corporate vision into business plans or product concepts to create systemic explicit knowledge. In short, the combination process combines, edits, and breaks down explicit knowledge (Nonaka and Toyama, 2003).

One way that explicit knowledge is combined within the organisational innovation process is through creating prototypes. Prototypes provide a mechanism by which organisations can obtain the maximum level of information, with a minimum level of expended energy (Nonaka, 1994). The act of building a prototype may be seen as a play-like time, where participants assemble things from what is at hand and make them into a new object without losing track of the original concept (Ichijo and Nonaka, 2007). 
Ichijo and Nonaka provide a comprehensive definition and description of a prototype: "The prototype is a tangible form of the concept, and it is achieved by combining existing concepts, products, components, and procedures with a new concept, in other words, combining new explicit knowledge with existing explicit knowledge (2007, p. 294).

\subsubsection{Unified Model of Dynamic Knowledge Creation}

The SECI model shows how an organisation creates knowledge through the interaction between explicit and tacit knowledge. This interaction between the two types of knowledge is referred to as knowledge conversion; it is when tacit knowledge is made explicit that knowledge is crystallised (Nonaka et al, 2000).

The concept of knowledge conversion is seen as fundamental to Organisational Knowledge Creation Theory as it explains how new ideas emerge as individuals tap into rich practices and acquire the tacit knowledge of these practices (Nonaka and von Krogh, 2009). In short, Nonaka and von Krogh (2009) maintain that knowledge conversion explains, theoretically and empirically, the interaction between tacit and explicit knowledge and how tacit and explicit knowledge interact along a continuum.

It is important to make the distinction between individual knowledge creation and organisational knowledge creation which takes place when all four modes of knowledge creation are organisationally managed to form a continual cycle. In his original paper Nonaka, (1994) showed the four modes of knowledge creation in a simple diagrammatical form, as depicted in Figure 2. 


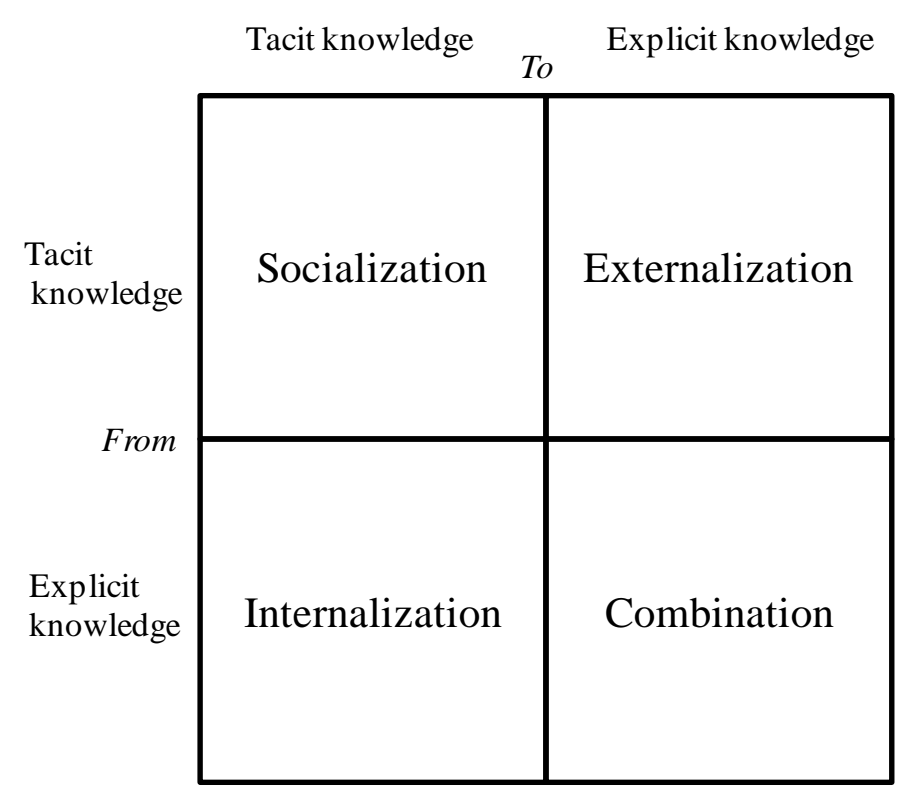

Figure 2: $\quad$ Modes of knowledge creation

While the basic model and framework have stayed the same, the individual processes have been continually developed and built upon by Nonaka and Konno, (1998); Nonaka et al, (2000); Nonaka and Toyama, (2003); Nonaka and Toyama, (2007); and Nonaka and von Krogh (2009) as previously discussed. The key properties and dimensions of these four modes of knowledge creation are summarised in Figure 3. 


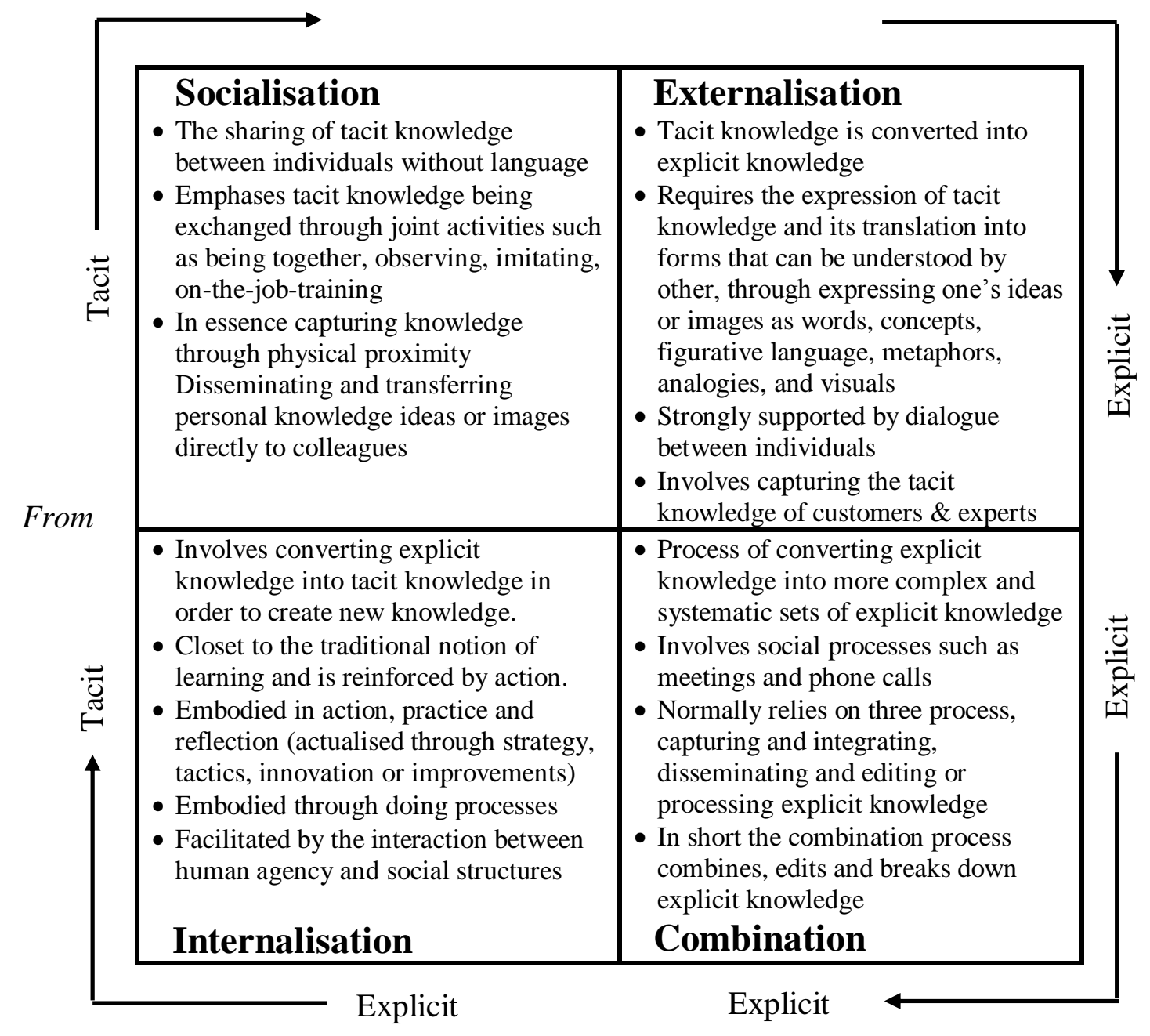

Figure 3: Key properties and dimensions of the four modes of knowledge creation

Taken from Nonaka and Konno, (1998); Nonaka et al, (2000); Nonaka and Toyama, (2003); Nonaka and Toyama, (2007); and Nonaka and von Krogh (2009)

\subsubsection{The concept of $b a$}

Information and knowledge are context specific in that they both depend on the situation and are created in the social interaction between people (Ichijo and Nonaka, 2007). This shared context within which individuals interact in order to create new knowledge is known as $b a$ (Nonaka et al., 2000). The word $b a$ is a Japanese concept which roughly translates to the English word "space" and it refers to a shared space for emerging relationships. Nonaka et al. (2000) describe 
$b a$ as a place where information is interpreted to become knowledge; it does not necessarily mean a physical space, but can be a virtual space such as email or a mental space such as shared ideals. Participants of $b a$ cannot be mere onlookers but must be committed to $b a$ through action and interaction. Knowledge is acquired through individual experience or reflections on others' experience, within any of these shared spaces. To participate in $b a$ means to become engaged in knowledge creation, through transcending one's own limited perspective or boundaries. When knowledge is separated from a $b a$ it becomes information so that it can be communicated beyond the ba (Nonaka et al., 2006).

A good $b a$ needs participants with multiple viewpoints so they can represent various contexts while at the same time fostering a shared context amongst the individuals. Within self-setting boundaries from which participants can come and go, it is a self-organising place with its own intention, direction, or mission. Participants within a $b a$ share time and space through direct experience, both physically and virtually. In addition, the $b a$ allows participants to have the viewpoint of both insider and outsider at the same time, while limiting the way in which the participants view the world as insiders of that world. It is not limited to the boundaries of a single organisation but can exit across organisational boundaries and between companies (Nonaka and Toyama, 2003). Consequently Nonaka and Toyama define $b a$ "as a shared context in motion, in which knowledge is shared, created, and utilized" (2003, p. 06).

There are a number of different types of $b a$, each offering a shared context for a step in the knowledge creation process, yet they are not mutually exclusive (Nonaka et al., 2000). The different types of $b a$, as reported by Nonaka and his colleagues in their various publications, are summarised in Table 3. 
Table 3: $\quad$ Types of $B a$

\begin{tabular}{|c|c|}
\hline Type of $b a$ & Description \\
\hline Cyber ba & $\begin{array}{l}\text { A place of interaction within a virtual world (Nonaka and Konno, } \\
\text { 1998). Cyber } b a \text { may involve many hundreds of individuals } \\
\text { within an organisation through the use of information and } \\
\text { communication technologies (Nonaka et al., 2006). }\end{array}$ \\
\hline $\begin{array}{l}\text { Dialoguing } \\
b a\end{array}$ & $\begin{array}{l}\text { Defined by collective and face-to-face interactions where an } \\
\text { individual's mental model and skills are shared, converted into } \\
\text { terms and articulated as concepts (Nonaka et al., 2000). }\end{array}$ \\
\hline $\begin{array}{l}\text { Exercising } \\
b a\end{array}$ & $\begin{array}{l}\text { Supports the internalisation phase and facilitates the conversion of } \\
\text { explicit knowledge through action (Nonaka and Konno, 1998). }\end{array}$ \\
\hline $\begin{array}{l}\text { Interacting } \\
b a\end{array}$ & $\begin{array}{l}\text { Interacting } b a \text { can support internalisation, through individuals } \\
\text { working with peers and dialoguing their mental models and skills } \\
\text { are probed, analysed, and converted into common terms and } \\
\text { concepts (Nonaka et al., 2006). It can also support externalisation, } \\
\text { as Interacting } b a \text { is a place where tacit knowledge is made explicit } \\
\text { and thus it represents the externalisation process (Nonaka and } \\
\text { Konno, 1998). }\end{array}$ \\
\hline $\begin{array}{l}\text { Originating } \\
b a\end{array}$ & $\begin{array}{l}\text { Originating } b a \text { is the primary } b a \text { from which the knowledge } \\
\text { creation process begins and consequently is associated with the } \\
\text { socialisation phase. It is the shared world where individuals share } \\
\text { feelings, emotions, and mental models with others within that } \\
\text { context. Through doing so the individual sympathises or } \\
\text { emphasises with others therefore removing the barriers between } \\
\text { them (Nonaka and Konno, 1998). }\end{array}$ \\
\hline $\begin{array}{l}\text { Systemising } \\
b a\end{array}$ & $\begin{array}{l}\text { Systemising } b a \text { is characterised by collective and virtual } \\
\text { interaction where explicit knowledge is combined so that it can be } \\
\text { easily transmitted to a large number of people in written form } \\
\text { through the aid of information and communication technologies } \\
\text { (Nonaka et al., 2000). }\end{array}$ \\
\hline
\end{tabular}

As a concept, $b a$ transcends the boundary between micro and macro; it exists at many levels, to form a multilayered $b a$ which is effectively a knowledge ecosystem (Nonaka et al., 2000). Through interactions within the ecosystem a firm creates knowledge and that knowledge changes the ecosystem (Nonaka and Toyama, 2007). Just as the $b a$ for individuals is the team, the organisation is the $b a$ for the team; these interconnected levels may come together to form a greater $b a$ which may be referred to as a basho (Nonaka and Konno, 1998). 


\subsubsection{In summary: Organisational Knowledge Creation Theory as it relates to innovation}

Organisational Knowledge Creation Theory originates, in part, from an exercise in new technology innovation. Within the theory, tacit and explicit knowledge are seen as complementary and operate as a continuum. New knowledge is created through interactions between social structures and human agency which facilitates the process of knowledge conversion. This interaction and conversation takes place within a shared space, referred to as $b a$.

Knowledge Creation Theory focuses on organisational knowledge creation and not the specific actions of human agents. Nonaka accepts the importance of interaction between human agency and structure, with Nonaka and Toyama (2003) deferring to Giddens's Structuration Theory to aid in explaining the interaction. While innovation is intrinsically linked with Organisational Knowledge Creation Theory, there has been little discussion on the linkage between entrepreneurship and knowledge creation, a point that is acknowledged by Nonaka et al. (2006).

Where Knowledge Creation Theory refers to the shared space within which individuals create new knowledge as $b a$, the notion of structure (a similar but different concept to $b a$ ) is advanced within social theory based perspectives by Giddens's (1984) Theory of Structuration. 


\subsection{Theory of Structuration}

The theory as developed in this study is informed not only through Organisational Knowledge Creation Theory, but also through referencing the Theory of Structuration. Within this section the Theory of Structuration is described and discussed with specific focus on: the notion of structure, the "duality of technology", and the duality of structure and human agency within social structures.

\subsubsection{The notion of structure}

As summarised by Orlikowski (2000), Giddens (1979; 1984) proposed the notion of structure as the set of enacted rules and resources that mediate social action through the three dimensions of facilities, norms, and interpretive schemes. As human agents go about their business and interact with others in their recurrent social practices, they draw on their tacit and explicit knowledge of their prior action, the situation at hand, and the norms that inform their ongoing practices in order to "structure" their current actions.

Orlikowski (2000) uses Giddens's notion of structure to emphasise the capacity of human agents to enact social structures through their use of technology. By doing so, she seeks to direct researchers' attention to what people do with technology in practice and how their use of technology is structured by the rules and resources implicated in their ongoing action.

The structurational perspective is inherently "dynamic" and grounded in ongoing human action and Orlikowski (2000) maintains that for these reasons it has potential to explain emergence and change in technologies and use.

Where Orlikowski links human action with technology use, Giddens links human action with social structures. As Giddens (1979) maintains, the user/social actor knows a great deal about the conditions of reproduction of the society of which he or she is a member. Giddens $(1979 ; 1984)$ is concerned with understanding and 
explaining the nature of human action and the acting self, specifically how this interaction is conceptualised within institutions. Many social activities are not created by social actors but rather they are recreated by them, and through their activities agents reproduce the conditions that make the activities possible. These activities are bound by time and space and it is this structural property which makes it possible for discernibly different social practices to exist across varying spans of time and space and in essence give structure to the social practices. This structure is not physical but "virtual" and is but a memory trace orientating the conduct of knowledgeable human agents (Giddens, 1984).

Sewell (1992) points out that it is embarrassingly difficult to define the term structure without using the word structure or one of its variants. This is something that Giddens (1984), too, is keenly aware of, commenting that the term "structuration" is an unlovely term at best and conceding that he is unable to think of a more engaging word to express the views that he wishes to convey.

Giddens's view that structures are virtual and but a memory trace, is a point of contention with Jones and Karsten (2008), who provide a comprehensive review of Structuration Theory within Information Systems research.

Structuration Theory emphasises the interplay between individuals and society rather than focusing on one aspect in preference to the other; and it deals with matters of process rather than static properties or patterns (Jones and Karsten, 2008). Jones and Karsten (2008) conclude that Giddens sought to distinguish between how the physical world affects action and how social structure influences social practice.

Through focusing on comments that Giddens makes in Giddens and Pierson (1998), Jones and Karsten conclude that with specific reference to Information Systems "structure as defined by Giddens cannot be inscribed or embedded in technology, since to do so would give it an existence separate from the practices of social actors and independent of action"(2008, p. 132). Thus, Jones and 
Karsten conclude that those Information Systems studies which identify themselves as structurational and identify structures within technology are not describing structures as Giddens would understand them. The authors maintain that Giddens sees social structures only existing in the instant of action.

Jones and Karsten (2008) make particular reference to one specific study, Orlikowski's (1992) notion of duality of technology where she presents a view of technology that draws upon Giddens's Structuration Theory.

\subsubsection{Duality of technology}

Orlikowski (1992) develops a view of technology that presents it both as an objective reality and as a socially constructed product. She summarises the organisational technology debate as falling into two camps: (a) technology is an objective external force that has deterministic impacts on organisational properties; and (b) technology is influenced by humans and is the outcome of strategic choice and social action. She maintains that neither perspective was complete and that a reconceptualised view is required that takes both perspectives into account.

When defining technology, Orlikowski restricts its scope to "material artifacts (various configurations of hardware and software)" (1992, p. 403), and maintains a theoretical distinction between the material nature of technology and the human activities that design or use those artefacts. By decoupling artefacts from human action, she is able to conceptualise artefacts as the outcome of coordinated human action and hence as inherently social; in essence the technology artefact is both structurally and socially constructed.

Orlikowski (1992) introduces a recursive notion of technology which she calls the "duality of technology" whereby "technology is created and changed by human action, yet it is also used by humans to accomplish some action" (p. 405). She goes on to explain that technology is both physically constructed by actors working in a given social context, and socially constructed by actors through the 
different meanings they attach to it and how they use its feature sets. In addition, as it is the ongoing action of human agents which objectifies and institutionalises technology, agency and structure are not independent.

Through their actions human agents are responsible for technology creation; as Orlikowski (1992) states, technology is the product of human action and is the outcome of creative human actions such as design, development, appropriations, and modification. Through design, human agents build into technology: (a) certain interpretative schemes, for example, rules reflecting knowledge of the work being automated; (b) certain facilities, for example, resources to accomplish that work; and (c) certain norms, for example, organisational rules for how work is to be done.

By seeing technology as the product of human action, Orlikowski (1992) places emphasis not only on the fact that technology comes into existence through creative human action, but that it is also a product of human actions associated with its ongoing maintenance, adoption, and use. Without human agency technology is of "no import"; it plays no meaningful role in human affairs and it can only exert influence through use; in sum, "it is only through human action that technology qua technology can be understood" (p. 410).

Orlikowski (1992) points out that the institutional conditions and human agents involved in technology development and use are different; a technology may be developed by one organisation, used by another, and transferred into a third. In order to study this reciprocal interaction of the social actors and institutional properties, Orlikowski uses Giddens's (1984) Structuration Theory to undertake the research connected with her $\mathrm{PhD}$ thesis. Orlikowski acknowledges that while Giddens positions his Theory of Structuration at the level of society it is also equally relevant at multiple levels of analysis such as a firm or team. 


\subsubsection{Duality of structure}

Orlikowski (1992) maintains that support for such a position can be seen in Giddens's notion of the duality of structure "where the rules and resources drawn upon in the production of social action are at the same time the means of system reproduction" (1992, p. 19). As Giddens (1992) explains, agents and structures are not two independent sets of phenomena - a dualism - but represent a duality. Thus, as Orlikowski (1992) maintains, it can be reasonably extrapolated that such actions, production, and reproduction take place not only at the national level but also at the organisational and community level. These actions are undertaken by human agents who engage in agency, which Giddens sees as not only the intention of people to do things but also their capability to do things in the first place.

Giddens' notion of duality of structure and agency conceptually positions the two aspects as mutually constitutive and necessarily linked; "such that agents cannot act without drawing upon structural properties whose own existence depends upon their instantiation by agents" (Archer, 1995, p.3).

While Giddens (1992) sees structures as a duality, both a medium and an outcome of action, Archer (1995) argues for the separation of structure and agency so that the interplay between them and the effects they have on each other may be examined. Similar to Orlikowski (1992), Archer (1995) proposes a morphogenetic approach to conceptualising the interplay between structure and agency, whereby: (a) structure may necessarily pre-date the action(s) leading to its reproduction (morphostasis) or transformation (morphogenesis); and (b) structural elaboration necessarily post-dates the action sequences which give rise to it.

Within this perspective the conditional and generative mechanisms operating between structure and agency are pivotal. As Dey (1999) summarises, activity both predates and postdates the emergence of structures, thus allowing both the analytic histories of emergent structures and the ways in which people either reproduce or transform those structures to be studied. 


\subsubsection{Human actors and human agency}

Structures are enacted by what Giddens calls "knowledgeable human agents" or what Sewell (1994) summarises as people who know what they are doing and how to do it. Those referred to as agents are capable of putting their structurally formed capacities and knowledge to work in creative and innovative ways.

Within the social theory based literature the terms "agent" and "actor" are used interchangeably to describe the human actor, while the term "agency" is used to describe human action. Giddens (1984) acknowledges the fact that he uses the terms "human agents" and "actors" interchangeably as both terms include inherent aspects of what people do as well as their capacity to understand what they do while they do it. In addition, Giddens (1984) maintains that "what agents know about what they do. And why they do it - their knowledgeability as agents - is largely carried in practical consciousness" (p. xxiii).

However, this mutually constitutive perspective of the knowledgeable actor operating within omnipresent structures is rejected by Archer (1995) as he holds that people do not have, and cannot achieve, "discursive penetration" of many unacknowledged conditions of action. As Archer explains "agents have differential knowledgeability according to social position and some agents have defective, deficient, and distorted knowledge owing to the cultural manipulation of others" (1995, p. 252). Archer (1995) clearly distinguishes between the human being - the person, the social actor, and the social agent - with all three seen as indispensable in social theorising but as irreducible to one another. This trinity comprises: (a) the person and the defining properties of people that are necessary conditions for any kind of life; (b) actors who can acquire a social identify as well as a person's identity through investing themselves in a role and personifying it in a particular way; and (c) agents, because as we live we must act and our actions have social consequences (Dey, 1999). 
Table 4: $\quad$ Different Kinds of Agency in Interaction (Dey, 1999, p. 198)

Different Kinds of Agency in Interaction

- Persons - whose needs must be as a condition for any kind of social life

- Actors - who invest in social roles and identities

- Agents - who collectively share interests and life chances

The terms "person" and "actor" refer to the singular, whereas Archer (1995) sees "agent" as plural denoting a group or collective; everybody is inescapably an agent in some of their doings. Archer distinguishes between "corporate" and "primary" agents thus: (a) corporate agents recognise and actively promote their own vested interest in coordinated interactions; and, conversely, (b) primary agents neither express interests nor organise for their strategic pursuit and merely react and respond through uncoordinated interactions.

The concept of human agency is starting to appear within the Information Systems domain through research such as that of Orlikowski (2000), Levina and Vaast (2005), and Chu and Robey (2008). Levina and Vaast (2005) explore the concept of agents as boundary spanners and find that some agents partially transform their practices in local settings so as to accommodate the interests of their counterparts. Chu and Robey (2008) investigate changes in learning and work practices associated with the implementation of an online learning system and apply Emirbayer and Mische's (1998) temporal Theory of Human Agency that disaggregates agency into elements reflecting an actor's orientations to the past, present, and future.

\subsubsection{Human agency and social sciences based perspectives}

Social actors are embedded in many temporalities at any given moment - the past, the present, and the future - although they may be primarily oriented to one or another of these within any one emergent situation. The way in which social actors understand their own relationship to past, present and future influences 
their actions; social actors do not merely repeat past routines, they are also the inventors of new possibilities for thought and action (Emirbayer and Mische, 1998).

Emirbayer and Mische contend that social actors change their "agentic" orientation and reconstruct the internal composition of their past, present, future triad so that "they may increase or decrease their capacity for invention, choice, and transformative impact in relation to the situational contexts within which they act” (1998, p. 1003).

The structural contexts profoundly influence how actors in different periods and places see their worlds. How these actors act within their situational contexts is referred to as human agency, which Emirbayer and Mische (1998) define as:

the temporarily constructive engagement by actors of different structural environments - the temporalrelational contexts of action - which, through the interplay of habit, imagination, and judgement, both reproduces and transforms those structures in interactive response to the problems posed by changing historical situations. (p. 970)

While emphasising the impact of different structural environments and temporal elements, this definition of human agency places importance on the interplay of habit, imagination, and judgement. Within this context, Emirbayer and Mische see habit as inherently plastic and educable, rather than a matter of mere stimulus and response. Judgement is also seen as an important dimension of human agency by Bandura (1989) as agents/people can effect change in themselves and their situations through their own efforts and judgements.

While Emirbayer and Mische (1998) see the different dimensions as important, they maintain that none by themselves catch the full complexity of human agency 
as it is the "dynamic" interplay among these dimensions and how they interplay with different structural contexts within the flow of time which is at the heart of the concept. They maintain that only through recognising variability will it be possible to understand how the structural environments of action are both dynamically sustained by, and also altered through, human agency. Chu and Robey (2008) however, point out that while Emirbayer and Mische (1998) claim that human agency is socially influenced they offer little detail on how such influence is exerted and experienced.

Explaining the socially influenced aspects of human agency has been the focus of research by Bandura (1989; 1996a; 1996b) and Sewell (1992). Prior to Emirbayer and Mische's temporal Theory of Human Agency, Bandura (1989) explored the nature and function of human agency through the psychological mechanisms by which personal agency is exercised. Drawing upon aspects of social cognitive theory, by looking at the human characteristics of being able to exercise control over one's own thought processes, motivation, and action, Bandura developed the cognitive based Theory of Human Agency.

Central to Bandura's Theory of Human Agency is the view that people make causal contributions to their daily lives through exercising mechanisms of personal agency, with the most important mechanism being the belief of personal efficacy (Bandura, 1996a). Self efficacy beliefs are defined as "people's judgments of their capabilities to organize and execute courses of action required to attain designated types of performances (Bandura, 1986, p. 391). Bandura (1986) maintains that people can effect change in themselves and their situations through their own efforts.

The outcomes that people achieve differ from person to person as social realities are strewn with difficulties, impediments, failures, adversities, setbacks, frustrations, and inequities which must be overcome in order to succeed in the attainment of the person's goals. In order to achieve their goals in the face of such difficulties, people must have a robust sense of personal efficacy in order to 
sustain the required effort. Some people quickly lose faith in their capabilities, while others regain their self assurance; thus it is the resiliency of self belief that counts (Bandura, 1986). When reviewing his earlier work and its subsequent treatment within the literature some years later, Bandura (1996a) goes so far as to say that where performance determines outcomes, efficacy beliefs account for most of the variation in expected outcomes (p. 6).

Personal agency is also exercised through the capacity of forethought. People do not simply react to immediate environmental influences like weathervanes at the mercy of the wind. Instead people undertake purposeful action; they set goals for themselves and plan courses of action likely to achieve desired outcomes, while at the same time anticipating likely consequences of their actions (Bandura, 1986).

The capacity to inflict change on one's environment while at the same time undertaking reflective thought leads Bandura $(1986 ; 1996 a)$ to address the dualism of the self as agent and self as object. As Bandura (1996a) explains, within the field of personality, people are said to be agents when they act on the environment, but objects when they reflect and act on themselves. Yet, as Bandura argues, it is the same person doing the strategic thinking and later reflecting on their actions, as it is who carries out the action. The shift in perspective does not transform one from an agent to an object as the dualist view of the self advocates. Bandura maintains that in self-reflection and self-influence individuals are simultaneously agent and object; one is just as much an agent when reflecting on one's experience as when exerting self-influence on one's environment.

While Bandura (1986; 1996a; 1996b) focuses on cognitive based aspects to explain agency, Sewell (1992) emphases environmental aspects, specifically resources.

Access to and control of resources is central to Sewell's (1992) view of human agency as agents are empowered by resources of one kind or another. Sewell 
maintains that agents are empowered by structures which enable them to access resources and that through access to resources they are able to enact schemas. Thus, Sewell (1992) defines agency as "as entailing the capacity to transpose and extend schemas to new contexts...the actor's capacity to reinterpret and mobilize an array of resources in terms of cultural schemas other than those that initially constitute the array" (pp. 18-19).

In addition, agency entails the ability to coordinate one's actions with others and against others; to persuade, coerce, or monitor one's own activities or the activities of others. Agency characterises all persons and when exercised by persons it is collective in both its sources and its modes of exercise. Specific expressions of agency will vary enormously according to cultural and historical determinants, yet the capacity for agency is as much a given for humans as the capacity for respiration (Sewell, 1994).

\subsubsection{Economic based perspectives of structuration and human agency}

In a similar vein to the notion that agency for humans is as fundamental as breathing, Oakley (2002) notes that most things worth studying within the economics field are created through human action. As Oakley asserts, his view of economics as a discipline is based on a universe of reality in which most things that warrant study have been created by situated human action and therefore it is not possible to deny the complexity of the human realm. Oakley (2002) aligns with the view that the actual freedom enjoyed by the agents in their social activities is never absolute because human action "is always undertaken in the presence of, and integrated into, situational structures and conditions" (p. 14). In nearly all aspects of human life people exist, make decisions, and act with a particular situation within a multiplicity of structures and conditions.

The intentional actions of human agents are the origins of economic behaviour. In order to understand intentional action, Oakley turned to the work of Alfred Schutz, a noted social philosopher and acknowledged phenomenologist. Schutz (1967) perceived action as an experience in process with specific meaning for the 
agent and consequently arrived at the conclusion that action can be defined as "(1) a lived experience that is (2) guided by a plan or project arising from the subject's spontaneous activity and (3) distinguished from all other lived experiences by a peculiar act of attention" (p. 215). Schutz further differentiated between the action (actio) as an experience in process, and the complete act (actum).

Using Oakley's work as the base framework, and combining it with economic theories using a realist ontology that touches on innovation and agency, such as the teachings of Schumpeter, Courvisanos (2007) develops and explores a contingency of agency-structure relationships. These relationships range from those that are based in free ranging agency to those that are based in containmentstructure and situations that are heavily contained. Courvisanos asserts that this continuum can be used to model innovation decision making and action. The continuum of contingency and containment is depicted and summarised in Figure 4.

(C) (C)

\section{Contingency}

- 'Free-to-choose' agency concept that is strongly qualified by what agents know or have learnt based on their cumulative experiences

- Entrepreneurship literature that espouses spontaneous responses to economic and social conditions

- Normally associated with radical innovation

Figure 4: $\quad$ Different Kinds of Agency in Interaction (Dey, 1999, p. 198)

The wide gamut of entrepreneurial activity that can be counted as innovation ranges from the strongly contingent to the heavily constrained. Agents of change, entrepreneurs, operate in a messy world of contingency and uncertainty in which agents use bounded rationality to direct their behaviour in a complexitybased world (Courvisanos, 2007). For Courvisanos (2007), innovation is central 
to the study of economics, for "if there is no innovation, society stagnates" (p. 53). Within this context, Courvisanos defines innovation as "the creative application of knowledge to increase the set of techniques and products commercially available in the economy" (2007, p. 46). This creative application of knowledge is induced through entrepreneurial action.

\subsubsection{Collective agency}

Human agency focuses on the engagement and actions of an actor within a specific context, but as Bandura (1996b) points out "people do not live their lives as isolates. They work together to produce the results they desire" (p. 08). Accordingly, Bandura calls for the analysis of human agency to extend beyond the single actor to encompass the collective efforts of people working together to achieve a common result, a situation which he refers to as collective agency.

Bandura also extends the notion of collective agency to collective efficacy, where people's shared belief in their collective capabilities contributes to the obtainment of a result. Personal and collective efficacy differ in the unit of agency, but in both situations Bandura sees them as serving similar functions and operating through similar processes: "people's beliefs in their collective efficacy influence the type of futures they seek to achieve, how well they use their resources, how much effort they put into their group endeavour" (1996b, p.8).

Human influence, whether individual or collective, is a two way process, not just a unidirectional flow. If an actor or group of actors chooses to lessen the amount of influence they seek to bring to bear on a given situation, they in turn will relinquish more control to others. Actors with a high sense of personal or collective efficacy will mobilise their resources to cope with external obstacles they seek to change or overcome to a greater degree than those actors who are convinced of their collective or individual powerlessness (Bandura, 1996b).

The notion of collective agency is supported by Emirbayer and Mische (1998) and Sewell (1992). Emirbayer and Mische (1998) do not specifically use the term 
"collective agency" but instead refer to the concept of collective action thus: "historical actions and choices are deeply conditioned by how collective actors conceive of the binding power of the past, the malleability of the future, or the capacities of actors to intervene in their immediate situations" (p. 1011). Sewell (1992) is firmly of the view that agency is collective as well as individual: "the transpositions of schemas and remobilizations of resources that constitute agency are always acts of communication with others" (p. 210).

Within the Information Systems domain Van de Ven (1993a; 2005) has been a leading advocate of the collective and coordinated efforts of "packs". However, Van de Ven's "running in packs" analogy is not totally congruous with collective agency as it is not a coordinated effort towards achieving a collective goal; rather, as demonstrated in the bicycle racer analogy, at the end of the day it comes down to "may the best person win".

\subsubsection{In Summary: structuration, human agency, and collective agency}

Human agents and structures are intertwined, a duality. Structures are created by human agents, while, at the same time, social structures mediate and reflect human actions and interactions. This duality is also extends to technology, which is socially constructed and created by human action.

Structures are enacted by knowledgeable human agents, who have differing roles and levels of knowledgeability. The term "person" or "actor" refers to the singular, with "agent" denoting the plural. How actors and agents act within situational contexts is referred to as "agency" and entails the ability to coordinate one's actions with others and against others. Agency may refer to the agency of the actor or the agency of the collective. Agency is both individual and collective; it is as fundamental to humans as breathing. 


\subsection{Chapter summary}

The literature review has identified a call for IT innovation research to move beyond the dominant paradigm of traditional research focused on issues of diffusion, adoption, and use, to include the role and actions of the entrepreneur and intrapreneur in the creation of the IT artefact.

The entrepreneur is found to be someone who undertakes change and combines resources to create new combinations. The "pure" entrepreneur derives rent from resources they have yet to control and the "not so pure" entrepreneur uses resources located within institutions of which they are members.

Modern day literature differentiates between the roles and actions of the entrepreneur and the intrapreneur as they have differing motivations, access to resources and rent based outcomes. Within economic literature that focuses on human action and entrepreneurship, the entrepreneur is seen to undergo change after they establish their firms, to create their innovation and then work within it.

Firms and institutions play a crucial role in the innovation process as they provide a shared context, within which humans can interact and carry out the resource combining activities needed to make the tacit idea a tangible reality.

Technology innovation is closely linked with ideas and knowledge. The technology artefact is initially an idea in the entrepreneur's mind, a tacit thought. The idea becomes a tangible reality through the actions of the entrepreneur and their interaction with others.

The literature refers to this action as agency, which is carried out within social structures $(b a)$, by actors (singular) and agents (plural). Actors and agents create structures and are, in turn, influenced in their actions by structures; such interaction is described as a duality. The actions of the entrepreneur and intrapreneur and their interactions with other social agents within shared social structures is crucial to the creation of the IT artefact. 


\section{RESEARCH STRATEGY AND METHODOLOGY}

\subsection{Chapter overview}

In this chapter, I outline my research strategy and methodology. The research aim is to explore and determine factors that drive, enable, and inhibit resource acquiring relationships of entrepreneurial actors within information technology firms. I adopted an interpretivist epistemology and used the qualitative research method of grounded theory, in particular the Glaserian variant as interpreted for use in IS studies.

I begin by discussing the research paradigm and research strategy and confront philosophical questions as to the nature of knowledge, how the researcher sees the world and interprets and assigns meaning to phenomena. Specific reference is made to the role of theory development in IS research. A key focus of the chapter is to provide justification for the adopted method and clearly articulate how it is to be used in order to generate theory; particular reference is made to how the method has been interpreted, used, and adapted within the IS discipline.

\section{Chapter Contents}

3.2 The research paradigm

3.3 The research strategy and methodology

3.4 Research method: Grounded Theory

3.5 The role of the researcher

3.6 Issues of rigour, credibility and validity in grounded theory research

3.7 Chapter summary 


\subsection{The research paradigm}

All research begins at the philosophical level and is often influenced by the researcher's view of the world which dictates the nature of the research they engage with (Pickard, 2007). The researcher's belief system or paradigm as it is referred to may be viewed as a set of basic beliefs that deal with first principles, defining for its holder: (a) the nature of the world, (b) the individual's place in it, and (c) the range of possible relationships to that world (Guba and Lincoln, 1994).

When searching for knowledge (understanding) researchers embrace particular ontological positions (their belief as to the nature of reality) which reflect that slice of reality which the researcher chooses to address (Hirschheim, 1992). Three categories of underlying research epistemology - the theory of knowledge - and, in particular, how we acquire knowledge are offered by Chua (1986): (a) positivist, where researchers seek realism which can be measured; (b) interpretive, where reality is socially constructed; and (c) critical, where reality is historically constructed and reproduced by people though social action based in language, labour, and domination.

Positivist-based studies are premised on the existence of a priori fixed relationships within phenomena and typically investigated with structured instruments (Orlikowski and Baroudi, 1991). Critical theorists examine material conditions and systems of ideology that reproduce class structures; for instance, power and domination (Denzin and Lincoln, 1998a).

My central world view in regards to this research is that it comprises neither immutable object(s) nor is the phenomenon produced through ideology and domination. Accordingly the positivist and critical perspectives were not considered for this analysis. The philosophical approach for this research is, therefore, interpretivism. The interpretive approach maintains that realities vary in nature and are time and context bound, and therefore, there is no universal truth (Pickard, 2007). Studies based within the interpretivist paradigm assume that 
people create and associate their own subjective and inter-subjective meanings as they interact with the world around them (Orlikowski and Baroudi, 1991).

By adopting an interpretive position, my knowledge of reality was able to be gained through social constructions such as language, consciousness, and shared meanings. As a researcher, I was equipped with a perspective that enabled phenomena to be understood through the meaning that people assigned to them and as I interpreted the response. Through analysing respondents' statements, the researcher can interpret comments made and compare and contrast them with other statements to build an understanding of the phenomena being studied (Klein and Meyers, 1999).

\subsection{The research strategy and methodology}

Fundamentally there are two research methodologies underlying the theoretical perspective of research: quantitative and qualitative (Pickard, 2007). A third approach, mixed methods, combines both quantitative and qualitative methodologies and is used where the researcher seeks to base knowledge claims on pragmatic grounds (Creswell, 2003).

A quantitative approach is one in which the researcher primarily uses positivist claims for developing knowledge and collects data via predetermined instruments, such as a survey, that yield statistical data (Creswell, 2003). While this research study was initially guided by a predetermined research it was open to change as the research progressed therefore a quantitative approach was rejected, as was a mixed methods approach. A qualitative approach, where the researcher may seek to establish the meaning of a phenomenon from the views of participants, aligns well with my research intentions to explore how entrepreneurial actors go about securing resources to create new innovative IT artefacts.

The research study adopted and used qualitative research methods as it encompasses, “....research about persons’ lives, stories, behaviour, but also about 
organizational function, social movements or interactional relationships" (Strauss and Corbin, 1990, p. 17).

Qualitative research is multi-method in focus, involving an interpretive naturalistic approach. The qualitative researcher studies things in their natural settings, attempting to make sense of phenomena in terms of the meanings people bring to them (Denzin and Lincoln, 1998b). Within IS research, qualitative research methods allow for a shift in focus away from technological issues to focusing on managerial and organisational issues (Myers, 1997).

Operating at an applied level are strategies of enquiry that provide specific direction for procedures in the research design and contribute to the overall research approach (Creswell, 2003). Creswell (2003) associates five specific strategies of enquiry with qualitative research: (a) ethnographic, studies of intact cultural groups over time; (b) grounded theory, where the researcher seeks to derive theory; (c) case study, an in-depth investigation of an event, activity, process, or individual bounded by time and activity through the use of a variety of data collection procedures; (d) phenomenological research, where the researcher identifies the essence of human experiences concerning a phenomenon as described by participants; and (e) narrative research where the researcher studies the lives of individuals and asks one or more individuals to provide stories about their lives.

\subsubsection{Determining the research methodology}

Initially, I sought to identify factors that drive, enable and inhibit resource acquiring relationships between actors within entrepreneurial information technology firms and their network brokers. This meant that I needed to understand the phenomenon as it is experienced by the participant and due to this fact I initially considered phenomenology as my choice as research method for the study. 
Phenomenology is a strategy of inquiry which is used to seek a detailed understanding of the phenomenon under investigation as it is experienced by the individual (Pickard, 2007). Pickard (2007) sees phenomenological based studies as being concerned with discovering the underlying structure of experiences.

Phenomenology as both a philosophy and a methodology has been used to develop an understanding of complex issues that may not be immediately implicit in surface responses (Goulding, 2005). A phenomenological approach to studying a problem "includes entering the field of perception of participants; seeking how they experience, live, and display the phenomenon; and looking for the meaning of the participants' experiences." (Creswell, 1998, p.31). The phenomenon that is the focus of the enquiry may be emotions, relationships, a program, an organisation or a culture (Patton, 2002, pp.104-105).

Two important implications for phenomenological based studies are highlighted by Patton (2002), with the first implication stressing the importance of knowing what people experience and how they interpret the world. As Patton points out this is the subject matter and focus of the phenomenological inquiry. The second implication identified by Patton is in regards to methodology as the only way for researchers to really know what another person experiences is to experience the phenomenon as directly as possible for ourselves.

To aid the researcher in focusing exclusively on the topic and question of interest key information is "placed in brackets" a process referred to as bracketing which allows everything else to be set aside (Moreno, 1999). Moreno (1999) advocates that when taking such an approach all possible accounts of the phenomenon should be considered in a pre-reflective collection of information. This allows the researcher to engage in a reflective process aimed at grasping the full nature of the phenomena.

The issue of bracketing is also seen as a key feature of phenomenological methods by Cassell and Symon (2004), as it emphasises the need for the researcher to 
consciously set aside their presuppositions about the phenomenon under investigation. The researcher must reflect on the presuppositions they hold and remain alert to how they may colour every stage of the research process.

The need to set aside prior understanding and beliefs while always important was of special importance for me as I had extensive previous experiences within the topic area as a practitioner (see section 3.5.1.1). This meant that I needed a research methodology that would allow me to enter the field of study as someone with prior experience of the phenomenon.

As a novice researcher, I was not confident that phenomenology provided me with an appropriate set of tools to bracket and set-aside my prior experiences in the early phases of the research. Consequently, I investigated alternative methodologies and metatheoretical tools. One such tool is Sense-making as it provides researchers with a metatheoretical framework from which to design user studies, facilitate dialogue and allows diverse needs to be heard while bracketing the practitioner/researchers own views (Cheuk, 2008).

Sense-making research relies extensively on grounded approaches that seek to grasp people's understandings and, through systematic comparison techniques, aims to reveal regularities and systematic associations in the structuring process of sense-making and organising (Allard-Poesi, 2005). In a broad conceptualisation, sense-making is a motivated continuous effort by researchers to understand connections among people, places and events in order to anticipate their trajectories and act effectively (Klein, Moon and Hoffman, 2006)

Combining Phenomenology with sense-making was a viable option, but as I explored further the use of grounded theory began to emerge as a viable fit for my researcher requirements, as it: (a) allowed me understand the phenomenon from the perspective of the participants; (b) allowed for researchers with prior experience in the topic area; (c) provided proven tools and processes to manage researcher bias; and (d) as a methodology it was specifically developed as a tool 
to derive theory that is grounded in the data (see section 3.4, for a full discussion of the grounded theory method).

While I wanted to find out how entrepreneurial managers seek out and leverage resources they do not have or even know about in order to bring their IT-based innovation to market, the research was being undertaken for the degree of Doctor of Philosophy in Information Systems. It is a requirement for such research to develop new knowledge in the topic area, for example a new theory. In addition, while the fields of entrepreneurship and innovation are rich in theories, the IS discipline as Weber (2003) comments has few theories of its own and relies mainly on theories borrowed and adapted from other disciplines.

This is especially so for research focusing on the creation of Information Systems innovation. I had already determined that this particular area of research was a relatively under researched topic area from the IS perspective. The grounded theory method is particularly suited to research where there is comparatively little known about a phenomenon where there is no prior theory to explain what has happened or existing theories fail to explain a particular set of circumstances (LoBiondo-Wood and Haber, 1994).

\subsubsection{Additional methodologies considered}

The use of network theory based methodologies was considered for use, but deemed unsuitable given their focus on aspects of network structure. This research seeks to depart from a focus on network structure as Snowden (2005) summarises, Social Network Analysis or SNA is about mapping the various interactions between actors in a network so as to better understand how things happen in order to intervene and make structural network changes to better reflect organisational objectives. It confuses the individual as a personality from that individual's role or function and it adds to confusion between the formal and informal aspects of an individual. 
Case study analysis was also considered; as case analysis allows the researcher to analyse a single person or organisation, or several people or organisations (Corbin and Strauss, 2008). Within case study based research the researcher "explores in depth a program, an event, an activity, a process, or one or more individuals" (Creswell, p. 15, 2003). While case analysis would provide me with a research method to study both entrepreneurial actors and brokers, as a method it does not specially cater for the knowledgeable researcher or provide detailed mechanism to handle prior experience. As Lehmann (2010) comments that within classical case research “...no satisfactory method is provided on how not to 'dirty' the slate with the inevitable bias any researcher will always bring with him" (p.7).

As a novice researcher this was a prime concern and I believed the data collection and analysis processes, specifically the constant comparison process and extensive use of memos within the grounded theory methodology provided me with a comprehensive tool set of procedures to mitigate potential researcher bias, which case research did not. A comprehensive discussion of the grounded theory method is contained in the next section.

\subsection{Research method: Grounded Theory}

Grounded theory is an inductive approach to developing or building a theory of a topic of interest, while at the same time, grounding that development in the empirically collected data (Martin and Turner, 1986).

The main distinction between grounded theory and other qualitative research methods is that grounded theory places great emphasis on the analysis process known as the "constant comparison method" in which the core category subsumes the major categories and explains much of the variation in the data (Glaser \& Strauss 1967). In order to do this, the researcher must be sensitive to the underlying meaning of the data. Within the grounded theory method this sensitivity is referred to as "theoretical sensitivity" whereby a researcher displays his/her knowledge, understanding, and skills, and is able "to generate concepts 
from data and to relate them according to the normal models of theory in general" (Glaser, 1992, p.22).

Core grounded theory methodology was developed in the mid 1960s by Barney Glaser and Anselm Strauss for the purpose of building theory from data (Corbin and Strauss, 2008). Glaser and Strauss provided the first outline of the method in the publication of their book, "The Discovery of Grounded Theory" (Glaser and Strauss, 1967), and in doing so they constructed a research methodology that sought to systematically derive theories of human behaviour from empirical data (Urquhart, Lehmann and Meyers, 2009).

Glaser and Strauss' original intention of the method was to inductively generate formal theory via the route of substantive theory (Urquhart, 2001). A formal theory is the highest level of abstraction and focuses on conceptual entities, with the substantive theory pertaining to a particular area that may lead into a bigger or more formal theory (Strauss, 1987). As Glaser (2005) emphasises, the prime goal of grounded theory is to produce "just a theory" and not an accurate description of the phenomenon.

This "just a theory" is not preconceived in advance and must emerge from the data through induction. If the researcher looks at data first and then forms hypotheses, it is inductive; whereas if the researcher first forms hypotheses by conjecture and then seeks to verify them, the research is deductive (Fernandez, 2003; Glaser, 1998). Fernandez (2003) provides a representation of the cycle of induction and deduction in the grounded theory method, as depicted in Figure 5. 


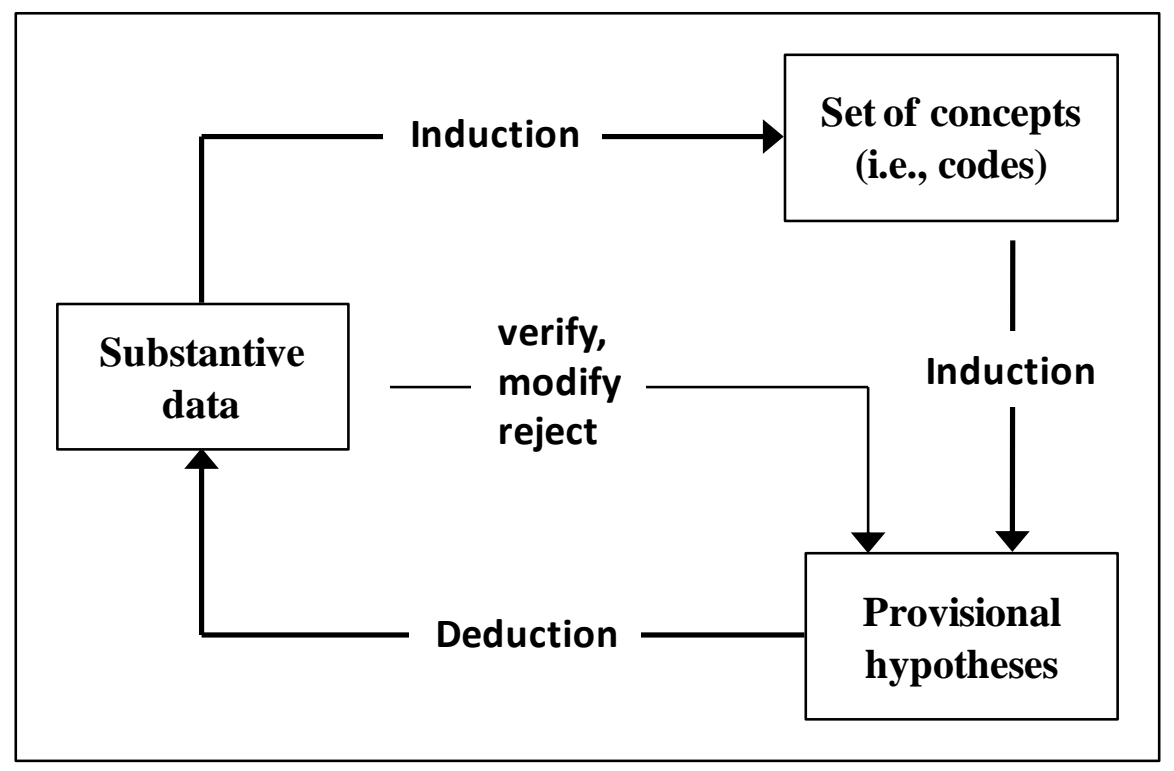

Figure 5: $\quad$ The inductive-deductive cycle of the grounded theory method (Fernandez, 2003)

\subsubsection{Variations of the grounded theory method}

Following a divergence of approach and opinion between the co-authors, Glaser and Strauss, in the early 1990s, the grounded theory method split into two base variations which are referred to as the "Straussian" and "Glaserian" versions (Stern, 1994).

\subsubsection{Straussian variant}

A prescriptive approach was proposed by Strauss and Corbin (1990) who advocate that the researcher progresses through a process of open coding, axial coding, and selective coding. Open and selective coding is common to both of the variants and is described in detail within the discussion of the Glaserian variant as interpreted for use in IS studies in section 3.4.3. Axial coding is specific to the Straussian variant of analysis and revolves around the "axis" of one category at a time, resulting in cumulative knowledge about relationships between the category, and other categories, and subcategories (Strauss, 1987). 
Within the Straussian variant, intense analysis is done around one category at a time to identify conditions and consequences (Strauss, 1987). To facilitate this analysis process Strauss and Corbin (1990) recommend the use of a coding paradigm which aids the analyst in making connections between data categories. The paradigm provides cues for how to identify and relate structure to process Strauss and Corbin, 2008).

The Straussian variation places emphasis on action and interaction and their relations to meso and macro social contexts. This was primarily because Strauss was a theorist of action and not of individuals; for him, action formed the core of experience and of sociological analysis (Bryant and Charmaz, 2007a).

\subsubsection{Glaserian variant}

The Glaserian variant as explained by Bryant and Charmaz (2007b) takes the fundamental position that "all is data" and that the researcher must let the data emerge and must not preconceive it, either through applying extant concepts or asking extensive questions of research participants.

Responding to what he saw as Strauss and Corbin's (1990) corruption of the method, Glaser (1992) provides an updated definition describing the grounded theory approach as "a general methodology of analysis linked with data collection that uses a systematically applied set of methods to generate an inductive theory about a substantive area" (p. 16).

The Glaserian approach uses open coding, selective coding, and theoretical coding to achieve theoretical integration. Theoretical codes (TCs) conceptualise how the substantive categories may relate to each other and integrate into a theory, thereby weaving the fractured story back together (Charmaz, 2006).

Theoretical codes show the essential relationship between data and theory, with the code conceptualising the underlying pattern of a set of indicators within the 
data (Glaser, 1978). The practice of coding derives and develops concepts from data (Corbin and Strauss, 2008).

To understand how codes and categories may relate to each other, the researcher must be sensitive to theoretical codes through preconscious processing. This requires researchers to be sensitive to a full array of theoretical codes, not only from within their own disciplines but through undertaking theoretical reading in other disciplines and substantive areas (Glaser, 2005).

In "The Grounded Theory Perspective III: Theoretical Coding” Glaser (2005) provides a detailed account of the theoretical coding process and repeatedly stresses the need for the researcher to develop a repertoire of as many theoretical codes as possible. As Glaser (2005) goes on to explain, the more theoretical codes the researcher unearths, the greater is the ability to see variation and stay open and sensitive to whatever theoretical codes emerges from the data. Although inventing a theoretical code is possible this would be very unlikely compared to finding an existing one or using a combination of other theoretical codes. As shown in the next chapter this research does not identify a new theoretical code and on fact uses the one theoretical code that Glaser himself identified, the Basic Social Process.

\subsubsection{Differences between the two variants}

The process of theoretical coding and how the relevant theoretical codes emerge from the data is the main point of difference between the Straussian and Glaserian variants. The introduction of the coding paradigm into the method by Strauss and Corbin (1990) was seen by Glaser (1992) as a corruption of the method that both he and Strauss had conceived. For Glaser (1992) the use of the coding paradigm forced preconceptions from the data "if you torture the data long enough it will give up! this is the underlying approach in forcing preconceptions of full conceptual description" (p.123). 


\subsubsection{Ongoing evolution of the grounded theory method}

The grounded theory method is continually evolving to reflect the interpretations of second and now even third generation researchers. Such continual change is foreseen by Morse (2009) who predicts that new methods will emerge and change the basic modus operandi of doing grounded theory and ultimately the end product.

An example of such an adaption is proffered by Charmaz (2006) who borrows from both the Glaserian and Straussian variants and proposes a hybrid approach that involves a process of open coding, focused coding, axial coding, and theoretical coding. For Charmaz (2006) the grounded theory method is not a set of prescriptions but a set of principles and practices that can complement other approaches to qualitative data analysis rather than stand in opposition to them.

While not a variation of method, Urquhart et al. (2009) develop and advocate the use of a set of guidelines for grounded theory studies in IS research, as discussed in the following section 3.4.2. They do so in the hope that the guidelines may aid the development of new theories of the information systems phenomenon.

\subsubsection{Grounded theory in IS research}

The grounded theory method has been used within the IS discipline since the mid 1980s; yet while it is seen as being perfectly positioned to help IS researchers generate theory due to its clear procedures for analysing data, it is rare for such studies to generate substantive grounded theories through using the method (Urquhart, 2007). Many grounded theory-based IS studies use grounded theory only as a coding method and a qualitative data analysis tool as opposed to a theory building tool (Urquhart, 2007; Urquhart et al., 2009). 


\subsubsection{Best Practice}

The method secured widespread legitimacy in the IS discipline through the publication of Orlikowski's (1993) paper on the adoption and use of computer aided software engineering (CASE) tools as a means of organisational change (Urquhart and Fernandez, 2006). The paper is considered by Urquhart et al. (2009) as being the high water mark for theorising in IS studies using the grounded theory method as it: (a) pays great attention to relationships between concepts, (b) exhibits iterative conceptualisation, (c) systematically explores those relationships, and (d) provides a chain of evidence. Orlikowski (1993) found that the grounded theory approach allowed her to focus on contextual and process elements as well as the actions of key players associated with organisational change. Such elements, she comments, are often omitted in IS studies given IS researcher preference for variance models and cross-sectional qualitative data. Within this study, Orlikowski's paper plays a dual role; not only does it set the bar for the use of the method within an IS study, but it also uses structuration theory and relates it to the development of her own theory. The theory developed within this research study is informed, in part, by Structuration Theory as human actors interact within social structures to create innovation.

\subsubsection{Guiding Influences}

A second study within the IS discipline by Fernandez (2003) guided the presentation of the research analysis. Glaser (2005) singles out this dissertation for comment with particular reference to how Fernandez (2003) acknowledges, acquires, and uses theoretical codes and the role they play in building theory. Fernandez references and builds upon a grounded theory process model first published by Fernandez, Lehmann and Underwood (2002) which is based on the original work of Lehmann (2001a). The process model and subsequently expanded research model is adapted based on experience gained during this research and offered as a contribution of this study in Chapter 8, section 8.3. 
Additional studies influencing the presentation of this study are those of Urquhart et al. (2009); and Andersen (2008). While not IS-specific, Andersen (2008) uses the grounded theory method for her research study and presents her research data and analysis in a way that I found to be clear, logical and easy to follow.

\subsubsection{Approach adopted: Glaserian as interpreted for use in IS studies}

The approach adopted for this research is the Glaserian variant as interpreted and recommended for use in IS studies. The Glaserian variant allows theory to emerge from the data, free from any claims of forcing and as a process has support from senior researchers within the IS field.

My understanding and application of the Glaserian approach has been informed not only by reading Glaser's key publications (Glaser and Strauss, 1967; Glaser, 1978; Glaser, 1992; Glaser and Holton, 2004; Glaser, 2007a; and Glaser, 20007b); but also through the interpretations and application by notable researchers such as Charmaz, (2006); Fernandez, (2003); Lehmann (2001a, 2001b); Orlikowski, (1993), Urquhart (2001; 2002; 2007); Urquhart and Fernandez, (2006); and Urquhart et al. (2009).

An illustration of the grounded theory cycle is provided by Fernandez, Lehmann and Underwood (2002). The representation which is based on the original work of Lehmann (2001a) depicts the process as a spiral that starts by collecting slices of data in a substantive area of enquiry. The slices of data are then codified and categorised in a continuous process that moves toward saturation and results in the theoretical densification of concepts represented by a substantive theory (Fernandez, 2003). Fernandez (2003) adopts this depiction and expands upon it to create a research model to guide his $\mathrm{PhD}$ research. The original model by Fernandez, et al. (2001) and its adaptation by Fernandez (2003) are shown in Figure 6. 
The iterative model of the grounded theory cycle was modified by Fernandez (2003) to show the important role that extant literature in the substantive topic area played in the formulation of the grounded theory, and to show the key role theoretical memos have in the grounded theory process. Within the expanded model, Fernandez (2003) includes a starting point at which the researcher enters the field to undertake the first research action to be conducted in the context where the phenomenon is found.

A further adaptation of this iterative model is proffered in Chapter 8, section 8.3, as a contribution of this study. The alterations reflect my interpretation and application of the grounded theory method during the course of the research.

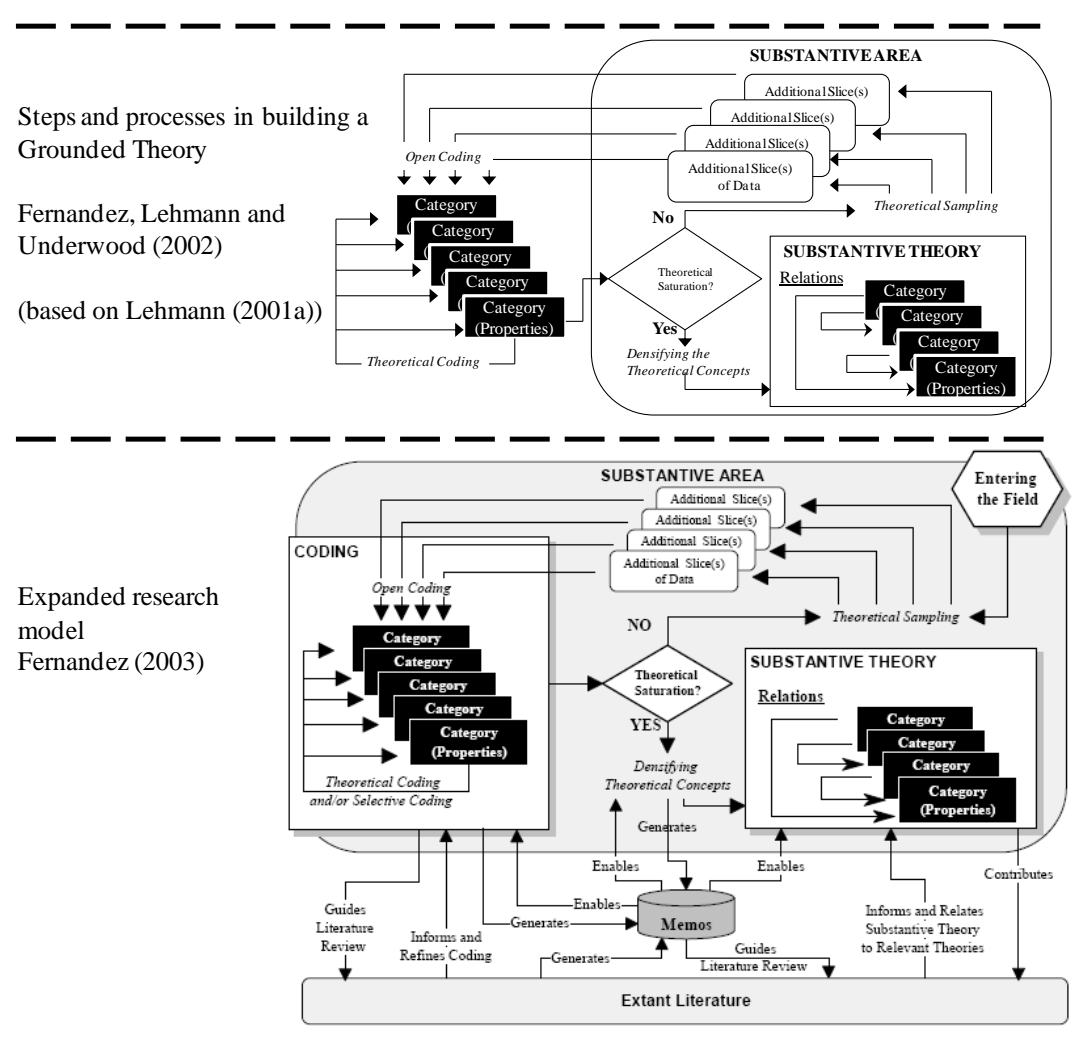

Figure 6: A Research Model: steps and processes in the grounded theory process (Fernandez et al., 2002; Fernandez, 2003; Lehmann, 2001) 
Seeking to document the sequence of events that a researcher undertakes when employing the Glaserian approach, Lehmann (2001a) reviews and references Glaser's early publications (Glaser and Strauss 1967; and Glaser, 1978). Lehmann (2001a) does so as the original method was not described in the sequence of events the researcher undertakes. The steps as sequenced by Lehmann (2001a) provide a framework to describe the grounded theory method and the processes used in detail, see sections 3.4.3.1 - 3.4.3.6.

\subsubsection{Comparing incidents applicable to each category}

Data analysis within grounded theory begins with open coding (Strauss, 1987). As Dey (1999) explains, the open coding process involves breaking the research data down into discrete parts and assigning labels, referred to as codes, to the slices of data. These slices are later stitched together again through identification of theoretical connections.

The process of open coding allows the analyst to see the direction in which to take his/her study by theoretical sampling, see section 3.4.3.4, before he/she becomes selective and focused on a particular problem (Glaser, 1978).

As the analysis progresses, via a procedure called constant comparison analysis incidents are compared with other incidents and assessed for similarities and differences; when found to be conceptually similar they are given the same conceptual label and put under the same code. Each new incident that is coded adds to the general properties and dimensions of its respective code, elaborating it, and bringing in variation (Corbin and Strauss, 2008). Through the constant comparisons of incident to incident, categories and their associated properties are generated (Glaser, 1992). 


\subsubsection{Integrating categories and their components}

The constant comparison method gives rise to the emergent categories and ultimately a core category which subsumes the major categories and explains much of the variation in the data. Categories (or themes) are higher-level concepts under which the researcher groups lower-level concepts according to shared properties (Corbin and Strauss, 2008).

Categories are of two types: sociological constructs assigned by the researcher based on his/her interpretation and understanding, and in-vivo codes. In-vivo codes are taken from or derived directly from the language of the substantive field and are often labelled with a term used by participants in that field (Strauss, 1987).

The categories/themes are grounded in the data rather than being derived from a preconceived conceptual framework. This implicitly requires awareness of self and the consciously reflective process of reflexivity (McGhee et al., 2007). This reflexivity, within the grounded theory method is achieved through writing memos. When writing memos, the researcher frees him/herself to explore ideas about categories and how they integrate (Charmaz, 2006).

A memo can be a sentence, a paragraph or a few pages. One particular type of memo, the theoretical memo, allows the researcher to write up ideas about codes and the relationships as the ideas occur to the analyst during coding. It also allows the researcher to sound off with nothing crucial at stake (Glaser 1978).

\subsubsection{Developing concepts}

Through abstraction, the data is seen not merely as a label, but a conceptualisation that provides a meaningful picture of some key feature (Dey, 1999). As seen by Corbin and Strauss (2008) concepts are interpretations; the products of analysis and are words that stand for ideas contained in data. They are generated from 
evidence and the evidence is used to illustrate the concept (Glaser and Strauss, 1967).

In order to see and develop concepts the researcher needs theoretical sensitivity, see section 3.4.4, the ability to generate concepts from data and to relate them according to the normal models of theory in general. If the researcher does not have theoretical sensitivity, a grounded theory will not eventuate (Glaser, 1992).

\subsubsection{Theoretical sampling}

As the research progresses, the researcher narrows the focus to investigating issues associated with the core category and emergent theory. This is done through selective coding and theoretical sampling.

Selective coding allows the researcher to delimit the coding to only those variables that relate to the core variable. In addition, the core variable becomes a guide to further data collection and theoretical sampling (Glaser, 1978).

Via theoretical sampling, the researcher jointly collects, codes, and analyses the data and decides what data to collect next and where to find the data, in order to develop the theories as they emerge (Glaser, 1978). This activity informs the theoretical coding process and gives rise to theoretical codes that show the essential relationships between categories (Urquhart, 2007).

Progressing through the iterative stages of open, selective, and theoretical coding and refining the data collection, results in the formulation of a theory containing inferential and/or predictive statements, sometimes in the form of hypotheses, about the phenomenon (Urquhart et al., 2009). 


\subsubsection{Theoretical saturation}

Research progresses until theoretical saturation is reached. This is the point in the analysis where all the categories become well developed in terms of properties, dimensions, and variation. Further data gathering and analysis add little new to the conceptualisation (Corbin and Strauss, 2008). Once the data no longer offers any distinctions of conceptual importance, categories can be described as saturated and no further evidence needs to be collected (Dey, 1999).

\subsubsection{Writing the theory}

Throughout the process, the researcher needs to be mindful that an integral part of the method itself is the writing of theory. The way data is coded, ideas are vocalised through the use of memos, and how memos are sorted are all partly focused on designing and facilitating the writing of the theory (Glaser, 1978).

Writing and sorting memos during each analytic phase prompts the researcher to make the analysis progressively stronger and clearer, and provides a logical framework for writing the theory (Charmaz, 2006). In addition, memos written during the analytic process allow the theory to be expanded and supplemented or even perhaps revised (Dey, 1999).

\subsubsection{Theoretical pacing}

The steps and sequencing provided by Lehmann (2001a) are silent on one key aspect; theoretical pacing. While not a process or step, according to Glaser theoretical pacing is a key aspect of the application of the grounded theory method, and it is at the heart of the methodological differences that arose between Glaser and Strauss. A grounded theory must emerge from the data in its own time; it should not be forced into appearing. 
Glaser (1978) introduces the notion of theoretical pacing to guide the use of processes and events within the method. As Glaser states:

Generating grounded theory takes time. It is above all a delayed action phenomenon. Little increments in coding, analyzing and collecting data cook and mature then to blossom later into theoretical memos. Significant theoretical realisations come with growth and maturity in the data, and much of this is outside the analyst's awareness until it happens. Thus the analyst must pace his patience, and not just be patient, accepting nothing until something happens, as it surely does. (1978, p. 18)

\subsubsection{Reading for Theoretical Sensitivity}

The researcher's skill and ability to be able to conceptualise concepts and develop theory from the data is dependent in part on prior knowledge gained from reading widely on scholarly matters (Seldén, 2005). Yet, within the Glaserian variant, undertaking a review of the substantive literature prior to the emergence of a core category violates the basic premise of grounded theory. Theory should emerge from data and not extant theory or the researcher runs the risk of clouding their "ability to remain open to the emergence of a completely new core category" (Glaser and Holton, 2004, p. 12).

The main issue for Glaser is not what to read, but when to read it. Glaser (1978) sees grounded theory as primarily an inductive approach where field data is collected first and once the theory seems sufficiently grounded and developed, then the substantive literature is read and related to the emerging theory. Glaser (1992) provides a distinction between unrelated literature and related literature, with the reading of unrelated literature keeping "up the researcher's continual theoretical sensitivity to conceptualisations of data and to theoretical codes, which are replete in the literature" (p. 35). 
The early positions of Glaser (1978) and Glaser and Strauss (1967) on related literature have been a source of much debate within the grounded theory research community as they express concerns that "literature might contaminate, stifle or otherwise impede the researcher's effort to generate categories" (Glaser, 1992, p. 31). As Charmaz (2006) explains, Glaser and Strauss believe that by delaying the literature review the researcher will avoid seeing the data through the lens of earlier ideas, a concept referred to as "received theory", and will avoid importing preconceived ideas and imposing them on the work.

Conversely, Walsham (1995) argues that it is possible for the researcher to access existing knowledge of theory in a particular subject domain without being trapped in the view that it represents final truth in that area. A pragmatic compromise is offered by Urquhart and Fernandez (2006) who advocate that the researcher should not take a position about the research to be done. They recommend that a preliminary literature review is conducted "on the understanding that it is the generated theory that will determine the relevance of the literature” (p. 461) and that the literature review is revisited and extended once the theory has been generated from the data. Urquhart and Fernandez lament that it is unfortunate that the grounded theory method may be seen as not being rigorous due to calls to delay the literature review, pointing out "the very crux of GTM is the rigorous generation of theory using systematic procedure" (2006, p. 461).

\subsubsection{Use of qualitative software analysis programs}

As with the role and place of the literature review, another topic of debate within the grounded theory method relates to the use of qualitative software analysis programs.

The use of qualitative software analysis programs was not an option available to early grounded theorists, but more recent versions of the available software packages seem to increasingly support the research process (Corbin and Strauss, 2008). Nevertheless, while acknowledging the benefits provided by computer programmes and their ability to provide increased transparency of the research 
process, Corbin is quick to point out "that the analytic process remains a researcher-driven thinking and feeling process, even with the supplementation of a computer program" (2008, p. xi).

The primary role of the researcher within the grounded theory method is something both the Straussian and Glaserian variations emphasise. Glaser (2005), while accepting that "computer sorting will result in a GT product, no doubt" (p. 29), leaves the reader in no doubt that he is of the belief that the final theory will not be as rich as that produced by the hand sorting of memos. Glaser (2005) maintains that true creativity of grounded theory is stultified by computer sorting; that when using traditional pencil and paper and hand sorting methods, the researchers are able to vary their coding practices in small ways to better meet their personal research needs and creative styles. Glaser makes specific reference to Walter Fernandez's (2003) thesis work and his use of the qualitative data analysis tool "ATLAS.ti" for open coding and memoing, and specifically Fernandez's assertion that such use of computer-aided tools provides a substantial advantage. Glaser points out that this is an unsubstantiated claim since Fernandez did not compare his computer sorting to hand sorting and also suggests that Fernandez's creativity might have been dulled through the computer software forcing its own framework on the research.

However, the question remains how Glaser (2005) can make such an assertion given he has not undertaken a direct comparison of Fernandez's data using hand sorting. Perhaps the understanding adopted by Charmaz (2006) is most appropriate: while grounded theory is a method to study process, it is, moreover, a method in process; and rather than thinking of it as fixed and static it is changing and has room to, and is able to, incorporate changes and differing perspectives. 


\subsubsection{Unit of Analysis}

Grounded theory research is the study of abstract problems and their processes, not units (Glaser, 1992). While I sought to research the actions of human actors' involved in the IT creation process, the actors themselves are not the unit of analysis for my research, nor are the organisations that they interact with. The unit of analysis became the Basic Social Process (BSP) that entrepreneurs and intrapreneurs go through in order to create the IT artefact and bring its first tangible form into being. A BSP is a "core variable, which recurs frequently in the data, links the various data together and explains much of the variation in the data" (Glaser, 2005, p. 124).

In addition to accounting for much of the variation in the pattern of behaviour, the core category has several other important functions: (a) categories and their properties are related to it, consequently it is subject to much qualification and modification because it is dependent on what is going on in the action; (b) relations between categories and their properties have the prime function of integrating the theory and rendering it dense and saturated as the relationships increase; and (c) it delimits the theory and thereby the research project. Once identified and chosen only those variables that are related to the core category are to be included in the resulting theory; the researcher must only focus on one core category, delimiting and demoting other categories. As the researcher starts coding, categories tend to appear quickly and often, yet over time the core category will emerge from the many through extensive and repeated coding and analysis where the core is verified by saturation, relevance, and workability (Glaser, 1978).

A core category may be a BSP (yet not all core categories are BSPs) with the primary distinction being that BSPs are processural and "process out", given they have two or more clear emergent stages. In addition, some core categories may not have any stages or provide for movement over time. The BSP is something that occurs over time and involves change over time with discernable breaking 
points such that the stages can be perceived as theoretical units with conditions, consequences, and properties unique to each particular stage. A stage has: (a) a time dimension with a perceived beginning and end, where the length of time may or may not be fixed; and (b) a transition from one stage to another which is normally contingent on one or more things happening, yet the set of indicators marking the transition may be blurry (Glaser, 1978).

There are two types of BSPs: (a) the Basic Social Psychological Process (BSPP) referring to the social psychological processes such as becoming and highlighting; and (b) the Basic Social Structural Process (BSSP) referring to social structure in processes usually connected with growth and deterioration, for example centralised bureaucracy or recruiting and redundancy procedures (Glaser, 1978).

This research produces a BSSP which explains the "preneurial" actions undertaken by "preneurs" in the IT creation process. It is not a static representation and accounts for movement and change in a process, hence staticbased theoretical codes did not suit this research. The core variable is based on action, more specifically an action that I term preneurial agency which represents the actions undertaken by the preneur in the IT creation process.

How the BSP emerges from the data and under goes modification and change in its development is the focus of the following Chapter 4. The stages associated with the BSP of preneurial agency, their properties, and delimitations are developed and related to the extant literature in Chapter 6.

\subsection{The role of the researcher}

In this research, I undertook the role of an interpretive researcher. Walsham (1995) identifies two different roles that can be played by the interpretative researcher: (a) the outside observer, who maintains some distance from the respondents, does not have a direct personal stake in various interpretations and outcomes, and may gain restricted access to confidential and sensitive information 
which respondents are usually uncomfortable sharing with an "outsider"; and (b) the involved (participant) researcher who becomes part of the field group or organisation, even if only temporarily, in order to get an inside view and access to confidential and sensitive issues.

In the context of this study, I had prior working relationships with some of the respondents, which ensured trust and respect was present in the interviews, so allowing respondent to open up to me and share sensitive views; yet I was not a temporary member of the respondents' teams observing their actions as part of the research study. I cannot claim I maintained distance from all respondents, as in some cases, I traded off our personal relations and past experiences to gain access and insights. Consequently, I do not comfortably fit with either of the two roles of interpretive researcher as specified by Walsham (1995).

An alternative perspective on the role of the interpretive researcher is offered by Reed and Procter (1995): (a) the outsider who is a researcher with no professional experience and a visitor to the area of study; (b) the "hybrid" researcher who undertakes research into the practice of other practitioners and is familiar with that research area; and (c) the "insider" who is the actual practitioner-as-researcher looking into their own and known colleagues' practice.

As I am familiar with the broad research area through previous experience as an intrapreneur within corporate organisations involved in the ICT industry, I adopted the hybrid researcher role for this study. I have played an instrumental role in the development of a number of new IT-based innovations. I have also acted in resource acquiring and network broker roles in other situations and organisations, sometime in connection with the creation and commercialisation of new IT-based innovations. In some interviews, I had a prior knowledge of some of the participants, organisations, the participants themselves, and the role they played. In regards to one particular IT innovation, I had an intimate understanding of it and a close relationship with the respondents as I had played a crucial role in commercialising the innovation internationally in the early stages of the venture. 
Consequently, I entered into this research with prior experience and knowledge gained as a practitioner. Within the grounded theory method Glaser does not acknowledge pre-understanding but rather stresses the need for lack of prejudice and reflexivity (Selden, 2005).

\subsubsection{The knowledgeable researcher and reflexivity}

Researchers using grounded theory must be knowledgeable enough about the phenomenon they are studying to ensure the issues being addressed are understood, both when coding and when conducting interviews. Interviewees must have confidence that the interviewer truly understands what they are saying, or they may lose interest through lack of confidence that the researcher has the required deep technical knowledge to understand what is being said, especially when interviewing "elite" interviewees (Lings and Lundell, 2005). For Lings and Lundell (2005), having a deep understanding of the technical phenomenon under investigation was, as they report, fundamental to the success of their application of the grounded theory method and did not inherently threaten their sensitivity to the data.

As Dey (1999) emphasises, there is a difference between an open mind and an empty head. This is point is reinforced by Charmaz (2006) who comments that this is especially true for the grounded theory method where guiding interests, sensitising concepts, and disciplinary perspectives often provide the researcher points of departure for developing ideas, rather than limiting their ideas.

To prevent prior knowledge distorting the researcher's perception of knowledge, grounded theorists must acknowledge and reflect on their prior experience (McGhee, Marland and Atkinson, 2007). This process is known as reflexivity which McGhee et al. (2007) define as "the explicit quest to limit researcher effects on the data by awareness of self, something seen as integral both to the process of data collection and the constant comparison method essential to grounded theory" (p. 334). 
Mantzoukas (2005) goes so far as to say that researchers conducting reflective studies are bound by a different set of rules that require the researcher's bias to be included, rather than excluded. This is done in the form of reflective commentary which becomes an explicit and integral part of the study. Mirroring the position of Dey (1999), Mantzoukas (2005) maintains that keeping an open mind as a researcher should not be equated with having an empty head. As he comments, reflective studies are only meaningful "if the researcher can use the virtues of previous experiences, expertise, knowledge, language and expectations to design, interpret and present the research findings" (p. 291).

Within the grounded theory method, reflexivity is an essential part of the process and is achieved through the writing of memos (Glaser (1978; 1992; Strauss and Corbin 1990; Strauss 1987). Memos act as the narrated record of the theorist's analytical conversations with him or herself about the data; it forces the writer to question what they know and how they know it (Lempert, 2007).

\subsection{Issues of rigour, credibility and validity in grounded theory research}

As a method, grounded theory can help IS researchers produce both relevant and rigorous research that generates theory, and it is especially suited to research aimed at investigating emerging phenomena (Fernandez, et al., 2002). Summarising and extending the work of Glaser $(1978 ; 1998 ; 2001)$, Fernandez et al. (2002), and Fernandez (2003) state that the grounded theorist must:

1. Tolerate confusion - there is no need to know a priori and no need to force the data

2. Tolerate regression - the researcher might get briefly "lost" before finding his or her way

3. Trust emerging data without worrying about justification - the data will provide the justification if the researcher adheres to the rigour of the method 
4. Have someone to talk to-grounded theory demands moments of isolation to get deep in data analysis and moments of consultation and discussion

5. Be open to emerging evidence that may change the way the researcher thinks about the subject matter, and to acting on the new evidence

6. Be able to conceptualise and derive theory from the data

7. Be creative - devising new ways of obtaining and handling data, combining the approach of others, or using a tested approach in a different way

8. Aid their proficiency in the method though networking with other research using the method, read a wide range of grounded theory literature and participate in relevant discussion grounds where possible

9. Be sensitive to the field under study, this may be through having extensive experience as a practitioner in the field.

Grounded theory studies can be strengthened through situating the theory in its social, historical, local, and interactional contexts. When the study is situated and generality is allowed to emerge from the analysis, the researcher constructs a safeguard against forcing data into the analyst's favourite categories and pet theoretical codes (Charmaz, 2006). In addition, Charmaz maintains, the grounded theorist needs to consider who the audience will be as ultimately they "will judge the usefulness of our methods by the quality of our final product" (2006, p. 182). Thus, the grounded theorist should seek to adopt the following three criteria by seeking to answer the associated questions in the affirmative, as shown in Table 5. 
Table 5: $\quad$ Criteria for improving grounded theory studies

(Charmaz, 2006, pp. 182-183)

\begin{tabular}{|l|l|}
\hline Criteria & Considerations \\
\hline 1. & $\begin{array}{l}\text { Has your research achieved intimate familiarity with the setting or } \\
\text { topic? } \\
\text { Is the data sufficient to merit your claims? } \\
\text { Have you made systematic comparisons between observations and } \\
\text { between categories? } \\
\text { Do the categories cover a wide range of empirical observations? } \\
\text { Are there strong logical links between the gathered data and your } \\
\text { argument and analysis? } \\
\text { Has your research provided enough evidence for your claims to } \\
\text { allow the reader to form an independent assessment - and agree } \\
\text { with your claims? }\end{array}$ \\
\hline $\begin{array}{l}\text { Originality } \\
\text { Are your categories fresh? Do they offer new insights? }\end{array}$ & $\begin{array}{l}\text { Does your analysis provide a new conceptual rendering of the data? } \\
\text { What is the social and theoretical significance of this work? } \\
\text { How does your grounded theory challenge, extend, or refine } \\
\text { current ideas, concepts and practices? } \\
\text { Have you drawn links between larger collectives or institutions and } \\
\text { individual lives, when the data so indicates? } \\
\text { Does your grounded theory make sense to your participants or } \\
\text { people who share their circumstances? Does your analysis offer } \\
\text { them deeper insights about their lives and worlds? }\end{array}$ \\
\hline $\begin{array}{l}\text { Do the categories portray the fullness of the studied experience? } \\
\text { Have you revealed both liminal and unstable taken for granted } \\
\text { meanings? } \\
\text { Have you drawn links between larger collectives or institutions and } \\
\text { individual lives, when the data so indicate? } \\
\text { Does your analysis offer your participants deeper insights about } \\
\text { their lives and worlds? }\end{array}$ \\
$\begin{array}{l}\text { Does your analysis offer interpretations that people can use in their } \\
\text { every day worlds? } \\
\text { Do your analytic categories suggest any generic processes? } \\
\text { If so, have you examined these generic processes for tacit } \\
\text { implications? } \\
\text { Can the analysis spark further research in other substantive areas? } \\
\text { How does your work contribute to knowledge? How does it } \\
\text { contribute to making a better world? }\end{array}$ \\
\hline
\end{tabular}

Seeking to raise the bar for grounded theory studies in IS research, Urquhart et al. (2009) develop and advocate a refined set of guidelines to guide grounded theory researchers within the IS discipline. The guidelines draw attention to the key features of the method: (a) constant comparison to ensure the categories and the 
resulting theory are properly grounded; (b) iterative conceptualisation where the dynamic interplay between analysis and data collection happens and relationships are build between concepts in an iterative manner; (c) theoretical sampling which increases the relevancy and density of the theory; (d) scaling up to help increase the level of abstraction; and (e) theoretical integration, where the generated theory is related to other theories to aid in bringing disparate theory building efforts together.

These guidelines by Urquhart et al. (2009) provide a framework which can be used in writing up the data collection and analysis chapter of this research. In Chapter 4, I use these five guidelines to structure the presentation and discussion of how I applied the processes and procedures within the Glaserian variant as specified in section 3.4.3.

\subsection{Chapter summary}

In this chapter an outline of the research strategy and methodology has been provided, starting with the research paradigm and stating that the epistemological approach for this research is interpretivism and the methodological approach is qualitative. The chosen research method of grounded theory, which was further refined to Glaserian variant, is described in detail. Reference is made to ISspecific issues and use of the method and theory development. A set of guidelines for writing up and presenting grounded theory research within an IS study is introduced. This framework is used in the next chapter as an aid to structuring and describing the data collection and analysis process. 


\section{DATA COLLECTION AND ANALYSIS}

\subsection{Chapter overview}

Like an artist at the various stages of the design process, the qualitative researcher must choreograph the research story in all its complexity, context, originality, and passion (Janesick, 1998). Within this chapter, I choreograph my research story. The chapter acts as the spine - the backbone of the research study - as it shows how I interpreted and applied the grounded theory method in order to identify the core category.

I start with the research process which covers the aims and objectives of the research, research protocol, and the participant profile. I then proceed to describe how I first entered the study prior to entering the field. Discussion of the data collection and analysis is structured to adhere to the guidelines for grounded theory researchers within the IS discipline as developed and advocated by Urquhart et al. (2009). In addition, reference is made to reading for theoretical sensitivity and how the process contributed to the theory development.

\section{Chapter Contents}

4.2 The research process

4.3 Reading for coding sensitivity

4.4 Entering the field in the general topic area

4.5 Iterative conceptualisation

4.6 Theoretical sampling

4.7 Scaling up and theoretical integration

4.8 Progressing beyond the Basic Social Process of entrepreneurial agency

4.9 Theoretical saturation

4.10 Chapter summary 


\subsection{The research process}

In this section, I discuss the research question guiding the initial enquiry and how it was refined as the research progressed. I then discuss how the research data was collected, coded and analysed.

\subsubsection{Research question(s)}

All research inquiries necessitate a question of some sort to guide them (Corbin and Strauss, 2008). While a question may guide the initial enquiry, the grounded theory research process relies on the discovery of relevant questions in the data, which then direct the enquiry (Glaser and Holton, 2004).

During the data analysis relevant questions were discovered which then directed the research enquiry to answer the central question:

How do entrepreneurs and intrapreneurs act, and interact with other people in order to secure and combine the resources required to make their entrepreneurial vision a tangible reality?

In keeping with the requirements of the grounded theory method, a broad research question was set to guide the initial enquiry.

The research question guiding the initial enquiry was:

What are the drivers, enablers, and inhibitors of resource acquiring relationships between entrepreneurial actors within information technology firms and their network brokers?

Two sub-questions were also posed so that information may be obtained to assist entrepreneurial actors and network brokers to better understand the nuances in managing resource acquiring network relationships: 
4) How do these driving, enabling, and inhibiting factors influence or moderate how the parties obtain benefit from the relationship?

5) What similarities, differences, and complementarities exist between the parties in regard to the identified drivers, enablers, and inhibitors?

As the study progressed past the theoretical coding stage, it focused increasingly on the actions of the entrepreneur and intrapreneur and their interaction with other people in order to secure and combine the resources required to realise their entrepreneurial vision. The data had taken me away from the initial research question, to the point where I had removed the term "network brokers" from the study. The broker was replaced by the more inclusive term "collective agents" to represent key participants that entrepreneurs interacted with and aided them to create the IT innovation.

The term "collective agents" reflects Archer's (1995) position of "agents" being the plural, denoting a group or collective who share interests and life chances; as opposed to the singular perspective of the person as an actor. It also incorporates Orlikowski's (1992) view that human agents, through their collective actions are responsible for technology creation.

Consequently, as used in this research study "collective agents" is defined as human agents who through their collective actions assist in the creation of innovation.

\subsubsection{Research location and setting}

The research was predominately carried out in Wellington, New Zealand. All respondents were New Zealand citizens. All but one of the participants lived within the greater Wellington region. One participant, now living and conducting her IT web-based business abroad, was interviewed on a visit to Wellington. 
The research did not seek to be geographic specific or to identify geographic specific factors, but sought to interview people associated with Information Technology innovations.

\subsubsection{Research protocol}

Victoria University of Wellington requires that any research involving human participants be submitted to the Human Ethics Committee (HEC) for approval before the research is embarked upon. Appendix A contains a copy of the HEC application which was submitted and Appendix B contains the approval notification.

Each interviewee was provided with a research information sheet, which was changed after the identification of the initial BSP during the analysis of the second group of interviews, so that it more accurately reflected the refined research objective (see Appendix C and Appendix D). Consistent with grounded theory, the topic description changed as the research progressed and the study shifted from the general topic area, to the substantive topic area.

The research information sheet used for the first twelve interviews stated that the "focus for this research is on how entrepreneurial managers/firms seek out and leverage resources they do not have or even know about in order to bring their innovation to market. One particular relationship that has been found to be extremely powerful and critical to the success of such resource acquiring activities is the relationship between the entrepreneur/entrepreneurial managers and network brokers. The broker is often seen as a conduit, a pipe, through which previously unseen resources may flow". For a detailed discussion of the role of brokers and social networks in the innovation process see Thistoll and Pauleen (2010). Due to brokers being removed as a focus for this study, a detailed discussion of their role is absent for the literature review as any discussion does not support the emergent theory and substantive topic area of the revised study. 
The revised research information used for the remaining interviews stated that "the entrepreneur, though his/her actions or agency, as it is commonly referred to, are located in and participate in, social structures such as personal social networks and firms. In these social structures they interact with other people in order to secure and combine the resources required to bring their entrepreneurial vision into being. These interactions are a specific focus of the research study".

Interviewees were informed that the interview would take approximately one hour and would be recorded and that all interview notes, recordings, and transcripts would be kept in confidence and destroyed within five years of the conclusion of the doctoral research. They were offered the opportunity to verify the interview transcript for accuracy, assured that no information that they provided would be attributed to themselves or their organisation, and that neither they nor their organisations would be identifiable in any way. As required by the Victoria University Human Ethics Committee, participants were asked to confirm that they either had authority to participate, or had obtained approval from an appropriately authorised manager. All participants signed a research consent form (see Appendix E).

At first, questions asked in the interviews were guided by an interview guide and schedule (see Appendix F). Careful preparation of open-ended questions in advance of the interview helps novice researchers to avoid asking loaded questions and forcing responses into narrow categories (Charmaz, 2006). This was the case, through using the interview guide when doing my first group of interviews; I was able to ask the full range of questions that I required.

As the interviews progressed, I became more experienced and comfortable with the process. Participants were asked to tell their story with only minor prompting from me. Where needed, specific questions were asked in order to probe more deeply into an issue and elicit more information from the respondent and also to allow them to reflect on what they were saying and what they meant by what they had said. 
The range of topics areas explored within grounded theory based interviews becomes increasingly narrowed as the interviews progress, as the researcher seeks to gather data specific to the emerging theoretical framework (Charmaz, 2006). As interviews progressed within the study, the range of questions changed and became increasingly focused around the emergent theory. As the nature of questions changed, so too did the participant profile.

\subsubsection{Data Collection}

I undertook the primary research in groups of six interviews, so that I could compare and contrast between interviews within the group, but also between groups. This process allowed for specified formal review points, where I would meet with my supervisors to discuss my analysis and findings, and we would discuss and agree how best to proceed with theoretical sampling for the next round of interviews. In all, four rounds of six interviews were conducted, comprising 24 interviews with 22 participants, two of whom were interviewed twice.

One participant was interviewed twice in relation to two separate roles and functions (a) as a supplier of software development services to entrepreneurial actors seeking to innovate with IT; and (b) as an IT entrepreneur developing and commercialising his own IT-based innovation. The other was a very experienced entrepreneur who had created both IT and non IT- based innovations. The opportunity arose to interview this person a second time to explore other innovations that he had developed.

In the first half of this chapter, I use traditional notions of "entrepreneur" and "intrapreneur" to describe participants, as discussed in Chapter 2, section 2.4.1 and 2.5. However, when applying the constant comparative and theoretical coding processes during the third round of interviews, I began to see entrepreneur and intrapreneur differently but interrelated. I shall leave such discussion to when it occurred in the research. 


\subsubsection{Interviewees: First Group of Six}

A brief description of the first group of interviewees, including the classification assigned to them at the time of initial data analysis is contained in Table 6.

Table 6: $\quad$ First group of six - interviewee description and initial classifications

\begin{tabular}{|c|c|c|c|l|l|}
\hline $\begin{array}{l}\text { Inter- } \\
\text { viewee } \\
\mathbf{N}^{\mathbf{0}}\end{array}$ & $\begin{array}{l}\text { Entre- } \\
\text { preneur }\end{array}$ & $\begin{array}{l}\text { Intra- } \\
\text { preneur }\end{array}$ & $\begin{array}{l}\text { Collective } \\
\text { Agent }\end{array}$ & $\begin{array}{l}\text { Interview } \\
\text { Inter- } \\
\text { relationship }\end{array}$ & Comment / Description \\
\hline 1 & & $\checkmark$ & & & $\begin{array}{l}\text { Founder of new educational programme using a } \\
\text { new and innovative online diagnostic tool to } \\
\text { assess competency }\end{array}$ \\
\hline 2 & & & $\checkmark$ & $2 \& 18$ & $\begin{array}{l}\text { Project manager for e-learning fibre optic } \\
\text { infrastructure development project }\end{array}$ \\
\hline 3 & $\checkmark$ & & & & $\begin{array}{l}\text { Founder of a new start-up company with a } \\
\text { technology innovation }\end{array}$ \\
\hline 4 & $\checkmark$ & & & 13 & $\begin{array}{l}\text { Founder and creator of multiple companies and } \\
\text { innovations, both technical and non-technical }\end{array}$ \\
\hline 5 & $\checkmark$ & & & & $\begin{array}{l}\text { Founder and creator of multiple companies and } \\
\text { innovations, both technical and non-technical }\end{array}$ \\
\hline 6 & $\checkmark$ & & & & $\begin{array}{l}\text { Founder and creator of firm with a web-based } \\
\text { technology innovation }\end{array}$ \\
\hline
\end{tabular}

The column titled "interview interrelationship", in Table 6, indentifies where there is a connection between interviewees. To inform the emerging theory, and in accordance with the dictates of theoretical sampling, additional perspectives were obtained and follow-up interviews carried out as needed. The interrelationships are discussed throughout this chapter.

The first interview was conducted with a person who met the requirements for the study in that they had championed and established a new educational programme that used an online diagnostic tool to assess skill competency. The interviewee identified himself as an entrepreneur, while also being an educationalist.

However, as he was employed within an established organisation and used the organisation's resources to establish the innovation, I categorised that interviewee (I-1) as an intrapreneur. I explore and discuss this discrepancy in more depth in section 4.7.1.

Interviewee (I-2) was involved in the coordination of resource acquisitions and direction of the use of those resources in the establishment of a fibre optic loop 
designed to support e-learning initiatives in a local community. The interviewee saw this as a networking exercise, stating:

One of the mantras I use is that I don't won't to be the gatekeeper for anything, so I don't try and gate keep that knowledge... so I have acted as the broker of those conversations and have introduced those people, so a lot of my emails start with the phrase "e-introduction" (I-2).

In the above statement, the interviewee self-identifies as a broker further clarifying, "if I join some of those dots and something has happened then that is a success in its own right" (I-2). Such statements conform to the traditional definition of brokers as; "people or firms who link parties having complementary interests, transferring information or resources, and facilitate the interest of those not directly connected to one another" (Dubini and Aldrich, 1991, p. 310). Within this study, I classified the participant with the more inclusive title of collective agent, as through their actions they assisted in the creation of innovation.

Interviewees (I-3, I-4, I-5, and I-6) saw themselves as entrepreneurs, founders of their companies, and creators of their respective IT-based innovations.

The third interviewee (I-3) started out by solving a problem that he and his friends were having and through their encouragement began seeing the IT-based innovation as a business opportunity.

Interviewee (I-4), a self described "entrepreneur, designer and inventor”, had established a successful design company. During the normal operation of that business, he had identified a new way of storing and transferring graphic images between the organisation and client sites and between the clients' own internal business units. This innovation was at a time when broadband access to the internet was in its infancy. The interviewee has gone on to create a number of innovations through other entities, which were the subject of interview (I-13). 
Interviewee (I-5) had much in common with interviewee (I-4) in that she could be described as a serial entrepreneur having established multiple companies and having developed innovations in a number of different industries. As interviewee (I-5) commented:

Just to back up, I have done three... I had a ... company for quite a long time, from 2001 and it still exists but I am just not actively involved any more. I have a manager in place. The second company is software related but ended up getting taken over by the third idea, so for a while there we were trying to develop two companies. This one we are working on right now took over, and looked like it was going to move faster (I-5).

Interviewee (I-6), in conjunction with a business partner, had started up a company to develop and sell a hosted web application service based on an innovative idea that he had had.

\subsubsection{Interviewees: Second Group of Six}

A brief description of the second group of interviewees including the classification assigned to them at the time of initial data analysis is provided in Table 7.

Table 7: $\quad$ Second group of six - interviewee description and initial classifications

\begin{tabular}{|c|c|c|c|l|l|}
\hline $\begin{array}{l}\text { Inter- } \\
\text { viewee } \\
\mathbf{N}^{\mathbf{0}}\end{array}$ & $\begin{array}{l}\text { Entre- } \\
\text { preneur }\end{array}$ & $\begin{array}{l}\text { Intra- } \\
\text { preneur }\end{array}$ & $\begin{array}{l}\text { Collective } \\
\text { Agent }\end{array}$ & $\begin{array}{l}\text { Interview } \\
\text { Inter- } \\
\text { relationship }\end{array}$ & Comment / Description \\
\hline 7 & & & $\checkmark$ & 7 & $\begin{array}{l}\text { Provider of web-based consultancy and software } \\
\text { development services }\end{array}$ \\
\hline 8 & $\checkmark$ & & & $\begin{array}{l}\text { Founder and creator of firm with a web-based } \\
\text { technology innovation }\end{array}$ \\
\hline 9 & & & $\checkmark$ & $\begin{array}{l}\text { Operations manager for a new technology-based } \\
\text { payment system }\end{array}$ \\
\hline 10 & $\checkmark$ & & & $\begin{array}{l}\text { Founder of a firm specialising in innovative open } \\
\text { source e-learning solutions }\end{array}$ \\
\hline 11 & & & $\checkmark$ & $\begin{array}{l}\text { Business Solution Consultant with international IT } \\
\text { based business solutions provider }\end{array}$ \\
\hline 12 & $\checkmark$ & & & $\begin{array}{l}\text { Founder and creator of multiple companies and } \\
\text { web-based innovation }\end{array}$ \\
\hline
\end{tabular}


Interviewee (I-7) was interviewed as a provider of software development services to clients seeking to innovate with IT-based innovative solutions. During the course of the interview, the interviewee mentioned his own web-based IT innovation. A second interview was subsequently conducted to interview the participant as an entrepreneur and to ascertain their experiences and action in creating an IT innovation. Therefore, due to different roles, the same person was classified both as a collective agent in the creation process interviewee (I-7), and as an entrepreneur, interviewee (I-8).

The context and subject matter of the interview influenced how I saw him. In one view he was a collective agent helping entrepreneurs to create their IT-based innovation through providing web-based consultancy and software development services and when talking about his own innovation, I then saw him as an entrepreneur. These roles and transitions are picked up upon and explored in detail in the next chapter.

Interviewee (I-9) was not the entrepreneur originally responsible for the idea, nor did he determine the design of the innovation, yet he played a crucial role in the development of the IT innovation: "My role was basically taking what was, I guess, a concept and a technology project being delivered to a ... company and to basically put some infrastructure in place and commercialise it" (I-9). This person was classified as a collective agent who played a crucial role in making the innovation happen.

The next interviewee (I-10) had established a new business in conjunction with some business partners to provide innovative business solutions based on open source software. The interviewee did not "necessarily self-identify as being an entrepreneur" yet acknowledged that "I know other people see me as an entrepreneur" (I-10); and that:

I do see, I do occasionally recognise that I see some ideas really clearly and see how they could impact - and that 
clarity around the idea, I recognise, is sometimes not unique but, you know, rare. So in that sense ...I get a little bit single-minded then, which I think is probably a characteristic of an entrepreneur (I-10).

When acknowledging that his company's management team checks the profit and loss statements every month to see whether they are still in still in business, the interviewee commented "I still have I guess leeway within my business environment to pursue ideas and that's my role within the business. And the rest of the business has to make money to allow me to do that" (I-10).

Although this comment has similarities to those made by interviewee (I-1), who had leeway within his organisation to look for new concepts and was able to secure funding to progress them when warranted, I categorised (I-1) as an intrapreneur and (I-10) as an entrepreneur - similar to (I-4, I-5, I-6 and I-8) who had established their own businesses. While interviewee (I-10) was an intrapreneur at the time they originally created the innovation, they had subsequently established their own company to progress new innovations and opportunities stemming from the original innovation.

The eleventh interviewee (I-11) was a business solutions consultant, someone who was employed by an international consulting firm which also provides enterprise wide IT development services. The interviewee (I-11) recounted a story where he had taken some clients who wished to innovate with IT and develop new business processes on an international trip. The purpose of the trip had been so the clients could see instances within the international network of client sites that his organisation serviced, where such new technologies were being used, I classified this participant as a collective agent, who had provided input into the creation process.

The twelfth interviewee (I-12) self-identified as "Work-wise I am an entrepreneur... I mean, I've started so many things that, you know, I'm a serial 
entrepreneur". The interviewee had developed a number of IT web-based innovations and made the memorable statement "You're leading it, everybody else is a supplier" (I-12).

\subsubsection{Interviewees: Third Group of Six}

A brief description of the third group of interviewees including the classification assigned to them at the time of initial data analysis is provided in Table 8 .

Table 8: $\quad$ Third group of six - interviewee description and initial classifications

\begin{tabular}{|c|c|c|c|l|l|}
\hline $\begin{array}{l}\text { Inter- } \\
\text { viewee } \\
\mathbf{N}^{\mathbf{0}}\end{array}$ & $\begin{array}{l}\text { Entre- } \\
\text { preneur }\end{array}$ & $\begin{array}{l}\text { Intra- } \\
\text { preneur } \\
\text { Agent }\end{array}$ & $\begin{array}{l}\text { Collective } \\
\text { Interview } \\
\text { Inter- } \\
\text { relationship }\end{array}$ & Comment / Description \\
\hline 13 & $\checkmark$ & & 4 & $\begin{array}{l}\text { Follow-up and in-depth interview with (I-4). } \\
\text { Founder and creator of multiple } \\
\text { companies/innovations, both technical and non- } \\
\text { technical }\end{array}$ \\
\hline 14 & & & $\checkmark$ & $16,17,19$ & $\begin{array}{l}\text { Business consultant to and previous CEO of } \\
\text { technology venture start-up established by (I-17) }\end{array}$ \\
\hline 15 & $\checkmark$ & & & $\begin{array}{l}\text { Founder of telecommunications infrastructure } \\
\text { company and innovative communication solutions }\end{array}$ \\
\hline 16 & & & $\checkmark$ & $14,17,19$ & $\begin{array}{l}\text { Business mentor and initial investor in technology } \\
\text { venture start- up established by (I-17) }\end{array}$ \\
\hline 17 & $\checkmark$ & & & $14,16,19$ & $\begin{array}{l}\text { Founder and creator of new technology venture } \\
\text { start-up and innovative IT product }\end{array}$ \\
\hline 18 & & $\checkmark$ & & $\begin{array}{l}\text { Founder and sponsor of an e-learning fibre optic } \\
\text { infrastructure development project }\end{array}$ \\
\hline
\end{tabular}

The third round of interviews is where I considered I entered the field within the substantive topic area. I had identified what I thought at the time was the core BSP. I had refined my focus, moving away from including the role of broker and sought to focus on aspects related to entrepreneurial agency and issues associated with the social structures they enabled.

For the third round of interviews I needed to develop the social structure aspect and get more than a one-sided view of the social structure. I decided to interview additional collective agents who aided the entrepreneur in the creation of an IT innovation. 
The third group of six interviews, included three interviewees (I-14, I-16, I-17) associated with one particular innovation. A fourth person interviewee (I-19) who was also involved with this innovation was interviewed in the fourth and final group of interviews. The analysis and comments made by some of the interviewees in the third group along with the direction the emerging theory was taking meant that the additional perspective of this person, interviewee (I-19) would aid in informing particular aspects of the theory.

Interviewees (I-13, I-15 and I-18) focused on how entrepreneurial actors involved in the IT creation process recruited/identified the collective agents who aided them on their journeys and how they structured their interactions with them. Interviewee (I-18) was the driving force behind the innovation first explored in interview (I-2), see section 4.2.4.1.

\subsubsection{Interviewees: Fourth Group of Six}

A brief description of the fourth group of interviewees including the classification assigned to them at the time of initial data analysis is provided in Table 9.

Table 9: $\quad$ Fourth group of six - interviewee description and initial classifications

\begin{tabular}{|c|l|c|c|l|l|}
\hline $\begin{array}{l}\text { Inter- } \\
\text { viewee } \\
\mathbf{N}^{\mathbf{0}}\end{array}$ & $\begin{array}{l}\text { Entre- } \\
\text { preneur }\end{array}$ & $\begin{array}{l}\text { Intra- } \\
\text { preneur }\end{array}$ & $\begin{array}{l}\text { Collective } \\
\text { Agent }\end{array}$ & $\begin{array}{l}\text { Interview } \\
\text { Inter- } \\
\text { relationship }\end{array}$ & Comment / Description \\
\hline 19 & & & $\checkmark$ & $14,16,17$ & $\begin{array}{l}\text { Chief Software Development Manager of } \\
\text { technology venture established by I-17 }\end{array}$ \\
\hline 20 & & & $\checkmark$ & & $\begin{array}{l}\text { Senior Programme Manager of IT-based } \\
\text { development projects }\end{array}$ \\
\hline 21 & & $\checkmark$ & & & $\begin{array}{l}\text { Founder of a collaborative e-learning capability } \\
\text { pilot within a specific industry }\end{array}$ \\
\hline 22 & & & $\checkmark$ & & Project manager of IT-based development projects \\
\hline 23 & & $\checkmark$ & & & $\begin{array}{l}\text { Co-creator and developer of an IT-based innovation } \\
\text { within a large organisational environment }\end{array}$ \\
\hline 24 & & $\checkmark$ & & $\begin{array}{l}\text { Creator and developer of IT business process } \\
\text { innovations within a software solutions company }\end{array}$ \\
\hline
\end{tabular}

It was during the fourth set of interviews that I reached the point of theoretical saturation. Interviews within this round were focused on exploring, in greater depth, actions associated with intrapreneurship and the intrapreneur. As in the previous round of interviews, I sought to do this through interviewing some 
collective agents that worked closely with intrapreneurs, while also interviewing additional intrapreneurs.

Interviewee (1-19) had played an instrumental role in the development of a world leading IT innovation within a particular market niche, as perceived by industry experts. Interviewee (I-17) had enticed this person to join him and help create his IT innovation. The interviewee (I-19) was a software development engineer who had increasingly been diverted into management, stating "I have been there since 2003- that is seven years. I've never been in a job that long before. I started off on the technical side and I got suckered into the management side. I'm trying to get back into the technical side" (I-19).

While originally joining a new IT-based start-up company for the fun and challenge of developing a revolutionary IT innovation, interviewee (I-19) after seven years had found himself working within a role with which he was not entirely comfortable. This echoed statements made by other participants; for instance, in the first round of interviews, interviewee (I-6) stated "I used to change my job every 2 to 3 years, now I can't. I am stuck in the same job and you kind of go, 'well wouldn't it be cool if I could do something different'" (I-6).

Interviewees (I-20) and (I-22) were very experienced project managers. Interviewee (I-20) had risen to the top of his career and had become a senior programme manager responsible for managing a number of projects within an interrelated programme of work. Both interviewees recounted how they had worked with intrapreneurs across a number of companies in order to create an IT innovation. The interviewees commented on the actions they saw the intrapreneur take and the role the intrapreneur played in the creation of the IT innovation.

The remaining three interviewees (I-21, I-23, and I-24) were intrapreneurs who had undertaken IT-based innovations with an existing organisation and had used resources found within those organisations to help create the innovation. Interviewee (I-24) was interviewed as an intrapreneur, but at the time of the 
interview he had just left the organisation he had spent the last nine years working in.

I classified Interviewee (I-24) as an intrapreneur, yet he had just set out to build a business with some friends, an act traditionally associated with an entrepreneur. As the participant recounts, colleagues in his previous firm saw him as an entrepreneur rather than an intrapreneur; "The director that I started the ... group with, when I told him he basically said 'Yep, I knew it would happen, you know, you're an entrepreneur'. And I thought, 'yeah, maybe'. I didn't think much of it, you know, but that was the term he used, and he definitely is an entrepreneur"

As the interviews started with an issue of classification, in how the participant saw themselves or how others perceived them, it also finished with such an issue. The participant description did not align with traditional perspectives within the extant literature on entrepreneurship and intrapreneurship. Interviewee (I-1) saw himself as an entrepreneur, yet I classified him as an intrapreneur as he worked inside an existing institution, as did interviewee (I-24). While I classified Interviewee (I24) as an intrapreneur, he commented in the interview that his manager and colleagues saw him as an entrepreneur. This inconsistency is explained and resolved in Chapter 5.

Further discussion on how interviewees were selected, based on theoretical sampling in order to inform the emerging theory, is provided in section 4.6.

\subsection{Reading for coding sensitivity}

Data does not generate theory; it is the researcher who generates theory. Conceptualisations emerge from the data through analysis and interpretations given to them by the researcher and are dependent on the extent to which he or she has read widely in scholarly matters (Seldén 2005). Therefore, the starting point for this study was not when I entered the field, but earlier, when I started to read for coding sensitivity and to identify my research aims. 
The role and place of the literature review is a source of considerable methodological debate within grounded theory and the different perspectives are often a source of confusion for novice researchers (McGhee, Marland, and Atkinson, 2007). But as Urquhart (2007) notes, graduate students often have no choice but to do a literature review as it is a mandatory requirement of university research committees.

This study was also done to fulfil the requirements for the degree of Doctor of Philosophy in Information Systems. During the initial phase of the research study, I had provisional registration status and was expected to produce a formal research proposal to the School's Research Degrees Committee. It was expected that the proposal should: (a) establish that the researcher has sufficient knowledge and understanding of the topic; (b) establish that the proposed research is original or adds value to existing knowledge; and (c) places the research into the existing body of knowledge (School of Information Management, 2009).

I sought to meet the requirements of my university research committees, while also ensuring I had the prerequisite academic skills to conduct an exemplary research study. Through preparing a comprehensive research proposal, I sought to become conversant with the wider topic area, to develop my skills and ability to interpret data, develop concepts, codes and relationships. As Charmaz (2006) emphasises, the development of a focused literature review strengthens the credibility of the researcher and their research. This is something that I sought to achieve.

As I read extensively, I began to assign meaning to data contained within the extant literature. The first step was through using an article summary template to capture standardised information for each journal article (see Appendix G). Such information included methodological approach, article purpose, claims, achievement, key definitions, concepts, and my own observations and reflections. The article summary forms are similar to the concept of theoretical memos used within grounded theory. A system of designating critical articles as "waypoints" 
was devised so as to create acknowledged milestones in the process of enquiry. A waypoint as I understood and used it is a marked spot on the journey that the researcher can always refer back to and which guides the journey. An abridged example of the article summary form is shown in Appendix H.

During the reading for coding sensitivity phase of my research, I processed approximately 170 articles in this manner, with perhaps another 75 articles treated in the same manner during the reading for theoretical sensitivity phase. In total, approximately one third of the 800 articles, book sections, and books I read during the progression of the research were subjected to this treatment. Other articles were either directly incorporated into the literature review or they were excluded at the time of reading as being of marginal relevance.

In accordance with coding practices within the grounded theory method, and consistent with the qualitative research software methodology as described by Beekhuyzen (2007), article summary forms were imported into NVivo 7 for coding and to allow categories to emerge from the extant data. For a detailed account of how I applied the coding process associated with grounded theory to the literature process see Thistoll, Pauleen, and Hooper (2009).

Coding tables were developed as part of the proposal, which summarised the conceptual codes and their associated properties. Table 10 illustrates this process for the conceptual codes of knowledge boundaries and boundary spanners. 
Table 10: Examples of conceptual codes identified from the extant literature and their properties

\begin{tabular}{|l|l|}
\hline $\begin{array}{l}\text { Conceptual } \\
\text { Code }\end{array}$ & \multicolumn{1}{c|}{ Properties and Dimensions, by Author(s) } \\
\hline $\begin{array}{l}\text { Knowledge } \\
\text { Boundaries }\end{array}$ & $\begin{array}{l}\text { Connect distinct knowledge areas (Carlile, 2002; Mitchell and Nicholas, 2006; } \\
\text { and Tushman, 1977); three progressively complex processes - transfer, } \\
\text { translation, and transformation (Carlile, 2004); three properties of knowledge at a } \\
\text { boundary - difference, dependence and novelty (Carlile and Rebentisch, 2003); } \\
\text { novelty f uncertainty (Carlile, 2004); differences, difficulties, and dependencies } \\
\text { provide opportunity for organisations to develop a knowledge-based competitive } \\
\text { advantage (Brown and Duguid, 2001; Carlile, 2004; Levina and Vaast, 2005). }\end{array}$ \\
\hline Boundary & $\begin{array}{l}\text { Transfer knowledge across boundaries and perform the "facework" with other } \\
\text { organisations (Hexmoor et al., 2006; Lane, 1998); supply colleagues with external } \\
\text { information (Adams, 1976; Aldrich and Herker, 1977; Johnson and Chang, 2000; } \\
\text { Mitchell, 2006); facilitate both formal and informal communication (Mitchell, }\end{array}$ \\
$\begin{array}{l}\text { 2006); have greater access to the external world, critical resources, and } \\
\text { information (Dodgson 1994); also work across internal boundaries and act as both } \\
\text { filters and facilitators of information (Pawlowski and Robey, 2004); may be } \\
\text { nominated, empowered ,or act without official nomination (Levina and Vaast, } \\
\text { 2005); engage in different types of activities, ambassador, task coordinator, scout } \\
\text { and guard (Ancona and Caldwell, 1988:2007); and need to possess essential } \\
\text { intrapersonal and relational characteristics (Reynolds and Johnson, 1982). }\end{array}$ \\
\hline
\end{tabular}

Thirty one conceptual codes and their associated properties and dimensions were identified (see Appendix I). This process provided a relevant set of codes and perspectives which I could draw upon in the open coding stage as discussed in the following section 4.4 .

\subsection{Entering the field in the general topic area}

When I first entered the field to conduct my research, I sought to interview entrepreneurial actors and network brokers involved with the creation of innovative IT artefacts. I sought to explore the broad topic area of entrepreneurial actions associated with resource acquiring relationships, extending to include the actions of network brokers in the process. 
I do not consider the point where I first entered the field as being the substantive topic area, as previously shown in Figure 6, Chapter 3; steps and processes in the grounded theory process by Lehmann (2001); Fernandez et al. (2002); and Fernandez (2003). For me that point did not occur until after I had completed two groups of interviews and had progressed through a first round of theoretical coding.

An illustrative tool, as introduced in Figure 7, is used as an aid in choreographing the research story in all its complexity and context. The model shows: (a) a time based scale along the $y$-axis to represent at what stage key activities and events occurred during the research study; (b) theoretical integration along the x-axis, showing the progression and application of coding processes; and (c) theoretical saturation, which is shown as a third element to represent the research undertaken to obtain a theory that explains much of the variation in the data being studied.

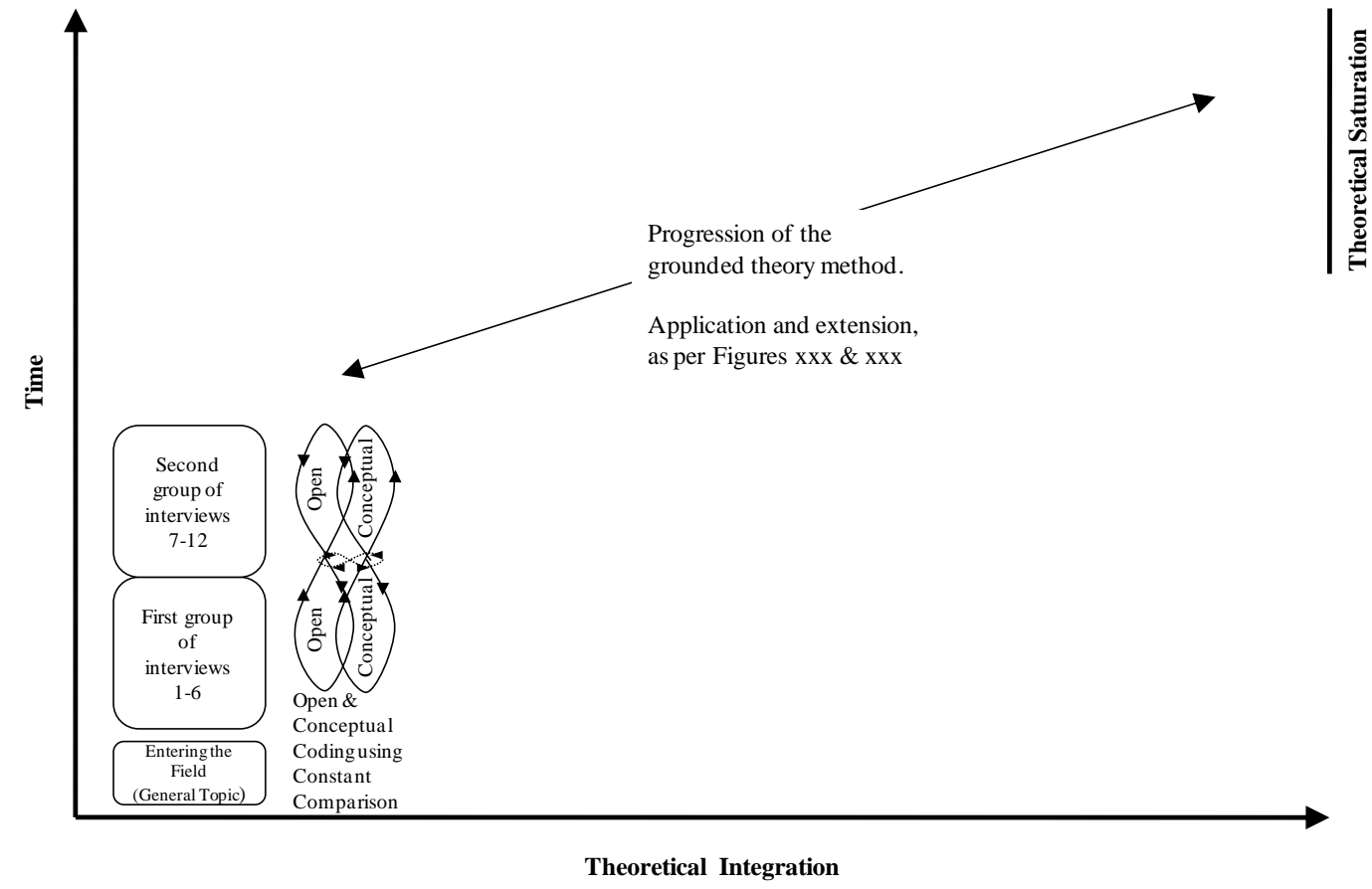

Figure 7: Model of inductive theory generation: initial open and conceptual coding 
The model as depicted in Figure 7 shows the initial application of the grounded theory method as applied in this research study. Additional processes of selective and theoretical coding and ongoing use of the constant comparison are shown in extended versions of this model (see Figure 12 \& Figure 14).

The first twelve interviews which were conducted in two waves of six interviews each, with both the individual interview and group of interviews subjected to open coding and constant comparative analysis as depicted in Figure 7. This resulted in the generation of conceptual codes as discussed in the next section.

\subsubsection{Open coding - constant comparison of incidents to incidents}

It took just over four weeks to open code the first group of six interviews and assign high-level codes. Such a slow start is not unusual; for example Urquhart (2001) commented that she took sixty hours to code her first interview. In accordance with conventional grounded theory methodology interviews were coded at the line and sentence level, with line coding being the predominant unit.

An example of the open coding process adopted for the first group of six interviews is shown in Table 11. The example shows a paragraph taken from a group one interview. As I read the interview to assign meaning to the statements made by the interviewee, I underlined and/or highlighted key words and then assigned a code, either an interpretation of what the interviewee had said and meant or an "in-vivo" code. In-vivo codes "are taken from or derived directly from the language of the field: essentially the terms used by the actors in that field themselves" (Strauss, 1987, p. 33). 


\begin{tabular}{|c|c|}
\hline Interview data - Open coding & Open Codes \\
\hline $\begin{array}{l}\text { Initially it was two people and one developer, and then built the } \\
\text { team up but, really, without a product we don't have a business, } \\
\text { so we have put most of the money and resources into } \\
\text { development. }\end{array}$ & $\begin{array}{l}\text { Built a team } \\
\text { Product based business } \\
\text { Prioritised resource use, } \\
\text { Priority on development, }\end{array}$ \\
\hline $\begin{array}{l}\text { But yeah, our potential target market for our product is pretty } \\
\text { much any company in the world that sells to consumers, so it is } \\
\text { a big market that could be... honestly we have priced and built } \\
\text { it so that the tiniest little business could use it right up to... } \\
\text { we've had .... and we have had (names removed) and other big } \\
\text { companies using it. }\end{array}$ & $\begin{array}{l}\text { identified market } \\
\text { Ambitious } \\
\text { Designed to be scalable. } \\
\text { Beta clients. } \\
\text { Large beta clients. }\end{array}$ \\
\hline $\begin{array}{l}\text { So for us, that little team, to go out to the world and try and sell } \\
\text { it on our own, there is no way that we could cover enough } \\
\text { ground, so I think actually partnership is going to be our best } \\
\text { strategy. }\end{array}$ & $\begin{array}{l}\text { Big ambitions. } \\
\text { Being realistic. Limited } \\
\text { Bandwidth, Partnering } \\
\text { strategy. } \\
\text { Had a strategy }\end{array}$ \\
\hline $\begin{array}{l}\text { There are two approaches; we could go out and try and get a lot } \\
\text { of venture capital funding and build up our own sales force, but } \\
\text { with the market being the way they are, I just think that would } \\
\text { not be the most efficient way to do it, so actually what the plan } \\
\text { is, and what we have started doing, is partnerships and working } \\
\text { with other companies to reach our target market. }\end{array}$ & $\begin{array}{l}\text { Identified options. } \\
\text { Environment was not } \\
\text { conducive, Exercised } \\
\text { commercial judgement } \\
\text { Had a plan, Partnering } \\
\text { strategy. Leverage existing } \\
\text { channels to market }\end{array}$ \\
\hline
\end{tabular}

The interview transcripts associated with interviews one to twelve were inputted into NVivo and the open codes assigned to relevant passages of the text. As the coding progressed, each incident was compared to other incidents. Figure 8, below, is an edited screen capture of the NVivo coding associated with the incident of trying to "cajole resources". Interviewee (I-2) had used the words "trying to cajole resources" to explain an activity that comprised a major focus of their week, and this term was used as an "in-vivo" code as it captured the meaning in the activity. In a subsequent interview, a similar activity was describe by interviewee (I-5) and I assigned the in-vivo code of "trying to cajole resources" to that incident. I had then captured two incidents which conformed to the activity of cajoling. These instances were subsequently associated with the conceptual code of resource leveraging. 


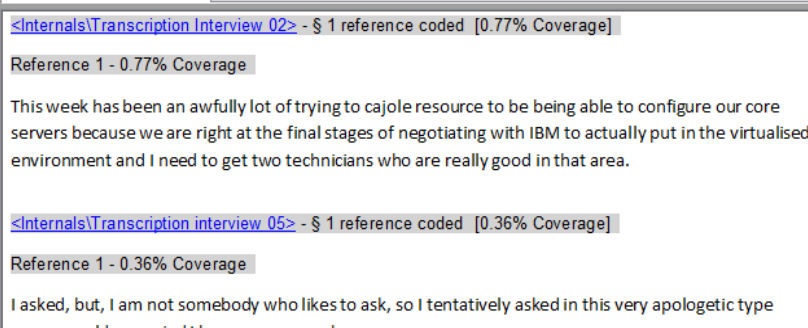

Figure 8: $\quad$ Edited NVivo screen capture of comparing incident to incident

Consideration was given to using an a-priori coding framework as derived from the preliminary literature review which identified a number of codes and coding categories associated with the drivers, enablers, and inhibitors impacting on the entrepreneurial and innovation process and resource acquiring relationships.

However, using such a framework, gathered from a preliminary literature review in advance of undertaking primary research, would not be in accordance with a formal grounded theory research approach as espoused by Glaser (1992) who maintains a forcing-based stance "thwarts and frustrates the discovery of what is truly going on in the substantive area under study, and undermines grounded theory at every turn by preconceived forcing of the data" (p. 03). Given this, an a-priori based approach was rejected and instead codes were allowed to emerge from the data and categorised as they fell naturally.

With the second group of six interviews, I moved away from coding at the line level and focused coding on the concept and issue that the participant was trying to convey. This was in response to guidance and recommendations from my supervisors when discussing the coding method used in the first group of six interviews. Coding against the concept did not preclude coding at the line level, where appropriate. Dey (1999) cautions against strictly adhering to line-by-line coding as the research progresses, as it may not be the most productive approach if it inhibits the identification of how parts relate to each other and to the whole.

This shift to focusing on the concept, saw me place greater emphasis on the context within which the concept and comment was situated. The line by line 
coding as undertaken in the first group of interviews was by its nature more mechanistic and self contained. For example in the first group of interviews, a line may have been coded as getting experience. Through focusing on the concept and taking into account the context, the coding is extended to include what the participant got experience in. Interviewee (I-10) sought to become more experienced in Open Source Technologies.

The incidents became the empirical data which supported the generation of the grounded theory as discussed in the following sections and chapters. The incidents were grouped under conceptual codes. An example is provided in Table 12 for the conceptual codes of piloting and protecting. These conceptual codes were obtained from the open coding and constant comparative processes which were applied to interviews 1-12.

Table 12: $\quad$ Example of conceptual codes and properties

\begin{tabular}{|l|l|}
\hline Conceptual Code & Properties - Open Codes \\
\hline & Beta product \\
& Encouraging and supporting experimenting \\
& Encouraging "skunk works" \\
& Getting runs on the board \\
& Getting experience \\
& Incremental learning \\
& Incremental improvement \\
& Initial experience \\
& Mocking up \\
& Proof of concept \\
& Needs additional resources to fix mistakes \\
& Prototyping \\
& Restrained by lack of resource \\
& Rudimentary version \\
& Requires software developers \\
& Trial and error approach \\
& Will be better off though experimenting \\
\hline \multirow{5}{*}{ Protecting } & Go the extra mile \\
& Learning from previous experience \\
& Maintaining probity (integrity) \\
& Matter of faith - trust \\
& Implemented through stealth \\
& Through contracts \\
& Awareness of the need to \\
& Through patents \\
\hline &
\end{tabular}


The open codes associated with the research data obtained from interviews 1-12, are too numerous to state and show within the dissertation. For this reason, I have shown examples of the codes that I assigned in Table $11 \&$ Table 12 . These codes were grouped by meaning and relationship and a conceptual code assigned. These conceptual codes while many in number can be revealed in a meaningful way, as depicted in Figure 9 to show the conceptual substance of the general area under study.

\begin{tabular}{|c|c|c|c|c|}
\hline $\begin{array}{l}\text { Boundary } \\
\text { - Boundary Innovation } \\
\text { Opportunity } \\
\text { - Boundary Innovation } \\
\text { - Trigger } \\
\text { - Boundary Spanning } \\
\text { - Champion } \\
\text { - Funding Boundaries } \\
\text { - Reacting to } \\
\text { Brokers } \\
\text { - Barriers } \\
\text {-Benefits } \\
\text { - Benefits - example } \\
\text { - Broker - Role } \\
\text { - Consultants } \\
\text { - Enablers } \\
\text { - Entrepreneur as a } \\
\text { broker } \\
\text { - Triggers } \\
\text { - Types of Brokers } \\
\text { - Venture Capitalists } \\
\\
\text { Networking } \\
\text { - Bandwidth } \\
\text { - Bridging } \\
\text { - Geographical location } \\
\text { - Motivational Benefits } \\
\text { - Network building } \\
\text { - Network Facilitator } \\
\text { - Networking up } \\
\text { - Networking with a } \\
\text { purpose } \\
\text { - Open Network } \\
\text { - Restricting size }\end{array}$ & $\begin{array}{l}\text { Entrepreneur } \\
\text { - Barriers to entrepreneurship } \\
\text { - Co-entrepreneur } \\
\text { - Early adopter } \\
\text { - Entrepreneur skill set } \\
\text { - Entrepreneurial manifestations } \\
\text { - Exit } \\
\text { - Frustration } \\
\text { - Future looking - the next one } \\
\text { - Intrapreneur } \\
\text {-Leader } \\
\text { - Learning from past experience } \\
\text { - Leaving behind } \\
\text { - Motivations } \\
\text { - Perceived elements } \\
\text { - Perceived roles } \\
\text { - Reliance } \\
\text { - Self sacrifice } \\
\text { - Serial Entrepreneur } \\
\text { - Specialist Skill } \\
\text {-Trapped } \\
\text {-Vision }\end{array}$ & $\begin{array}{l}\text { Innovation } \\
\text { - - Barriers - Innovation } \\
\text { - - Branding } \\
\text { - Business Model } \\
\text { - Business Requirements } \\
\text { - Change } \\
\text { - Channels to Market } \\
\text { - Commercialisation path } \\
\text { - Communicating } \\
\text { - Complexity } \\
\text { - Corporate innovation } \\
\text { - Demand } \\
\text { - Differences } \\
\text {-Differences between Technology } \\
\text { and non Technology } \\
\text { - Diffusion } \\
\text { - Descriptions } \\
\text { - Environment } \\
\text { - Failure } \\
\text { - Funding } \\
\text { - Growth } \\
\text { - Intellectual property } \\
\text { - Invented } \\
\text {-Lack of understanding of innovation } \\
\text { specifics } \\
\text { - Opportunity } \\
\text { - Perceived advantages } \\
\text { - Perceived benefits of their innovation } \\
\text { - Pre enabling Infrastructure } \\
\text { - Problem Solving } \\
\text { - Product - service niche } \\
\text { - Risk } \\
\text { - Stakeholders } \\
\text { - Success } \\
\text { - Technical Requirements } \\
\text { - Time } \\
\text { - Users } \\
\text { Supplier perspective } \\
\text { - Communication } \\
\text { - Need to have local } \\
\text { representation } \\
\text { - Opportunity is rare } \\
\text { - Seen as } \\
\text { - Supply just part of the } \\
\quad \text { solution } \\
\end{array}$ & $\begin{array}{l}\text { Innovation } \\
\text { Development } \\
\text { - Approaches } \\
\text { - Beta Clients } \\
\text { - Competitive activity } \\
\text { - Component integration } \\
\text { - Creating Infrastructure } \\
\text { - Delaying } \\
\text { - Deliverables } \\
\text { - Design } \\
\text { - Execution } \\
\text { - Expectations } \\
\text { - Experimental use } \\
\text { - Experimenting - Piloting } \\
\text { - Functionality } \\
\text { - Interconnecting } \\
\text { - Layers } \\
\text { - Learning from others } \\
\text { - Lifecycle Management } \\
\text { - Promotion } \\
\text { - Resourcing } \\
\text { - Sales } \\
\text { - Standardisation } \\
\text { - Time } \\
\text { - Triggers } \\
\text { - User Design } \\
\text { Organisational } \\
\text { Organ } \\
\text { - Activities } \\
\text { - Cash flow } \\
\text { - Consequences } \\
\text { - Failure } \\
\text { - Focus } \\
\text { - Location } \\
\text { - Organisational Structure } \\
\text { - Ownership structure } \\
\text { - Partners } \\
\text { - Process } \\
\text { - Reputation } \\
\text { - Role } \\
\text { - Teams } \\
\text { - Trusted Brand }\end{array}$ & $\begin{array}{l}\text { Resources } \\
\text { - Alignment } \\
\text { - Business Partners } \\
\text { - Competitors } \\
\text { - Customers as a resource } \\
\text { - Distribution channel } \\
\text { related } \\
\text { - Environmental Impacts } \\
\text { - Flow on effect } \\
\text { - In-house Resource } \\
\text { - Knowledge } \\
\text { - Money } \\
\text { - Moral support } \\
\text { - Outsourced Resources } \\
\text { - Personal Time } \\
\text { - Professional Advice } \\
\text { - Resource Broker } \\
\text { - Resource Funding } \\
\text { - Resource Leveraging } \\
\text { - Resource Limits } \\
\text { - Resource management } \\
\text { - Scale } \\
\text { - Social Capital } \\
\text { - Suppliers } \\
\text { - Venture Funded Resources }\end{array}$ \\
\hline
\end{tabular}

Figure 9: $\quad$ Conceptual substance of the general area under study

\subsubsection{A change away from using Nvivo}

While I used the constant comparison process diligently in all three distinct coding phases, the tools that I used changed. During the open coding phase, I used NVivo, the qualitative software analysis tool, extensively and exclusively in the coding process. I made extensive use of memo writing, as per the 
requirements of the method, and used the memo writing facility within NVivo to write, store, and link memos. But when it came to sorting memos in order to identify and develop the core category and what was to become the BSP at the heart of this study, the use of NVivo became restrictive forcing me (as it seemed at the time) to use structures already existing within the coding tables that I had created. Eventually, I began to hand sort the memos and started to break away from using NVivo. I subsequently stopped using it for the theoretical coding phases and reverted to using tables in a word document, and pencil and paper.

The drill down and tree based nature of NVivo, meant that to see the range of connections associated with more than one node a number of mouse clicks were required to navigate and open the tree nodes. Often they did not all fit into the same screen window, with the window needing to be scrolled. Hand sorting memo cards on a table, allows the entire view to be easily seen at any one time and changes could be made in the time it takes to shift a card from one pile to another.

Freeing oneself from using qualitative software programmes is something that is recommended to researchers by Corbin and Strauss, (2008) who see such tools as being of supplementary benefit only. Glaser (2005) is more emphatic on the matter and sees such use as something to be avoided in the first place. The use of qualitative software analysis programs was not an option available to early grounded theorists but more recent versions of the available software packages seem to increasingly support the research process (Corbin and Strauss, 2008). Nevertheless, while acknowledging the benefits provided by computer program analysis and their ability to provide increased transparency of the research process, Corbin is quick to point out "...that the analytic process remains a researcher-driven thinking and feeling process, even with the supplementation of a computer program" (p. xi). Glaser (2005) while accepting "computer sorting will result in a GT product, no doubt" (p.29), leaves the reader in no doubt he is of the belief that the final theory will not be as rich as may have been experienced through hand sorting of memos. 
Glaser (2005) maintains that true creativity of grounded theory is stultified by computer sorting, as when using traditional pencil and paper and hand sorting methods the researcher is able to vary their coding practices in small ways to better meet their personal research needs and creative style. Glaser makes specific reference to Walter Fernandez's (2003) thesis work and his use of the qualitative data analysis tool "ATLAS.ti" for open coding and memoing, and specifically Fernandez's assertion that such use of computer aided tools provides a substantial advantage. Glaser points out that this was an unsubstantiated claim since Fernandez did not compare his computer sorting to hand sorting and also suggests that Fernandez's creativity might have been dulled through the computer software forcing its own framework on the research.

One particularly useful element of the "pencil and paper" approach that was constant throughout the research study was a corkboard, on which I pinned handwritten notes. The corkboard was placed strategically to the left of my desk so that I could glance at it with ease. This allowed me to quickly capture emerging and fleeting thoughts, revisit them, and move them around the board and associate them with other thoughts as needed.

\subsection{Iterative conceptualisation}

The mechanistic application of coding stages does not yield the desired results in terms of theory; the key requirement of conceptualising relationships in the data is achieved by the researcher being alert to intuition and thinking beyond the labels they give to their data (Urquhart et al., 2009). The guidelines for grounded theory studies by Urquhart et al. (2009) nominate iterative conceptualisation as the second step; the researcher increases the level of abstraction and relates categories to each other through the use of theoretical coding and theoretical memos.

Within this section I discuss my use of theoretical memos, and leave the discussion of theoretical coding until section 4.7. As Glaser (1978) maintains significant theoretical realisations come with growth and maturity in how the 
researcher analyses the data, developing theoretical memos are a key part of the journey.

The categories, conceptual codes, and their properties determined during the open coding of interviews 1-12 and depicted in Figure 9, largely mirrored those in the extant literature. What is not shown and captured in Table $11 \&$ Table 12 or Figure 8 and Figure 9 is the significance of the conceptualisation process which began during the coding of the very first interview through writing theoretical and reflective memos.

Throughout the research, I used memos extensively as a narrated record to myself, to record what I was seeing in the data, why it had come to my attention and to acknowledge any connection, bias, or prior understanding of the issue (see Appendix $\mathbf{J}$, for examples). I first began using memos when I initiated the study and read to develop my coding sensitivity and indentify the research objectives as discussed in section 4.3 and section 4.2. In many cases, key memos were shared with my supervisors.

During the data collection and analysis stages, I adopted a process of developing both: (a) reflective memos (to discuss with myself and on many occasions with my supervisors) issues related to methodology and methodological thoughts; and (b) theoretical memos that reflected on issues, themes, and categories arising from the data analysis.

Urquhart et al. (2009) comment that novice researchers often struggle at the theory building stage. Because it is essentially a creative process, it cannot be achieved by following procedures alone. Glaser (1978) uses the term "drugless trip" to explain how through the use of memos, memo sorting, and creative thought data metamorphose to the next level of abstraction. Such was my own journey. 
To reach the final level of abstraction and resultant grounded theory required progressing through two lower levels of abstraction which allowed me to see the data in a completely new way. The two levels of abstraction were (a) an interim BSP of Entrepreneurial Agency; and (b) the refined BSP of Preneurial Agency in IT Creation.

The abstraction process was achieved through (a) reading for theoretical sensitivity, not once but twice; (b) undertaking theoretical coding associated with each level of abstraction; and (c) the extensive use theoretical memos at all stages and at all times. In the proceeding sections, I discuss these activities in detail and provide examples to explain and demonstrate their application.

\subsubsection{The category of entrepreneurial vision}

As I went through the open coding and memo writing activities associated with the first two groups of interviews, the concept of the entrepreneurial vision was consistently emerging from the data as an issue of prime importance and something that potentially linked the categories. In many cases, respondents used and made references to the term "vision". Interviewee (1-12) stated, "then about 4 o'clock in the morning I woke up, sat up on the bed, and this whole thing was right there on the bed - I mean, it was not physically there on the bed but it was this whole vision, boom right there".

In other incidences, the vision is shared with and adopted by the collective agents who give credit to the entrepreneur as the originator of the vision: "so that was where, if you like, the initial vision came from" (I-9) and "...a lot of the vision behind this came from..." (I-2).

One interviewee described himself as the visionary, "I am the visionary for a lot of the stuff we do. I do a lot of art direction;. I call it art direction in all senses; art direction of your lawyer..." (I-4). 
The picture of this entrepreneur that was emerging from the data was of a person that not only creates the vision, but directs it and must sustain it on their journey to make it a reality. As interviewee (I-6) commented "So firstly you have to have this sort of dream (aka vision) that you want to execute and then you have to have that wherewithal to take the knocks to get there, or just to keep going and maybe never getting there and just disbelieving falsely or whatever that you are going to get there" (I-6).

Applying the coding processes to interviews 1-12 revealed the following conceptual codes and properties, which I categorised as "entrepreneurial vision" as shown in Table 13.

Table 13: $\quad$ Category of entrepreneurial vision, dimensions, and properties

\begin{tabular}{|c|c|c|}
\hline Category & Conceptual code & Properties - Open Codes \\
\hline \multirow[t]{2}{*}{$\begin{array}{c}\text { Entrepreneurial } \\
\text { Vision }\end{array}$} & Vision & $\begin{array}{l}\text { - Continuity } \\
\text { - Whole vision } \\
\text { - Interpreted by others } \\
\text { - Unravelling the vision } \\
\text { - Renegotiating the vision } \\
\text { - Comprises a view of an exit } \\
\text { - Includes vision of the business model } \\
\text { - Can be seen as a spiders web } \\
\text { - Interpreted differently by different people } \\
\text { - Something that is shared } \\
\text { - Something the crosses boundaries } \\
\text { - Something to be protected } \\
\text { - Aspects of the vision are not shared } \\
\text { - Focused }\end{array}$ \\
\hline & Visionary & $\begin{array}{l}\text { - Entrepreneur source of vision } \\
\text { - Driver of the vision } \\
\text { - Providing visionary leadership } \\
\text { - Innovator } \\
\text { - Focusing on }\end{array}$ \\
\hline
\end{tabular}

The entrepreneurial vision is a key part of a process but it is not the whole process. It does not explain the actions of the entrepreneur on their journey to create the IT innovation, nor does it explain their interactions with collective agents. 


\subsubsection{Reading for theoretical sensitivity}

While the entrepreneurial vision was a critical component of the process, it did not account for most of the variation in the data, specifically the actions of the entrepreneur in making the vision a reality. To account for the actions and the interactions the entrepreneur undertook, I began to read for theoretical sensitivity and reviewed extant literature associated with creation. This investigation identified the collective works of Nonaka and colleagues (1994:2009) as being of particular relevance.

Nonaka's (1994) theory of organisational knowledge creation sought to explain how a tacit thought and belief (knowledge) became explicit. This was similar to what was happening in the research data as the entrepreneur sought to make their intangible vision a tangible reality.

The interplay of tacit and explicit knowledge aligned with intangible and tangible aspects that I had identified within my data as vision/innovation started out as an intangible/tacit idea which must become a tangible/tacit reality. This interplay is depicted in the following Figure 10:

Intangible-Tacit

Tangible- Explicit

Figure 10: Interplay between Intangible-Tacit and Tangible-Explicit in the IT creation process

By themselves, the readings associated with organisational knowledge creation theory were inadequate to explain issues around the actions of the person and issues of collective agency. Nonaka's (1994) theory of organisational knowledge creation, for instance, was focused on the organisation as the unit of analysis.

Seeking to resolve gaps in my knowledge associated with the person as a unit of analysis, I explored social cognitive based perspectives, specifically Giddens's (1984) theory of structuration and other associated readings focused on structure 
and human agency. This was the crucial key that allowed me to identify the initial BSP of Entrepreneurial Agency.

As I became immersed in reading associated with structuration theory, I began to feel that this was a crucial piece of the jigsaw and resolved a number of concerns that I was feeling at the time. While I was spending an increasing amount of time alone with my data from my first twelve interviews and reinterpreting them in many different ways, I was becoming increasingly aware that I needed to account for the situational context within which the interview participants were operating. I also needed to explain the situational context that the entrepreneurial vision was bound within. Nonaka and colleagues' concept of $b a$ (see Nonaka et al., 2000; Nonaka and Krogh, 2009) started to show support for the importance of looking at the context, but this was amplified and made explicitly clear by structuration theory and its critical role in understanding human agency.

\subsubsection{Theoretical coding: Emergence of initial BSP Entrepreneurial Agency}

The third level of analysis within the grounded theory method primarily relies on memo writing and theoretical coding, so that the researcher may think about the data in more theoretical ways rather than the descriptive view associated with the previous levels.

Armed with my new knowledge and sensitivity to theoretical issues associated with human agency, I revisited my data. I went through another round of applying the constant comparative and coding, this time focusing on those instances that specifically related to individual agency. I produced additional memos for the new and existing codes associated with individual agency, titled the memos, and created memo cards for hand sorting. It was at this point that I abandoned NVivo for my primary data analysis and started to rely on "pencil and paper", so that I could free up my mind to see the data in new ways. I also refamiliarised myself with Glaser's (1978) coding families, with specific attention paid to the process family (stages, phases, progressions, transitions, steps etc). 
It was when I starting sorting my memos by hand, grouping and regrouping the memos in new and different ways, that I experienced my own "drugless trip". I started to see the data in process terms and stages that the entrepreneur goes through to take to take an intangible vision and make it tangible. The initial BSP of Entrepreneurial Agency took a human agency centric perspective and focused on the activities that that entrepreneur went through on the journey to create the IT artefact.

The process of entrepreneurial agency as developed, does not start with the idea recognition as that involves cognitive processes outside the scope of the research study. The focus is on explicit actions that the entrepreneur undertakes in the process of IT innovation. The entrepreneurial vision has to become tangible so that it can be communicated to others and developed. The innovation has to be designed; therefore the entrepreneur must give the innovation form which can be communicated to others via model, sketch, diagram, or drawing for example. As interviewee (I-5) commented, "I cannot code, but I can map out flowcharts and I can map out needs. This is what the company needs, and this would be the ideal solution..."

As the entrepreneur journeys through the process they start to extricate their self so they can move on to the next thing; as interviewee (I-10) states, "I still have, I guess, leeway within my business environment to pursue ideas and that's my role within the business". A similar comment is made by interviewee (I-5), "I had a ... company for quite a long time, from 2001, and it still exists but I am just not actively involved any more. I have a manager in place". Interviewee (I-5) had increasingly extracted herself from past ventures so that she could initiate and pursue new entrepreneurial opportunities.

The BSP of Entrepreneurial Agency, as shown Table 14, was an important transition point which took the category of entrepreneurial vision and expressed it as a basic social process that more adequately explained variation in the research data. This explanation was limited to issues of human agency and was yet to 
account for issues related to structuration, more specifically the social structures associated with the agency. While reference is made here to the BSP of Entrepreneurial Agency as an important part of the journey, I have specifically limited the discussion and provided but a cursory explanation. The detailed discussion is best suited for when I introduce the BSP of Preneurial Agency in section 4.8, and discuss in detail in Chapter 5.

Table 14: $\quad$ Transition BSP of Entrepreneurial Agency

\begin{tabular}{|c|c|c|}
\hline Category & Sub-category & Example of initial Properties - open codes \\
\hline \multirow{5}{*}{$\begin{array}{c}\text { Interim } \\
\text { Basic Social Process } \\
\text { of } \\
\text { Entrepreneurial Agency }\end{array}$} & Designing & $\begin{array}{l}\text { - Feeding off } \\
\text { - Borrowing From } \\
\text { - Articulating emerging vision } \\
\text { - High level design } \\
\text { - Making sense of it all } \\
\end{array}$ \\
\hline & Directing & $\begin{array}{l}\text { - Energising } \\
\text { - Feeding of one's own or others' networks } \\
\text { - Harnessing and capturing the contribution of others } \\
\text { - Building solid legal foundations and protections } \\
\text { - Documenting, sketching out the design details }\end{array}$ \\
\hline & Validating & $\begin{array}{l}\text { - Prove concept } \\
\text { - Rudimentary basic version } \\
\text { - Obtain feedback } \\
\text { - May have to educate how to use } \\
\text { - Fix faults, errors }\end{array}$ \\
\hline & Extricating & $\begin{array}{l}\text { - Change in mindset and communication style } \\
\text { - Maturity } \\
\text { - Exploring options to exit } \\
\text { - Living with consequences of earlier decisions and actions } \\
\text { - Focus is on users }\end{array}$ \\
\hline & Realising & $\begin{array}{l}\text { - Reality sets in } \\
\text { - May include social benefits } \\
\text { - When the outcome is largely unknown } \\
\text { - May not happen } \\
\text { - Envisage from the start }\end{array}$ \\
\hline
\end{tabular}

The labels given to the sub-categories within the Transition BSP of Entrepreneurial Agency emerged over a period of time. They evolved as the constant comparison process progressed, and through writing memos. For example, the label "Designing" has its origins in a memo that I had titled "innovation focus" versus "individual focus". At the time, I wrote the following to myself.

The process as depicted does not reflect the individual agency perspective on what the entrepreneur goes through on their journey, their story as opposed to the inventions story. I have identified a strong pattern around the formation of a concept within the entrepreneur's mind and how they come to understand that, 
think about it and visualise it (individual codes, concepts being things like: idea, think, invented, thinker, spawned, saw, conceptualise, picturing, create, conceive, believing, clarity, vision). All these things can be related to a category of conceiving which is something done by an individual.

\begin{tabular}{|l|l|}
\hline \multicolumn{1}{|c|}{ Context } & \multicolumn{1}{|c|}{ Seeds } \\
\hline Encepts & $\begin{array}{l}\text { New idea, Intrapreneur, big picture, Champion, Need, capability, } \\
\text { advice, consideration of business model, external encouragement, } \\
\text { restricting information flow, personal motivation, Lateral thinker, } \\
\text { ability to protect, data collector, processing facilitator, Invented, } \\
\text { think, enabled by prior experience, Competing ideas, uncertain, } \\
\text { Spawned, better way, focus, Leveraging - saw opportunity, } \\
\text { Conceptualise, picturing success, create, conceive, believing, right } \\
\text { time, see ideas clearly - clarity, ambition }\end{array}$ \\
& \\
& $\begin{array}{l}\text { Conceiving ultimately gave rise to Designing which better described } \\
\text { the actions the entrepreneur undertakes to give initial form to the } \\
\text { vision } \\
\text { something from the mind - to think up something such as a plan or } \\
\text { an invention that could be put into action - to understand something }\end{array}$ \\
\hline
\end{tabular}

Figure 11: Emergence of the label "Designing" from the data

The category of Designing had originally been labelled "seed", where a new idea takes seed within the entrepreneurs mind. They are able to see the bigger picture of what the opportunity and innovation looks like as well as commercial aspects including possible exit options. But this did explain the actions of the entrepreneur, consequently the category was re-examined and the label "Conceiving" was given to it and over time that label changed as well to 
Designing which better explained the actions the entrepreneur undertakes to give initial form to their vision. The identification of the five other labels followed a similar evolution.

\subsubsection{Summary of the activities leading to the first level of abstraction}

The data collection and analysis activities associated with obtaining the first level of abstraction involved undertaking twelve interviews which were subjected to open and conceptual coding using the constant comparison process. A category of entrepreneurial vision emerged from the analysis, but more in the form of the story of the innovation than the entrepreneur's journey and the interactions the entrepreneur engaged in to make the vision a reality. Extant literature was reviewed so that a wider perspective could be obtained and relevant theory identified so that I could become more "in tune" theoretically with the data and to connect with the emerging theory. Two grand theories, Nonaka's (1994) Organisational Knowledge Creation Theory and Giddens's (1984) Structuration Theory were identified that could allow me to re-engage and connect with data in a more theoretical way.

Nonaka's (1994:2009) Organisational Knowledge Creation Theory stresses the fact that knowledge creation takes place within a context, a $b a$, and that it is in the interactions of people within specific social contexts that knowledge is converted from a tacit state to an explicit state and vice versa. Giddens's (1984) Structuration Theory reinforces the duality and interplay between social structures and human agency which give form to structures and they in turn inform our actions.

The data associated with interviews 1-12 were revisited with a specific focus on the actions of entrepreneur/s and collective agents in the process of turning the entrepreneurial vision into a tangible reality. Through the development of memos and hand sorting them, a basic social process which was labelled "entrepreneurial agency" emerged from the data. Data from interviews 1-12 were selectively 
coded against the sub-categories associated with entrepreneurial agency. These processes, activities, and outcomes are depicted in Figure 12.

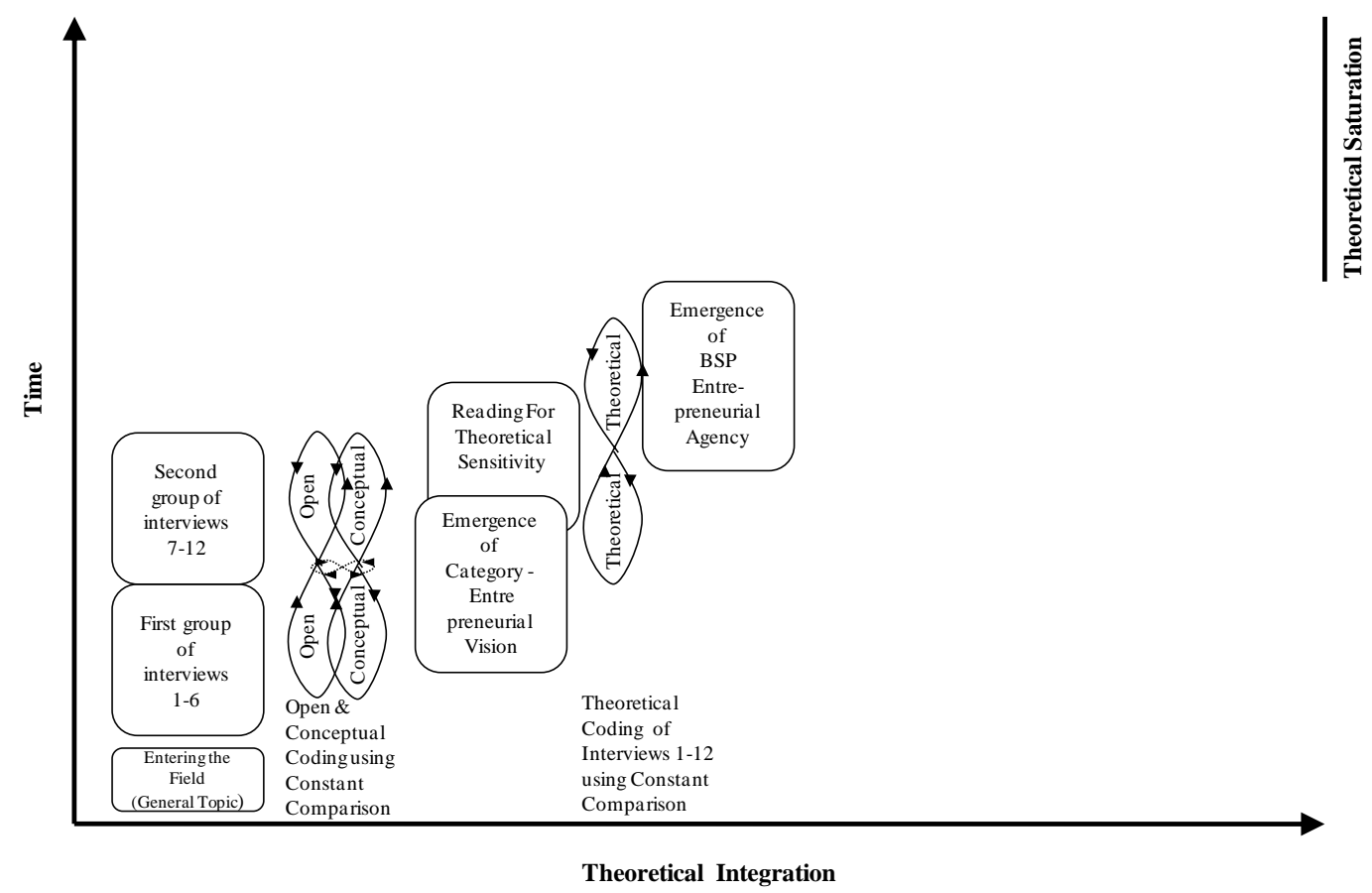

Figure 12: Model of inductive theory generation: first level of abstraction

The research had moved away from including brokers, and was increasingly becoming focused on the actions of the entrepreneurial actor and their interactions with key participants - referred to as collective agents. At this point, I had narrowed down and refined the general topic area to a point where I had identified the substantive topic area. 


\subsection{Theoretical sampling (associated with interview groups one to three)}

Theoretical sampling must be flexible and adaptive to the emergent theory as it evolves, with sampling decisions based on the preceding analysis (Dey, 1999). Groups are selected for their ability to add the slices of data needed to firm up propositions and provide new insights (Lehmann, 2010). As Lehmann (2010) states "Theoretical sampling therefore concentrates on the categories and areas that are not yet considered to be theoretically saturated" (p.91).

This guidance aptly describes how theoretical sampling was employed within this research project. The analysis of each round of interviews informed the next, leading to the emergence and identification of the core BSP, with the research continuing until theoretical integration and ultimately theoretical saturation, were obtained.

The first round of interviews began to identify a number of categories and subcategories; specifically issues associated with entrepreneurship, personal aspects, organisational related factors, the innovation and how the innovation was developed. In the second round of interviews, I wished to explore in greater detail issues associated with the entrepreneur and their personal characteristics. As I obtained a greater understanding of the entrepreneur through analysing the second round of interviews, I then needed to understand how the entrepreneur interacted with other people to develop the innovation. 
Table 15: Theoretical sampling interviewee groups one to three

\begin{tabular}{|c|c|c|}
\hline & Group one to group two & Group two to group three \\
\hline $\begin{array}{l}\text { Unsaturated } \\
\text { Categories }\end{array}$ & $\begin{array}{l}\text { Personal aspects, characteristics of } \\
\text { the entrepreneur } \\
\text { - Skill sets } \\
\text { - preparing one's self } \\
\text { - Vision } \\
\text { - Frustrations } \\
\text { - Trapped } \\
\text { - Personal Behaviour } \\
\text { - Personal networking }\end{array}$ & $\begin{array}{l}\text { Relationships } \\
\text { - Benefits } \\
\text { - Communication } \\
\text { - Enablers } \\
\text { - Establishment } \\
\text { - Protecting } \\
\text { - Success } \\
\text { Innovation Development } \\
\text { - Business / technical requirements } \\
\text { - Beta clients } \\
\text { - Creating infrastructure } \\
\text { - Design } \\
\text { - Experimental use } \\
\text { - Execution }\end{array}$ \\
\hline $\begin{array}{l}\text { Saturated } \\
\text { Categories }\end{array}$ & & $\begin{array}{l}\text { Personal aspects, characteristics of the } \\
\text { entrepreneur } \\
\text { - Skill sets } \\
\text { - Frustrations } \\
\text { - Personal Behaviour } \\
\text { - Personal networking } \\
\end{array}$ \\
\hline $\begin{array}{l}\text { Requirement } \\
\text { for next } \\
\text { round }\end{array}$ & $\begin{array}{l}\text { Gain a greater understanding of the } \\
\text { entrepreneur, how do they go about } \\
\text { what they do and what barriers do } \\
\text { they face? } \\
\text { This meant that additional } \\
\text { entrepreneurs were needed to be } \\
\text { interviewed. }\end{array}$ & $\begin{array}{l}\text { Gain a greater understanding how the } \\
\text { entrepreneurs interacts with other people } \\
\text { that aid them. Also to understand what } \\
\text { makes IS innovation development } \\
\text { different. } \\
\text { The best way to achieve this I determined } \\
\text { was to focus on a particular IS innovation } \\
\text { and key people the entrepreneur interacted } \\
\text { with to develop the innovation. }\end{array}$ \\
\hline
\end{tabular}

The categories shown in Table 15 are the main categories that emerged from the date and which were future explored. Other categories were identified and coded against but they reflected items that were not central to the emerging theory and research focus or they were sufficiently common knowledge within the entrepreneurship and innovation-based fields and consequently they did not require further development.

The third round of interviews was guided by the emergent theory and BSP of Entrepreneurial Agency. At this stage, I sought to resolve issues and discrepancies that had arisen when analysing the first two groups of interviews. How I viewed actors and agents within both the research study was still unclear. Was the central phenomenon entrepreneurial agency or was it perhaps collective agency? 
A detailed review and discussion of human agency is provided in Chapter 2, sections 2.7.4 \& 2.7.5. Agency can be either individual or collective (Sewell, 1992). Entrepreneurial agency as seen with this research study focuses on the actions of a single actor the entrepreneur. The notion of collective agency conforms to Bandura's (1996b) concept of collective agency that encompasses the collective efforts of people working together to achieve a common result.

This interplay between individual and collective agency, has started to emerge from the data analysis as a key issue for further exploration. The analysis up until this point also suggested that the relationships between the entrepreneurial actor and collective agents were not equal; the entrepreneurial actor directs and shapes the interaction so that they may achieve their vision. Others may "buy into" and participate in making the vision a reality, but the entrepreneur shapes the discussion. Yet, the entrepreneurial actor cannot do it alone and needs to recruit others in order to carry out the various activities required to make the vision happen.

These issues became the basis for informing the sample selection for the third round of interviews as shown in Table 15 (Theoretical sampling issues' guiding the fourth group of interviews is discussed in Chapter 5, section 5.3). As I needed to flesh out the social structure aspect and get more than a one-sided view of the social interaction I sought to interview a number of different actors who had been involved in the creation of an IT innovation and who had interacted closely with the entrepreneur. Where possible I also sought to revisit some of the innovations already captured in the study in order to obtain additional perspectives.

\subsection{Scaling up and theoretical integration}

This section addresses issues associated with scaling up and theoretical integration, the fourth and fifth steps within the guidelines for grounded theory studies by Urquhart et al., (2009), as discussed in Chapter 3, section 3.4.2. The analysis is taken to a higher level of abstraction and broader themes and recursive 
relationships are identified. The emergent theory is theoretically related to economic based theories of the "acting man" and the phenomena of intrapreneurship and institutional entrepreneurship.

Following on from the identification of BSP of the Entrepreneurial Agency, I reentered the field, this time within the substantive topic area. I had refined my focus and moved away from including the role of brokers, seeking to focus on aspects related to entrepreneurial agency and issues associated with the social structures they enabled. I also sought to see the process of entrepreneurial agency in the creation of IT innovation through the perspective of collective agents who interacted with the entrepreneur and also played a key role in the creation of the IT artefact.

The third round of interviews allowed me to investigate what distinguishes entrepreneurial agency from entrepreneurial behaviour found elsewhere in everyday life. I began to see the entrepreneurial actor as the initiator of new social structures such as a new institution.

A fundamental discrepancy began to emerge from the data: the IT innovation is initiated by either (a) an entrepreneur who is seen to exist outside of established structures at the time of initiating the design activities associated with formulating the high level look and feel of the innovation, or (b) an intrapreneur who is part of an existing institution and the innovation is seen as being beneficial to that organisation and complementary to the existing resource combinations associated with that entity.

This external and internal institutional view of the entrepreneur and intrapreneur is depicted in Figure 13. The entrepreneur (a) is shown as residing outside the institutional boundaries and the intrapreneur (b) residing within the institution's external and internal boundaries. 


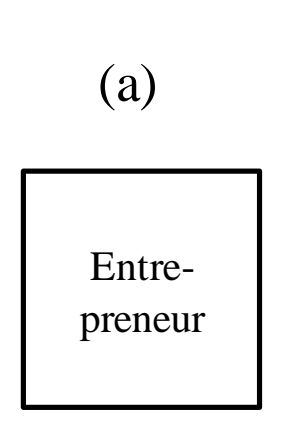

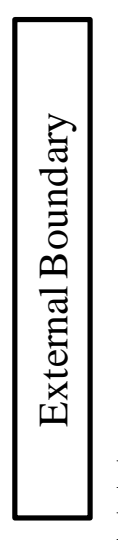

(c)
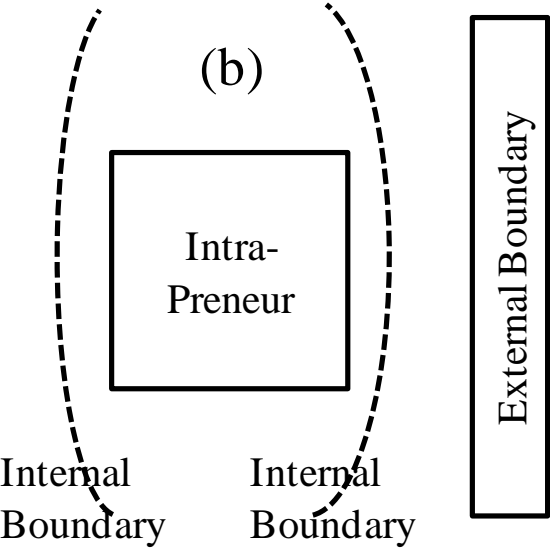

(d)

Figure 13: $\quad$ Boundary based view of entrepreneurs, intrapreneurs and the institution

Boundaries reflect the demarcation points between an institution and its environment; and they speak to why organisations are unique and why they fail (Santos and Eisenhardt, 2005). Advocating a knowledge based view of the firm, Carlile (2004) believes a firm can be "more completely described as a bundle of different types of boundaries where knowledge must be shared and assessed" (p.566).

Boundaries, which Mitchell and Nicholas (2006) refer to as knowledge boundaries also reside within the firm as cognitive borders around organisational units, such as communities of practice or functional areas. The external boundaries (c) and internal boundaries (d) are both shown within Figure 13.

Given this fundamental difference, the BSP of Entrepreneurial Agency did not explain most of the variation in the data. The BSP was focused on the actions of the entrepreneur, yet in the research, IT innovation was also associated with intrapreneurship.

\subsubsection{Disconnect within the research data}

This disconnect was evident from the very first interview in which Interviewee (I- 
1) self-identified as an entrepreneur, while also being an educationalist, "(I-1) I am an entrepreneur yes, I think in mind and in action and in body I am, but I am an educationalist in experience by training and education".

Interviewee (I-1) often championed ideas within the organisation he was employed by, which he felt that no one else in the organisation believed were worthwhile. Such a position aligns with Chisholm's (1987) notion of an intrapreneur, someone inspired by the challenge of overcoming organisation barriers. As evidenced in the following Table 16, comments from interviewee (I1) also align with Luchsinger and Bagby's (1987) characteristics of an intrapreneur.

Table 16: Alignment to Luchsinger and Bagby's (1987) characteristics of an intrapreneur

\begin{tabular}{|l|l|}
\hline $\begin{array}{l}\text { Characteristics of the Intrapreneur } \\
\text { (Luchsinger and Bagby, 1987) }\end{array}$ & Comments made by Interviewee I-1 \\
\hline $\begin{array}{l}\text { Operates within the setting of an established } \\
\text { organisation with structural and procedural } \\
\text { constraints }\end{array}$ & $\begin{array}{l}\text { - Other resources are a struggle when an } \\
\text { organisation has an approval process that is } \\
\text { incredibly complex and slow. } \\
\text { - I have been told by our IT department I cannot } \\
\text { have so many personal files on my hard drive. }\end{array}$ \\
\hline Have low control over their environments & $\begin{array}{l}\text { - I couldn't get the resources to move any faster } \\
\text { here. }\end{array}$ \\
\hline $\begin{array}{l}\text { Financial risk is borne by the intrapreneur's } \\
\text { company }\end{array}$ & $\begin{array}{l}\text { - I think that there needs to be a remedial } \\
\text { meeting now, before we (read organisation) } \\
\text { throw away the hundred thousand or so that we } \\
\text { (read organisation) have invested in this. }\end{array}$ \\
\hline Can return to the parent organisation & $\begin{array}{l}\text { - If it closes down the project and keeps me then } \\
\text { it is probably going to put a little bit of a rein on } \\
\text { me for a while and I am going to have to accept } \\
\text { that. }\end{array}$ \\
\hline $\begin{array}{l}\text { The innovative company can provide a source } \\
\text { of administrative and operational support. }\end{array}$ & $\begin{array}{l}\text { - my ... manager made it really clear that he } \\
\text { likes the idea, that I can come up with hundreds } \\
\text { of ideas, but he is not so sure that I am the } \\
\text { person to follow a lot of them through to the } \\
\text { detail, which is what he is good at, what ... is } \\
\text { good at; they cover my arse, if you like, on } \\
\text { some of the detail that needs to be done. }\end{array}$ \\
\hline $\begin{array}{l}\text { Likely to report to a superior and must seek } \\
\text { internal sponsorship especially in the face of } \\
\text { internal criticism or resistance. }\end{array}$ & $\begin{array}{l}\text { We got the executive to sit round a table and } \\
\text { myself and (I-1's manager) sat down at the } \\
\text { table. I did a presentation showing what we } \\
\text { could do for them and they bought in straight } \\
\text { away }\end{array}$ \\
\hline
\end{tabular}


Interviewee (I-1) was clearly an intrapreneur, yet self-identified as an entrepreneur. Furthermore, when obtaining an additional perspective around the entrepreneurial activities associated with the innovation at the centre of interview (I-2), a second intrapreneur was identified within the interviews - interviewee (I18). Interviewee (1-18) self-identified first and foremost as a teacher who become interested in harnessing the power of ICT as an aid in the learning process, stating, "What has always excited me about technology is the way that you can reinvent processes and do things differently and for better advantage" (I-18).

For this participant, the most important aspect was not personal ownership of the vision but being the custodian of the vision and obtaining collective buy-in, as evidenced by "I think it's a stewardship. It's not about ownership; it's about collective ownership actually" (I-18). At this point the study had clearly identified an unanticipated conflict.

\subsection{Progressing beyond the Basic Social Process of entrepreneurial agency}

The emergence of two intrapreneurs forced a decision. Should the three intrapreneur-related interviews (I-1, I-2, and I-18) be retained or excluded? If they were excluded, the BSP of Entrepreneurial Agency could be retained to explain the variation found within the data, as it was refined through selective coding and theoretical sampling. But, if the intrapreneur-related interviews were to be retained, then the BSP as it currently stood would not account for the majority of variation in the data.

As the analysis progressed, the research increasingly sought to explain how an intangible vision of an IT innovation becomes tangible and expressed as a prototype. Clearly, while entrepreneurial agency would account for the particular phenomenon of entrepreneurship, it would be inadequate to include and account for intrapreneurship. Both phenomena play a crucial role in the IT innovation creation process. 
This dilemma highlighted an interesting question: What does the common root word "preneur" mean? And how are entrepreneurs and intrapreneurs different from the root word, preneur? This simple question exposed my limited understanding of the root concept, and how the two were linked and interrelated. To resolve this required me to do two things: (a) to read for enhanced sensitivity to the historic root definitions of entrepreneurship and intrapreneurship; and (b) to conduct additional interviews with intrapreneurs and to interview project managers that interact closely with them.

By committing to these courses of action, I made the conscious decision to move beyond focusing solely on entrepreneurial agency, and to take the research to a higher level of abstraction which sought to explain the wider phenomenon of preneurship. This additional analysis and abstraction, along with discussion of the fourth and final group of interviews is contained in the next Chapter 5. The discussion is more suited to a standalone chapter that focuses on the phenomenon of preneurship and how it was arrived at using the grounded theory method, as opposed to this chapter which sought to show how the grounded theory method was applied in this research study.

\subsection{Theoretical saturation}

The research study extended beyond the identification of a BSP associated with Entrepreneurial Agency and sought to account for the actions of both the entrepreneur and intrapreneur in the creation of IT innovation. This abstraction resulted in the identification of the core BSP of Preneurial Agency in IT Creation, introduced in the next Chapter 5, and explained in detail in Chapter 6. The core BSP of Preneurial Agency in IT Creation explains the actions of both the entrepreneur and intrapreneur, and places them within a joint context. The traditional notion of entrepreneurship was found wanting and it did not explain the actions of both the entrepreneur and intrapreneur. 
Through applying the analytical coding processes associated with the grounded theory method, the emergent theory was abstracted and integrated to a point where a theory beyond the initial BSP of Entrepreneurial Agency emerged to explain the wider phenomena. I have called this a Grounded Theory of Preneurial Agency in IT Creation. This theory accounts for much of the variation found within the data as explained in this chapter. The full range of analytical processes as and when they were deployed in the research study are shown in Figure 14.

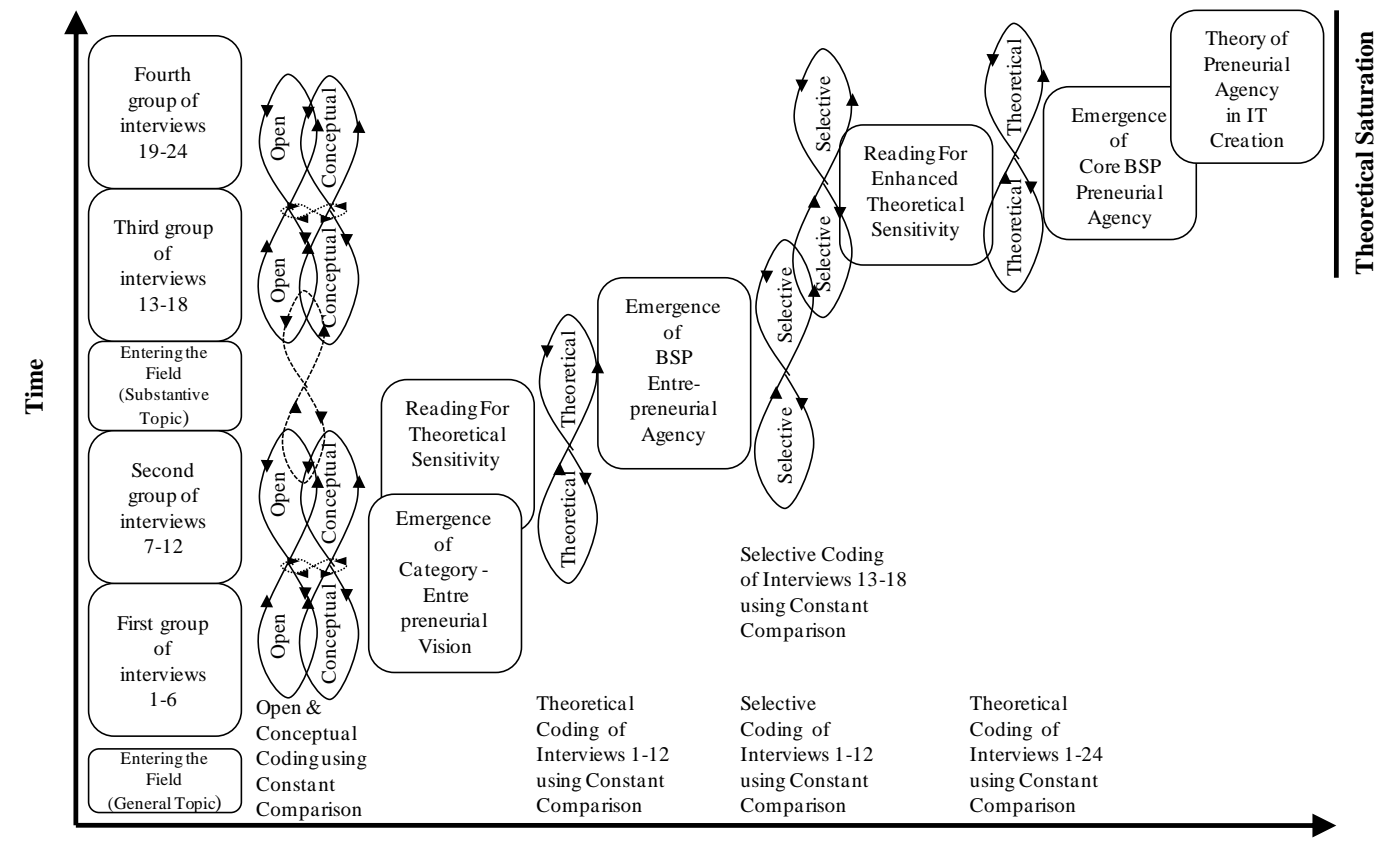

Theoretical Integration

Figure 14: Model of inductive theory generation: application of the grounded theory method to point of theoretical integration and saturation

The fully informed model of inductive theory generation as depicted in Figure 14 shows how the grounded theory method was applied until the points of theoretical integration and saturation were reached. The model provides a visual tool to show at what point in the study certain processes were conducted and how they were repeated throughout the study as higher levels of abstraction and theoretical integration were reached. 


\subsection{Chapter Summary}

This chapter provides a detailed and structured description of how the research data were collected and analysed using the grounded theory coding processes. Specific focus is placed on how I interpreted and applied the grounded theory method in order to identify and substantiate the initial emergent BSP of Entrepreneurial Agency in IT creation. The traditional notion of entrepreneurship was found wanting as it did not explain all the variation in the data.

A model of inductive theory generation was used as an aid to choreograph the research story. This model was built upon and extended as the analysis progressed to show the analytical processes that were applied, and when they were applied, until theoretical integration and saturation was reached.

How the core BSP of Preneurial Agency in IT Creation emerged from the data analysis is discussed and substantiated in the next Chapter 5. Chapter 5, also places context around the theory and defines the base concepts of the preneur, preneurship and preneurial agency. Then in Chapter 6 , a detailed discussion of the Grounded Theory of Preneurial Agency in IT Creation is provided and related to the relevant literature. 


\section{PRENEURSHIP}

\subsection{Chapter overview}

In this chapter, I explain how the BSP of Preneurial Agency emerged from the data and I provide definitions for the key terms: Preneurial Agency, Preneurship, Preneur, and the Preneurial ba.

To move beyond the BSP of entrepreneurial agency and incorporate intrapreneurial agency into the emergent theory, additional interviews and analysis were required. The chapter starts with a focused review of the extant literature related to intrapreneurship and IT innovation, to build sensitivity within the substantive topic area. Then theoretical coding and analysis associated with the wider concept of preneurship, incorporating both external (entre) preneurship and internal (intra) preneurship is explained, starting with the fourth group of interviews. The analysis extends to a re-examination of the data from the very first interview, resulting in the identification of transitions of preneurship.

Through identifying the transitions, the stages of preneurship are identified and related to the interim BSP of Entrepreneurial Agency, and in the process the Grounded Theory of Preneurial Agency in IT Creation is created. Finally, to substantiate and situate the research findings within the extant literature, the notion of Preneurial Agency is related to the traditional views of entrepreneurship.

\section{Chapter Contents}

5.2 Reading for enhanced sensitivity to preneurship and IT innovation

5.3 Theoretical sampling: to explore issues of intrapreneurship

5.4 Selective coding: accounting for issues of intrapreneurship

5.5 Transitions of preneurship

5.6 BSP of Preneurial Agency

5.7 Preneurial Agency: alignment to traditional notions, and study, of entrepreneurship

5.8 Preneurship defined

5.9 Chapter summary 


\subsection{Reading for enhanced theoretical sensitivity to preneurship and IT innovation}

An in-depth exploration and review of literature associated with IT innovation had been precluded from the study up until this stage. This was so that I would be free to see the phenomenon of IT innovation with unbiased eyes and not through the theoretical lens and teachings of established researchers in the field. Such a stance is advised by Glaser $(1978 ; 2005)$.

The substantive topic area had emerged from the data; it was not forced and it was free of undue influence from prior research. It was now appropriate to read in the substantive topic area of IT innovation, explore the history of entrepreneurship in greater depth and look for reference to internal intrapreneurship. Literature associated with the substantive topic area is discussed in detail within the literature review in Chapter 2, along with literature associated with Knowledge Creation Theory and Structuration Theory both of which inform the emergent theory. Within this section, I highlight how my reading within the substantive topic evolved.

Within the IT innovation literature, I found a specific line of research called institutional entrepreneurship. This research addresses the entrepreneurial actions of institutions and relates them to structuration theory (see Fligstein, 1997; Scott 2008; 2010). Seeking to address the neglected question of human agency within institutional entrepreneurship, DiMaggio (1998) applied the term "institutional entrepreneur" to explain how new institutions arise through the actions of such individuals. 
The research field associated with institutional entrepreneurship directly associates the phenomenon of entrepreneurship to organisations and those people that work within them who act entrepreneurially. Similarly Burgelman (1983) directly associates the phenomenon of entrepreneurship with entrepreneurial activity found within corporations and labels such activities as corporate entrepreneurship.

Researching the historical roots of entrepreneurship within economic literature led to a focus on the treatment of entrepreneurship within what is commonly known as the Austrian School of Economics. The work of economists such as Hayek and Mises, in the early to mid $20^{\text {th }}$ century, placed specific focus on the "acting man" and his/her purposeful behaviour, referred to as "agency". This line of investigation was extended by Kirzner in the mid to late $20^{\text {th }}$ century. Kirzner (1973) saw the entrepreneur transition to a point where they were no longer seen as a "pure entrepreneur" after they established their firm.

The separate phenomenon of intrapreneurship emerged through the work of Pinchot (1985) and his development of the term "intrapreneur" to describe someone, who may be the creator or inventor, who takes practical responsibility for turning an idea into a profitable reality within an organisation.

\subsection{Theoretical sampling: to explore issues of intrapreneurship}

The fourth and final group of interviewees for this study, for example were selected on their ability to explore issues associated with intrapreneurship. Interviewee (I-19) had joined the entrepreneur (I-17) shortly after he (I-17) had established his institution and over the proceeding seven years interviewee (I-19) had played a crucial role in developing the software architecture behind the innovation. Interviewees (I-20) and (I-22) were experienced programme and project managers who had worked in a variety of organisations and had worked with intrapreneurs to develop ICT-based innovations. The remaining three participants (I-21), (I-23), and (I-24) were intrapreneurs that had been involved 
with creating an ICT-based innovation (a summary of participants in the fourth group of interviews is provided in Chapter 4, Table 9).

As discussed in Chapter 4, section 4.6 the theoretical sampling associated with interviewee groups two and three had concentrated on understanding personal aspects associated with the entrepreneur and then how he/she went about interacting with other people to create his/her IT innovation. These categories had become saturated from the entrepreneur's perspective after the analysis of the third group of interviews, but not from the perspective of intrapreneurs. These categories (see Table 17) were revisited in the fourth group of interviews, to gather data from intrapreneurs to compare and contrast their perspectives and comments with those of the entrepreneurs.

Table 17: Theoretical sampling interviewee group three to four

\begin{tabular}{|l|l|l|}
\hline & Group three to four & Group four \\
\hline Unsaturated & $\begin{array}{l}\text { Personal aspects, characteristics } \\
\text { of the intrapreneur e.g. } \\
\text { - Skill sets } \\
\text { - preparing one's self } \\
\text { - Vision } \\
\text { - Frustrations } \\
\text { - Personal Behaviour } \\
\text { - Personal networking } \\
\text { Relationships Intrapreneur } \\
\text { Innovation Development }\end{array}$ & \\
\hline $\begin{array}{l}\text { Saturated } \\
\text { Categories }\end{array}$ & $\begin{array}{l}\text { - Relationship aspects } \\
\text { (entrepreneur perspective) } \\
\text { Innovation Development } \\
\text { (entrepreneur perspective) }\end{array}$ & $\begin{array}{l}\text { - Personal aspects, characteristics of } \\
\text { the intrapreneur } \\
\text { - Relationships aspects (intrapreneur) } \\
\text { - Innovation development from the } \\
\text { intrapreneurs perspective }\end{array}$ \\
\hline $\begin{array}{l}\text { Requirements for } \\
\text { next round }\end{array}$ & $\begin{array}{l}\text { Gain a greater understanding of } \\
\text { the issues from the perspective of } \\
\text { the intrapreneur. } \\
\text { Identifying and securing } \\
\text { additional intrapreneurs for the } \\
\text { study. }\end{array}$ & $\begin{array}{l}\text { None as the emergent theory had } \\
\text { reached the required level of } \\
\text { theoretical saturation }\end{array}$ \\
\hline
\end{tabular}

Identifying and enrolling intrapreneurs for this research study proved more difficult than for identifying entrepreneurs. For example, the news media often profiles successful entrepreneurs, yet seldom reports the intrapreneurs behind successful corporate based IT innovations. 
In the first group of interviews, for example, interviewee (I-5) was brought to my attention through a news story that profiled her as an entrepreneur and described a recent success that she had achieved. After reading about her experience with creating an IT-based innovation, I made contact with her. But the identification of intrapreneurs was not so easy.

To recruit intrapreneurs for the fourth round of interviews, I had to not only leverage my personal and professional networks but I also had to provide a description of what an intrapreneur was, so that my contacts could recognise one, and alert me to them.

It was not only my personal contacts who did not know what an intrapreneur was; this also extended to some of the intrapreneurs themselves. It was only when I had posted a message on a social networking board seeking to find intrapreneurs for this study that interviewee (I-21) self-identified as being a possible intrapreneur.

I've never had it explained to me before, the difference between an entrepreneur and an intrapreneur. In fact I don't think I've ever seen the word intrapreneur. But it makes sense. (I-21)

In the case of interviewee (I-24), a personal contact recognised, from the description that I had provided, the elements of an intrapreneur in someone she worked with. I had originally sent my personal contact an email saying "I was hoping that you could keep an eye out for an intrapreneur that I could interview for my $\mathrm{PhD}$ research. Intrapreneurs are similar to entrepreneurs, but they work within existing organisations and identify an opportunity for a new innovation that would benefit the organisation and then act to make it happen”.

Based on this limited description she immediately thought of somebody, but then she had to convince him to participate in the research study. The potential participant did not see himself that way and initially he did not see how he could add value to the research study. This is something that he specifically commented on during the interview: 
Well, (personal contact name removed) said, "still that's the context". My gut reaction is, "well, there's no point, 'cos I'm not one", and therefore I thought about it and I thought "well, actually fact I am, and you know, why am I not acknowledging that and necessarily celebrating it more?" (I-24).

During the course of the interview this intrapreneur, (I-24), described instances of where he had had an innovative idea and then worked to obtain the resources, support, and approvals needed to make it happen. How such intrapreneurs go about using institutional resources is analysed and described in the following section.

\subsection{Selective coding: accounting for issues of intrapreneurship}

Interviews (I-19) to (I-24) were selectively coded against the BSP of Entrepreneurial Agency, exposing an underlying tension. The sub-category of "Directing" was initially adequate to describe the actions of the entrepreneur when they organised the resources needed in order to bring the innovation into being. The entrepreneur was associated with being a company founder and therefore able to direct and approve the use of resources. However, this was not the case for the intrapreneur.

The intrapreneur is often an employee in a company and may not have an outright leadership position or the authority to make the final decision. This was evidenced in the following statements associated with interviews conducted in the fourth group.

Interviewee (I-22) described ownership processes whereby someone who has the vision does not have the status, authority, or skills to own the responsibility for taking the vision forward:

Often a person who has the idea and sponsors it may not have the skills and knowledge to be a project sponsor... So if you had an idea and I was your manager, you would profile that idea to me and I would make a decision 
whether I was going to sponsor that forward for investment (I-22).

Such was the situation for interviewee (I-21) who commented:

I'm not a business owner, I'm not a sponsor... there are two managers above me...I'm part of a team (I-21).

This intrapreneur, (I-21), was not in a formal position to approve the organisational resources allocations needed to make the innovation happen or even to have the final say on what the innovation looked like:

...not my immediate manager but another manager trotted out with some statements and when I challenged those statements as the entrepreneur, and commented "well, I thought this" he commented "well, you thought wrong" (I21).

The intrapreneur did not have the positional power to override his manager's manager. He could influence the outcome, but he did not have the full authority to make the decision. This with also the case for interviewee (I-24) who, while feeling empowered, never felt that he had true ownership of his vision:

One of the comments I made to a lady as I was leaving..., I always have to ask for the cookie out of the jar and now I really do feel empowered... I always felt that, from a respect point of view, I had ownership of my ideas and initiatives that I drove through... But at the end of the day, that thing that really came down to ....I wasn't on the Board, I didn't get to make the decisions. And at the end of the day (Directors name removed)... was a $51 \%$ shareholder... he distributed the cookies to everyone (I24).

Such experiences and frustrations are consistent with extant literature on intrapreneurship. The intrapreneur's ability to execute their innovative idea is dependent on their ability to get organisational support, and at times they may become frustrated from having to get the required approvals at many different levels (Rodrigues, 2010). 
The intrapreneur does not work in isolation. They are often expected to work within a team where the team members work together to solve problems. The activities and existence of the team will, at some point, require the approval of managers in the overall corporate structure (Cunningham and Lischeron, 1991).

As the intrapreneur is often seen as someone that does not have the authority to approve all the actions of the team, the descriptive of directing - as contained in the BSP of Entrepreneurial Agency - did not adequately extend to describing the actions of the intrapreneur. In order to explain both the actions of the entrepreneur and intrapreneur, a new term was required to describe how they coordinated the actions of the collective agents.

\subsubsection{Guiding}

The theoretical analysis of the final round of six interviews led me to view the role of the intrapreneur as that of guiding and shaping the creation of the innovation. The Shorter Oxford English Dictionary's (1973) definition of guide is "one who leads or shows the way" (p. 901). The term "guiding" makes a distinction between leadership (directing) and the co-opting approach (showing the way).

The Shorter Oxford English Dictionary provides further clarification of the definition, adding, "especially to a traveller in a strange land" (1973, p. 901). In the context of the research, the collective agents accompanying the preneur can be seen as travellers, with the strange land being the entrepreneur's vision, which they travel together in order to make the innovation a tangible reality.

The term "guide/guiding" also fits with the actions of the entrepreneur as it accommodates both leading and showing the way. Changing the sub-category of "directing" to "guiding", therefore, more fully catered for incidences found within the data; contributing to the development of the core BSP of Preneurial Agency in IT Creation. The remaining contribution came from seeing the entrepreneur and the intrapreneur as being able to be same person. 


\subsection{Transitions of preneurship}

As I sought to tease out the differences between the entrepreneur and intrapreneur, I came to the realisation that the entrepreneur at some point becomes an intrapreneur. The entrepreneur works within structures they initiate to create the innovation. They use the institution's structures and resources to undertake subsequent refinements and develop new related innovations. Such a transition is hinted at by Kirzner (1973) who argues that the entrepreneur is no longer a "pure entrepreneur" after establishing his/her firm.

This shift in my thinking began in the third round of interviews, where I started to make connections to the changing nature of the institutional structures the entrepreneurs went through as they sought to make their innovation(s) happen. For example, this transition was clearly evident with interviewee (I-17) who initiated the innovation and established the institution to create it seven years prior to the interview. Since then, the IT innovation has gone through a number of iterations and complete model changes, as well as encompassing a multitude of sub-innovations. The interviewee did not act as an entrepreneur when initiating and progressing these sub-innovations, but as an intrapreneur in that he used institutional resources to develop the sub-innovations which were progressed for the benefit of the organisation.

This realisation caused me to revisit the data to identify such transitions; consequently four basic transitions of preneurship were identified: (a) entrepreneur to intrapreneur; (b) institutional actor to intrapreneur; (c) intrapreneur to institutional actor; and (d) intrapreneur to entrepreneur where the cycle of preneurship is repeated.

Within the last group of interviewees, intrapreneurs (I-21) and (I-23) were employed to do functional roles such as teaching or computer and software support, and in the course of their normal role they envisaged new innovative solutions that would benefit their organisations. Each of them then acted through 
their Preneurial Agency to make their visions realities, while still maintaining (to varying degrees) their functional roles.

In the case of interviewee (I-24), he left his position and organisation to pursue his personal entrepreneurial aspirations. See Table 18 for the transitions the intrapreneurs in the fourth group of interviews went through.

Table 18: $\quad$ Transitions of preneurship within the fourth group of interviews

\begin{tabular}{|c|l|l|}
\hline Interviewee & Transition & Description \\
\hline \multirow{4}{*}{$($ I-21) } & $\begin{array}{l}\text { Institutional actor to } \\
\text { intrapreneur }\end{array}$ & $\begin{array}{l}\text { This person does his preneurial agency within an } \\
\text { organisation, while employed within a functional role. }\end{array}$ \\
\cline { 2 - 3 } & $\begin{array}{l}\text { Intrapreneur to } \\
\text { institutional actor }\end{array}$ & $\begin{array}{l}\text { Functional role continued during and after the creation of } \\
\text { the innovation. }\end{array}$ \\
\hline \multirow{4}{*}{ (I-23) } & $\begin{array}{l}\text { Institutional actor to } \\
\text { intrapreneur }\end{array}$ & $\begin{array}{l}\text { This person does his preneurial agency within an } \\
\text { organisation, while employed within a functional role. }\end{array}$ \\
\cline { 2 - 3 } & $\begin{array}{l}\text { Intrapreneur to } \\
\text { institutional actor }\end{array}$ & $\begin{array}{l}\text { Functional role continued during and after the creation of } \\
\text { the innovation. }\end{array}$ \\
\hline \multirow{4}{*}{ (I-24) } & $\begin{array}{l}\text { Institutional actor to } \\
\text { intrapreneur }\end{array}$ & $\begin{array}{l}\text { This person had originally worked for an existing } \\
\text { organisation where he routinely initiated innovation } \\
\text { solutions. }\end{array}$ \\
\cline { 2 - 3 } & $\begin{array}{l}\text { Intrapreneur to } \\
\text { institutional actor }\end{array}$ & $\begin{array}{l}\text { Functional role continued during and after the creation of } \\
\text { the innovation. }\end{array}$ \\
\cline { 2 - 3 } & $\begin{array}{l}\text { Intrapreneur to } \\
\text { entrepreneur }\end{array}$ & $\begin{array}{l}\text { Ultimately the person left the institution to progress his } \\
\text { own entrepreneurial aspirations. }\end{array}$ \\
\hline
\end{tabular}

In accordance with the grounded theory method and the need for constant comparative analysis, at this point all the interview data were reviewed for instances of transitions.

\subsubsection{Reanalysing the first group of interviews}

The first group of interviews, as summarised in Table 19, shows interviewee (I-1) as an institutional actor who transitioned to being an intrapreneur and then returned to his functional role. Four of the participants (I-3), (I-4), (I-5), and (I-6) started out as entrepreneurs who established shared social spaces, within which they went on to become institutional actors. Interviewees (I-4) and (I-5) both left one institution to establish another entity so they could progress unrelated innovations. This is shown as the transition of intrapreneur to entrepreneur. 
Table 19: Transitions of preneurship within the first group of interviews

\begin{tabular}{|c|c|c|}
\hline Interviewee & Transition & Description \\
\hline \multirow{2}{*}{ (I-1) } & $\begin{array}{l}\text { Institutional actor to } \\
\text { intrapreneur }\end{array}$ & $\begin{array}{l}\text { This person had a functional role within an existing } \\
\text { organisation and acted preneurially to progress the IT- } \\
\text { based innovation. }\end{array}$ \\
\hline & $\begin{array}{l}\text { Intrapreneur to } \\
\text { institutional actor }\end{array}$ & $\begin{array}{l}\text { Functional role continued during and after the creation of } \\
\text { the innovation. }\end{array}$ \\
\hline \multirow[t]{2}{*}{ (I-3) } & $\begin{array}{l}\text { Entrepreneur to } \\
\text { intrapreneur }\end{array}$ & $\begin{array}{l}\text { This person was the creator of a locally based IT } \\
\text { innovation and the founder of firm used to create it }\end{array}$ \\
\hline & $\begin{array}{l}\text { Intrapreneur to } \\
\text { institutional actor }\end{array}$ & $\begin{array}{l}\text { The participant was a sole trader at the time of the } \\
\text { interview and undertook a range of activities related to } \\
\text { managing the wider business }\end{array}$ \\
\hline \multirow{3}{*}{ (I-4) } & $\begin{array}{l}\text { Entrepreneur to } \\
\text { intrapreneur }\end{array}$ & $\begin{array}{l}\text { This person had created multiple structures to develop his } \\
\text { various innovations. }\end{array}$ \\
\hline & $\begin{array}{l}\text { Intrapreneur to } \\
\text { institutional actor }\end{array}$ & $\begin{array}{l}\text { The participant also had to undertake operational activities } \\
\text { in his various ventures }\end{array}$ \\
\hline & $\begin{array}{l}\text { Intrapreneur to } \\
\text { Entrepreneur }\end{array}$ & $\begin{array}{l}\text { He stepped out of one venture into another to progress a } \\
\text { new innovation. }\end{array}$ \\
\hline \multirow{3}{*}{ (I-5) } & $\begin{array}{l}\text { Entrepreneur to } \\
\text { intrapreneur }\end{array}$ & $\begin{array}{l}\text { This person had created multiple structures to develop her } \\
\text { various innovations. }\end{array}$ \\
\hline & $\begin{array}{l}\text { Intrapreneur to } \\
\text { institutional actor }\end{array}$ & $\begin{array}{l}\text { The participant also had to undertake operational activities } \\
\text { in her various ventures }\end{array}$ \\
\hline & $\begin{array}{l}\text { Intrapreneur to } \\
\text { Entrepreneur }\end{array}$ & $\begin{array}{l}\text { She stepped out of one venture into another to progress a } \\
\text { new innovation. }\end{array}$ \\
\hline \multirow{2}{*}{$(\mathrm{I}-6)$} & $\begin{array}{l}\text { Entrepreneur to } \\
\text { intrapreneur }\end{array}$ & $\begin{array}{l}\text { This person started the business in order to develop the } \\
\text { innovation. }\end{array}$ \\
\hline & $\begin{array}{l}\text { Intrapreneur to } \\
\text { institutional actor }\end{array}$ & $\begin{array}{l}\text { The person became "trapped" while having to balance } \\
\text { operational roles while he developed the innovation. }\end{array}$ \\
\hline
\end{tabular}

At the time of the interview, interviewee (I-3) was slightly different from other entrepreneurs in the study, as he had yet to acquire and employ collective agents within his shared space. He was the founder of a company he used to create the innovation, but he had not yet directly employed any collective agents to aid him in his task.

While interviewee (I-3) had not employed any one to join him in his venture he did seek advice from collective agents:

I have a few people I speak to for technical advice, and I have some people that I talk to exclusively for business advice, business, legal, tax issues... and there is somebody that I have asked quite frequently about complex technical question. (I-3). 
This participant, (I-3), personally undertook a variety of roles connected with creating the innovation and running the company and, where needed, he sought advice and assistance to aid him in his activities.

\subsubsection{Reanalysing the second group of interviews}

The second group of interviews revealed a new fourth transition; interviewee (I10) started out as an institutional actor or spotted an opportunity for an ICT-based open source innovation and created the innovation within the institution he worked for. Interviewee (1-10) then left that organisation to start up a new institution to progress his own innovative opportunities and, over time, become both an intrapreneur and institutional actor in an institution that he had established.

Table 20: $\quad$ Transitions of preneurship within the second group of interviews

\begin{tabular}{|c|l|l|}
\hline Interviewee & Transition & Description \\
\hline \multirow{5}{*}{$($ I-8) } & $\begin{array}{l}\text { Entrepreneur to } \\
\text { intrapreneur }\end{array}$ & $\begin{array}{l}\text { This person started his business and then initiated the } \\
\text { development of the innovation. }\end{array}$ \\
\cline { 2 - 3 } & $\begin{array}{l}\text { Intrapreneur to } \\
\text { institutional actor }\end{array}$ & $\begin{array}{l}\text { The person had to balance operational and cash flow } \\
\text { generating roles while progressing the development of his } \\
\text { innovation. }\end{array}$ \\
\hline \multirow{5}{*}{ (I-10) } & $\begin{array}{l}\text { Institutional actor to } \\
\text { intrapreneur }\end{array}$ & $\begin{array}{l}\text { This person established the initial concept while working } \\
\text { within an existing corporate structure and did the pilot } \\
\text { there. }\end{array}$ \\
\cline { 2 - 3 } & $\begin{array}{l}\text { Intrapreneur to } \\
\text { Entrepreneur }\end{array}$ & $\begin{array}{l}\text { He then left and set up his own entity to take the } \\
\text { opportunity further. }\end{array}$ \\
\cline { 2 - 3 } & $\begin{array}{l}\text { Entrepreneur to } \\
\text { intrapreneur }\end{array}$ & $\begin{array}{l}\text { He is now working on new innovations within new sub- } \\
\text { structures within the firm he initially setup. }\end{array}$ \\
\cline { 2 - 3 } & $\begin{array}{l}\text { Intrapreneur to } \\
\text { institutional actor }\end{array}$ & $\begin{array}{l}\text { The person has to balance operational and cash flow } \\
\text { generating roles while progressing the development of his } \\
\text { innovation. }\end{array}$ \\
\hline \multirow{5}{*}{ (I-12) } & $\begin{array}{l}\text { Entrepreneur to } \\
\text { intrapreneur }\end{array}$ & $\begin{array}{l}\text { This person is a serial preneur that goes from one } \\
\text { innovation and venture to another. }\end{array}$ \\
\cline { 2 - 3 } & $\begin{array}{l}\text { Intrapreneur to } \\
\text { institutional actor }\end{array}$ & $\begin{array}{l}\text { The participant also had to undertake operational activities } \\
\text { in his various ventures }\end{array}$ \\
\cline { 2 - 3 } & $\begin{array}{l}\text { Intrapreneur to } \\
\text { entrepreneur }\end{array}$ & $\begin{array}{l}\text { He stepped out of one venture into another to progress a } \\
\text { new innovation. }\end{array}$ \\
\hline
\end{tabular}




\subsubsection{Reanalysing the third group of interviews}

Like the second group of interviews, the third group of interviewees (see Table 21) contained participants that had started out as both entrepreneurs and intrapreneurs. The participants had all established shared spaces where collective agents interacted with the participant to create the respective innovations.

Table 21: $\quad$ Transitions of preneurship within the third group of interviews

\begin{tabular}{|c|l|l|}
\hline \multirow{3}{*}{$($ I-15) } & $\begin{array}{l}\text { Entrepreneur to } \\
\text { intrapreneur }\end{array}$ & $\begin{array}{l}\text { This person had established the main business 15 years } \\
\text { previously and since then used the original structure as a } \\
\text { vehicle for new innovations under the umbrella company. }\end{array}$ \\
\cline { 2 - 3 } & $\begin{array}{l}\text { Intrapreneur to } \\
\text { institutional actor }\end{array}$ & $\begin{array}{l}\text { The person has to balance operational and cash flow } \\
\text { generating roles while progressing the development of his } \\
\text { innovations. }\end{array}$ \\
\hline \multirow{3}{*}{$(\mathrm{I}-17)$} & $\begin{array}{l}\text { Entrepreneur to } \\
\text { intrapreneur }\end{array}$ & $\begin{array}{l}\text { This person was the founder of a company to progress his } \\
\text { innovative idea. }\end{array}$ \\
\cline { 2 - 4 } & $\begin{array}{l}\text { Intrapreneur to } \\
\text { institutional actor }\end{array}$ & $\begin{array}{l}\text { The person has to balance operational and cash flow } \\
\text { generating roles while progressing the development of his } \\
\text { original and subsequent innovations. }\end{array}$ \\
\hline \multirow{3}{*}{ (I-18) } & $\begin{array}{l}\text { Institutional actor to } \\
\text { intrapreneur }\end{array}$ & $\begin{array}{l}\text { This person was senior manager, in charge of an } \\
\text { established institution when she first became an innovator } \\
\text { with ICT-based innovations. }\end{array}$ \\
\cline { 2 - 3 } & $\begin{array}{l}\text { Intrapreneur to } \\
\text { institutional actor }\end{array}$ & $\begin{array}{l}\text { Since then she has gone on to innovate and act preneurially } \\
\text { in number of institutions and initiatives she had } \\
\text { established. }\end{array}$ \\
\hline
\end{tabular}

This third group of interviews contained two entrepreneurs, (I-15) and (I-17), who had established their own organisations to progress the development of their respective innovations. The re-analysis highlighted the fact that both of the participants had established their respective institutions a number of years earlier, 15 and 7 years respectively. It was a long time since they had been "just" entrepreneurs and progressed opportunities with resources of which they did not, as yet, have ownership or control. Since starting the ventures many years ago they had been using the institutions' resources to progress and create new innovations. While starting out as entrepreneurs they had each become an intrapreneur and an institutional actor.

Like interviewees (I-15) and (I-17), all the other participants in the study who had started out as entrepreneurs and established their own institutions went on to become intrapreneurs who used the resources of that entity to create the 
innovation, progress subsequent improvements, and create new related innovations. Some of those participants stayed in those ventures while others moved on and established new ventures to progress unrelated innovations. These distinctions are shown and summarised in Table 22 and depicted in Figure 15.

Table 22: Occurrences of transitions associated with preneurship

\begin{tabular}{|c|c|c|c|c|c|}
\hline Interviewee & \multicolumn{5}{|c|}{ Transition } \\
\hline & $\begin{array}{c}\text { Entrepreneur } \\
\text { to } \\
\text { intrapreneur } \\
\text { (a) }\end{array}$ & $\begin{array}{c}\text { Institutional } \\
\text { actor to } \\
\text { intrapreneur } \\
\text { (b) }\end{array}$ & $\begin{array}{c}\text { Intrapreneur } \\
\text { to institutional } \\
\text { actor } \\
\text { (c) }\end{array}$ & $\begin{array}{c}\text { Intrapreneur } \\
\text { to } \\
\text { entrepreneur } \\
\text { (d) }\end{array}$ & $\begin{array}{c}\text { Serial } \\
\text { "Preneur" } \\
\left(\mathrm{n}^{+}\right)\end{array}$ \\
\hline (I-1) & $\checkmark$ & $\checkmark$ & & \\
\hline (I-3) & $\checkmark$ & & $\checkmark$ & $\checkmark$ & $\checkmark$ \\
\hline (I-5) & $\checkmark$ & & $\checkmark$ & $\checkmark$ & $\checkmark$ \\
\hline (I-6) & $\checkmark$ & & $\checkmark$ & & \\
\hline (I-8) & $\checkmark$ & & $\checkmark$ & $\checkmark$ & \\
\hline (I-10) & $\checkmark$ & $\checkmark$ & $\checkmark$ & $\checkmark$ & \\
\hline (I-12) & $\checkmark$ & & $\checkmark$ & & \\
\hline (I-15) & $\checkmark$ & & $\checkmark$ & & \\
\hline (I-17) & $\checkmark$ & & $\checkmark$ & & \\
\hline (I-18) & & $\checkmark$ & $\checkmark$ & & \\
\hline (I-21) & & $\checkmark$ & $\checkmark$ & & \\
\hline (I-23) & & $\checkmark$ & $\checkmark$ & & \\
\hline (I-24) & & & & & \\
\hline Total & 9 & & & & \\
\hline Occurrences & & & $\checkmark$ & & \\
\hline
\end{tabular}

The transitions, as shown in Table 22, show that all the entrepreneurs in the study had become intrapreneurs and institutional actors. They had established shared spaces which facilitated their interactions with collective agents. The resources required to create their respective innovations were combined within the boundaries of the shared spaces they had established and within which they subsequently operated.

The boundary based view of entrepreneurs, intrapreneurs, and the firm as developed in Chapter 4, section 4.7 and depicted in Figure 13, can be extended to show the transitions that an entrepreneur or intrapreneur is able to make. The extended model shows: (a) the entrepreneur transitioning to an intrapreneur; (b) the institutional actor transitioning to an intrapreneur; (c) the intrapreneur transitioning to an institutional actor; (d) the intrapreneur transitioning to an 
entrepreneur; and $\left(\mathrm{n}^{+}\right)$denoting repetitive transitions associated with the entrepreneur progressing new unrelated opportunities through establishing new institutions.

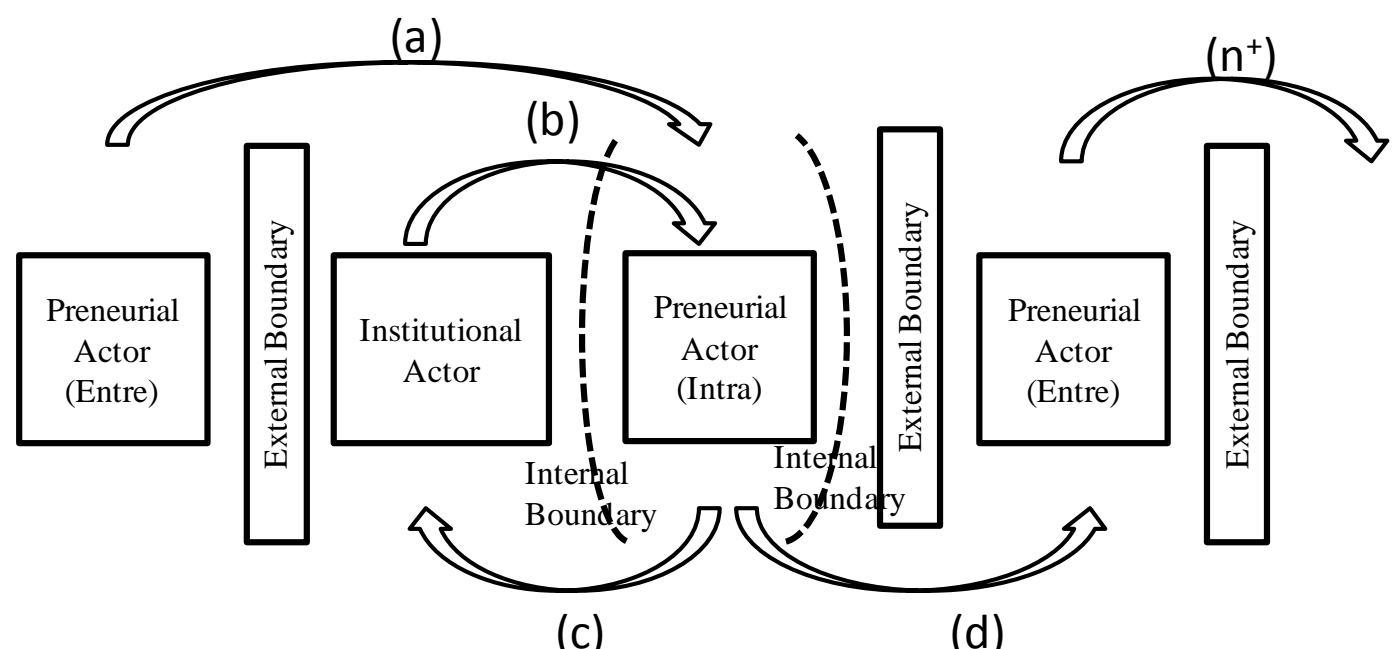

Figure 15: Transitions of preneurship

The preneurial actor's designation is a point in time construct, as they be either a (a) entrepreneur, (b) intrapreneur, or (c) institutional actor. Their status is dependent on what activity they were undertaking at that point in time and whether they are external or internal to an institution.

The entrepreneur, while starting out as external to an institution, at some point acts internally within the shared space that they establish to create the IT artefact. The institutional actor, who becomes an intrapreneur, also seeks to establish a shared space to acquire and guide the institutional resources and collective agents they need to aid them in their task.

Both the entrepreneur and intrapreneur share the commonality of acting to establish shared spaces where they guide the actions of collective agents in the creation of the IT innovation. 


\subsubsection{Establishing the "preneurial ba"}

To progress the creation of the IT innovation, the entrepreneurs and intrapreneurs interviewed for the study either established new institutions or new internal project teams within existing institutions - as shown in Table 23.

Table 23: $\quad$ Shared space associated with each preneur

\begin{tabular}{|c|c|}
\hline Interviewee & Shared space \\
\hline$(\mathrm{I}-1)$ & Internal project team \\
\hline$(\mathrm{I}-3)$ & New institution \\
\hline$(\mathrm{I}-4)$ & Internal project team \\
\hline$(\mathrm{I}-5)$ & New institution \\
\hline$(\mathrm{I}-6)$ & New institution \\
\hline$(\mathrm{I}-8)$ & Internal project team \\
\hline$(\mathrm{I}-10)$ & Internal project team \\
\hline$(\mathrm{I}-12)$ & New institution \\
\hline$(\mathrm{I}-15)$ & New institution \\
\hline$(\mathrm{I}-17)$ & New institution \\
\hline$(\mathrm{I}-18)$ & New institution \\
\hline$(\mathrm{I}-21)$ & Internal project team \\
\hline$(\mathrm{I}-23)$ & Internal project team \\
\hline$(\mathrm{I}-24)$ & Internal project team \\
\hline
\end{tabular}

Whether it was a new institution or a new project team that was established, both the entrepreneur and intrapreneur acted to establish a shared space where they could interact with collective agents and guide their activities.

Within this research study, the shared space is being used as a place holder term to describe the social structure where the entrepreneurial and intrapreneurial actor interacts with collective agents to create the IT innovation. The term was initially derived from the work of Nonaka and colleagues (see Nonaka et al., 2000; Nonaka and Toyama, 2003; and Nonaka et al., 2006) and represents the physical, virtual, or mental space where knowledge is acquired and combined.

Where Nonaka and colleagues use the term "shared space", sociologists (see Giddens, 1984; Sewell, 1992) use the term "social structures" to describe the 
space where human actors interact within and relate to each other. As discussed in Chapter 2, section 2.7, Giddens had trouble describing the notion of structure without referring to and using the word "structure" within its own definition.

Nonaka and colleagues overcame this problem through using the concept of $b a$ to describe the space where knowledge is shared, created, and utilised through the committed actions and interactions of participants to a common objective. The term $b a$ also allowed Nonaka and colleagues to differentiate between the different types of shared spaces as shown in Chapter 2, Table 3.

For this research, the notion of the preneurial $b a$ is offered as a shared structure where the preneur interacts with collective agents so that they may collectively undertake activities to create the IT innovation. Through adding the specific descriptor of "preneurial", context is given to the generic term of $b a$. This allows for the associations of entrepreneurship, intrapreneurship, and human agency in the pursuit of innovation to be garnered through the differentiated term.

\subsubsection{Establishing}

Through the identification of transitions of preneurship, when combined with related theory, it became clear that both entrepreneurs and intrapreneurs establish shared spaces, the preneurial $b a$, so that they can guide the actions of the collective agents in creating the IT innovation.

By identifying that the preneur acts to establish a preneurial $b a$, I had identified another stage of the PA process. Establishing, therefore, is a key part of the preneurial process as the entrepreneurs and intrapreneurs act to put in place foundation structures within which to build the IT innovation, as shown in Table 24. 
Table 24: Establishing

\begin{tabular}{|l|l|l|l|}
\hline $\begin{array}{l}\text { Sub- } \\
\text { category }\end{array}$ & Description & Concept & Properties \\
\hline Establishing & $\begin{array}{l}\text { Putting in } \\
\text { place the } \\
\text { foundations }\end{array}$ & Preneurial $b a$ & $\begin{array}{l}\text { New institutions } \\
\text { Internal project teams }\end{array}$ \\
\hline
\end{tabular}

The analysis also identified another critical stage of the preneurial process - before the entrepreneurs and intrapreneurs can guide the actions of the collective agents within the preneurial $b a$ they must acquire their services. The data analysis showed that both the entrepreneur and intrapreneur acted to develop a conceptual design of the innovation and the associated business model.

\subsection{BSP of Preneurial Agency}

As the design stage is common to both the entrepreneur and intrapreneur, it provides the starting point for the BSP of Preneurial Agency. The analysis identified two additional stages of Establishing and Acquiring following the design stage. How these stages emerged is not specifically discussed, rather a detailed discussion of how the stage of Designing emerged from the data analysis, see Chapter 4 section 4.5.3, is used to illustrate the process. Once the resources are acquired, the entrepreneur and intrapreneur are able to guide the actions of the collective agents. These changes to the interim BSP of Entrepreneurial Agency to the more inclusive BSP of Preneurial Agency are shown in Figure 16. 


\begin{tabular}{|c|l|l|l|l|l|}
\hline \multicolumn{6}{|c|}{ Interim BSP of Entrepreneurial Agency } \\
\hline $\begin{array}{l}\text { Sub- } \\
\text { category }\end{array}$ & Designing & Directing & Validating & Extricating & Realising \\
\hline Description & $\begin{array}{l}\text { Developing } \\
\text { and } \\
\text { articulating } \\
\text { the vision }\end{array}$ & $\begin{array}{l}\text { Harnessing } \\
\text { and capturing } \\
\text { contribution of } \\
\text { others }\end{array}$ & $\begin{array}{l}\text { Proving the } \\
\text { concept }\end{array}$ & $\begin{array}{l}\text { Exploring } \\
\text { options to } \\
\text { exit }\end{array}$ & Reality sets in \\
\hline Sub-category & Designing & Establishing & Acquiring & Guiding \\
\hline Description & $\begin{array}{l}\text { Developing and } \\
\text { articulating the } \\
\text { vision }\end{array}$ & $\begin{array}{l}\text { Putting in place } \\
\text { the foundations }\end{array}$ & $\begin{array}{l}\text { Securing the } \\
\text { required } \\
\text { Collective } \\
\text { Agents }\end{array}$ & $\begin{array}{l}\text { Showing and/or } \\
\text { leading the way }\end{array}$ \\
\hline
\end{tabular}

Figure 16: Transitioning to the BSP of Preneurial Agency

The transitioning of the BSP of Preneurial Agency accounts for the actions of the entrepreneur and intrapreneur from the Designing stage to the Guiding stage.

Within the BSP of Entrepreneurial Agency, after the directing stage there are three stages in which the entrepreneur directs the actions of the collective agents:

Validating, Extricating, and Realising. These stages had to be reconciled with the emerging BSP of Preneurial Agency

\subsubsection{Validating and Extricating}

The actions of both the entrepreneur and intrapreneur were found to be the same when Validating the concept. Both produce a prototype of the innovation and then act to prove and improve the innovation based on actual experience with the basic working model of the innovation.

While the first definition may describe the act of making something real, the second definition makes reference to a cognitive process. Rather than being a separate stage of the process, then, realising is, in fact, a subset of Extricating and the other stages. Once the entrepreneur or intrapreneur realised something they would then move to act appropriately. 
The remaining stage, Extricating, was found to be common to both the entrepreneur and intrapreneur as they both acted to remove him/herself from the innovation specific process so that they could move on to the next opportunity or focus on their role as an institutional actor.

On further analysis the stage of Realising was found to be more associated with cognitive processes, than with explaining the actions of either the entrepreneur or intrapreneur. Realising means both: (a) to make real, to give reality to; and (b) to make real as an object of thought and to bring vividly and clearly before the mind (The Shorter Oxford English Dictionary, 1973).

\subsubsection{Emergence of the BSP of Preneurial Agency}

Through interviewing additional intrapreneurs and collective agents who interacted with intrapreneurs, and by analysing the new data and comparing it with previous analysis, the BSP of Preneurial Agency was allowed to emerge from the data.

The BSP of Preneurial Agency was not forced; it emerged from the data through additional analysis and new data, till a point of saturation was reached. The interim BSP of Entrepreneurial Agency only accounts for the actions of the entrepreneur, whereas the BSP of Preneurial Agency accounts for the actions of the entrepreneur and intrapreneur when creating IT innovation.

The additional level of abstraction and analysis (as depicted in Chapter 4, Figure 14) saw the interim BSP of Entrepreneurial transition to the BSP of Preneurial Agency through: (a) retaining the first stage of Designing as the common starting point; (b) introducing two new stages - Establishing and Acquiring; (c) substituting the more inclusive term Guiding for directing; (d) retaining the stages of Validating and Extricating; and (e) discarding the stage of Realising which was not bound in action. This emergence and depiction of the BSP of Preneurial Agency is shown in Figure 17. 


\begin{tabular}{|c|c|c|c|c|c|c|}
\hline \multicolumn{7}{|c|}{ Interim BSP of Entrepreneurial Agency } \\
\hline $\begin{array}{l}\text { Sub- } \\
\text { category }\end{array}$ & Designing & Directing & \multicolumn{2}{|c|}{\begin{tabular}{|l|l} 
Validating & 1
\end{tabular}} & Extricating & Realising \\
\hline $\begin{array}{l}\text { Descript } \\
\text {-ion }\end{array}$ & $\begin{array}{l}\text { Developing } \\
\text { and } \\
\text { articulating } \\
\text { the vision }\end{array}$ & $\begin{array}{l}\text { Harnessing } \\
\text { and capturing } \\
\text { contribution of } \\
\text { others }\end{array}$ & \multicolumn{2}{|c|}{$\begin{array}{l}\text { Proving the } \\
\text { concept }\end{array}$} & $\begin{array}{l}\text { Exploring } \\
\text { options to exit }\end{array}$ & Reality sets in \\
\hline \multicolumn{7}{|c|}{ BSP of Preneurial Agency } \\
\hline $\begin{array}{l}\text { Sub- } \\
\text { category }\end{array}$ & Designing & Establishing & Acquiring & Guiding & Validating & Extricating \\
\hline $\begin{array}{l}\text { Descript } \\
\text {-ion }\end{array}$ & $\begin{array}{l}\text { Developing } \\
\text { and } \\
\text { articulating } \\
\text { the vision }\end{array}$ & $\begin{array}{l}\text { Putting in } \\
\text { place the } \\
\text { foundations }\end{array}$ & $\begin{array}{l}\text { Securing } \\
\text { the } \\
\text { required } \\
\text { Collective } \\
\text { Agents }\end{array}$ & $\begin{array}{l}\text { Showing } \\
\text { and/or } \\
\text { leading } \\
\text { the way }\end{array}$ & $\begin{array}{l}\text { Piloting, } \\
\text { proving, } \\
\text { and testing } \\
\text { the basic } \\
\text { prototype }\end{array}$ & $\begin{array}{l}\text { Removing } \\
\text { oneself from } \\
\text { the process }\end{array}$ \\
\hline
\end{tabular}

Figure 17: Emergence of the BSP of Preneurial Agency

Guiding, as opposed to Directing was a key change between the two social processes as Guiding accounts for the actions of both intrapreneurs and Entrepreneurs. Directing does not explain the actions of the intrapreneur as often they do not have the position power to direct resources. The concept of guiding better explains the actions of a preneur as someone who guides the actions of collective agents.

The full discussion of the BSP of Preneurial Agency and its properties is contained in the next Chapter 6, where participant comments are used to describe the process and reinforce the key points. The theory, as offered in Chapter 6, is limited to the creation of IT innovation and the actions of entrepreneurs and intrapreneurs whose innovations contain software and consequently need software development expertise to create it.

The notion of the Preneurial Agency, as developed in this chapter, is grounded on the premise that the entrepreneur at some point may become an intrapreneur and institutional actor. It also asserts that the intrapreneur may become an entrepreneur and, ultimately, becomes an intrapreneur and institutional actor yet again as previously depicted in Figure 15. 
Such an explicit assertion and view is absent from the extant literature within the entrepreneurship, intrapreneurship, and innovation based research domains. While a higher level abstracted perspective of preneurship may be absent from the extant literature, such transitions are hinted at - as discussed in the next section.

\subsection{Preneurial Agency: alignment to traditional notions, and study, of entrepreneurship}

The term "entrepreneurship" has been in use for centuries, yet it remains an elusive concept that resists precise definition (Morris and Trotter, 1990). Not only does it resist efforts to define it, the field of entrepreneurship research also continues to struggle with domain issues, substance issues, and outcome issues (Morris, 2003)

While there is generally no accepted definition or model of what an entrepreneur is or does, a number of trends have emerged which distinguish between individual entrepreneurship and corporate entrepreneurship (Cunningham and Lischeron, 1991).

Alignment 1 The lack of a precise definition supports the proposition that the activity of entrepreneurship is open to interpretation and redefining.

What is generally accepted is that entrepreneurship entails a process that generally comprises: (a) an entrepreneurial event that can be divided into stages; (b) an entrepreneurial process that is manageable; (c) an ongoing and continuous process; and (d) a process can be applied to a variety of contexts from start-ups to larger established companies (Schindehutte, Morris, and Kuratko, 2000).

As a process or activity, entrepreneurship is being applied to all forms of businesses and it can be studied at the individual, organisational, and national levels (Luke, Verreynne, and Kearins, 2007). While able to be studied at differing 
levels, it should also best be studied through differing theoretical lenses, with: (a) a foundation perspective focusing on creation processes and models; (b) an economic based perspective, largely from the lens of Austrian economics; and (c) a social science based perspective covering opportunity, exploration, recognition, and exploitation (Brush, et al., 2003).

Alignment 2 The BSP of Preneurial Agency aligns with the generally accepted belief that entrepreneurship is a process comprising definable stages and encompasses a wide variety of contexts from start-ups to existing large institutions.

Alignment 3 This research examined the phenomena of entrepreneurship and intrapreneurship at the individual actor level and analysed their actions using the three differing theoretical lenses: foundation, economic, and social sciences based perspectives.

Rather than aligning with any one definition or view of entrepreneurship, Cunningham and Lischeron (1991) identify and discuss six schools of thought which are influential in describing entrepreneurial activity: (a) the great person school of entrepreneurship; (b) the psychological characteristics school of entrepreneurship; (c) the classical school of entrepreneurship; (d) the management school of entrepreneurship; (e) the leadership school of entrepreneurship; and (f) the intrapreneurship school of entrepreneurship.

The first two schools of entrepreneurship, (a) and (b), are focused on assessing the personal qualities of the entrepreneur. The third school (c) emphasises the innovative behaviour of the entrepreneur with the fourth and fifth schools, (d) and (e) examining issues associated with entrepreneurial actions and managing the process. Finally the remaining school, (f) the intrapreneurship school of entrepreneurship, focuses on the need for adapting an existing institution. 
These six approaches to describing entrepreneurship are summarised by

Cunningham and Lischeron (1991) in table form, reproduced as Table 25.

Table 25: $\quad$ Summary of approaches for describing entrepreneurship (Cunningham and Lischeron, 1991)

\begin{tabular}{|c|c|c|c|c|}
\hline $\begin{array}{l}\text { Entre- } \\
\text { preneurial } \\
\text { Model }\end{array}$ & $\begin{array}{l}\text { Central Focus } \\
\text { or Purpose }\end{array}$ & Assumption & $\begin{array}{l}\text { Behaviours } \\
\text { and Skills }\end{array}$ & Situation \\
\hline $\begin{array}{l}\text { "Great Person" } \\
\text { School }\end{array}$ & $\begin{array}{l}\text { The entrepreneur has an } \\
\text { intuitive ability - a sixth } \\
\text { sense - and traits and } \\
\text { instincts he/she is born } \\
\text { with. }\end{array}$ & $\begin{array}{l}\text { Without this "inborn" } \\
\text { intuition the individual } \\
\text { would be like the rest of } \\
\text { us mortals who "lack } \\
\text { what it takes". }\end{array}$ & $\begin{array}{l}\text { Intuition, } \\
\text { vigour, energy, } \\
\text { persistence, and } \\
\text { self-esteem. }\end{array}$ & Start-up \\
\hline $\begin{array}{l}\text { Psychological } \\
\text { Characteristics }\end{array}$ & $\begin{array}{l}\text { Entrepreneurs have unique } \\
\text { values, attributes, and needs } \\
\text { which drive them. }\end{array}$ & $\begin{array}{l}\text { People behave in } \\
\text { accordance with their } \\
\text { values, behaviour } \\
\text { results from attempts to } \\
\text { satisfy needs. }\end{array}$ & $\begin{array}{l}\text { Personal values, } \\
\text { risk taking, need } \\
\text { for } \\
\text { achievement, } \\
\text { and others. } \\
\end{array}$ & Start-up \\
\hline Classical School & $\begin{array}{l}\text { The central characteristic of } \\
\text { entrepreneurial behaviour is } \\
\text { innovation. }\end{array}$ & $\begin{array}{l}\text { The critical aspect of } \\
\text { entrepreneurship is in } \\
\text { the process of doing } \\
\text { rather than owning. }\end{array}$ & $\begin{array}{l}\text { Innovation, } \\
\text { creativity, and } \\
\text { discovery. }\end{array}$ & $\begin{array}{l}\text { Start-up } \\
\text { and early } \\
\text { growth }\end{array}$ \\
\hline $\begin{array}{l}\text { Management } \\
\text { School }\end{array}$ & $\begin{array}{l}\text { Entrepreneurs are } \\
\text { organisers of an economic } \\
\text { venture; they are people } \\
\text { who organise, own, manage } \\
\text {,and assume the risk. }\end{array}$ & $\begin{array}{l}\text { Entrepreneurs can be } \\
\text { developed or trained in } \\
\text { the technical functions } \\
\text { of management. }\end{array}$ & $\begin{array}{l}\text { Production, } \\
\text { planning, } \\
\text { people, } \\
\text { organising, } \\
\text { capitalisation, } \\
\text { and budgeting. }\end{array}$ & $\begin{array}{l}\text { Early- } \\
\text { growth } \\
\text { and } \\
\text { maturity }\end{array}$ \\
\hline $\begin{array}{l}\text { Leadership } \\
\text { School }\end{array}$ & $\begin{array}{l}\text { Entrepreneurs are leaders of } \\
\text { people; they have the ability } \\
\text { to adapt their style to the } \\
\text { needs of people. }\end{array}$ & $\begin{array}{l}\text { An entrepreneur cannot } \\
\text { accomplish his/her } \\
\text { goals alone, but } \\
\text { depends on others. }\end{array}$ & $\begin{array}{l}\text { Motivating, } \\
\text { directing, and } \\
\text { leading. }\end{array}$ & $\begin{array}{l}\text { Early- } \\
\text { growth } \\
\text { and } \\
\text { maturity }\end{array}$ \\
\hline $\begin{array}{l}\text { Intra- } \\
\text { Preneurship } \\
\text { School }\end{array}$ & $\begin{array}{l}\text { Entrepreneurial skills can } \\
\text { be useful in complex } \\
\text { organisations; } \\
\text { intrapreneurship is the } \\
\text { development of independent } \\
\text { units to create, market, and } \\
\text { expand services. }\end{array}$ & $\begin{array}{l}\text { Organisations need to } \\
\text { adapt to survive; } \\
\text { entrepreneurial activity } \\
\text { leads to organisational } \\
\text { and entrepreneurs } \\
\text { becoming managers. }\end{array}$ & $\begin{array}{l}\text { Alertness to } \\
\text { opportunities, } \\
\text { maximising } \\
\text { decisions. }\end{array}$ & $\begin{array}{l}\text { Maturity } \\
\text { and } \\
\text { change }\end{array}$ \\
\hline
\end{tabular}

Cunningham and Lischeron (1991) maintain that to fully understand the actions of the entrepreneur and their ventures requires criteria from each facet of the overall process. The BSP of Preneurial Agency does not seek to explain all the facets of the entrepreneur and intrapreneur as it is focused on their actions and not their psychological characteristics. Nor does it view the entrepreneur or intrapreneur as the great person with an innate ability and as the producer of all change in society.

What it does explain is aspects of entrepreneurial behaviour and the process of doing, issues typically associated with the Classical School. In addition, the BSP 
of Preneurial Agency also seeks to explain the actions of entrepreneurial actor within organisations, issues typically associated with the Intrapreneurship School.

Alignment 4 The view of preneurship as developed in this research aligns with the classical and intrapreneurship approaches and partially aligns with the management and leadership based approaches.

These facets are described in detail in Chapter 5, where the words of the participants are used to describe and substantiate the actions of the entrepreneur and intrapreneur in the innovation creation process. The entrepreneur and intrapreneur are both shown as preneurial actors who undertake actions and combine resources to create the innovation.

What differentiates the entrepreneur and intrapreneur is their location respective to where the resources reside. Burgelman (1983), one of the earliest proponents of the intrapreneurship based school of thought, saw both the external entrepreneur and internal corporate entrepreneurs as resource combiners. The difference lay in where the resources primarily resided.

The resources used by the external entrepreneur were largely located in the wider environment, whereas the resources used and combined by the internal corporate intrapreneur were, to some extent, nested in the larger resource combinations residing within the institution.

These similarities and differences are evident in Stevenson and Jarillo's (1990) definition of entrepreneurship as a process whereby "individuals - either on their own or inside organizations - purse opportunities without regards to the resources they currently control" (p. 23). The individuals share the commonality of pursuing opportunities without regards to the resources they currently control but are separated by one of the actors, the external entrepreneur, being on their own, and the other, the internal intrapreneur, being inside an organisation. 
This distinction is depicted in Figure 18 where the higher level abstraction shows the preneurship as comprising both the (entre) preneur and the (intra) preneur who each occupy different positions in relation to institutional boundaries.

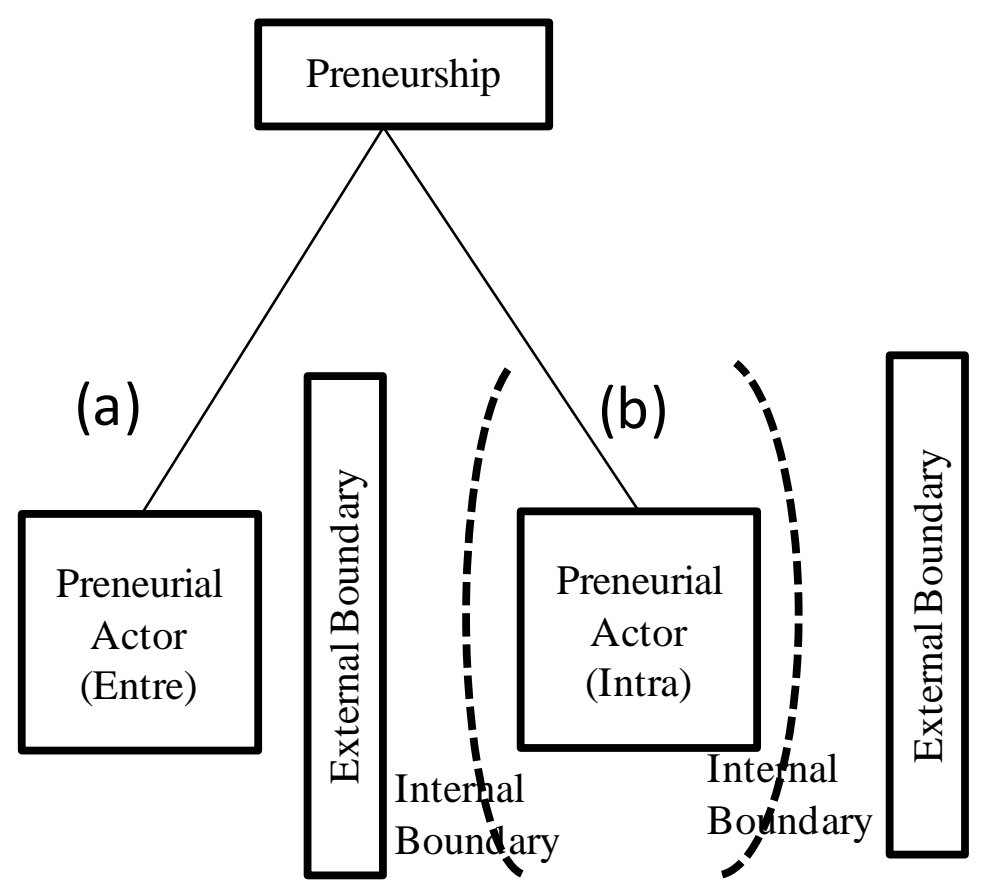

Figure 18: $\quad$ A boundary based view of Preneurship

The boundary based view of preneurship, as depicted in Figure 18, differentiates between: (a) the (entre) preneur who resides outside the institutional boundary, and (b) the (intra) preneur who resides within the institutional boundary. This differentiation is at the core of the Grounded Theory of Preneurial Agency in IT Creation as developed in this research, as it accounts for the actions of both the (entre) preneur and (intra) preneur to create IT-based innovation.

The theory uses the inclusive term Preneurial Agency to describe the common actions and activities undertaken by the preneur as they go about creating the IT innovation. The prefixes of (entre) and (intra) are attached to the noun to differentiate their status as an external (entre) preneur and internal (intra) preneur. 


\subsection{Preneurship defined}

For the purposes of this study, Preneurship is defined as:

The creation process a preneur undertakes to make their innovative idea a tangible reality

The Preneur is seen as:

An actor who may be external (entre) and/or internal (intra) to an existing institution and who is involved in the creation process and undertakes actions to create their innovative idea and make it a tangible reality

The Preneur acts through their Preneurial Agency. The term Preneurial Agency describes:

The actions the preneur undertakes to create their innovative idea and make it a tangible reality

The view of preneurship, as provided, is a one dimensional perspective based on how the preneur acts; it does not seek to account for: (a) issues associated with the preneurial opportunity, (b) environmental issues, or (c) the personal characteristics of the preneur.

\subsection{Chapter summary}

This chapter shows how the BSP of Preneurial Agency emerged from the data and accounts for both the actions of the external (entre) preneur and the internal (intra) preneur in the creation of IT innovation. The Grounded Theory of Preneurial Agency in IT Creation accounts for the actions of the Preneur and how they act to create the IT innovation. 
The traditional notion of entrepreneurship is shown to suffer from the lack of a precise definition and, therefore, may be viewed from a number of different perspectives. The Grounded Theory of Preneurial Agency in IT Creation aligns with the classical and intrapreneurship schools of thought.

Both the (entre) preneur and (intra) preneur are shown to establish shared spaces, which I have termed the preneurial $b a$, where they are able to interact with the collective agents and guide them in their actions. The preneurial $b a$ has internal and external boundaries which the preneurs transition. At the time of starting the Preneurial Agency process the (entre) preneur is located externally to the institutional boundaries, and (intra) preneur internally within them. As the process progresses the (entre) preneur transitions to become an (intra) preneur and institutional actor.

The process of Preneurial Agency is described in detail in Chapter 6, using participant comments. Each of the six stages is explained through discussing key concepts and properties related to that stage. The process is made specific to IT innovation and the creation of the IT artefact, through the unique necessity of having to combine software development resources. 


\section{PRENEURIAL AGENCY IN IT CREATION}

\subsection{Chapter overview}

In this chapter, the Grounded Theory of Preneurial Agency in IT Creation is described in detail. The process is presented in a narrative style that ties together the actions of preneurs and their interactions with collective agents as they go about creating IT innovations. To retain the preneurs' voices, interviewee comments and quotes are interwoven into the story and, where required, are supported, enhanced, and reflected upon through the commentary of the collective agents that aid the preneurs in their actions. In addition, extant literature and scholarly commentary is woven into the narrative to enhance the story and provide greater depth and clarity to the discussion.

The narrative has a clear beginning, middle, and end that are sequenced in time. The story starts by describing the actions of the preneur at the stage of Designing the innovation and associated business model. It then progresses to how the preneur goes about Establishing the preneurial $b a$ and Acquiring the resources required to transform their innovations into tangible realities.

The middle stages Guiding and Validating describe how the innovation starts to take a tangible form. The actions of the preneur are described, and interviewee comments are used to illustrate how the preneur guides the actions of the collective agents. Through this collective agency, resources are combined according to the design blueprint established in the first stage of the Preneurial Agency (PA) process. Once the first beta prototype of the IT artefact is created, the preneur is able to validate assumptions and improve the design concept.

As they journey through the PA process, the preneurs' agency is diluted with that of the collective agents and, over time, their agency is overtaken by that of the collective. The end stage, Extricating, describes how the preneur acts to withdraw $\mathrm{him} /$ herself from the innovation specific PA process, so they can move on to their next venture or focus on their role as an institutional actor. 
The Grounded Theory of Preneurial Agency in IT Creation, associated concepts and properties described in this chapter are depicted in Table 26.

Table 26: Grounded Theory of Preneurial Agency in IT Creation

\begin{tabular}{|c|c|c|c|}
\hline BSP & Sub-Category & Concept & Properties \\
\hline \multirow{9}{*}{ 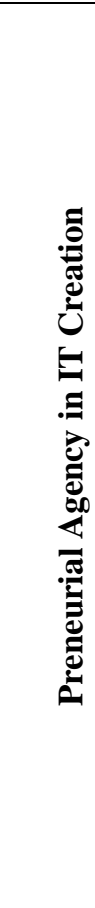 } & \multirow[t]{2}{*}{ Designing } & $\begin{array}{l}\text { Architecting the } \\
\text { road map }\end{array}$ & $\begin{array}{l}\text { - Innovation } \\
\text { - Business model }\end{array}$ \\
\hline & & Leveraging & $\begin{array}{l}\text { - Prior knowledge } \\
\text { - Network relationship }\end{array}$ \\
\hline & Establishing & $\begin{array}{l}\text { Establishing the } \\
\text { Preneurial } b a\end{array}$ & $\begin{array}{l}\text { - New institution (Start-up) } \\
\text { - Internal project team }\end{array}$ \\
\hline & \multirow[t]{2}{*}{ Acquiring } & $\begin{array}{l}\text { Addressing skill } \\
\text { gaps }\end{array}$ & $\begin{array}{l}\text { - Acquiring software } \\
\text { development expertise }\end{array}$ \\
\hline & & Sharing the vision & - Information asymmetry \\
\hline & Guiding & $\begin{array}{l}\text { Combining } \\
\text { preneurial and } \\
\text { collective agency }\end{array}$ & $\begin{array}{l}\text { - Additive impact } \\
\text { - Problem solving } \\
\text { - Knowledge conversion }\end{array}$ \\
\hline & Validating & $\begin{array}{l}\text { Proving and } \\
\text { improving }\end{array}$ & $\begin{array}{l}\text { - Beta, piloting } \\
\text { - In an agile and adaptive } \\
\text { manner }\end{array}$ \\
\hline & \multirow[t]{2}{*}{ Extricating } & Appropriating & - Preneurial rent \\
\hline & & $\begin{array}{l}\text { Diluting \& } \\
\text { Withdrawing }\end{array}$ & $\begin{array}{l}\text { - Ownership } \\
\text { - Control } \\
\text { - Transform } \\
\text { - Oneself (moving on) }\end{array}$ \\
\hline
\end{tabular}

Table 26 provides a reference point for the reader and places the evolving narrative into context. The chapter is structured into six main sections with each section corresponding to a stage of the PA process

\section{Chapter contents}

6.2 A Grounded Theory of Preneurial Agency in IT Creation

6.3 Designing

6.4 Establishing

$6.5 \quad$ Acquiring

6.6 Guiding

$6.7 \quad$ Validating

$6.8 \quad$ Extricating

6.9 Chapter summary 


\subsection{A Grounded Theory of Preneurial Agency in IT Creation}

The Grounded Theory of Preneurial Agency in IT Creation is a social processbased theory. The theory looks at the actions the preneur undertakes to create IT innovation and how they unfold over time in six definable stages: Designing; Establishing; Acquiring; Guiding; Validating and Extricating. It has two primary constructs Preneurial Agency and Collective Agency which when combined together within a social structure called the preneurial $b a$ creates IT Innovation.

The Grounded Theory of Preneurial Agency in IT Creation comprises six theoretical propositions (which are provided as recommendations for practice and discussed in detailed in Chapter 8, section 8.5.2):

1. The preneur will undertake actions to give initial form to the vision.

2. The preneur will undertake actions to establish the preneurial $b a$.

3. The preneur will undertake actions associated with articulating and sharing the vision, to attract and acquire the required resources.

4. The preneur will undertake actions that show the way to collective agents and guide their actions so that they can combine the resources into new combinations to make the innovation tangible.

5. The preneur will undertake actions to demonstrate, validate and improve the innovation in an agile and adaptive manner.

6. The preneur will undertake actions "at some point" that seek to remove him/herself from direct, hands-on involvement with the innovation and its associated process.

Each of these theoretical propositions relate to a stage of the Preneurial Agency process as developed within this Chapter. 


\subsection{Designing}

The foundation action within the Grounded Theory of Preneurial Agency in IT Creation is the development of a high level design for the innovation. The preneur must take his/her preneurial vision as described in Chapter 4, section 4.5.1 and make it explicit in some rudimentary form, such as sketch, model, flow chart, document, story, in order to communicate it to collective agents.

The word "must" is used purposively; in order to secure the services of the collective agents and guide their actions to make the IT innovation a tangible reality, the preneur must be able to share and communicate his/her knowledge of the innovation concept, its benefits, and development requirements.

During this stage, the preneur architects a road map which establishes the high level parameters of how they are going to undertake his/her preneurial vision and make it reality. The road map is more than just a rudimentary vision of the innovation; it extends to the business model and structures needed to acquire and combine the necessary resources to develop the innovation.

In designing the architectural roadmap, the preneur leverages his/her personal networks, prior knowledge, and personal experiences. These actions are underpinned by the preneur's self belief, commitment, and focus. The concepts and properties associated with the Designing stage of the PA process are shown in Table 27.

Table 27: Concepts and properties related to the stage of Designing

\begin{tabular}{|c|c|c|c|c|c|}
\hline \multicolumn{6}{|c|}{ The Preneurial Agency Process in IT Creation } \\
\hline Designing & & Acquiring & Guidin & Validating & Extricating \\
\hline $\begin{array}{l}\text { Stage } \\
\text { (sub-category) }\end{array}$ & \multicolumn{5}{|c|}{ Designing } \\
\hline Concept & \multicolumn{3}{|c|}{ Architecting the road map } & \multicolumn{2}{|c|}{ Leveraging } \\
\hline Properties & \multicolumn{3}{|c|}{$\begin{array}{l}\text { - Innovation } \\
\text { - Business model }\end{array}$} & \multicolumn{2}{|c|}{$\begin{array}{l}\text { - Prior knowledge } \\
\text { - Network relationships }\end{array}$} \\
\hline
\end{tabular}


The IT artefact is seen as being created through the actions of either the (entre) or (intra) preneurial actor. The actor, the preneur, is an individual who may previously have been labelled an entrepreneur or intrapreneur, but has, at some point on their journey to create their respective innovations, become an institutional actor.

The preneur may have started out as an external (entre) preneur or as an internal (intra) preneur, but in either situation they have given form to his/her entrepreneurial vision through developing the conceptual design for the IT innovation and then undertaken actions to create their innovative idea and make it a tangible reality.

\subsubsection{Architecting the road map}

\subsubsection{The innovation}

When developing the high level design for their IT innovation, the preneur becomes the architect of a road map that acts as a blueprint for the journey they seek to embark on. The preneur does not need to have deep IT-based technical knowledge, as evidenced by interviewee (I-5) who openly credits herself and her business partner with the origination of the idea and the underlying business solution:

We definitely invented the idea; we came up with the idea...a solution for businesses (I-5).

But as interviewee (I-5) further comments, she did not personally need to have a detailed knowledge of IT:

I really had no idea that I could be involved in making software, I thought that was for people who were trained in that.... I cannot code, but I can map out flowcharts and I can map out needs. This is what the company needs, and this would be the ideal solution (I-5). 
In this case, these flows charts became a blueprint, a boundary object that interviewee (1-5) could share with software developers in the later stages of the PA process. A boundary object in the form of a tender provided the triggering event which initiated the innovation design and development associated with the IT-based innovation of interviewee (I-10).

Interviewee (I-10), who was classified as an intrapreneur when designing his respective innovation, was similar to interviewee (I-5) in that he also did not have a deep IT-based technical knowledge. This participant was engaged as a business analyst at the time of conceptualising his innovation. The triggering event for this participant was the release of a tender by an external funding agency. The participant saw an opportunity to respond, through the innovative use of open source tools, which were not yet used for the specific application within the geographic region and context the tender addressed.

Such triggering events push or pull an individual into entrepreneurship and may originate from either inside or outside the institution (Schindehutte, Morris, and Kuratko, 2000). According to Ireland, Kuratko, and Morris (2006), the greatest stimulus for initiating entrepreneurial behaviour and entrepreneurship comes from the external environment.

External events triggered the preneurial activities of interviewees (I-5) and (I-10). Changes to the external environment and technology associated with social networking provided an opportunity for interviewee (I-5); and the release of an external tender by a funding agency was the trigger that motivated interviewee (I10) to become a preneur.

These triggers spark the preneurs' imagination into action and they start to envisage what the (entre) preneurial opportunity and innovation may look like. At this point in the PA process, the preneur does not see the innovation in all its detail, but sees it in broad conceptual terms. As interviewee (I-4) comments: 
I did not see the detail when I started, I saw the finished..., I saw the end goal, and from the end goal as you precede down the path you had challenges within challenges (I-4).

This view of the preneur as someone who sees the broad conceptual picture is supported by a collective agent, interviewee (I-19) who played a critical role in taking the innovative design proposition articulated by interview (I-17) and embedding it into the software architecture and development that enabled the innovation. As this interviewee comments:

That is what is different between us and the big picture people - it is like the story where you are cutting a path through the jungle and you give instructions to the person ahead to chop down that bush, and the leader goes up a tree and says we are in the wrong jungle. They have a different perspective; we need to know how to make it and do it, they need to know the much bigger picture (I-19).

The big picture not only relates to the innovation design but also to the potential business model as described in the next section 6.3.1.2.

The innovations discussed by interviewees covered a wide-spectrum ranging from enterprise-based Information Systems, hosted web-based solutions and Information and Communication Technology based-solutions. A number of the solutions required the establishment or modification of hardware-based infrastructures to support the operation of the innovation, while the remainder utilised existing infrastructure as shown in Table 28. 
Table 28: Innovation Design and Development Requirement

\begin{tabular}{|l|c|c|c|}
\hline Innovation Description & $\begin{array}{l}\text { Software Design } \\
\text { \& Development } \\
\text { Required }\end{array}$ & $\begin{array}{l}\text { Infrastructure } \\
\text { Design \& } \\
\text { Development } \\
\text { Required }\end{array}$ & $\begin{array}{l}\text { Hardware } \\
\text { Design \& } \\
\text { Development } \\
\text { Required }\end{array}$ \\
\hline Online diagnostic tool & $\checkmark$ & $\mathbf{x}$ & $\mathbf{x}$ \\
\hline $\begin{array}{l}\text { E-learning fibre optic infrastructure } \\
\text { development }\end{array}$ & $\checkmark$ & $\checkmark$ & $\mathbf{x}$ \\
\hline Broadband usage meter & $\checkmark$ & $\mathbf{x}$ & $\mathbf{x}$ \\
\hline Hosted graphics database & $\checkmark$ & $\mathbf{x}$ & $\mathbf{x}$ \\
\hline $\begin{array}{l}\text { Social networking based online promotions } \\
\text { solution }\end{array}$ & $\checkmark$ & $\mathbf{x}$ & $\mathbf{x}$ \\
\hline Hosted online survey solutions & $\checkmark$ & $\checkmark$ & $\mathbf{x}$ \\
\hline Website and data-base solutions & $\checkmark$ & $\mathbf{x}$ & $\mathbf{x}$ \\
\hline $\begin{array}{l}\text { Web-based accommodation availability and } \\
\text { booking system }\end{array}$ & $\checkmark$ & $\checkmark$ & $\mathbf{x}$ \\
\hline E-payment system & $\checkmark$ & $\checkmark$ & $\mathbf{x}$ \\
\hline E-learning solutions & $\checkmark$ & $\mathbf{x}$ & $\mathbf{x}$ \\
\hline Banking and loan management system & $\checkmark$ & $\checkmark$ & $\mathbf{x}$ \\
\hline Web-based accountability system & $\checkmark$ & $\mathbf{x}$ & $\checkmark$ \\
\hline Wireless communication solutions & $\checkmark$ & $\checkmark$ & $\mathbf{x}$ \\
\hline $\begin{array}{l}\text { Data capture device for Geographical } \\
\text { Information Systems (GIS) }\end{array}$ & $\checkmark$ & $\mathbf{x}$ & $\mathbf{x}$ \\
\hline Banking solutions & $\checkmark$ & $\mathbf{x}$ \\
\hline E-learning solutions & & $\checkmark$ & \\
\hline Banking / Investment solutions & $\checkmark$ & $\checkmark$ & $\checkmark$ \\
\hline
\end{tabular}

Only one innovation, the data capture device for Geographical Information

Systems as shown in Table 28 involved the preneur designing and creating new hardware, whereas all the innovations required the designing and development of new software-based solutions. Detailed descriptions of the innovations that were initiated and progressed by the interviewees have been excluded from the narrative in this chapter. This is done partly to maintain interviewee anonymity and partly to retain focus on the actions of the preneur, as opposed to the telling the story of the innovation. As Stevenson and Jarillo (1990) and Shane (2003) stress, the opportunity and innovation are devoid of agency. 


\subsubsection{The business model}

The preneur not only needs to conceptualise his/her understanding of the innovation but also to develop a view as to how they are going to go about creating the IT artefact. For interviewee (I-10) he thought the best way forward was to build his business model around open source technologies.

The open source community provided access to software tools and applications as well as marketing networks that this preneur (I-10) could not afford to replicate. A similar collaborative based business model was adopted by interviewee (I-5) in that she did not seek to develop her own sales and marketing channels, but to build partnerships and leverage the resources of existing networks.

Such partnering strategies are highly recommended within the IT industry, with Van de Ven $(1993 ; 2005)$ being a leading proponent of such collaborative business models which he refers to as "running in packs". Van de Ven (1993; 2005), for instance, views technology innovation as fundamentally a collective process of building an infrastructure that reduces the time, cost, and risks for each participating actor; each actor-firm is advised to build on his/her own distinctive competencies and become nodes in value chain networks.

This stance is reinforced through a study by Cho and Mathiassen (2007) who investigated a telehealth innovation that provided remote medical assistance to stroke patients in a network of collaborating hospitals. The innovation failed to become firmly established beyond the initial pilots. This failure, the authors concluded, was due to the innovators paying little attention to developing a sustainable, long-term business model for investments, rewards, and expenses across the participating hospitals and lack of collaboration and coordination among major stakeholders.

The experience and outcome as reported by Cho and Mathiassen (2007) is similar to that described by interviewee (I-1). A partnering business model was 
envisaged from the outset; however, while the partnership enabled the creation, it also contributed to its demise:

The partnership has dissolved itself, this is one of the reasons that the ... has not taken off. They promised us our first 150 clients (I-1).

Compromises to the business model came not only from external parties but also arose internally within the institution. To obtain the necessary institutional support and buy-in to create the innovation, the (intra) preneur may have to make compromises that endanger the viability of the envisaged business model:

The problem is fitting that into our institution we made some bastardisation to it... and the vehicle we used was ... and that was probably one of the weakest points. But then again I am a realist and I have to make compromises to get things done sometimes (I-1).

For interviewee (I-1), then, his institution was an enabling structure for the creation of the IT innovation, but at the same time it required them to compromise his design. The Designing stage establishes the base foundations for the innovation. The impacts from many of the decisions that the preneur makes in this stage of the PA process will only be known at the later Validating stage.

When making these decisions during the Designing stage, the preneur will draw upon and leverage his/her prior experience and knowledge. They do so through the action of leveraging; leveraging both his/her prior knowledge and personal networks to create the IT innovation as described in the following section 6.3.2.

\subsubsection{Leveraging - prior knowledge and network relationships}

The (entre) preneur requires a variety of different skills such as negotiating tactics, the ability to innovate, and skill in the less glamorous aspects of business management such as inventory management and quality control (Casson, 1982). 
New venture actors such as (entre) preneurs are also skilled in leveraging their personal networks in order to obtain resources initially outside their reach and obtain information that they are not aware of through intermediaries (Burt, 1992). How (entre) preneurs manage their network relationships and extract maximum value from the relationships can be crucial to the outcome of their innovation efforts (Burt 1992; 2005).

The preneur when designing the innovation and deciding how to go about the task, draws upon his/her prior knowledge and personal networks so as to inform their actions. If (entre) preneurs possessed the same beliefs and information as everyone else then there would be no (entre) preneurial opportunity (Shane and Cable, 2002).

\subsubsection{Leveraging - prior knowledge}

The personal knowledge and networks are different for each preneur, as is the degree to which they may seek to leverage these resources. When describing how her innovation originated, interviewee (I-5) makes reference to how she drew upon and leveraged experience gained from custom software development for a previous business she and her partner had established:

So the initial foray into technology came with the ... company, we really needed some sort of technology to manage our payments and our collecting customer information and managing customer bookings, so we actually looked around for different vendors and could not find anything that would work, so we custom made our own software just for our company... Prior to that, I really had no idea that I could be involved in making software, I thought that was for people that were trained in that (I-5). 
This prior knowledge, then, gave interviewee (1-5) the skills and confidence to progress the creation of her new IT web-based innovation. As she concedes:

We learned a lot through that...well it didn't necessarily go well, we made lots of mistakes, but I learned that it was something that I could be involved in (I-5).

In respect to how he drew upon and leveraged his prior personal knowledge, the story told by interviewee (I-10) is very similar to that of interviewee (I-5). When responding to a tender, interviewee (I-10) saw an opportunity to respond with an innovative Open Source based solution. At the time, he had a basic understanding of, and experience with, Open Source technologies:

In 2003 I knew a bit about Open Source, not a lot though... I had been using Open Source technologies but I'd been using them in the past to make, to create bespoke solutions (I-5).

The interviewee, (I-10), had enough understanding of the Open Source technologies to know that it provided a possible solution, on which he could base his design. Recognising that his understanding was limited the interviewee set out to increase his understanding:

So when this came about I didn't actually know that much about how the dynamics worked of Open Source but I knew I should find out more and it had potential in the context of what... was looking for. So I started investigating Open Source and how mature it was within the...environment, and it wasn't that mature (I-10).

Both interviewees (I-10) and (I-5) used their personal knowledge gained from prior experiences as a critical aid in designing their respective innovations. Such personal knowledge comes either from particular educational training or from 
professional experience and can be either explicit or tacit (Dew, Velamuri, and Venkataraman, 2004).

Differences in people's personal knowledge, and in particular the differences in knowledge held by (entre) preneurs is at the heart of Dew et al's. (2004) entrepreneurial based theory of the firm. These authors maintain that the creation of new routines, innovations, and firms is explained in part through different people, knowing different things.

Simply, if everyone knew the same thing, there would be no differences and if there are no differences there are no entrepreneurial opportunities, and therefore no entrepreneurship. Entrepreneurship relies on the entrepreneur having different personal knowledge, to other people around them.

The (entre) preneur's personal knowledge comes not only from prior educational training or professional experience as focused on by Dew et al. (2004), but is also obtained through personal networks. In instances where the preneur does not have the specialist knowledge needed, they will seek to acquire it from others, using their personal and professional networks.

\subsubsection{Leveraging-network relationships}

Within this research, examples of how preneurs leverage his/her personal and professional networks range from obtaining business advice on how they should proceed, to getting input on what features the innovation may need to have and how best to position the innovation to meet perceived needs.

In interviewee (I-5)'s case, a friend provided critical information which helped clarify her thinking and provided a potential way forward for the idea and how to position it as a business solution: 
We kind of discussed it with our friend at....and that is what put the idea into our head...he was probably the one that inspired us to think about a solution for business (I-5).

Seeking advice and knowledge from friends was also important to interviewee (I3), he describes the benefit to him, as like have a second brain which allows him to see things differently from how he would normally see them.

It is like having a second brain to deal with these issues, because quite often if you are dealing with something yourself, you know you may neglect some more far flung ideas if you like, but sometimes those ideas turn out to be quite valuable (I-3).

These two preneurs, interviewees (I-5) and (I-3) leveraged their personal relationships to provide them with new knowledge and to enable them to see things differently through somebody else's perspective. In other instances, the preneur sought to increase their understanding of an issue through leveraging their networks.

In the case of interviewee (I-23), an (intra) preneur who had a technical background and role, tapping into personal and professional relationships provided a mechanism to understand the business and user requirements in greater depth:

I could talk to people and then almost immediately translate it into how we could come up with the technical solution to it, if more clarification was needed I would go back to that person or the other developer that I had (I-23).

Like the previous examples, interviewee (I-23) supplemented his own personal knowledge and understanding with the different knowledge that was held by 
others. A further example of relationship leveraging is provided by interviewee (I-16), this time from the collective actor's perspective who was asked by a family friend interviewee (I-17), to meet up with him, and help him work through some business issues he was having.

So I went and talked to him, and I reasonably quickly saw that he's very smart and very inventive and can do all this electronic stuff, so we sort of sat around and... I said to him I think you could expand this machine that you're making 'cos it's quite restrictive in what it does... it's got a very limited audience (I-16).

In this instance the collective agent used his personal knowledge to comment on the innovative idea itself, what its shortcomings were as he perceived them, and how its design could be potentially improved. From that point on, he became the founding investor and personal mentor to interviewee (I-17).

Actors such as interviewee (I-17) and the other preneurs in this study are connected with collective agents through a variety of social and economic relationships, constituting what Gulati (2007) calls a social network. Such social networks are described by Lavie (2007) as enduring patterns of relationship among interacting social actors.

In the case of interviewees (I-16) and (I-17) the enduring relationship extended beyond a simple extended family connection to a long term business relationship involving mentoring, and investment of both time and money.

The preneur is adding to his/her personal knowledge and social capital through leveraging their personal network of acquaintances. By leveraging their personal networks they are able to combine other people's knowledge and perspectives to enhance their own understanding and view of the innovation. 
The term "social capital" is used within the social networking literature, to describe the outcome of such interactions among social actors. Social capital can be broadly defined as the benefits that actors derive from their social relationships, (Coleman, 1988; Walter, Lechner, and Kellermanns, 2007). In the context of this research, the preneur through creating and leveraging his/her social capital, is in a better position to develop the design concept for their innovation.

This view of where the entre (preneur) adds to their own personal knowledge in order to design and create the innovation also aligns with the notion of distributed agency as advocated by Garud and Karnøe (2003). These authors maintain that technology innovation is not created through the (entre) preneur's agency in isolation, but rather a collective process involving entrepreneurial agency that is distributed across actors.

A similar collaboration based perspective is advocated by Van de Ven (1993; 2005) it can also be associated with the original work of Hayek (1945). As Hayek (1945) maintains, knowledge exists only in the dispersed bits of incomplete and frequently contradictory knowledge which all the separate individuals possess.

Through leveraging their network relationship the preneur is able access the knowledge and information helped by collective agents, and incorporate it with his/her own understanding so they are better able to design the innovation. The information flowing between the actors at this stage is mainly to the benefit of the preneur.

\subsubsection{Information Flow}

The information and knowledge flows mainly to the preneur, for them to make sense of and act upon. The preneur not only utilises his/her knowledge and experiences, but also draws upon personal and professional relationships to access knowledge they do not possess. 
The pattern of information flow between the preneur and collective agents within the Designing stage is depicted in Figure 19.

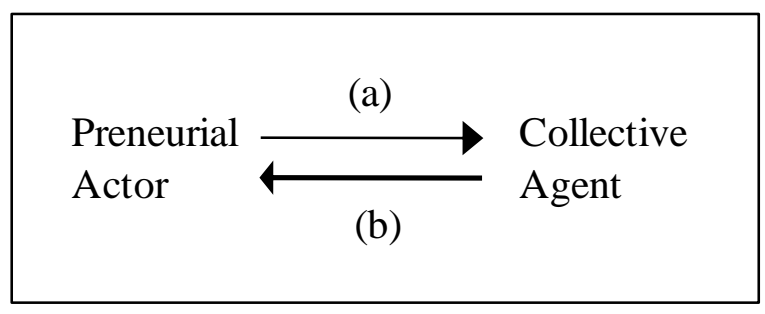

Figure 19: Information flow between the preneur and collective agent in the Designing stage of the PA process

In Figure 19, the smaller arrow (a) shows that the intrapreneur gives out less information that they receive within this stage; the large arrow (b) flowing from the collective agent to the preneur represents the greater flow of information flowing to the preneur. As suggested by interviewee (I-10)'s comment, "as long as the chief executive doesn't really find out that we're the pioneers with this thing then we should be able to deploy it here", the preneur does not always share everything.

In the later stages of the PA process the preneur must communicate and share some of his/her knowledge to the collective agents in order to acquire their services and guide their actions. While needing to share information, the preneur remains guarded in what they share as described in the next section, Establishing.

\subsubsection{In summary - Designing}

Within the Designing stage of the PA process, the preneur architects the road map for the innovation and associated business model and produces a conceptual design of the innovation which he/she uses to create the innovation. The flow of information and knowledge within this stage is mainly towards the preneur, for them to make sense of and act upon. The preneur not only utilises his/her prior knowledge and experiences, but also draws upon personal and professional relationships to access knowledge they do not possess. 
In the following stages of the PA process the preneur must communicate and share his/her knowledge with the collective agents in order to acquire their services and guide their actions. The next section, Establishing, focuses on the actions the preneur undertakes to establish new shared contexts so that they and the collective agents may interact with each other in order to create the IT innovation. 


\subsection{Establishing}

In the Designing stage the preneur develops a blueprint of the innovation and the business model; in the Establishing stage the preneur starts to give form to the enabling structures required to make the innovation a tangible reality. At this point the preneur needs to establish a shared space, so that they may acquire and combine the required resources needed to create the IT innovation.

The concepts and properties associated with the Establishing stage of the PA process are shown in Table 29.

Table 29: Concepts and properties related to the Establishing stage

\begin{tabular}{|c|c|c|c|c|c|c|}
\hline \multicolumn{7}{|c|}{ The Preneurial Agency Process in IT Creation } \\
\hline Designing & & ing & Acquiring & Guiding & Validating & Extricating \\
\hline \multicolumn{2}{|c|}{$\begin{array}{l}\text { Stage } \\
\text { (sub-category) }\end{array}$} & \multicolumn{5}{|c|}{ Establishing } \\
\hline \multicolumn{2}{|l|}{ Concept } & \multicolumn{5}{|c|}{ Establishing the "Preneurial $b a "$} \\
\hline \multicolumn{2}{|c|}{ Properties } & \multicolumn{5}{|c|}{$\begin{array}{l}\text { New institution } \\
\text { Internal project team }\end{array}$} \\
\hline
\end{tabular}

\subsubsection{Establishing the Preneurial ba}

The preneur must share his/her knowledge of the innovation design and road map with collective agents so that the tacit idea can become an explicit reality. This transfer of knowledge is carried out within shared contexts, a phenomenon referred to by organisational knowledge creation theory as $b a$. As described in Chapter, 2, section 2.6.10, the concept of $b a$ is extended and the notion of the preneurial $b a$ is developed to explain the structure the preneur establishes to aid them in their task. The preneurial ba may be a new institution or a new project team depending. 


\subsubsection{New institution}

The PA process requires structures. In some cases a structure precedes the innovation concept and enables the designing process; this was the case for interviewee (I-10) who read a tender document while employed as a business analyst, within an existing institution. In other cases the structure is formed specifically so that the innovation can be progressed, as in the case of interviewee (I-5) who established a new company to progress the creation and commercialisation of the innovation.

Interviewees (I-15), (I-8) and (I-17) all wanted to establish their own businesses but needed a product to fulfil that ambition:

I wanted to work with all my friends. The next thing that I thought was 'I wonder if it's possible to build a technology company where you could have a lot of fun, a company that keeps its promises and makes money', and that was kind of the idea that was rattling round in my head, and that's really where...came from (I-15).

Interviewee (I-8) formed a business with a business partner for lifestyle reasons and then used that business to further his preneurial ambitions.

Coming up with ideas was always what we were going to do...but what?...The idea hadn't happened. yet custom software is a great breeding ground for ideas because one person has a need for something and they can't find an off-the-shelf solution, then there's a need and is it resalable (I-8). 
The IT innovation at the heart of interview (I-8) was borne out of custom development software work the preneur did at a client site, as well as through leveraging experiences gained through working as a collective agent for someone else's innovation.

Like interviewees (I-15) and (I-8), interviewee (I-17) also wanted to establish and work in his own business. He had always envisaged the establishment of the company and the creation of something "cool" as a stepping stone and that he would sell the venture at some point:

Well, I think loosely it was that I wanted to build a company that I wanted to work in, and I wanted to do something kind of cool and build a company, and ultimately sell it (I-17).

In this case, the preneur did not want to establish just any shared space, but the right space that met the requirements of his design and one that he wanted to work within. This interviewee recounts an incident that occurred at a time when he was not the chief executive and he noticed that the culture had moved away from his original vision:

There was a departure from the vision, from our culture, and that was when...put up a notice in the toilet which informed people how to dispose of their toilet rolls (I-17).

Soon after that, (1-17) took over the CEO role and moved to re-establish the culture he desired. As he comment; removing the sign "was one of the first adjustments to the environment that I made" (I-17).

While the preneur, interviewee (I-17), visualised establishing and building a business, he did not see himself operating it: 
Certainly my vision wasn't to operate, to build that company and operate it (I-17).

This preneur (I-17) had focused his attention and vision on establishing a preneurial $b a$ and creating the innovation, he had not focused on what it was going to take to operate the institution that grew out of the preneurial $b a$.

The intuitions created by (entre) preneurs are seen to evolve through growth phases from start-up to early growth, to stable growth and on to maturity (Morris, 2001). The start up phase of evolution is often associated with an entrepreneurial venture receiving start-up funding from early investors or venture representatives, so that the start-up firm which is in its infancy has the necessary initial assets to develop and commercialise its innovation (Fichman and Levinthal, 1991).

The institution established by interviewee (I-17) went through the start-up phase using initial investment funding from interviewee (I-16). Going through such a start-up phase is considered by the Global Entrepreneurship Monitor (GEM) to be an essential requirement for a person to earn the title of (entre) preneur (Frederick and Carswell, 2001)

Research sponsored by the GEM (see Frederick and Carswell, 2001) to measure a countries level of entrepreneurial activity, asks potential respondents if they have been involved in any start-up activities so as to qualify them as being an (entre) preneur and being able to participant in the research. Respondents must answer affirmatively to one of the following two questions:

You are, alone or with others, currently trying to start a new business, including any type of self employment? Or you are, alone or with others, trying to start a new business or a new venture with your employer an effort that is part of your normal work 
Then the person must also answer affirmatively to:

Over the past twelve months have you done anything to help start this new business, such as looking for equipment or a location, organizing a start-up team, working on a business plan, beginning to save money, or any other activity that would help launch a business?

Only after a person answers the last question affirmatively and either the first two questions affirmatively are they then viewed as a "true" (entre) preneur by the GEM.

This perspective by the GEM on what makes a true (entre) preneur, combined with the views of Fichman and Levinthal (1991) and Morris (2001) provides the basis for associating the preneurial $b a$ to the start-up phase of the institution growth. It is in the start-up phase that the (entre) preneur establishes the institution, acquires the initial resources needed and undertakes activities to create the innovation. The focus is on creating the innovation, as before it can be commercialised and used it must be created first.

Where the external (entre) preneur establishes start-up institutions, the internal (intra) preneur typically establishes project teams.

\subsubsection{New internal project team}

When the preneur is operating within an existing company and seeks to use internal resources to progress the creation of the innovation, a new internal temporary substructure is required. Interviewees in the fourth group of interviews referred to this structure as a project team.

These teams are typically project based and temporary in nature. When a project or new opportunity arises team members are selected to work on the project based on their ability to contribute to that particular project. Some team members may 
work on the project for a short time, and others until the project is complete and then they will move on to new projects (Edmondson and Nembhard, 2009).

Comments made by interviewees within this study were consistent with Edmondson and Nembhard's (2009) portrayal of new project based product development teams. The internal project team was seen by interviewees (I-20) and (I-22) to be a temporary and dynamic structure focused on creating the innovation and, once the innovation was created, would disband. As interviewee (I-20), a collective agent, states:

Teams are built, plateau, and then slide away (I-20).

Interviewee (I-20) was an experienced project manager, as was interviewee (I-22). Both of these interviewees routinely interacted with (intra) preneurs and, by virtue of their functional role, played a key role in coordinating the internal resources needed to create IT innovations. Interviewee (I-22)'s description of the development team closely mirrored that of interviewee (I-20):

Projects by their nature are adaptive. They're new, they form quickly, they have a life, they end, they disperse...so they're just temporary structures by definition (I-22).

Such flux was the reality for interviewee (I-24). The nature of his business environment meant that much of his working career had involved going from one innovative project to another, as he explains:

(Company name removed) is all about delivering projects...The IT market's driven around projects, you know, these three, six month, nine month engagements (I24). 
This preneur, interviewee (I-24), continually established new project teams, so he and his institution could provide innovative solutions based around core IT platforms. Conversely, interviewee (I-1)'s involvement in IT-based innovative solutions was less frequent, so when he needed to obtain support to establish a project team and use institution resources he made a presentation to his institutions executive:

We got the executive to sit round a table...I did a presentation showing what we could do for them and they bought in straight away. So without that we would probably never have got the project off the ground (I-1).

In this way, interviewee (I-1) was able to secure support and approval to establish a new project initiative, within the wider institutional environment. While the innovation development can be nested within the wider institutional context, it can also be established as a separate entity within the local business unit context, as was the case for interview (I-23) who initially sought to establish a corporate sponsored initiative and use corporate resources, but acknowledges that:

The project was too large and they didn't have the resources to do it within the time available, so it was sort of left up to us (I-23).

The rejection at corporate level did not stop interviewee (I-23), however. He was able to secure the support of his head of department and establish the project within his business unit, as he explains:

I guess essentially there was a lot of buy-in from particularly...in terms of the projects we've got going on...we assign priorities to them and this was actually rated quite high (1-23). 
The (intra) preneurs who participated in this study did not establish the institutions or firms that they worked within at the time of pursing their PA. But through his/her PA they initiated the establishment of internal project teams. Such interplay between structure and IT innovation has previously been connected by Orlikowski (1992) with the diffusion and use of the IT artefact. Orlikowski's structuration model of technology is related to the Preneurial Agency process in the next Chapter 7, section 7.6.

In this research however, the focus is on the underexplored area of creating the IT innovation, it does not seek to explore the more popular research areas of diffusion and use of IT innovation.

\subsubsection{Summary, the Establishing stage}

To facilitate the later stages of the PA process, the preneur establishes a shared context, the preneurial $b a$. This creates a place and vehicle through which the preneur can acquire resources and guide the actions of collective agents to create the IT innovation. The preneurs associated with this research did this either by establishing new start-up institutions or new internal project teams.

In the next stage of the PA process, Acquiring, the preneur uses the outputs of the Designing stage and the establishment of the preneurial $b a$ to acquire the services of collective agents so they may aid him/her in creating the IT innovation. 


\subsection{Acquiring}

It is through the effective acquiring of resources, that (entre) preneurs and (entre) preneurial firms are able to develop and commercialise their technology-based innovations (Katila and Shane, 2005). The ability to leverage resources - that is to find and use resources more intelligently, more creatively, and in a more focused manner - is seen as one the most critical skills of successful (entre) preneurs (Morris, 2002). In particular, because every IT innovation requires some level of software development in order to become a tangible reality - the IT artefact is enabled by software - it is essential that IT- based preneurs must acquire software development expertise from others, should they not have it themselves.

In order to acquire the software development expertise, the preneur must share his/her vision of the innovative idea to secure the services of collective agents such as the software developer and later on guide the collective agent in their task. The preneur does not share his/her whole vision, as sharing some aspects of the business model, exit strategy, or personal motivations and viewpoints may be detrimental to acquiring the required resource and/or the long term achievement of their vision. Only those parts of the vision that the preneur deems necessary are shared, thus the exchange suffers from issues associated with information asymmetry as explained in this Chapter.

The concepts and properties associated with the Acquiring stage of the PA process are shown in Table 30.

Table 30: $\quad$ Concepts and properties related to the stage of Acquiring

\begin{tabular}{|c|c|c|c|c|c|}
\hline \multicolumn{6}{|c|}{ The Preneurial Agency Process in IT Creation } \\
\hline Designing & & Acquiring & Guiding & Validating & Extricating \\
\hline $\begin{array}{l}\text { Stage } \\
\text { (sub-category) }\end{array}$ & \multicolumn{5}{|c|}{ Acquiring } \\
\hline Concept & \multicolumn{3}{|c|}{ Addressing skill gaps } & \multicolumn{2}{|c|}{ Sharing the vision } \\
\hline Properties & \multicolumn{3}{|c|}{$\begin{array}{l}\text { - Acquiring software } \\
\text { development expertise }\end{array}$} & \multicolumn{2}{|c|}{$\begin{array}{l}\text { - Information } \\
\text { asymmetry }\end{array}$} \\
\hline
\end{tabular}


Software development expertise, whether the preneurs own or acquired from others, was acknowledged as an essential element by all the preneurs within the study. Other resources and types of collective agents are also commonly needed in the innovation process; for instance intellectual property (IP) lawyers and commercial lawyers:

Yes, I'll tell you what the starting point is these days - it is having a really good idea and having a good property lawyer and a really good contract lawyer (I-4).

We knew that we had a great idea, we want to patent it quite quickly...We knew this guy, we knew he was a patent lawyer, it was a good law firm, we signed up with them (I-5).

The differences between the commercial lawyer and the intellectual property lawyer were commented on by interviewee (1-12) who noted that a good commercial lawyer is required when "raising money or you want to sell a business to somebody". At such times, (1-12) believes, "a good transaction lawyer is better than an IP lawyer".

While preneurs such as interviewees (I-4), (I-5) and (I-12) stressed the importance of such collective agents, not all interviewees took this position. Interviewee (I10), for instance, who preferred to work as part of the open source community, did not seek to protect his intellectual property but chose to share it with others, and, reciprocally, to share in their IP. Similarly, for interviewee (I-18) the innovation process was about getting collective buy-in and adoption across the sector to the IT innovation, as opposed to protecting the commercial IP rights.

Acquiring the services of collective agents such as IP lawyers was important to only some of the preneurs within the study, some preneurs like interviewee (I-10) choose to work within the open source community where IP is shared. The IT artefact can be created without the preneur acquiring IP protections; such 
protections are more about the preneur's ability to secure a preneurial rent from his/her preneurial agency than about the creation of the IT artefact.

Due to these issues and for the purposes of conciseness and relevance, discussion in this section is focused on acquiring the essential resource of software development expertise in the IT creation process and does not cover issues associated with obtaining IP protections.

\subsubsection{Addressing skill gap - software development expertise}

While the research did not seek to quantify the level of software development skill held by preneurs, an assessment of their respective software development skill level can be made from evaluating comments from the interviews, and considering these in combination with the interviewees' backgrounds. The assessment of the preneurs' software development skill level along with the primary source of software development expertise is shown in Table 31.

None of the preneurs within the study provided any commentary that would tend to suggest that they viewed themselves as expert in software development practices. In fact, even the four preneurs who did comment that they had some software development expertise utilised the services of other software developers in the creation of their respective IT innovations to varying degrees. All of the fourteen interviewees classified as preneurs sought to acquire and utilise the services of experienced software developers at some point.

The extent to which the preneurs sought to acquire software development expertise varied widely, ranging from recruiting and/or using internal institutional resources, colleagues, and business partners to acquiring outsourced software development services from local software development teams or even from development teams located throughout the world. 
Table 31: Assessment of preneurs' software development skill level and primary source of software development expertise

\begin{tabular}{|c|c|c|}
\hline & $\begin{array}{c}\text { Preneurs' level of software development } \\
\text { skill }\end{array}$ & $\begin{array}{c}\text { Source of software development } \\
\text { resource }\end{array}$ \\
\hline$(\mathrm{I}-1)$ & None & External \\
\hline$(\mathrm{I}-3)$ & Some expertise & Own expertise \\
\hline$(\mathrm{I}-4)$ & None & External \\
\hline$(\mathrm{I}-5)$ & None & External (located internationally) \\
\hline$(\mathrm{I}-6)$ & Some expertise & Own expertise \& internal \\
\hline$(\mathrm{I}-8)$ & Some expertise & External \\
\hline$(\mathrm{I}-10)$ & None & External \\
\hline$(\mathrm{I}-12)$ & None & Internal \\
\hline$(\mathrm{I}-15)$ & None & Internal \\
\hline$(\mathrm{I}-17)$ & Limited & External \\
\hline$(\mathrm{I}-18)$ & None & External \\
\hline$(\mathrm{I}-21)$ & None & Colleague \\
\hline$(\mathrm{I}-23)$ & Some expertise & Internal \\
\hline$(\mathrm{I}-24)$ & Limited &
\end{tabular}

Because interviewee (I-4) did not have sufficient funds to acquire the level of software development expertise necessary to develop his web-based innovation, he sold part ownership of the preneurial $b a$ that he had established to facilitate the creation of the innovation. In other words, he traded ownership in return for software development services:

I went out and found an IT company, who I gave away 48 or $49 \%$ or something, so they paid for the technology development as their part, for a piece of the business... They had money and they also had a development team (I$4)$.

Funding the development of the IT innovation through trading ownership was part of interviewee (I-4)'s business model. Such a strategy was freely discussed and admitted to by interviewee (I-17) and is discussed in section 6.7, as part of the narrative on Extricating.

Where interviewee (I-4) brought a software development company into his venture as a business partner, interviewee (I-5) sought to include software development companies as part of her virtual team. She saw them as an integral 
part of the wider team. Unlike interviewee (I-4) she and her partner had the necessary funds to acquire the required software development expertise they needed without having to give away part ownership of their institution.

So we opted for very small company, two or three man shows where exactly the person that we were talking to is the person who was going to develop our product. By now they have basically become part of our team (I-5).

Interviewee (I-5) preferred to work with small developing teams to ensure she could talk directly with the person developing the innovation and communicate her vision of the innovation without interference or reinterpretation. She did not mind where the development teams were located and she was working with developers in New Zealand, Estonia, and Finland and would travel to meet with them when needed.

Even in instances where preneurs had some level of expertise in software development, they still needed to acquire and utilise additional expertise, due to advances in programming languages and the need to focus on wider aspects associated with the PA process. This was the case for interviewee (I-6):

I used to be the programmer...but then we brought in a programmer to...release me to do more of the business side of things (I-6).

Not only did interviewee (I-6) need to acquire and bring into his preneurial ba a programmer so that he himself could start to concentrate on the business side, he also needed someone who had more expertise in new software development languages:

One of the challenges with programming is that languages have changed over the last few years...because of the new 
languages it is way more technical and we need more expertise to do it (I-6).

A similar transition occurred in the development of the innovation associated with interviewee (I-17). Initially this preneur was attracted to the software development ability of a young programmer who was able to use initiative and be flexible in the role.

What attracted me to him was his ability to hook into pretty much anything and have a reasonable amount of success. There with minimal guidance...he was pretty much a "no fear" kind of character (1-17).

The preneur, interviewee (I-17), further noted that the young programmer:

Was a good example of somebody who could talk to a customer and could write software, and that was the sort of broad base of understanding I think you need to begin with but he "expired" (I-17).

As the task became more complex and more specialised interviewee (1-17) needed the services of a highly experience software developer and software architect, and he recruited interviewee (I-19). As interviewee (I-19) recalls:

I was working for a UK company when (I-17) said "come work for me but we cannot probably pay you". I would rather enjoy life than make lots of money working in a job I did not enjoy (1-19).

Interviewee (I-19), attracted by the challenge and motivated by the opportunity to have some fun, joined interviewee (I-17) within his preneurial $b a$. 
The resource acquiring activities of both interviewees (I-17) and (I-6) can be best described as being at the micro level where they sought to attract the services of specific collective agents. Within the technology innovation domain, research has tended to focus on institutional entrepreneurship and institutional arrangements between institutions (Scott, 2008; 2010). The focus of such research is on the institutional entrepreneur and entrepreneurial institution and how they acquire institutional level resources, as opposed to the micro level resource acquisition of individual developers or small teams of developers.

The micro level view is best found within the entrepreneurship literature, which associates the (entre) preneur as someone who is skilled in acquiring resources with little. The ability to leverage resources - that is, to find and use resources more intelligently, more creatively, and in a more focused manner - is seen as one the most critical skills mastered by successful entrepreneurs (Morris, 2002).

This skill was adeptly demonstrated by interviewee (I-17) who was able acquire the services of a highly skilled and highly paid software architect, (I-19), despite probably being not able to afford to pay him. In order to enlist such collective agents to come and aid the preneur on his/her journey, the preneur must share their vision.

\subsubsection{Sharing the vision, information asymmetry}

At the point at which they share their vision of the innovation with collective agents, the preneur obviously has significantly more knowledge of the innovation, the business model, and the nature of the preneurial $b a$ they desire than do the collective agents. Such unequal information dispersion conforms to Akerlof's (1970) notion of information asymmetry.

Akerlof (1970) uses the automobile market to explain the asymmetry of information between seller and buyers and the distortion to the market price that occurs due to this imbalance. The seller, having owned the car for a period of time, has knowledge of the quality of the car and whether or not it is a "lemon", 
whereas the buyer does not have access to this information. As Akerlof states "an asymmetry in available information has developed: for the seller now has more information about the quality of the car than the buyers" (p. 489).

Within the PA process in IT Creation the preneur is the seller, and the collective agents are the buyers, of the entrepreneurial vision. The exchange is sealed with a transfer of labour, money, or knowledge. The preneur needs to secure the services of the collective agents at time in the process where there is much uncertainty and an imbalance of information and experience in the preneurial process as shown in the interviewee's comments.

Collective agents interviewees (I-14), (I-16), and (I-19) engaged with the entrepreneurial vision shared by interviewee (I-17). Interviewees (I-14) and (I-19) contributed their time and labour, while interviewee (I-16), as the founding investor and mentor, contributed time and money to aid the preneur interviewee (I-17) in the creation of the IT artefact.

Interviewee (I-14) was an experienced manager and professional management contractor at the time of joining in the preneurial $b a$ associated with interviewee (I-17)'s innovation. As the interview comments indicate, he joined at his own personal expense and the experience was costly in terms of lost earnings:

... would never have hired a contractor at the kind of rates I charge. So you have to want to do it at personal expense if you decide to do it...with three years hindsight, the...experience personally cost about a quarter of a million dollars (I-14).

Collective agent, interviewee (I-14) acknowledges that he "had not worked it all out then", indicating that, with hindsight and experience, he is now aware of how the process works, and that based on this knowledge he would be unlikely to do such a thing again. At the time, he bought into the vision of the innovation 
without having a true understanding of what it really entailed, and suggests that the preneur did not have much understanding either:

At the beginning I just thought it was a really cool idea, so I suppose that means I brought into the vision. I don't think they really had a vision at that stage, other than they had a really neat gadget and I think we could probably sell a few. In fact I think that was the extent of the vision. Arguably there never was much more than that (I-14).

Similarly, interviewee (I-16), the initial investor in the innovation, expressed that his initial understanding had been limited and in hindsight found wanting:

I had no idea it would cost as much as it was going to develop, and that was pretty open-ended and we should have been much more restrictive and I should have set some very strong guidelines about what was going to happen (I-16).

While the innovation intrigued interviewee (I-16), it was not the innovation itself that enticed him to become involved, but rather the preneur and the type of activities he was seeking to undertake:

I'm not a gambler, but I do think the only thing I would gamble on is people if you like. And I thought (1-17) was a very able person and he is a very able person, so I could see that, so I suppose I'm a bit of a judge of people's attributes and I could see that he was going to really work at it (I-16). 
At the time of interviewing this "very able person", the preneur interviewee (I17), was still living his vision of working in a company (preneurial $b a$ ) that he wanted to work in and having an adventure based around something that he had invented. The product innovation was a way for him to obtain his wider goals of owning his own business that he could work in. He was mindful of the type of resource he needed to acquire to create the innovation, while at the same time he is also aware to the type of agent he would like to see working in his preneurial ba:

It started off as a company that I wanted to work in...then obviously the vision has transpired a bit to be centred instead of around the company I want to work in but centred around the product or the mission that we set ourselves, which is to sell gazillions of... (I-17).

This desire to establish and work in a company of his own design and making was also a prime motivation behind the actions of interviewee (I-15):

Well, I decided "what did I want to do with my life?" First thing I wanted to do was I wanted to wear jeans and a tee shirt to work because I'd had a guts full of corporates $(\mathrm{I}-15)$.

This interviewee, (I-15), now wears jeans to work in a very successful publically listed company that he founded both he and his institution have a history of successfully innovating within the ICT industry. During the interview the preneur was candid in his comments about his initial struggle to acquire collective agents for his venture. As he was not in a position to pay much, this resulted in him initially hiring friends and applicants who weren't necessarily best suited for the role: 
There's a lot of people who are quite frankly...who aren't necessarily there because of their abilities, they're simply there because they need a job and you're the only person who'll give them a job (1-15).

You're not a particularly attractive proposition unless you can offer equity...A lot of businesses you can't or you don't want to or whatever. So you end up building teams with less than capable people, shall I say (I-15)

While interviewee (I-15) was happy to acknowledge this fact, many years after establishing and enacting his (entre) preneurial vision, it raises the question of how open he was in telling others at the time that he was building his venture with less than capable people.

While interviewee (I-15) did not comment on how open he was in his comments during that start-up phase, interviewee (I-3) was, and at the time of the interview he was still in the early start-up phase.

I have been very cautious especially when I was just starting on this project to basically tell as few people as possible what I was doing and tell the people who know what I am doing as little as I can (I-3).

There is much that the preneur does not share, and the collective agents at times participate at their own risk. As discussed in section 6.2.3, interviewee (I-10) did not share with his institution's Chief Executive that they would be the first institution to develop and adopt that specific innovation in their country; and interviewee (I-3) openly admits to telling as little as he could. 
This asymmetric flow of information between the preneurial actor and collective agent/s is depicted in Figure 20. The thinner arrow (a) represents the incomplete flow of information from the preneurial actor to the collective agent, with the thicker arrow (b) showing the unrestrained information flowing back the collective agent during the Acquiring stage of the PA process.

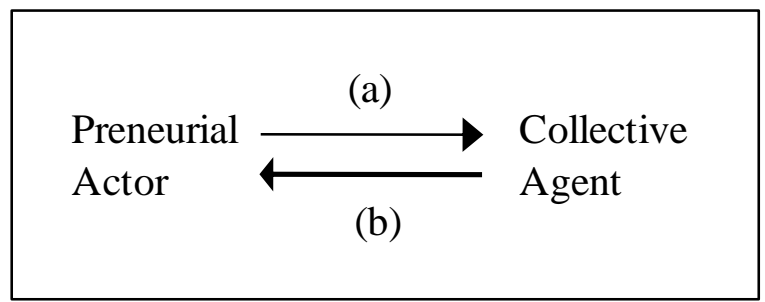

Figure 20: Asymmetric flow of information between the preneurial actor and collective agent

\subsubsection{Participation risk}

The topic of entrepreneurial risk within the field of entrepreneurship has historically been associated with the work of Knight (1921) who maintained that it is entrepreneurs who make decisions based in uncertainty and it is they who accept the consequences of their decisions. This view represents a point of divergence between Knight and Schumpeter; Schumpeter (1934) did not see the entrepreneur as a risk-bearer as he saw the risk lying with the capitalist who lends his funds to the entrepreneur. The entrepreneur only bore risk when they acted as their own capitalist.

Within the PA process, collective agents who give their labour and capital to the preneurial venture bear risk. They bear risk from having incomplete information, as the collective agent, interviewee (I-07), comments:

You (the preneur) need to tell us, what you've got, what you actually want to happen, not what you think we want to hear (I-07). 
By not having the complete information the collective agents may incur additional cost and even possibly impacts on his/her family life. As collective agent, interviewee (I-16) comments:

He (the preneur) talked me into giving up a quite a bit of money, and at one stage it was likely to break-up my marriage, as my wife was getting really upset with us putting money into this thing (I-16).

The preneur, as the seller of the vision, has more knowledge of the innovation and underlying business model than the collective agent who buys into the vision. Where Schumpeter (1934) sees risk residing with the capitalist who lends money to the (entre) preneur through issues of uncertainty, this research extends to viewing the collective agents bearing risk through issues of information asymmetry.

\subsubsection{In summary - Acquiring}

In order to create the IT innovation at the centre of their preneurial vision, the preneur must acquire the necessary services of the collective agents. When creating the IT artefact, the services of one specific collective agent, the software developer, is essential.

To enlist collective agents to aid the preneur in their journey of creation, the preneur must share part of his/her preneurial vision with them. This must be enough to secure collective agents' services, but at the same time the preneur may withhold information that they believe is not in his/her own best interest to share with the collective agent. The collective agents must then base their decision to participate on an imbalance of information, a phenomenon referred to as information asymmetry of the Akerlofian variety.

Once the collective agents have been recruited, the preneur must guide their actions in the respective tasks associated with creating the innovation. 


\subsection{Guiding}

Once the preneur has acquired the services of the collective agents, they must then guide their actions to create the IT innovation in accordance within their initial design concept. This interaction occurs within the preneurial $b a$ where collective agency of the preneur and those that aid them are combined together to create the IT artefact. In this stage, the preneur's tacit knowledge begins to be embodied into the emergent IT artefact and made explicit through the collective agency.

The (entre) preneur is often seen as the leader who, through his/her personality, power, and information, influences the process of (entre) preneurship (Miller, 1983). Within the PA process, the preneur may be the leader, or they may undertake a facilitative role and show the way. The description of a guide, as someone who may lead or show the way, is better suited to describe the actions of the preneur within the PA process as the preneur may not have the authority to lead.

During the process of taking the tacit idea and making it tangible, the preneur and the collective agents work together to solve the various problems they encounter along the way.

The concepts and properties associated with the Guiding stage of the PA process are shown in Table 32.

Table 32: $\quad$ Concepts and properties related to the stage of Guiding

\begin{tabular}{|c|c|c|c|c|c|}
\hline \multicolumn{6}{|c|}{ The Preneurial Agency Process in IT Creation } \\
\hline Designing & Establishing & Acquiring & Guiding & Validating & Extricating \\
\hline \multicolumn{2}{|c|}{$\begin{array}{l}\text { Stage } \\
\text { (sub-category) }\end{array}$} & \multicolumn{4}{|c|}{ Guiding } \\
\hline \multicolumn{2}{|l|}{ Concept } & \multicolumn{4}{|c|}{ Combining preneurial and collective agency } \\
\hline \multicolumn{2}{|l|}{ Properties } & \multicolumn{4}{|c|}{$\begin{array}{l}\text { - Additive impact } \\
\text { - Problem solving } \\
\text { - Knowledge conve }\end{array}$} \\
\hline
\end{tabular}




\subsubsection{Combining preneurial and collective agency}

The association of the (entre) preneur and (entre) preneurship as a special kind of labour, responsible for combining the factors of production is historically entrenched in the work of Batiste Say in the early 1800's (Etemad, 2004; Pender, 2009). A century later, another economist, Hawley $(1913 ; 1927)$, maintained that the factors of production only become economic when their results are combined by the (entre) preneur so that they may appropriate an entrepreneurial rent from their action.

\subsubsection{Additive impact and problem solving}

Two hundred years on, this fundamental process of combining resources is still practiced, with only the context changing. Through his/her agency, the preneur guides the collective agents in their actions and through combining their joint agency they create the IT innovation. Until this point, the innovation has been nothing more than an idea that has been expressed by way of a design produced in the Designing stages of the PA process:

Generally it starts with a concept paper which will have some text and some images that you've crafted yourself. This is what I have done anyway...And then...it's going to be PowerPoint, it's going to be...software mock-ups or website development screen shots...and it's that process of showing people the picture (I-12).

As interviewee (I-12) states, once a basic design has been developed, it is then a matter of showing people (collective agents) the picture, so that they can undertake the actions needed to create the IT innovation, and deliver on the preneur's vision. Interviewee (I-12) has learned that when seeking to get the best out of the software developers he uses, to motivate them and get them to rise to the challenge, he should pose a problem for the developers to solve: 
From years and years of managing technical people and understanding their drivers, their drivers are not financial generally. It's solving a problem. And it's sometimes the status that goes along with being the first to do something, or being the best at something...They'll crawl across glass to make that happen (I-12).

Similarly interviewee (I-18), a self confessed non-IT person, attributes her ability to innovate with IT to her ability ... to bring a diverse group of people together to explore an issue and then arrive at the correct solution. She calls this the "additive impact".

I'm not a technical person and it takes a long time for me to learn and understand a lot of the technicality...A talent that I have, that's somehow developed, is to be able to bring a diverse group of people together and to not know the right answer but to be able together to find the right way forward...So I'm a great believer in that additive impact really...But it depends on all parties being prepared to look for the best solution (I-18).

It is not only the preneur who places importance on their ability to solve problems; this sentiment is echoed by software developers involved in the process as explained by the collective agents, interviewees (I-7) and (I-19):

I mean the technology changes all the time anyway. But anyone can write software at the end of the day. It's actually solving the problem that's the hard bit. And I think it's difficult to be taught that, to be honest, you know, how to problem-solve (I-7).

I can see a problem and come up with a solution (I-19). 
Both of the interviewees (I-7) and (I-19) had acted as specialist software developers and had taken a vision shared by a preneur and converted it into software code. Through the additive impact, non-technical preneurs such as interviewees (I-8) and (I-18) can innovate with IT by drawing upon and using the skills of technical collective agents such as software developers (I-7) and (I-19).

The additive impact and the ability to problem solve is explained by Nonaka's Organisational Knowledge Creation Theory and subsequent four modes of knowledge creation: Socialisation, Externalisation, Combination, and Internalisation (SECI).

\subsubsection{Knowledge conversion}

Nonaka's (1994) Theory of Knowledge Creation was born out of an innovation development exercise associated with the new product development of an automatic home bread making machine. Like interviewees (I-12), (I-18) and the other interviewees in this study, Tanaka and her associates were not expert in all of the underlying processes needed to create the innovation. In Tanaka's case, the skill gap was in how to knead the dough correctly to make bread.

By watching the master baker at work kneading the dough, Tanaka's new product development team were able to see the master baker's tacit knowledge being explicitly expressed. Through identifying the "twist stretch" action, the development team were able to embed the now explicit knowledge into the technology innovation - the home bread making machine.

The example illustrates how the preneur and collective agents must work together, sharing their tacit knowledge, and, through the four modes of knowledge creation, embed their tacit knowledge into the new IT artefact. Such a perspective aligns with Orlikowski's (1992) recursive notion of technology whereby technology is created and changed by human action within given social contexts. 
While Orlikowski views technology as socially constructed by actors both through the different meanings they attach to it and how they use it, this research focuses on how IT innovation is created through the actions and interactions of the preneur and the collective agents within the preneurial $b a$. This interaction is described in Figure 21 using comments made by interviewee (I-15) which are set within Nonaka's dynamic model of knowledge creation.

Interviewee (I-15) established the preneurial $b a$, the company through which he created his respective ICT-based innovation. The preneurial $b a$ is depicted as the outer box within Figure 21; it is within the preneurial ba that the preneur guides the actions of the collective agents. Within the preneurial $b a$, are Nonaka's four modes of knowledge creation: Socialisation, Externalisation, Combination, and Internalisation (SECI) with comments made by interview (I-15) used to describe the knowledge conversion in the PA process.

Socialisation - the sharing of tacit knowledge, which is demonstrated by the example of one preneur who had established a "work hard, play hard culture" exemplified in the company motto of the time "kill more than you can eat" and "RIP...". The preneur shared these images and statements to socialise existing and new collective agents to the company culture.

Externalisation - the transfer of tacit to explicit knowledge, in this example the preneur wanted to send a clear message to his management team and through their actions to the rest of the collective agents. Through shaving their heads, a very explicit message was sent to all!

Combination - the process of converting explicit knowledge into more complex and systematic sets of explicit knowledge. In the example used here, the preneur had made a commitment to his collective agents that he would stand behind decisions they made, as if they were his own. He was called upon to honour that commitment and by doing so he gave rise to a story that was to become folklore within the company. 
Internalisation - the process of converting explicit knowledge into tacit knowledge so that new knowledge can be created is shown in the example where the preneur used the level of alcohol consumption to gauge the level productivity in the early days of the venture.

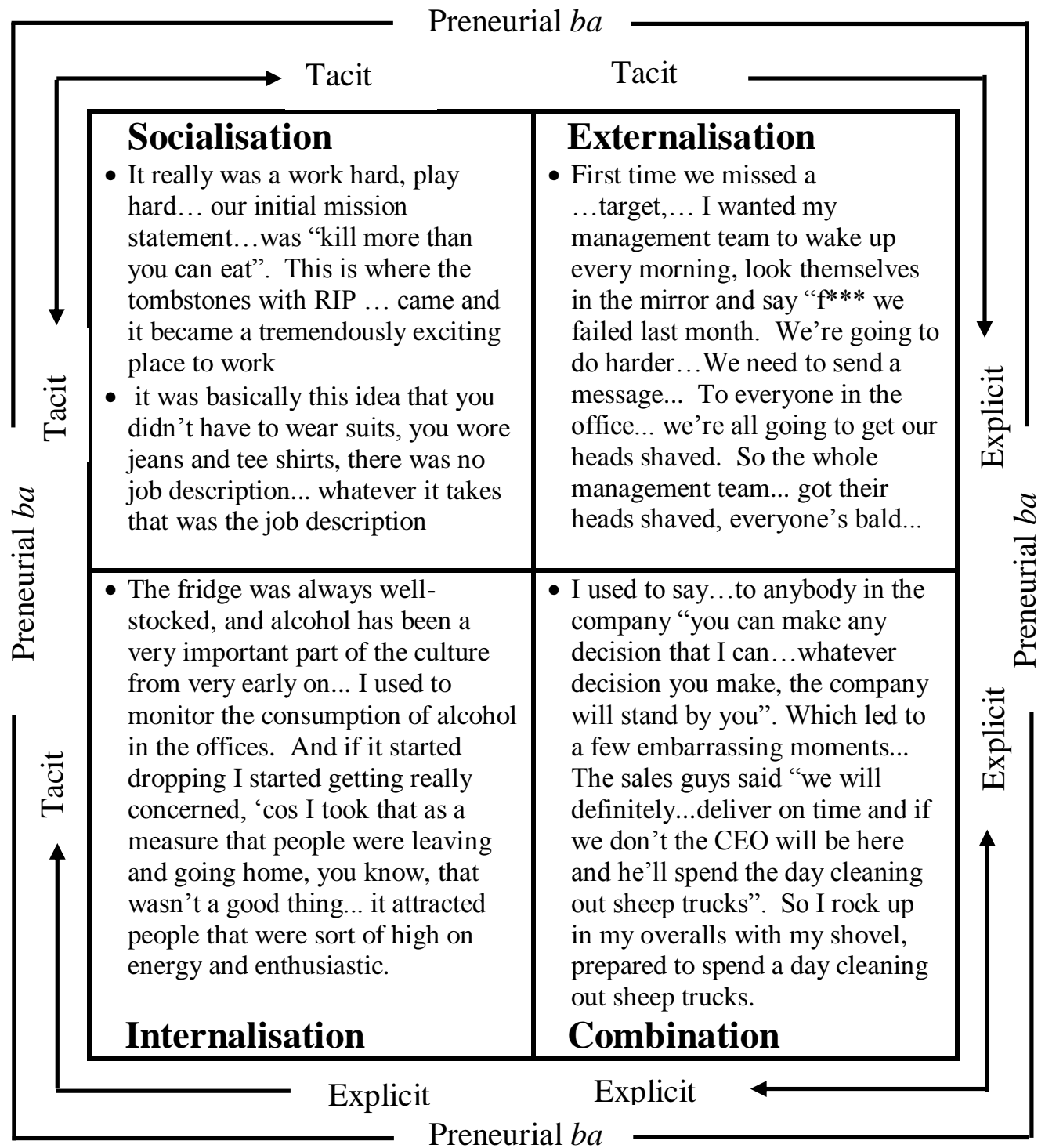

Figure 21: Examples of knowledge conversion within a preneurial $b a$ established by interviewee (I-15) 


\subsubsection{In summary - Guiding}

In this the fourth stage of the PA process, Guiding, the IT innovation starts to materialise through the combined agency of the preneur and collective agents. The preneur guides the actions of collective agents, so that that the outcomes are consistent with his early vision of the IT innovation. As they go about their tasks, the preneur and collective agents need to work together so that they can solve the numerous problems and issues that they encounter along the journey. This additive impact sees the tacit knowledge of both the preneur and collective agents combined together and embedded into the innovation.

With specific reference to the IT artefact, the preneur works with software developers to capture and embed their preneurial vision within software code.

In the next step of the PA process, Validating, the first tangible manifestation of the IT innovation is created, tested, and actual feedback obtained based on first use of the innovation. 


\subsection{Validating}

By guiding the actions of the collective agents and combining their agency with his/her own knowledge; the preneur is able to create a working prototype. Now that the preneur has a tangible expression of his/her innovative idea, they are able to use it internally and with trial users to validate initial assumptions. Through actual use they are able prove or disprove aspects of the initial design and build upon it where needed to improve the design concept.

When innovating with IT, it is best practice to act with agility (the ability to sense and respond swiftly to technical changes) and adopt agile development frameworks. This is done so that development activities can be managed in a quick and flexible way, where new features are able to be released to trial users so that feedback can be obtained.

The concepts and properties associated with the Validating stage of the PA process are shown in Table 33.

Table 33: Concepts and properties related to the stage of Validating

\begin{tabular}{|c|c|c|c|c|c|}
\hline \multicolumn{6}{|c|}{ The Preneurial Agency Process in IT Creation } \\
\hline Designing & Establishing & Acquiring & Guiding & Validating & Extricating \\
\hline \multicolumn{2}{|c|}{$\begin{array}{l}\text { Stage } \\
\text { (sub-category) }\end{array}$} & \multicolumn{4}{|c|}{ Validating } \\
\hline \multicolumn{2}{|l|}{ Concept } & \multicolumn{4}{|c|}{ Proving and improving } \\
\hline \multicolumn{2}{|l|}{ Properties } & \multicolumn{4}{|c|}{$\begin{array}{l}\text { - Beta, piloting } \\
\text { - In an agile and adaptive manner }\end{array}$} \\
\hline
\end{tabular}

\subsubsection{Proving and improving}

It is at the Validating stage of the PA process that the preneur has, for the first time, a rudimentary version of the innovation. To demonstrate the innovation and its features, it can now be used internally with selected early users:

So we first came out with a beta test, using a programme called... to demonstrate the process of... (I-4). 
The beta product allows the preneur and collective agents to trial the rudimentary vision and to obtain feedback from the early users and incorporate it into a refined design and incremental build process.

You put something out there... get the feedback and build on top of that (I-6).

In addition to obtaining feedback, at this point the preneur may also wish to be identified as being the first in a market, thus obtaining first mover advantages and visibly showing that they have something new and innovative:

We launched kind of a rudimentary version of what we are doing now within a month of that. So we had a product out there before anyone else (I-05).

The pilot was to first and foremost prove that...had a working system in...that people could come and visit and see (I-9).

Interviewee (I-9) stressed on a number of occasions that the pilot sought to do "the normal pilot stuff" but also, importantly, to demonstrate to their key market that the innovation was real and was capable of meeting the needs of users. The interviewee also commented that:

It was a technology implementation being managed...in an agile manner in an attempt to demonstrate...viable solution for New Zealand (I-9). 
The collective agent, interviewee (I-9), uses the word "agile" to describe the actions and behaviour of the preneur behind the innovation. This word is used by other participants (I-19), (I-20), (I-22) and (I-23) to describe the actions of the preneur and also specifically software developers involved in the PA process, see Table 34 .

Table 34: Interviewee comments related to acting in an agile way

\begin{tabular}{|l|l|}
\hline \multirow{4}{*}{ Agile } & \multicolumn{1}{|c|}{ Comments related to acting in an agile way } \\
\cline { 2 - 2 } & $\begin{array}{l}\text { We are now using agile developments to provide } \\
\text { incremental features all the time (I-19) }\end{array}$ \\
\cline { 2 - 2 } $\begin{array}{l}\text { We implemented that via an agile scrum implementation } \\
\text { (I-20) }\end{array}$ \\
\cline { 2 - 2 } $\begin{array}{l}\text { Agile means I want you to work really hard and do it very } \\
\text { quickly. Agile can mean they're following a framework } \\
\text { which is a formal framework of mostly technology } \\
\text { development. Agile can mean just being responsive (I-22) }\end{array}$ \\
\cline { 2 - 2 } $\begin{array}{l}\text { Being a fairly small unit we can be agile and sort of juggle } \\
\text { things quite nicely (I-23) }\end{array}$ \\
\hline
\end{tabular}

Within the IS domain, the term "agile" has specific meaning and is defined by Lyytinen and Rose (2006) as "the quality or capability of being quick moving and nimble" (p.183). With specific reference to IS Development (ISD) they define agility as “an ISD organization's ability to sense and respond swiftly to technical changes and new business opportunities" (p.183).

Interviewee comments in Table 34, on the ability to act incrementally, adaptively, and to juggle things, fit with Lyytinen and Rose's (2006) notion that agile system developers act quickly and nimbly in response to technical changes and opportunities.

\subsubsection{In a agile and adaptive manner}

The accelerated pace of software development coupled with the resulting time reduction in the development cycle has resulted in what Aoyama (1998) saw as a fundamental redesign of the software development process which he called the Agile Software Process (ASP). This refers to the process of architecture shifting 
from monolithic to modular, and the process of dynamics shifting from volumebased to time-based. This shift seeks to manage software development processes in an agile manner and in real time so as to manage dynamic behaviours within the development team.

Increasingly, software development process are tending to exhibit new forms of short cycle development processes that focus on: (a) completion speed, so as to react quickly and flexibly to environmental or market changes; (b) releaseorientated parallel prototyping, where prototyping is used to communicate with customers and obtain quick feedback; (c) adherence to a fixed architecture, in order to make parallel development possible; (d) negotiable quality, where product-based and process-based quality is traded off against fulfilling customer and user expectations; and (e) an ideal workforce, as time pressures increase reliance on top-notch developers is crucial (Baskerville and Pries-Heje, 2004).

The actions of the preneurs and collective agents, specifically the software developers within this research, were consistent with the notion of agility as accepted within the IS discipline. There was a focus on speed, prototyping, trading off priorities, and obtaining immediate initial user feedback.

Interviewee (I-19), the chief software development manager of the technology venture established by interviewee (I-17), used an agile software development technique known as Scrum within their innovation development process. They did this, to get new product features quickly into market and used by trial users so that feedback can be obtained:

We are now doing development cycles every two weeks, we use Scrum. There will be an engineering released every two weeks with a new feature, if we can't get something in that release we will allow it to slip into the next release (I-19). 
Through using the agile software development process and acting with agility interviewee (I-19) was able to quickly release a new feature to users. If they find they have attempted too many new features and additions in that release, they reprioritise some and move them into a future releases.

This interviewee, (I-19), combined the use of prototyping and agile frameworks so that, based on user feedback, they are able to continually prove or disprove something:

Prototyping often has been an enduring theme throughout the company's existence. Having an idea and doing something to prove or disprove it. It is easy to do in the agile framework where we are doing regular incremental releases and getting regular feedback (I-19).

Unfortunately for interviewee (I-6), he was not able to act agilely due to resource constraints. He lamented what it has cost him and acknowledged that if he could have done things again he would have ensured that he was funded to a level that would allow him to act in such a way:

We couldn't do that, or didn't do that. Because we were not funded, we were what is called bootstrapped and I would never do that again - if I want to execute properly I would make sure it is funded...

So I am still learning stuff about execution, and the problem with executing slowly is that others overtake you $(\mathrm{I}-6)$

The risks of executing slowly were well understood by interviewee (I-5) and with that in mind she choose to actively work with partners that had resources and established networks: 
I think we just need to move faster with this new business...because technology is changing very quickly... what we are doing the business has certain network effects I think. I think we need to move as quickly as possible to bring on as many businesses as we can to get our name out there to bring on partners. If we don't someone else will do it and it will be that much harder for us to succeed (I-5).

Interviewee (I-5), a self confessed non-technical person, did not use the words "agile" or "agile methods" but it is clear from her descriptions of her actions that she was acting with agility. She understood the need to move fast and release a rudimentary version to obtain a first mover advantage and to obtain user feedback. At the time of the interview she acknowledged that her company was:

...in closed beta stage, we are developing a product (and)

...we will launch it to the public in probably the first or second week of January. We have had clients but only clients that we have let into the system (I-5).

This preneur, interviewee (I-5), had clearly acted with agility, and at the time of the interview she could be seen to be in the Validating stage of the PA process. She was trialling a beta product with early users and fixing and improving the beta product before releasing the innovation publicly.

\subsubsection{In summary, Validating}

At the Validating stage of the PA process the preneur is able to validate and prove his/her original design concept through the demonstration and testing of a working prototype. Based on the feedback of early internal and external users, the preneur is able to make changes to improve the design where needed. 
Due to the pace of technology change, when innovating with IT it is best practice to act quickly and nimbly to technical changes and opportunities. This is not always possible due to resourcing constraints and may lead to situations where preneurs find themselves and their innovations being overtaken by others.

As the preneur moves through the PA process, his/her agency is increasingly diluted and combined with the agency of the collective agents they have acquired to aid them in their tasks. The dilution eventually reaches a point where the preneur's involvement is overtaken by that of the collective agents. Ultimately, preneurs will seek to extricate themselves so that they can move on to other challenges and activities. Extricating is the sixth and final stage of the PA process. 


\subsection{Extricating}

In the final stage of the preneurial process, Extricating, the preneur increasingly removes him/herself from the innovation specific tasks in order to be able to focus on the next innovation, the next preneurial opportunity, or to move back to an existing role or undertake additional duties as a collective agent within the wider institution.

The process of Extricating may start from the very first stage of the PA process, as the preneur dilutes his/her ownership and control so they can resource the venture and acquire the necessary collective agents to aid them in their journey. As the PA process proceeds, the collective agency starts to exceed that of the preneur and this allows the preneur to begin to withdraw. At times, however, events may occur that require the preneur to increase his/her personal agency relative to that of the collective agents. Such occasions, which may recur often throughout the PA process, require the preneur to re-engage and transform the preneurial $b a$.

At the time of extrication from an innovation specific PA process, the preneur may to seek to appropriate an (entre) preneurial rent in return for his/her agency.

The concepts and properties associated with the Extricating stage of the PA process are shown in Table 35.

Table 35: $\quad$ Concepts and properties related to the stage of Extricating

\begin{tabular}{|l|l|l|l|l|l|}
\hline \multicolumn{5}{|c|}{ The Preneurial Agency Process in IT Creation } \\
\hline \multicolumn{1}{|c|}{ Designing } & Establishing & Acquiring & Guiding & \multicolumn{1}{c|}{ Validating } & Extricating \\
\hline $\begin{array}{l}\text { Stage } \\
\text { (sub-category) }\end{array}$ & \multicolumn{4}{|c|}{ Extricating } \\
\hline Concept & Appropriating & Diluting and Withdrawing \\
\hline Properties & - Preneurial rent & $\begin{array}{l}\text { - Ownership } \\
\text { - Control } \\
\text { - Transform } \\
\text { - Oneself (moving on) }\end{array}$ \\
\hline
\end{tabular}




\subsubsection{Appropriating preneurial rent}

The exploitation of an (entre) preneurial opportunity requires the entrepreneur to believe that the expected value of the (entre) preneurial profit will be large enough to compensate for the opportunity cost of other alternatives and return a premium for bearing uncertainty (Kirzner, 1973; Schumpeter, 1934; Shane and Venkataraman, 2000).

The preneurs belief that they may appropriate a preneurial rent is continually challenged and reconfirmed throughout the PA process, and is often encapsulated within the Designing stage, as described by interviewee (I-5):

This company, the new company, is very much started with the concept that we will sell it, hopefully, and then you really do have to package it well from the start (I-5).

While envisaging a definitive end point, there are many milestones along the journey - both successes and failures - that may make the preneur and collective agents question their beliefs, if they shall ever get there, where the actual end point is, and if they will ever be able to appropriate a preneurial rent from the venture:

We've certainly had more successes than we've had failures. We're ahead in that way. Sometimes it doesn't look like that, you know, when the bank accounts at minus ...million dollars...and then you go "oh, is this successful”? Well, maybe... (I-17).

Such doubt as to if the opportunity to appropriate a preneurial rent is mirrored in comments by interviewee (I-6):

You have to have this sort of dream that you want to execute to and then you have to have that wherewithal to 
take knocks to get there, or just to keep going and maybe never getting there and just disbelieving falsely or whatever that you are going to get there. You also need to have the wins in there to keep the energy going (I-6).

The preneur's belief that they can appropriate a preneurial rent from creating the innovation, sustains him/her in their journey through the PA process. Such a perspective aligns with Bandura's (1996a) Theory of Human Agency and his view that personal agency is fuelled by persons belief of personal efficacy.

In the previous stages of the PA process, the resource acquiring and combining activities are undertaken prior to innovation having been created and tested. It is not until the Validating stage where the innovation is tested, proved, and improved that the uncertainty is reduced.

As Alvarez (2007) states, "entrepreneurs often must make resource coordination decisions that create entrepreneurial rents and rent appropriation decisions before the economic value associated with exploiting a market opportunity is known" (p. 428). Extending current theories of rent appropriations and theories of the firm, Alvarez (2007) proffers a theory of dual rent creation and appropriation.

At the heart of Alvarez's (2007) dual rent theory is the notion that the (entre) preneur faces a dual challenge of creating entrepreneurial rents and appropriating some of those rents. This challenge is exacerbated by the fact that the preneur must create the innovation at a time when the (entre) preneurial rents that might be created are unknown and unable to be determined with confidence.

(Entre) preneurs such as interviewees (I-3), (I-4), (I-5), (I-6), (I-12), (I-15), and (I17) will typically seek to appropriate an economic based (entre) preneurial rent in return for their agency and throughout the PA process they will act to protect this opportunity. 
As interviewee (I-6) comments:

It is about building the thing and selling it off completely (I-6).

This preneur was planning for, and envisaging, the time when he might be in a position to appropriate a substantial preneurial rent from his preneurial agency, and was very aware that he might need to draw upon the services of other collective agents to help in that process. He did not want to undervalue the IP and his own preneurial agency:

I just need to be smart enough to know that in one point in time I can't be the person negotiating our IP sale because I will undervalue it at that point as well; then my ultimate end goal to sell the business, I will have screwed up completely (I-6).

The (intra) preneurs (I-1), (I-18), (I-21), (I-23), and (I-24) were not a position to appropriate a preneurial rent associated with economic ownership of the resources, as the resources were owned by the institution. For them, the rewards were in job satisfaction, job recognition, promotions, and bonuses:

We did get rewarded through the professional performance review process (I-23).

And they'd provided me some amazing opportunities to grow some of my ideas internally and incubate them...I was amazingly empowered...They have given me a huge amount of financial opportunity and stability (I-24).

The creation of the IT innovation does not rely on the preneur or their institution appropriating a preneurial rent, it is belief that his/her PA will result in such an 
outcome that matters. The creation of the innovation often precedes any rent appropriation.

The preneur not only seeks to extract a preneurial rent from the innovation, but they also seek to extract his/herself from the process. As shown in the next section the preneur gradually withdraws from the specific PA process as the collective agency starts to exceed their agency. In addition, the preneur may have to dilute their ownership and/or control in order to overcome barriers.

\subsubsection{Diluting and Withdrawing}

\subsubsection{Ownership and control}

For the preneur, success is a moving target, a series of escalating and cascading, chasm-crossing events:

The chasm is far wider, than you ever imagined. You see it from a distance and you think it is just a little hurdle that I can just jump over when I get there... the first one you may be just able to jump across, and the next one you had to leap across, and the next one you may have the pole vault across and I guess get everybody in the framework of getting there (I- 4).

As the preneur crosses from one chasm to the next, and seeks to take the collective agents with them, they may need to sell part ownership of the innovation or preneurial $b a$, to fund his/her activities.

In the case of interviewee (I-5), from very early on she and her partner started diluting their ownership. She traded $1 \%$ of her company to the IP lawyer to fund their acquisition of intellectual property protection services. 
For the option of purchasing $1 \%$ of our company, they give us, I think, $\$ 30,000$ in legal fees free, no not free deferred. So, that in that respect they also became invested in us (I-5).

Interviewee (I-17) had continually sold off shares in his business - which equated to ownership control - to fund the PA process to a point where two directors of the business had become concerned for him and his opportunity to realise the appropriate level of rewards for his agency:

We've got two new directors that have come on recently and they're both independently said 'I'm actually really concerned for...because he's diluted himself and he hasn't got...the largest chunk of the company" (I-17).

However, interviewee (I-17) claimed that that was plan from the beginning. ....and my reply to that was, "Well, actually, you know, that was the whole idea. I'm not actually terribly worried about it, it doesn't motivate me". I think they understood that. (I-17).

This preneur knew from the beginning that he could not do it alone and would need to acquire the services of collective agents to aid him on their journey. For interviewee (1-17), that was part of the challenge and personal reward he got from his preneurial agency:

On one level it's the concept that people will give me money for something that I invented. That's pretty cool. And another one is that people want to come along with the adventure. And I think the biggest one is the adventure itself (I-17). 
This preneur, interviewee (I-17) equates the PA process as one big adventure, which he and the collective agents journey along. As shown in the next section, the adventure may involve the preneur having to transform him/herself and leave their old self behind.

\subsubsection{Transform}

Sometimes the extricating process is subject to recursive iterations, where the preneur may find it necessary to take back ownership or control or become more actively involved in the process.

To finance his original venture and the development of his ICT based innovation, interviewee (I-15) had to turn to international investors who took ownership control. During the PA process these investors went bankrupt in their core business and home market:

We were tracking to a business plan...throwing $\$ 20 \mathrm{M}$ or $\$ 30 \mathrm{M}$ at building a...and adding customers...Our owners went into Chapter 11, all of a sudden there was no money coming in (I-15).

Where some people may have seen themselves at the bottom of very large chasm, this preneur saw it as the catalyst for him to regain control:

So I stepped in. That was the first time I actually got shareholding control, so I bought the company for a dollar off the American courts, then I divided the shareholding up amongst four or five of my direct managers (I-15). 
The preneur sought to regain formal control of the preneurial $b a$; this was his personal preference. The PA process places emphasis on aspects of informal control and influence as opposed to formal control (this is discussed in section 6.5). Prior to this point, the preneur had been guiding the venture through influence.

From the bottom of the chasm, and point of bankruptcy where "literally we owed \$8M around town", interviewee (I-15) reversed the performance of his institution, to the point where it could be listed on the stock market as an Initial Public Offering (IPO). Yet again, he was transforming both himself and his institution while also extricating himself from the old in order to embark on the next phase.

This need for constant re/transformation is something that interviewee (I-17) also comments on:

So as the company reinvents itself, sometimes the people managed to make it and sometimes they didn't...unless they reinvent themselves as the company grows they tend to just fall off...

I'm quite surprised that I'm still there but I've managed to change what I want to do (I-17).

This preneur was able to reinvent himself many times throughout the PA process, yet, as he comments, many of the collective agents he acquired along the way to help him were unable to do so and "fell off" along the way.

While collective agents may fall off along the way, the preneur journeys on until such a point where they feel they are able to extricate him/herself so they may move to the next preneurial opportunity or focus on their role as an institutional actor. 


\subsubsection{Extricating oneself}

At the time of the interviews, all the (intra) preneurs involved in the study had removed or were in the process of removing themselves from the preneurial $b a$ that had been established to create their respective innovations. They had reduced their personal involvement so that they could return to their current roles or take up new functional roles. Two of the intrapreneurs, (I-18) and (I-24), had recently joined new organisations and were about to undertake new preneurial activities within those institutions.

At this point all of the (entre) preneurs in the study had retained some level of involvement with the entities they had established, despite many having commented that they saw their involvement in the process as having a fixed endpoint, and that they would exit the preneurial $b a$ :

This company, the new company, is very much started with the concept that we will sell it (I-5).

...my ultimate end goal to sell the business (I-6).

It was a cycle that had an end point. It was something that I'd let go of, I'd cash out (I-17).

While none of the entre (preneurs) had "cashed out" and exited their institutions, all of them had, to varying degrees, removed themselves from the original innovation specific preneurial ba, and had become institutional actors with the wider institutions, as previously discussed in Chapter 5 and shown in the following Table 36. Table 36 lists the functional roles of the preneurs within their wider institutions at the time of the interview. 
Table 36: Functional roles of the preneurs

\begin{tabular}{|c|c|}
\hline Interviewee & Institutional Role \\
\hline (I-1) & Teacher/Tutor \\
\hline (I-3) & Director \\
\hline$(\mathrm{I}-4)$ & Director \\
\hline$(\mathrm{I}-5)$ & Director and Manager \\
\hline (I-6) & Chief Executive \\
\hline$(\mathrm{I}-8)$ & Director and Manager \\
\hline$(\mathrm{I}-10)$ & Chief Executive \\
\hline$(\mathrm{I}-12)$ & Director \\
\hline$(\mathrm{I}-15)$ & Director and Chief Executive \\
\hline$(\mathrm{I}-17)$ & Director and Chief Executive \\
\hline$(\mathrm{I}-18)$ & Manager \\
\hline$(\mathrm{I}-21)$ & Teacher/Tutor \\
\hline$(\mathrm{I}-23)$ & Systems Administrator \\
\hline$(\mathrm{I}-24)$ & Manager \\
\hline
\end{tabular}

Once the innovation is made tangible in the Guiding stage, and then tested, proved, and improved in the Validating stage, the focus of the preneur transitions to managing issues associated with adoption and use; the traditional focus of IT innovation based research. This transition is shown in the comments of interviewee (I-6):

I know that one of things that I will be doing this coming week is getting out there and going, "actually right, now I am an expert in...I need to educate people in...so that they go and buy our tools" (I-6)

It is at this demarcation point, Extricating, that the PA process in IT creation finishes. The IT innovation is created and the collective agency has overtaken the preneur's preneurial agency. Subsequent actions of the preneur or collective agents in the adoption, use, and diffusion of the innovation are outside the scope of this research study. 


\subsubsection{In summary, Extricating}

During Extricating, the final stage of the PA process in IT creation, the preneur's agency is overtaken to such an extent that they can withdraw from that specific PA process. They have taken their preneurial idea from a point where it was an intangible thought and, through his/her own agency and that of the collective agents who aid then in their journey, have turned it into a tangible reality.

As they go through the process they have had to navigate a number of chasms, ensuring that they not only cross them but they are able to guide the collective agents across as well. As the journey progresses, the preneur may find themselves having to double back and tackle new and different chasms while also potentially changing their approach.

Once they have produced a tangible version of the IT innovation, new issues and opportunities demand the preneur's attention. The preneur increasingly leaves activities associated with creating the specific innovation to the collective agents, leaving the preneur free to move on to the next preneurial opportunity or to concentrate on their duties as an institutional actor.

While the preneur acts in such a way that they or their institution may be able to appropriate a preneurial rent from the PA process and the creation of the IT innovation, their ability to create and appropriate a rent is far from guaranteed. The establishment of the preneurial $b a$ and the creation of the IT innovation precede the rent appropriation as the economic value and extent of use of the innovation are still largely unknown. It is the belief of an opportunity for preneurial rent, and not the obtainment of it, that drives the preneur in their actions to create the IT innovation. 


\subsection{Chapter summary}

The Grounded Theory of Preneurial Agency in IT Creation has been explored in this chapter starting with how the preneur designs the innovation and associated business model through using his/her own agency. They design the innovation through using their own knowledge and leveraging their personal networks to acquire new knowledge. As the preneur progresses though the process they combine his/her agency with that of collective agents. The combining is carried out within a shared space, that I have called the preneurial $b a$. The preneur must establish a preneurial $b a$, a start-up company or new project team; so that they can acquire and combine the resources they need to create the IT innovation.

Through focusing on the creation of IT innovation, it was found that a specialist skill set of software development expertise was needed so that the IT artefact could be created. Preneurs who had some level of software development expertise complemented and added to their own expertise through acquiring the services of specialist software developers. In instances where the preneur did not have expertise in software development they used their conceptual design and knowledge of business processes and requirements to guide the actions of those collective agents with software development skills.

The preneur guides the actions of the collective agents and combines his/her own agency with that of the collective agents to create a tangible prototype that can be tested, proved, and improved in the Validating stage of the PA process. Ultimately, the preneur reaches a stage where his/her individual agency is overtaken by the collective agency and they are able to extricate themselves from that specific preneurial process, so that they may focus on the next preneurial opportunity or focus on their role as an institutional actor. 
The Grounded Theory of Preneurial Agency in IT Creation extends beyond the dominant paradigm of IT innovation research focusing on issues of diffusion and uses. It explores how the IT innovation is created through the actions of the preneur and it explains the actions of both the external (entre) preneur and internal (intra) preneur. 


\section{DISCUSSION OF THE THEORY}

\subsection{Chapter overview}

In this chapter, I discuss the nature of the theory, the Grounded Theory of Preneurial Agency in IT Creation, through addressing the nature of theory within IS research and within grounded theory-based studies. The theory is evaluated against Gregor's (2006) five types of inter-related theory and Urquhart et al's. (2009) framework for analysing grounded theories studies.

The Grounded Theory of Preneurial Agency in IT Creation is then related to existing IT Innovation-based theory, Organisational Knowledge Creation Theory, Structuration Theory, Theories of Entrepreneurship and Resource Based Theory. Included is a discussion of where the new theory extends and contradicts existing Theories of Entrepreneurship. The Chapter concludes with a discussion of alternative Social Psychology based theories of IT adoption and through applying the additional focus on IT creation a Reasoned Action Model of Preneurship is provided.

\section{Chapter Contents}

7.2 Within the context of Information Systems research

7.3 The nature of the theory

7.4 Relationship to existing theory of IT innovation

7.5 Relationship to existing theory of Organisational Knowledge Creation

7.6 Relationship to existing theory of Structuration

7.7 Relationship to existing theory of Entrepreneurship

7.8 Relationship to existing Resource Based Theory

7.9 Relationship to existing theory of IT Adoption

7.10 Chapter summary 


\subsection{Within the context of Information Systems research}

The IS discipline is heavily reliant on theories borrowed and adapted from other disciplines (Markus and Saunders, 2007; Weber, 2003). However, the emergence and survival of the IS discipline and its autonomy is dependent on the development of IS-specific theories that are directly related to the IT artefact (Markus and Saunders, 2007). To overcome this reliance, and aid in securing the independent future of the IS domain, Markus and Saunders (2007) call for IS scholars to theorise above and beyond the theories the discipline imports from other fields.

As an IS scholar and PhD candidate, I sought not only to produce a theory through the use of the grounded theory method, but also to contribute a theory that is directly related to the IT artefact and contributes to development of the IS discipline.

The development of theory is what sets academic researchers apart from practitioners and consultants (Gregor, 2006). As a practitioner, I have often been required to articulate how and why a phenomenon works, with specific focus on the what; it has not been a requirement to abstract and generalise within temporal and contextual boundaries, as I am required to do as an academic.

Within the IS discipline there are five inter-related theory types, distinguished by Gregor (2006) as (a) theory for analysing, (b) theory for explaining, (c) theory of predicting, (d) theory for explaining and predicting, and (e) theory for design and action. The Grounded Theory of Preneurial Agency in IT Creation as developed through this research and the application of the grounded theory method conforms to Gregor's theory for explaining. A theory for explanation states what is - how, why, when, and where - but does not aim to predict with any precision, nor are there any testable propositions (Gregor, 2006). 
An explanation of how, when, and why the preneur acts is provided in Chapter 6, and the theory states what will happen if certain preconditions hold true; in this case the actions of the preneur and their interactions with collective agents will lead to the creation of IT innovation. By explaining how the preneur acts, the stages they go through and that through interacting with especially software developers, the theory meets the requirements of a Theory of Explaining as specified by Gregor (2006) and Markus' (2009) need for abstracting and generalising within temporal and contextual boundaries.

The Grounded Theory of Preneurial Agency in IT Creation is grounded in the data and has empirical support. The theory extends its explanatory powers to a specific set of phenomena (entrepreneurship and intrapreneurship) that are related through the construct of Preneurial Agency.

\subsection{The nature of the theory}

In this section, I provide an assessment of how the Grounded Theory of Preneurial Agency in IT Creation fits Urquhart et al's. (2009) framework for analysing grounded theories studies. Seeking to raise the quality and aspirations of grounded theory studies within the IS discipline, Urquhart et al. (2009) developed and published a set of guidelines for use in such studies. The guidelines are based on a framework of theorising through focusing on conceptualisation and theory scope. The authors note that they have observed in their own grounded theory work that these two dimensions underlie the grounded theory process of theory building and aid the researcher in developing theories of greater scope, commenting, "The more the data analysis moves from description to theory, and the more the scope of the theory increases with the development of formal concepts, the better" (Urquhart et al., 2009, p. 9). The framework is depicted in Figure 22. 


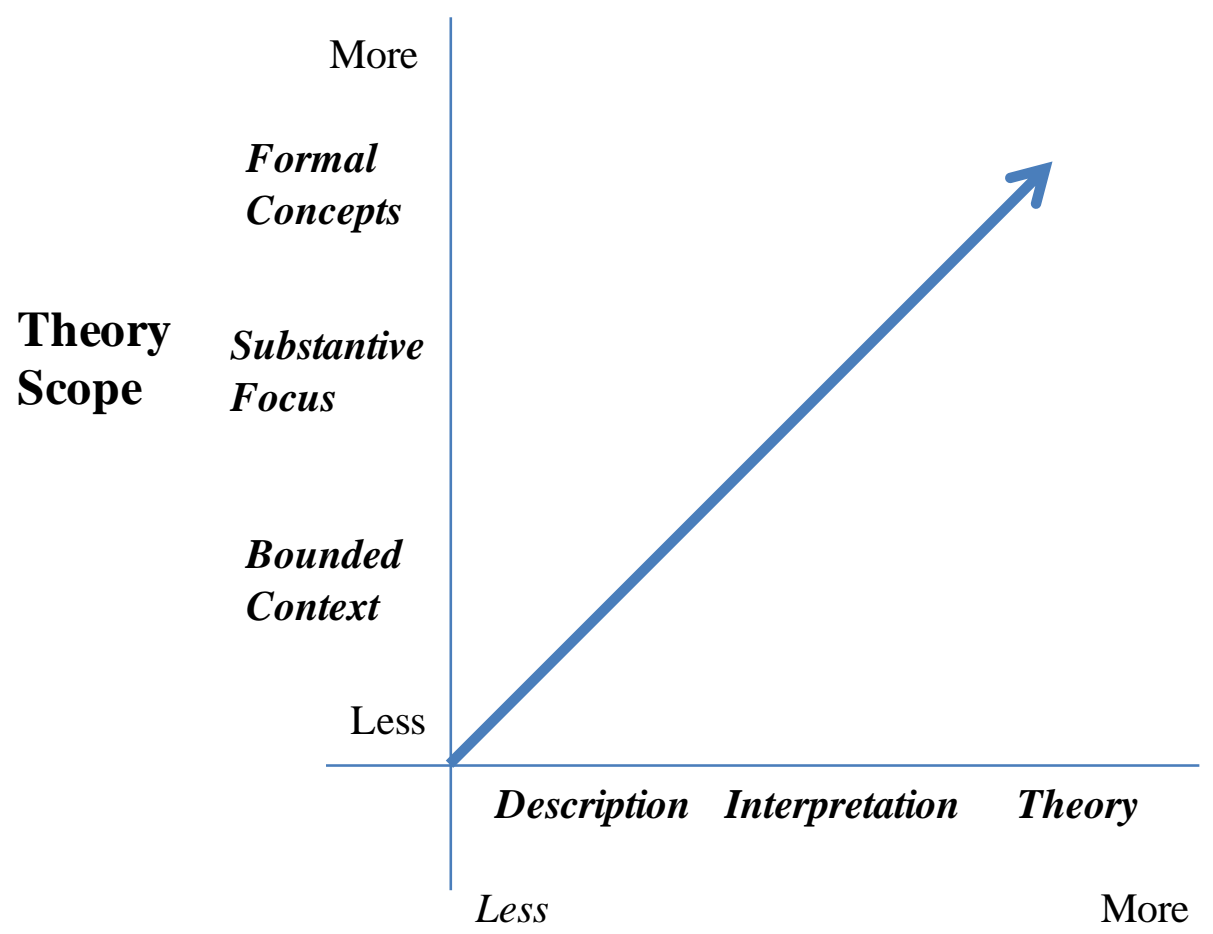

\section{Degree of Conceptualisation}

Figure 22: $\quad$ A framework for analysing grounded theory studies (Urquhart et al., 2009, p. 10)

The $\mathrm{x}$ axis depicts the degree of data analysis (Conceptualisation) and lists processes contained within the Glaserian variant to successively increase the depth of analysis, specifically: (a) Description - the most basic of conceptual constructs, the identification of concepts, categories and associated properties through undertaking the process of open coding; (b) Interpretation - through using selective coding, conceptual constructs are developed and refined that can help explain whatever interaction occurs between the descriptive categories; and (c) Theoretical coding - resulting in the formulation of a theory, with the intention of creating inferential and/or predictive statements about the phenomena through stipulating explicit relationships between individual interpretive constructs (Urquhart et al., 2009). 
The y axis depicts the scope of the theory, as the method seeks to develop theories of greater and greater scope, where: (a) Bounded context or narrow theories are the most basic, limited to their immediate context within a specific area of enquiry, and often little more than hunches; (b) Substantive focus equates to a substantive theory which extends its predictive and explanatory powers to the specific set of phenomena from where it was developed - such theories have empirical support; and (c) the development of a formal theory that uses formal concepts and applies them within a conceptual area that usually spans a family of several substantive areas (Urquhart et al., 2009).

Development of the Grounded Theory of Preneurial Agency in IT Creation progressed through Glaser's three principal stages of theory development: (a) description, (b) interpretation, and (c) theory, which are explained in Chapter 3, section 3.4.3. Within the first stage of description, categories and their detailed properties were arrived at through the process of open coding.

In the second stage, interpretation, selective coding allowed conceptual constructs to be developed and refined to help explain the interactions occurring between the descriptive categories. Thirdly, through theoretical coding, inferential comments were developed about the phenomenon of Preneurial Agency.

This places the Grounded Theory of Preneurial Agency in IT Creation at the right hand end of the degree of conceptualisation axis, within Urquhart et al's. (2009) framework for analysing grounded theories studies. The conceptualisation axis relates to the process of developing the theory; whereas the second axis, denoting theory scope, relates to the outcome of the process and the nature of the theory that was produced.

At the bottom of the second axis, are bounded theories which are little more than hunches (Urquhart et al, 2009). The Grounded Theory of Preneurial Agency in IT Creation is not a hunch; it has empirical support and extends to having predictive and explanatory powers. Consequently, it meets the requirement for being 
described as having substantive focus on the framework for analysing grounded theories studies as shown in Figure 23.

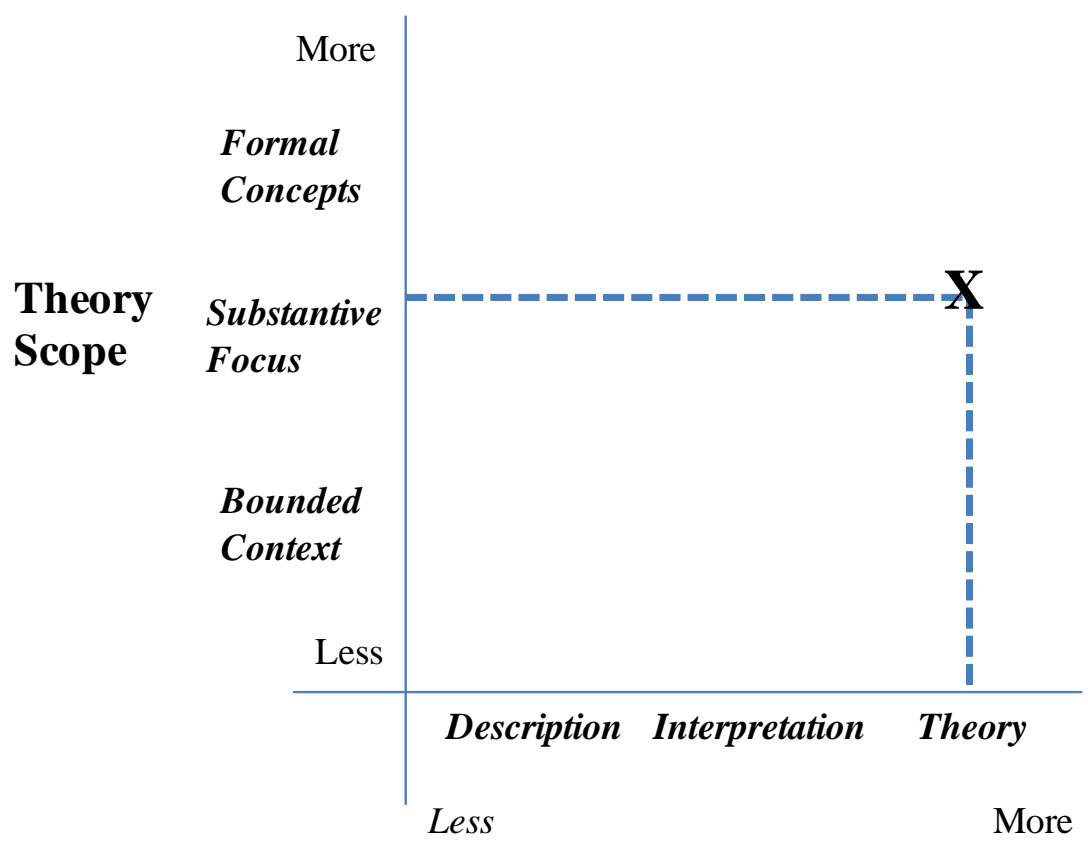

Degree of Conceptualisation

Figure 23: Assessment: Grounded Theory of Preneurial Agency in IT Creation

Within Figure 23, the Grounded Theory of Preneurial Agency in IT Creation is shown as theory that has been developed through a process extending to theoretical development and has a substantive focus. Within the Grounded Theory Method, substantive theory pertains to a particular area, and the idea is that, at a certain level, it shades into bigger or more formal theories (Strauss 1987). They apply to the substantive area of enquiry, but are independent of and beyond the data analysed and the incidents observed (Glaser and Strauss, 1967). Similarly the Grounded Theory of Preneurial Agency in IT Creation is at a level where it is independent of the data analysed and incidents observed, it is an abstracted view, but it shades into other more formal theories or entrepreneurship and structuration.

The theory as developed is unable to be classified as a theory having formal scope as, according to Urquhart et al. (2009), such theories have formal theoretical 
constructs which apply to a conceptual area that spans a set or a family of several substantive areas. While the Grounded Theory of Preneurial Agency does span a family of two substantive areas - entrepreneurship and intrapreneurship - it does not provide a broad base of generalisation where the core category emerges from several "other" substantive areas and explains phenomena in those areas. As presented the Grounded Theory of Preneurial Agency in IT Creation borrows from and is related to Structuration Theory. Structuration Theory is prime example of a theory that has formal scope that span several substantive areas such as this research that is based in entrepreneurship and IT innovation.

As Glaser (2007) defines it, a Formal Grounded Theory (FGT) is "a theory of a SGT core category's general implications generated from, as wide as possible, other data and studies in the same substantive area and in other substantive areas" (p. 4). SGT denotes a Substantive Grounded Theory. I did not analysis data in other substantive areas, nor did I seek to explain phenomena beyond those actions of the (entre and intra) preneurial agent to create IT innovation.

Substantive Grounded Theories, like any other theory, need to be put into the context of other theories (Urquhart et al, 2009). As Urquhart et al. (2009) acknowledge, Glaser (1978) suggests substantive theory can be analysed by comparing it with other substantive theories. In the remaining sections of this chapter, I analyse the theory against existing Theory of IT innovation Organisational Knowledge Creation Theory, Structuration Theory and Theories of Entrepreneurship.

\subsection{Relationship to existing theory of IT innovation}

To the best of my knowledge, the Grounded Theory of Preneurial Agency in IT Creation is unique and there is no other similar theory within the IS domain. Its focus is on how the (entre and intra) preneurial actor goes about creating IT innovation and extends beyond the dominant paradigm of IT innovation research. Traditionally, IT innovation-related research examined organisational and technological factors that determine IT adoption and diffusion through focusing 
on issues of firm size, scope, technological competence and firm benefits (Melville and Ramirez, 2008). Adoption and assimilation commences when the IT innovation begins to be absorbed into the work life of the firm and is demonstrated to be useful (Swanson and Ramiller, 2004).

Within such research, the assumption is made that the IT innovation exists in a tangible form, so that it may be adopted and used by the firm. This presupposition dates back to the original research and perspectives which inform the domain, such as that of Daft (1978). Daft (1978) describes the process of innovation as constituting an idea which is conceived and proposed followed by the decision to adopt and implement. Conspicuously absent from this description is how this innovation idea is made tangible so that it may be adopted and implemented.

This is not to say that all IT innovation research presupposes the existing of the IT artefact. Researchers such as King, Gurbaxani, Kraemer, McFarlan, Raman, and Yap (1994) acknowledge that the term "innovation" as a social phenomenon encompassing elements of invention and diffusion. But even then, the (entre \& intra) preneurial act of creation is glossed over as King et al. (1994) define invention as "a new idea or product which may or may not have economic value" (p.140).

While not specifically addressing this particular omission and research gap around the creation of the IT innovation, Lucas, Swanson and Zmud (2007) are driven to acknowledge that the field of IT innovation lacks a unifying theory or even a small assemblage of sub-theories that complement each other.

As developed, the Grounded Theory of Preneurial Agency in IT Creation draws upon and complements Organisational Knowledge Creation Theory and Structuration Theory as discussed in section 7.5 and 7.6. 


\subsection{Relationship to existing theory of Organisational Knowledge Creation}

The Grounded Theory of Preneurial Agency both complements and adds to Organisational Creation Theory through introducing the notion of the preneurial $b a$, which can be added to the types $b a$ as shown in Chapter 2, Table 3. As discussed in Chapter 2, section 2.6, Nonaka et al. (2006) acknowledge that there has been limited use of entrepreneurship based research and theory within Organisational Knowledge Creation Theory and in particular the origins of knowledge and the origins of the firm.

The Grounded Theory of Preneurial Agency in IT Creation firmly establishes the preneur as the originator of the knowledge and as the establisher of the preneurial $b a$, the start-up firm, or the internal project development team. By drawing upon his/her prior knowledge and experiences the preneur is able to design something new, which he/she then set out to create with the aid of collective agents. The collective agents engage in a generic process that specifically focuses on creating the innovation as conceptualised by the preneur. This is a point of divergence with Nonaka's view of Knowledge Creation.

As Nonaka and Toyama (2007) maintain, knowledge creation is implemented at every level of the organisation through daily practice and demands the active commitment of every individual in the organisation, not just a small group of elites. The Grounded Theory of Preneurial Agency in IT Creation sees the creation of innovation as a discrete activity that involves a specific set of actors the preneur and collective agents that aid them. While innovating may be an everyday activity, for those actors at that point of time it is a process with a beginning stage Designing, and an end, Extricating. At some point when the innovation has been created and their agency is no longer required in that innovation-specific PA process, the actors become institutional actors removed from the specific innovation.

While the Grounded Theory of Preneurial Agency in IT Creation aligns with Nonaka's belief that the process is not based only in the activities of a few elite, it 
does presuppose that the process is bound within a specific context and comprises the activities and interactions of a few. This is best explained through referencing Structuration Theory.

\subsection{Relationship to existing theory of Structuration}

The connection between human agency, structure, and technology within the IT domain is associated primarily with the foundational work of Orlikowski (1992; 1993). This body of work perceives technology as being physically constructed by actors working in a given social context, as well as socially constructed through the different meanings they attach to it (Orlikowski, 1992). Orlikowski's (1992) notion of duality of technology, which takes the position that technology is enacted by human agency and is institutionalised in structure, is shown in Figure 24, Structurational Model of Technology by Orlikowski (1992).

Orlikowski's (1992) Structurational Model of Technology comprises four components: (a) human agents - technology designers, users, and decision makers; (b) technology - material artefacts meditating task execution in the work place; (c) institutional properties of organisations that influence human actions in their interaction with technology; and (d) institutional consequences of interactions with technology.

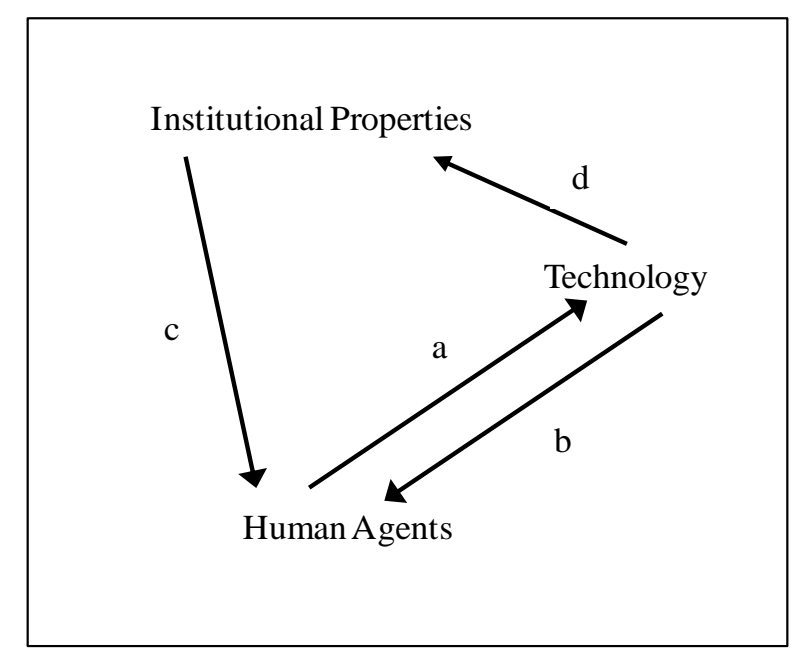

Figure 24: $\quad$ Structuration Model of Technology

(Orlikowski, 1992, p. 410) 
While Orlikowski (1992) sees a duality occurring when technology is used and institutionalised in structure, this research sees the technology artefact as being created through Preneurial Agency and the actions of collective agents who are guided by the preneur within the preneurial $b a$. The focus is on how technology is created rather than how it is used.

These interactions between the preneur and collective agents within the PA process are show in Figure 25. When related to the initial stages of the PA process - Designing, Establishing, and Acquiring - the model represents: (a) the actions that the preneur gives to articulating the innovation design and business model, (b) the collective agents required, (c) the agency that the preneur envisages is needed to create the IT innovation; and (d) the shared context, the preneurial $b a$, which the preneur needs to establish in order to facilitate interactions during the PA process. The preneurial $b a$ accounts for both the start-up institution established by the (entre) preneur and the new project team established by the (intra) preneur.

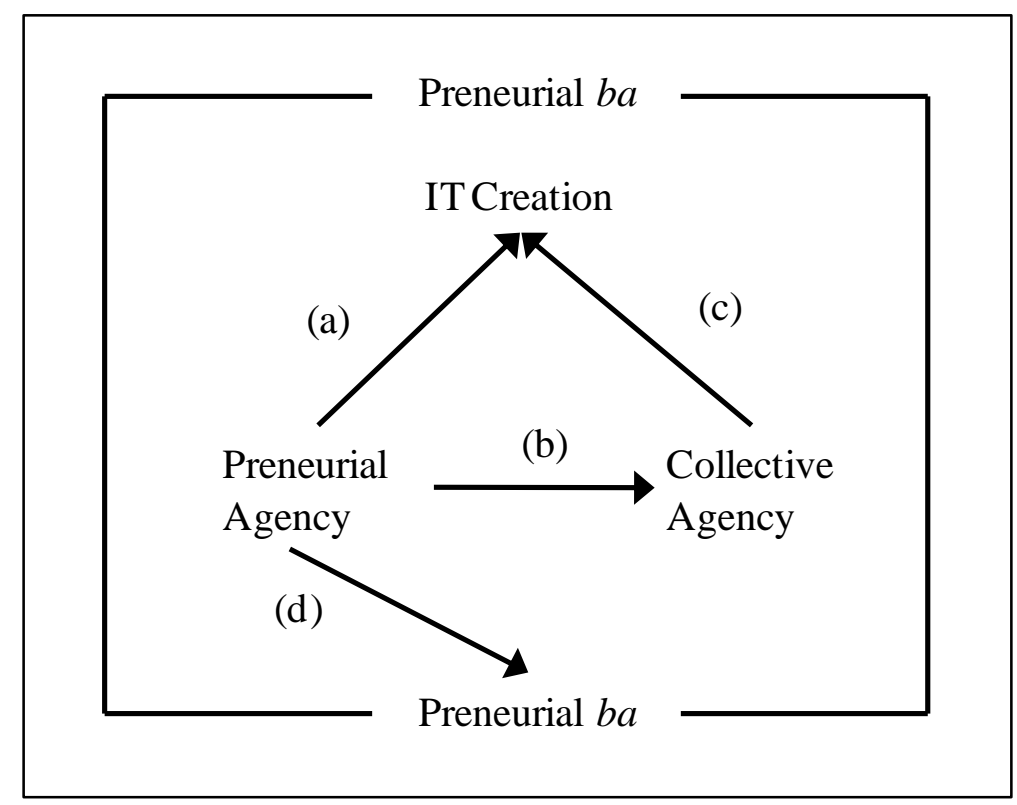

Figure 25: Structurational Model of IT Creation

The Structurational Model of IT Creation associates preneurial agency with the preneurial $b a$. This aligns with the views of Giddens (1979; 1984), Nonaka 
(1994), and Orlikowski (2000) that structures only exist in and through the activities of human agents. Orlikowski paraphrases Giddens' original work thus: "in social life, actors do not enact structures in a vacuum, in their recurrent social practices, they draw on their (tacit and explicit) knowledge of their prior actions and situation on hand" (Orlikowski, 2000, p. 409).

\subsection{Relationship to existing theory of Entrepreneurship}

Within Chapter 5, section 5.7, I relate the Grounded Theory of Preneurial Agency in IT Creation to the traditional notions of entrepreneurship and found that: (a) the activity of entrepreneurship is open to interpretation and redefining; (b) that the process of entrepreneurship comprises definable stages and encompasses a variety of contexts from start-ups to existing large institutions; (c) the phenomenon is often examined at the individual actor level; and (d) the theory best fits with the classical and intrapreneurship schools of research.

In this section, I use Cunningham and Lischeron's (1991) six approaches for describing entrepreneurship (as summarised in Chapter 5, Table 25) to show how the Theory of Preneurial Agency in IT Creation extends and contradicts previous theories of entrepreneurship and how they relate to the theory of Preneurship. 
Table 37: Support and contradictions to theories of Entrepreneurship

\begin{tabular}{|c|c|c|}
\hline & Contradicts & Supports and extends \\
\hline 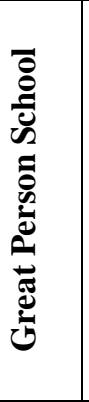 & $\begin{array}{l}\text { The process as described is seen to be } \\
\text { undertaken by the average person. The } \\
\text { preneur is not someone who occupies a } \\
\text { special place above all others, but rather } \\
\text { someone who undertakes actions that are } \\
\text { associated with entrepreneurial activity. } \\
\text { The person may be an employee of an } \\
\text { institution who acts preneurially to create } \\
\text { an innovation and once done revert back to } \\
\text { their previous role of an institutional actor. }\end{array}$ & $\begin{array}{l}\text { Within the great person school of thought } \\
\text { the entrepreneur is seen as someone with an } \\
\text { intuitive ability, vigour, and persistence. } \\
\text { Within this research the preneur is primarily } \\
\text { seen as someone with self-belief in their } \\
\text { vision and having the communications skills } \\
\text { necessary to show their vision to others. } \\
\text { They must be able to communicate the } \\
\text { previously unknown to collective agents } \\
\text { who aid them on their journey }\end{array}$ \\
\hline 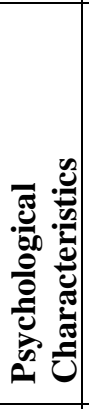 & $\begin{array}{l}\text { Within the Psychological School } \\
\text { entrepreneurs are seen as having unique } \\
\text { values, attributes and needs which drive } \\
\text { them. But as shown with the BSP of } \\
\text { Preneurial Agency it is the actions that } \\
\text { count, the person may have attributes and } \\
\text { personal characteristics of an entrepreneurs } \\
\text { or intrapreneur but unless they act and use } \\
\text { their personal abilities they are just } \\
\text { institutional actors or collective agents. }\end{array}$ & $\begin{array}{l}\text { The entrepreneur's values, attributes, and } \\
\text { needs which drive them were not examined, } \\
\text { only their actions were. Yet there was one } \\
\text { cognitive aspect that was present within all } \\
\text { the preneurs researched as part of the study, } \\
\text { they all had a vision of an innovative idea. } \\
\text { In this regard they were unique as they had } \\
\text { the innovative idea and the drive to act to } \\
\text { make the innovative idea a tangible reality. }\end{array}$ \\
\hline & $\begin{array}{l}\text { The Classical School emphasises the role } \\
\text { of entrepreneurial behaviour in the } \\
\text { innovation process. But it does not seek to } \\
\text { account for the actions of both } \\
\text { entrepreneurs and intrapreneurs and the } \\
\text { difference between the two and their } \\
\text { respective relativities to institutional } \\
\text { structures. Consequently the Classical } \\
\text { School does not account for issues of } \\
\text { structure. }\end{array}$ & $\begin{array}{l}\text { The BSP of Preneurial Agency aligns well } \\
\text { with the classical school as they both focus } \\
\text { on doing rather than owning, and both } \\
\text { emphasise the central role of innovation and } \\
\text { creativity. It also extends the Classical } \\
\text { School with its inclusion of the actions of } \\
\text { others, collective agents who are an essential } \\
\text { element as preneurship. Especially in IT } \\
\text { related innovation which is beyond the } \\
\text { capability of one person. }\end{array}$ \\
\hline 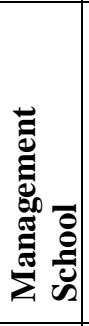 & $\begin{array}{l}\text { The Management School of thought } \\
\text { maintains that entrepreneurs are people } \\
\text { who organise, own, manage and assume } \\
\text { the risk. The BSP of Preneurial Agency } \\
\text { shows that this is not the case, as resource } \\
\text { ownership does not have to reside with the } \\
\text { preneur. They just have to be able to } \\
\text { acquire it for their use. }\end{array}$ & $\begin{array}{l}\text { The Managerial School emphasises aspects } \\
\text { such as relationship management and } \\
\text { problem solving, with the BSP of Preneurial } \\
\text { Agency emphasising the ability of the } \\
\text { preneur to acquire resources, communicate } \\
\text { their vision and subsequent requirements. } \\
\text { The preneur does not need formal authority } \\
\text { but the ability to co-opt resources. }\end{array}$ \\
\hline 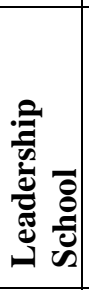 & $\begin{array}{l}\text { The notion of leadership was found to be } \\
\text { restrictive. The preneur is often not } \\
\text { someone who is recognised as a leader but } \\
\text { as someone who has unique knowledge of } \\
\text { an innovative idea and has the ability to } \\
\text { influence the actions of others. }\end{array}$ & $\begin{array}{l}\text { Like the Leadership School of thought the } \\
\text { preneur cannot accomplish his/her goals } \\
\text { alone, but depends of others. This notion of } \\
\text { other is expanded upon within the BSP of } \\
\text { Preneurial Agency and given the formal title } \\
\text { collective agent and their agency and } \\
\text { contribution in the process defined. }\end{array}$ \\
\hline صి & $\begin{array}{l}\text { The Intrapreneurship School of thought } \\
\text { does not account for the transitions of } \\
\text { preneurship and that over time an } \\
\text { entrepreneur becomes and intrapreneur and } \\
\text { institutional actor. }\end{array}$ & $\begin{array}{l}\text { A central premise of the BSP of Preneurial } \\
\text { Agency is that intrapreneurship occurs } \\
\text { within institutions and that the intrapreneur } \\
\text { is dependent on acquiring the assistance of } \\
\text { collective agents within the institution to aid } \\
\text { them in their task. }\end{array}$ \\
\hline
\end{tabular}


Each of the major schools of the thought associated with entrepreneurship is incomplete in their focus on and description of entrepreneurship. Similarly the Grounded Theory of Preneurial Agency is an incomplete explanation with its primary focus on the actions of the preneur and collective agents. But while primarily focusing on issues associated with agency, the theory's strengths and weaknesses can be compared against existing theories of entrepreneurship.

\subsection{Relationship to existing Resource Based Theory}

Resource acquisition, development and use are key parts of the entrepreneurial process and consequently entrepreneurship based research (Brush et al. 2003). Emphasis is placed on resource acquiring strategies, where entrepreneurs and entrepreneurial firms are able to develop and commercialise their technology based innovations through successfully acquiring and using resources differently (Katila and Shane, 2005).

Resource and associated performance differences are at the heart of resource based theory which seeks to explain how competitive advantage is achieved through the differences in resources that firms acquire and use more effectively than other firms. The resource based view was introduced into the Information Systems discipline as core theory by Wade and Hulland (2004). Where Wade and Hulland (2004), define resources are "assets and capabilities that are available and useful to detecting and responding to market opportunities or threats... together, assets and capabilities define the set of resources available to the firm" (p. 109).

Within the Grounded Theory of Preneurial Agency in IT Creation, the key resource is seen to be collective agents, and when their agency is combined with that of the preneurial actor IT innovation is created. Consequently to explain performance differences focus should be placed on the strategies preneurs use to acquire and guide resources (collective agents). 


\subsection{Relationship to existing theory of IT Adoption}

Research on individual-level adoption is one of the most mature streams of IS research (Venkatesh, Davis and Morris, 2007). This research stream has produced theories such as the Technology Acceptance Model (TAM); Task Technology Fit (TTF); and Unified Theory of Acceptance and Use of Technology (UTAUT) which have their historical routes in the field of Social Psychology and the Theory of Reasoned Action (TRA) developed by Fishbein and Ajzen, (1975); and (Ajzen and Fishbein, 1980).

According to TRA a person's performance of a specified behavior is determined by his/her behavioral intentions to perform the behaviour and behavioral intention is jointly determined by the person's attitude and subjective norm concerning the behaviour. Davies (1986) took the Theory of Reasoned Action and extended into the field of IS and introduced an adapted model of TRA, The Technology Acceptance Model which is specifically meant to explain computer usage behaviour. TAM posits that two particular beliefs, perceived usefulness and perceived ease of use are of primary relevance to computer acceptance behaviors.

While similar to TRA it differs in that behavioral intentions is viewed as being jointly determined by the person's attitude towards using the system and perceived usefulness. Davies, Bagozzi and Warshaw (1989) tested both TRA and TAM to see how well intentions predict usage and explain intention to use a computer system and found that perceived usefulness of the system strongly influenced peoples' intentions to use it.

Aspects of the TAM may extend to the BSP of Preneurial Agency, as the preneur has a belief as to the perceived usefulness of the innovation to future users and this in turn drives his/her behavioral intentions to create the IT innovation. Effectively the preneur has a belief of future user behavior based on of his/her behavioral intention to create an IT innovation. 
More recent focus within the field has moved to revisit technology use and revisit foundation theories of TRA and TAM. The proliferation of competing models with different sets of acceptance determinants motivated Venkatesh, Morris, Davis and Davis (2003) to develop a unified model called the Unified Theory of Acceptance and Use of Technology (UTAUT). This model, posits three direct determinants of intention to use (performance expectancy, effort expectancy and social influence) and two direct determinants of usage behaviors (intention and facilitating conditions). The UTAUT seeks to provide a useful tool for managers to assess the likelihood of success for new technology and to help them understand the drivers of acceptance in order to proactively design intervention targeted at intended users to improve potential adoption and use.

Subsequently, a call was made by Venkatesh et al. (2007) for research focused on interventions, contingences, and alternative theoretical perspectives (to the largely social psychology-based technology adoption research). The Grounded Theory of Preneurial Agency in IT Creation provides such an alternative theoretical perspective, but at a point to prior to that envisaged by Venkatesh et al. (2007) or even Davies (1986) and Davies et al. (1989). As before a user has the intention to use an IT system; it must first be created by a preneur who in turn has their own perception of the potential users' intention as sumamrised in Table 38.

Table 38: $\quad$ Support and contradictions to theories of IT Adoption

\begin{tabular}{|c|c|c|}
\hline & Contradicts & Supports and extends \\
\hline 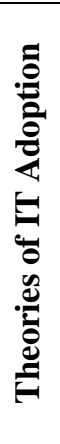 & $\begin{array}{l}\text { Existing theories of IT Adoption are based } \\
\text { on the assumption that the IT artefact is in } \\
\text { existence. But as the Theory of Preneurial } \\
\text { Agency shows, IT innovation is created } \\
\text { through Preneurial Agency and the belief } \\
\text { of the preneur as to the perceived } \\
\text { usefulness of the innovation by potential } \\
\text { future users. } \\
\text { Existing models only tell and account for } \\
\text { part of the process. }\end{array}$ & $\begin{array}{l}\text { The theory of Preneurial Agency in IT } \\
\text { Creation adoption is based on behavioural } \\
\text { intentions and perceptions of perceived } \\
\text { usefulness of the innovation. But it is not } \\
\text { just the perception of future users that need } \\
\text { to be accounted for, but also those of the } \\
\text { Preneur who create the innovation. }\end{array}$ \\
\hline
\end{tabular}


This would suggest that the basic TRA and TAM based theories are open to reinterpretation to the left of the existing models to factor in the beliefs of the preneur and their interpretation of perceived usefulness by potential future users prior to the creation of said artifact, as shown in Figure 26.

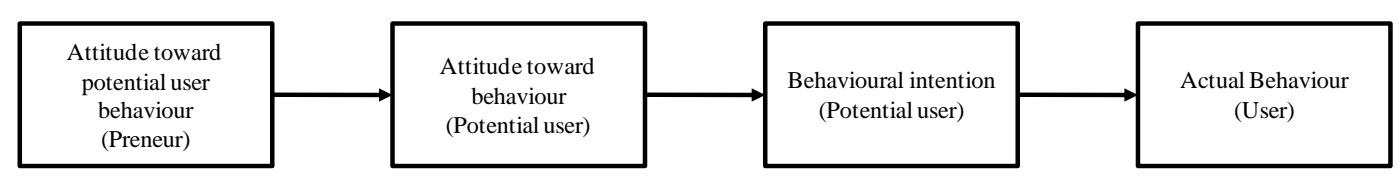

Figure 26: Reasoned Action Model of Preneurship

Within Figure 26, three base elements are taken from the Theory of Reasoned Action and restated to clarify a potential user versus an actual user and extended to include the Preneurs attitude towards potential future user behaviour.

\subsection{Chapter summary}

In this chapter I have discussed the nature of my newly developed theory, the Grounded Theory of Preneurial Agency in IT Creation, both within the context of IS-based research and within grounded theory-based studies. The theory was found to be a substantive theory for explaining in the context of the data collection environment in Wellington, New Zealand.

The new theory was then related to existing theory of IT innovation, Organisation Knowledge Creation Theory, Structuration Theory, Entrepreneurship-based theories and Resource Based Theory. Areas where the Grounded Theory of Preneurial Agency in IT Creation extended existing theories of entrepreneurship where identified as were areas where the theory conflicted with existing views. Finally an alternative perspective to technology adoption-based theories was provided to show how the Preneurs attitude towards potential future user behaviour can extend and inform current theories of IT adoption. 


\section{RELECTIONS, IMPLICATIONS, AND CONCLUSIONS}

\subsection{Chapter overview}

In this, the concluding chapter of the dissertation, I reflect upon my research findings and how I interpreted and applied the research method. Based on my experience, I offer an extended research model on the steps and processes in the grounded theory process as a contribution of this study. Then, using frameworks specifically developed for grounded theory-based research, I reflect on my application of the grounded theory method and examine the credibility and validity of the research findings and the new theory. Next, the main contributions and value of the research to academics and practitioners is identified and discussed, along with potential limitations of the research. Finally, directions for future research are explored and a concluding statement is made.

\section{Chapter Contents}

8.2 A review of the research aims

8.3 Reflections on the research method

8.4 Issues of rigour, credibility, and validity

8.5 Value and implications of the research

8.6 Limitations of the research

8.7 Directions for future research

8.8 Chapter summary

8.9 Concluding statement 


\subsection{A review of the research aims}

The original intent of this study was to explore the resource acquiring relationship between entrepreneurial actors and network brokers. However, the importance of such relationships did not emerge from the data. What did emerge was that (entre) preneurial actors interact and communicate directly with collective agents to create IT innovation; their interaction is not intermediated by network brokers. In accordance with Glaser's (1978) stipulation that the grounded theory and its categories must fit the data, the preconceived focus on brokers shifted to collective agents. In addition, a further shift to include intrapreneurs occurred midway through the study when the focus on entrepreneurial actors was found to be too narrow and unable to account for all the variation in the data.

The research question guiding the initial enquiry also sought to identify the drivers, enablers, and inhibitors of the resource acquiring relationship. As the research progressed it became evident that preneurial actors need to acquire and guide the services of the collective agents to aid them in creating the IT innovation. The driver is the need to create the IT innovation and the need to acquire the necessary skills and expertise required. With specific reference to IT innovation, software development expertise was found to be a critical resource requirement.

The critical enabler was found to be the preneurial $b a$ which the preneur establishes as a shared place within which to interact with collective agents and guide them in their actions to create the IT Innovation. An additional key enabler is the ability of the preneur to conceptualise the innovation design and to communicate it to the collective agents. Inhibiting the process is the underlying issue of uncertainty; the preneur and collective agents do not know what they do not know and their interactions are often subject to issues of asymmetric information flows with the preneur not sharing all that he/she knows.

Two sub-questions were also posed: How do these factors influence and moderate how the parties obtain benefit from the relationship and, what are the similarities 
and difference between the parties in regards to the identified drivers, enablers and inhibitors? The relationship is not between two equal parties with similar positions; the relationship is based in differences as the preneur is the originator and holder of preneurial vision and the guide who shows the way to the collective agents. To obtain maximum benefit from the relationship, the preneur has to dilute his/her agency over time, allowing the agency of the collective agents to overtake the preneur's agency.

In terms of the original aims of the research, the road that I travelled on had a fork within it. I am thankful to say that I had the courage and ability to turn off the known track and progress down the unknown path when required. Such is the journey of the grounded theorist researcher.

\subsection{Reflections on the research method}

When entering the research study I was a novice researcher, and I had not previously used the grounded theory method. A significant amount of my early focus was dedicated to reading and understanding grounded theory literature. While the method may seem straight forward in hindsight, it is far from simple when first studied. Not only did I have to understand the method as whole, I had to become knowledgeable on the subtle differences and variations between the Glaserian and Straussian variants.

For me, the task was further complicated by my early decision to apply a systematic and rigorous process to conducting a preliminary literature review. As I read more and more about the method, I became increasingly aware of the pitfalls of prior reading - the danger of adopting preconceived frameworks, and the forcing of the data to support popular theories.

At this time, I had not yet read Walter Fernandez's $\mathrm{PhD}$ thesis or his warning to fresh $\mathrm{PhD}$ students not to try and improve the method, as "there is no need to reinvent a method that has been used and has been proven to work in many areas of research for more than 35 years" (Fernandez, 2003. p. 299). 
A qualification is added by Fernandez: it is not that the method cannot be improved, but any improvement requires full understanding of a method, and to acquire this level of understanding can take up to a year of intense practical experience of the method. By attempting any significant modifications without the necessary experience, combined with input from supervisors experienced in the method, the student runs the risk of misunderstanding the method and contravening basic the tenets of it (Fernandez, 2003).

\section{The PhD student as a Preneur}

From my own experience, I acknowledge the wisdom of Fernandez's (2003) advice; I would even suggest that one year underestimates the time required to become full conversant with the method. In my case, my understanding of the method was tested throughout the whole process, with perhaps the greatest test coming when writing up and presenting the theory two and half years from beginning the study.

The $\mathrm{PhD}$ and the doctoral dissertation at its heart, is itself a process of Preneurial Agency; the $\mathrm{PhD}$ student takes an innovative idea, and through his/her actions and interactions with collective agents (such as $\mathrm{PhD}$ supervisors and research participants), creates new knowledge and makes it tangible in the form of a $\mathrm{PhD}$ thesis and emergent theory. Academic (entre) preneurship is not just limited to $\mathrm{PhD}$ students, but includes academic research in general as academics engage in innovation through "engaging in the process of creating and exploiting new opportunities from within the confines of an academic institution" (Kenny, 2009, p. 1225). It should be noted that Kenny's (2009) definition confuses the (entre) preneur with the (intra) preneur; the academic's preneurship is bound within the confines of an academic institution and therefore he/she should more correctly be seen as an (intra) preneurial academic. 
Based on my experience and understanding of the grounded theory method gained from engaging with this research, I offer an extension to the research model as developed by Fernandez et al. (2002); Fernandez (2003); and Lehmann (2001) which shows the steps and processes in the grounded theory method (see Chapter 3, Figure 6).

\subsubsection{An extended research model}

My research study began on the $3^{\text {rd }}$ of December 2007. At a meeting with my potential supervisors before being formally enrolled in the $\mathrm{PhD}$ programme, we agreed that the initial approach to the study should be around a broad and deep exploration of related subject areas.

As discussed in Chapter 4, section 4.3, the adoption and use of rigorous and systematic procedures within my research study began from the very first moment when I explored related subject areas in order to develop understanding of concepts, and to develop my skills and ability to interpret data, and to develop concepts, codes, and relationships.

When I entered the field, it was not in the substantive area as shown in Fernandez's (2003) research model (see Chapter 3, section 3.4.3) as that had not yet emerged from my data and so it was not known to me at the start. Hence, where I entered is more appropriately described as the general topic area. My original intent was to explore resource acquiring relationships between actors within entrepreneurial information technology firms and their network brokers.

At the time, I saw the topic area as including actors within entrepreneurial IT companies who were involved in the entrepreneurial process, and extending to include network brokers. Progression and focus on the substantive topic area came much later in my research when my initial core category of entrepreneurial agency began to emerge and I started reading to inform the theory and its relationship to existing theories. 
The grounded theory research model by Fernandez (2003) and steps and processes in the grounded theory process identified by Lehmann (2001a) and Fernandez et al. (2002) provide the core for my extended research model, as shown in Figure 27.

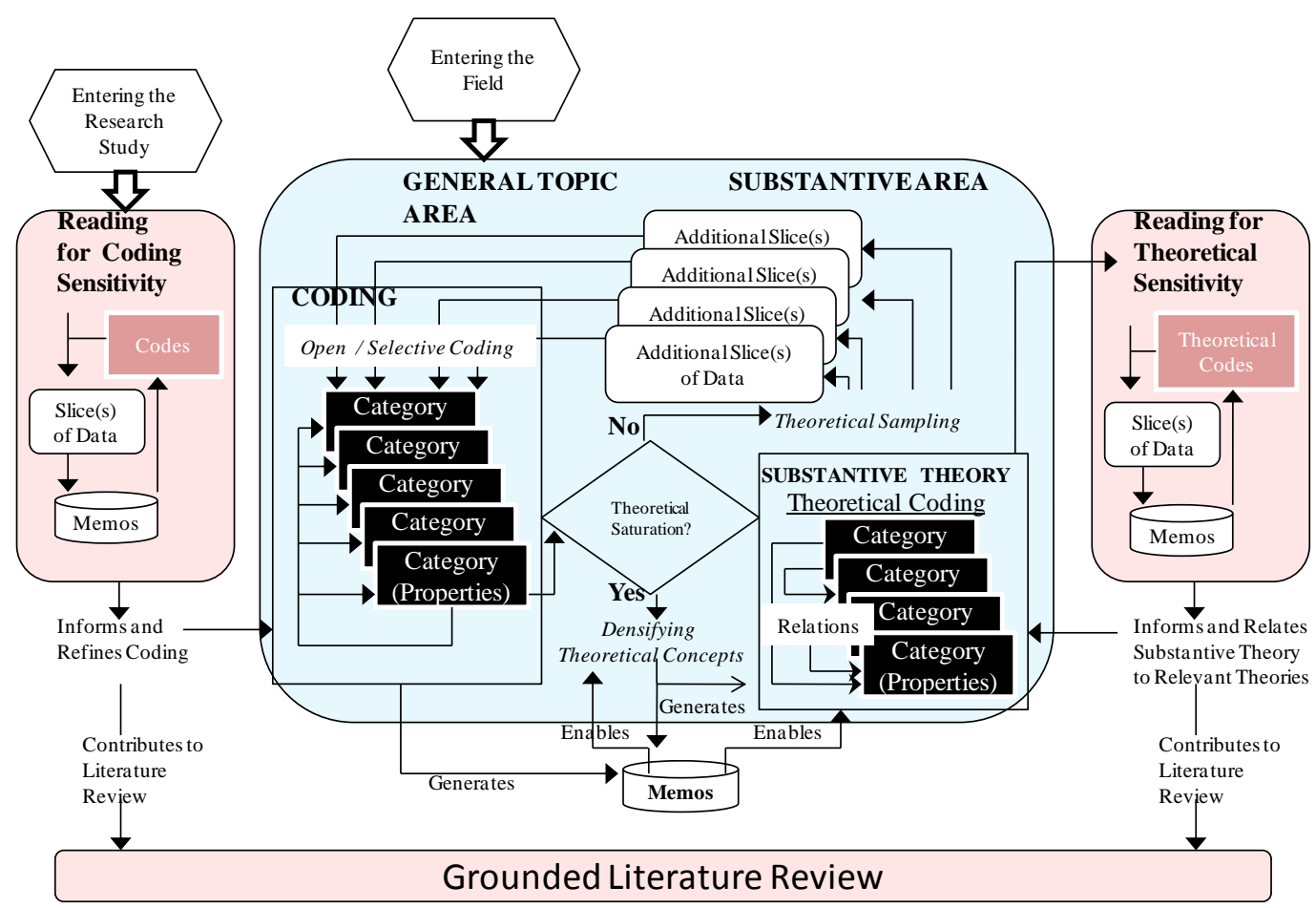

Figure 27: Extended research model: steps and processes in the grounded theory process

Within this extended research model, I have changed the diagrams and processes as previously shown in Chapter 3, Figure 6, thus: (a) an entry point into the research study being when I read extensively within the general topic area in order to develop my coding sensitivity and applied structured, rigorous, and systematic procedures to the process; (2) the entry point into the field was not the substantive topic area, but the general topic area; (3) reading of extant literature is split into two distinct phases - initially reading to develop sensitivity to codes in general and later reading for theoretical sensitivity and theoretical codes; and (4) specific inclusion of the development of a grounded literature review as part of the process, as a concise and relevant literature review is a key requirement of my $\mathrm{PhD}$ dissertation and of grounded theory-based studies in general. 


\subsubsection{Undertaking a Grounded Preliminary Literature Review}

The grounded theory method is known for its ability to develop rigorous theory through the application of systematic procedures; it is my contention that these systematic processes can be applied to undertaking a Grounded Preliminary Literature Review (GPLR). By conducting a GPLR, researchers (in particular graduate students) can acquire and develop their coding sensitivity, satisfy mandatory university requirements to conduct a substantial literature review prior to beginning formal research, and also meet generally accepted practice in the grounded theory method to delay reading in the substantive topic area until after the core category emerges from the data analysis.

While based in systematic and rigorous procedures, the GPLR is considerably different from the increasingly popular systematic literature review, though on first glance they bear similarities. A systematic review of the literature may be defined as a methodological assessment of a subject using a predetermined plan (Jones and Evans, 2000). Similarly, Houde (2009) sees the Systematic Literature Review (SLR) synthesising evidence found in the literature using a research methodology that is clearly articulated and provides the reader with the best available evidence derived from primary research studies (Houde, 2009). The SLR is also seen to have a number of distinctive features: relevancy criteria is formally specified; the review process must be replicable; the literature is searched exhaustively, the intention is to combine the findings of the various studies; and it is often concerned with providing answers to specific questions (Hammersley, 2001).

In contrast, while being grounded in systematic procedures the GPLR does not seek to: (1) specify relevance criteria, (2) search exhaustively, (3) be replicable, (4) combine the findings into a consistent picture, or (5) provide answers to specific questions of what or how things work. Rather it seeks to use systematic procedures to allow the researcher to build up an extensive repertoire of codes and a comprehensive understanding of prior research so that he/she can better analyse subsequent research data. Like the SLR, the GPLR provides a tool to aid 
researchers; a tool particularly applicable to and appropriate for subsequent grounded theory research

\subsubsection{Reading for Theoretical Sensitivity}

Reading for theoretical sensitivity is thus an essential part of a research study using the grounded theory method. As Urquhart and Fernandez (2006) point out, the very crux of the grounded theory method is its use of systematic procedures. It is my assertion that the systematic procedures of the grounded theory method can extend to include reviewing extant literature both prior to engaging in the empirical research phase and then as part of the theoretical coding stage. Both of these reading stages then contribute to the development of a Grounded Literature Review (GLR).

In addition to helping gain coding and theoretical sensitivity, I found the GLR process, as described above, to be a significant aid to writing up the theory and integrating it with key aspects of the literature. The articles' summaries and subsequent analysis provided a valuable resource which I could draw upon when writing up my dissertation.

\subsubsection{Reflections and assessment against guidelines and criteria specified by Fernandez et al. (2002); Fernandez (2003)}

Within Chapter 3, section 3.4.3, I introduced work by Fernandez et al. (2002) and Fernandez (2003) which sets out nine key guidelines to aid the development of rigour and relevance of research using the grounded theory method. In this section, I review and reflect on my research against these guidelines and criteria.

\subsubsection{Tolerate confusion - there is no need to know a priori and no need to force the data}

The research was not guided by a priori frameworks nor did it seek to test previously formed hypotheses. Initially, it was guided by broad research questions, but as the study proceeded the direction of the 
research changed - as explained in Chapters $4 \& 5$. Specifically, the focus changed so that all the variation in the data could be explained through abstracting to another level.

\subsubsection{Tolerate regression - the researcher might get briefly "lost" before finding his or her way}

Becoming lost in the data is not just a brief or isolated experience. It can and does happen, usually more than once and for more than a brief period; it may go on for weeks. The open coding process generates slices of data in their thousands. It was not until I broke away from using the tree-like structured coding process of Nvivo that I was able to see the data in new ways. Each time that involved me setting aside my previous coding and revisiting the interviews from the beginning to code against the new categories. This is illustrated in the model of inductive theory generation see Figure 7, Figure 12 and Figure 14.

\subsubsection{Trust emerging data without worrying about justification - the data will provide the justification if the researcher adheres to the rigour of the method}

Trusting the emerging data without thought of justification is hard for the novice research, especially $\mathrm{PhD}$ students as they must work closely with their supervisors who they must take with them on the journey. While, at times, I had to justify and explain to my supervisors what I was seeing in the data, more importantly I had to show to myself and my supervisors that I was not biasing the data and I was not seeing only what I wanted to see in it.

To gain trust in what the data was saying and how I saw the data, the constant development of theoretical and reflective memos was critical, especially at times of self doubt and when lost. There were many times when I had to retrace my steps and consult previous memos in order to revisit my original understandings and comments on an issue. This 
revisiting provided the confidence that my interpretation was based in logic and that through such memos my supervisors could themselves have confidence in how I was progressing and applying the method. The critical role that reflective memos play in the grounded theory method cannot be overstated. In the course of the research I produced in excess of 500 memos, ranging from simple, single sentence paragraphs to ten page essays where I needed to research and work though complex issues.

\subsubsection{Have someone to talk to-grounded theory demands moments of isolation to get deep in data analysis and moments of consultation and discussion}

This may be the sole area where the $\mathrm{PhD}$ student has an advantage over other researchers using the grounded theory method. The $\mathrm{PhD}$ student has supervisors who are not only experienced, but are also motivated and required to help their student. Like the contribution that collective agents make to the creation of IT innovation, the supervisors are essential collective agents in the creation of the $\mathrm{PhD}$ dissertation. It was only through combining my agency with that of my supervisors that the Grounded Theory of Preneurial Agency in IT Creation became a tangible reality.

This interaction was a key part of the process which, like all other parts of the grounded theory method, was managed in a systemic and rigorous manner. We agreed early in the process that I would submit work in advance for review at the meetings and that the supervisors would need time to reflect on the materials. Often, the material submitted was theoretical or reflective memos; with reflective memos discussing methodological issues and the theoretical memos focusing on issues arising from the data analysis. I also produced meeting minutes for each meeting, in part to demonstrate my understanding of what was said and discussed at the meeting. 
8.3.4.5 Be open to emerging evidence that may change the way the researcher thinks about the subject matter, and to acting on the new evidence

This is clearly evidenced in how the interim core category or entrepreneurial agency transitioned to preneurial agency through listening to the data and the role that (intra) preneurs played in the process and how the (entre) preneur transitioned to the role of intrapreneur.

\subsubsection{Be able to conceptualise and derive theory from the data}

The Grounded Theory of Preneurial Agency in IT Creation, was derived from the data, In addition to this theory, I also offer a structurational model of preneurship in IT creation. This was achieved through taking slices of data and comparing them against each other using the constant comparison method. By relating the codes to each other, concepts were formed and their associated properties identified. When combined with writing memos an abstracted view of the data was obtained, from which the Grounded Theory was derived.

8.3.4.7 Be creative - devising new ways of obtaining and handling data, combining the approach of others, or using a tested approach in a different way

As discussed in Chapter 3, a well tested and proven method was applied, the Glaserian variant of the Grounded Theory as interpreted and recommended for use in IS studies by Fernandez (2003), Fernandez et al. (2002), Lehmann (2001a), and Urquhart et al. (2009).

As discussed within section 8.3.1, of this chapter, the research model by Fernandez et al. (2002), Fernandez (2003), and Lehmann (2001) was extended to include a systematic review of the literature in a process I define as a Grounded Literature Review that involves reading for coding sensitivity as part of a GPLR. 
8.3.4.8 Aid their proficiency in the method though networking with other research using the method, read a wide range of grounded theory literature and participate in relevant discussion grounds where possible

In addition to reading extensively on the grounded theory method, I also sought to document my understanding and application of the method through a conference paper and journal article. I attended and presented a methodology-based paper at the $4^{\text {th }}$ European Conference on Entrepreneurship and Innovation held at the University of Antwerp, Belgium. In conjunction with a current and past supervisor, I have written a journal article on the initial stages of my research, which is currently under review with a qualitative research journal. I have received valuable insights and comments from reviewers, which I have taken on board for both a reworked paper and to inform my understanding and application of the method. Article writing has been an important part of the reflectivity process.

8.3.4.9 Be sensitive to the field under study, this may be through having extensive experience as a practitioner in the field.

As discussed in Chapter 3, section 3.5, I had significant sensitivity to the substitutive topic of IT innovation prior to entering into this research. In part, this experience and sensitivity provided motivation for the research. My experience as a practitioner is ongoing through part-time employment, attending conferences where relevant, and continuing to read extensively within the substantive topic areas.

These guidelines and criteria specified by Fernandez et al. (2002) and Fernandez (2003) mainly speak to issues of rigour and validity of the grounded theory process. As Charmaz (2006) counsels, researchers also need to consider their audience who will judge the usefulness of the methods by the quality of the final product. 


\subsection{Issues of credibility, originality, resonance and usefulness}

The endpoint of the study makes sense to the researcher as they have been immersed in the process. However, for the audience lines become blurred between process and product (Charmaz, 2006). To aid the researcher to obtain credibility for their research Charmaz (2006) proposes four criteria for evaluating their research: credibility, originality, resonance and usefulness. As she maintains these criteria address the implicit actions and meanings in the studied phenomenon and help to analyse how it is constructed. In this section, I evaluate my research and findings against these four criteria which were introduced and explained in Chapter 3, section 3.6.

\subsubsection{Assessment against Charmaz's (2006) criteria for grounded theory studies}

\subsubsection{Credibility}

Charmaz (2006) asks the researcher to question have they achieved intimate familiarity with the setting or research topic? Also is the data sufficient to merit the clams made and presented with strong logical links? The research achieved innate familiarity with the research topic through not only seeing the phenomenon through the words of the preneurial actors, but it also sought the input of the collective agents they interacted with, and the views of the collective agents helped describe the actions of the preneurs. Twenty four interviews were carried out that which rich in information as the interviewees were open and unguarded in their comments. Often this was because of the prior professional relationship that I have had with them.

I have taken care when presenting my argument to step the reader through the process so that they may understand how the leap in logic occurred, how my own drugless trip occurred, and that it is both believable and substantiated in the data, as shown in Chapter 5. In 
Chapter 5, I provide detailed evidence to support the claims using the words of the interviewees themselves. This will enable anyone reading this dissertation or any articles based on my research findings to form an independent assessment of my claims

\subsubsection{Originality}

Grounded theory research should challenge, extend, or refine current ideas, concepts, and practices (Charmaz, 2006). The categories within this study offer fresh and new insights and, to the best of my knowledge, no previous research has produced an integrated theory of the actions of both (entre) preneurs and (intra) preneurs in the creation of IT innovation. I offer the term preneurial $b a$, to describe the place which either the (entre) preneur and (intra) preneur establishes in order to interact with collective actors and guide them in their actions to create the IT innovation. I also offer a challenge to both researchers and practitioners to see well established (entre) preneurs not as (entre) preneurs but as (intra) preneurs and preneurs in general.

\subsubsection{Resonance}

The research must resonant with the intended audience and offer them deeper insights about their lives and it must also portray the fullness of the studied experience (Charmaz, 2006). The emergence and identification of the preneur as a guide, as somebody who shows the way to other travellers (collective agents) in a strange land, was a key milestone in the study. This shows the preneur as not having to be the leader, but as someone that has knowledge of the path that needs to be travelled and shares that with others so they can arrive at destination which, in the context of this study, is the creation of the IT innovation. 
The research encompasses both large and small enterprises, and preneurs who are just starting out, to those that are well established and even to those preneurs, the serial preneurs, who have acted to create multiple innovations through establishing a new preneurial $b a$ in addition to their previous venture.

\subsubsection{Usefulness}

Charmaz (2006) poses the questions (a) does your analysis offer interpretations that people can use in their every day worlds?, (b) do your categories suggest any generic processes?, and (c) how does your work contribute to knowledge and make the world a better place? In essence, these questions are about how useful the research is to both academic researchers and academics alike. I address these points in the remaining sections of this chapter, along with identifying the limitations of this study.

\subsection{Value and implications of the study}

This research has made a number of meaningful contributions to the study of IT innovation and entrepreneurship-based research in general. The contributions add value to both the academic and practitioner communities.

\subsubsection{Value and implications of the research to study}

For academics within the IS domain, this study provides an abstracted agencybased view of the innovation process from the point where the (entre) or (intra) preneur architects the first rudimentary road map of the innovation until the point where the innovation is made tangible in a prototype and the agency of the preneur is overtaken by that of the collective agents. This is done through displaying and explaining the key categories and their associated properties, while at the same time maintaining conceptual parsimony. 
The process of Preneurial Agency is shown as a Basic Social Process which is easy to understand and use. Six discrete stages are identified and described to show both how the preneur acts to create IT innovation and how they interact with collective agents to combine their collective agency to create IT innovation. Such a perspective reinforces the view espoused by researchers such as Van de Ven $(1993 ; 2005)$ and Lavie (2006) that innovation is a collective process.

The Basic Social Process of Preneurial Agency or more specifically the Basic Social Structural Process reflects the triality of interaction between structure, preneurial agency, and collective agency. Innovation is the product of the agency of the preneur, which is combined with the collective agents within the preneurial $b a$. This triality is depicted within a Structurational Model of IT Creation, which shows the preneur to be instrumental in creating the innovation, establishing the preneurial $b a$, and guiding the actions of the collective actors.

This triality-based view is independent of use and users; while there may be expectation of future use, the innovation must first be made tangible.

Consequently, innovation research needs to move beyond use and diffusion-based views to include creation-based perspectives to fully account for the phenomenon of IT innovation. It is the agency of the preneur and collective agents they interact with, not the agency of users that is important in the IT creation process. Through adding this perspective to IT innovation research, a unifying theory of IT innovation is one step closer.

The research indicates that IT innovation is unique from other forms of innovation in that it must involve the use of software developers. The preneur might act as his/her own software developer, but is more likely to seek the assistance of more experienced and skilled software developers. This would suggest that IT innovation is dependent not only on preneurial agency but also the agency of a software developer. 
For researchers within the entrepreneurship and innovation domains, this research offers an abstracted agency-based view of both the (entre) preneur and (intra) preneur, whereby the actions of either are able to be explained by a common Basic Social Process.

The research also offers a potentially valuable contribution to the ongoing debate about definition of an entrepreneur. The research shows that, over time, an entrepreneur transitions to being an intrapreneur. This suggests that using the term entrepreneur to describe the actor at that point in time is incorrect and that the term preneur may be more correct.

Both the Grounded Theory of Preneurial Agency in IT Creation and the Structurational Model of IT Creation can be used as teaching aids for innovation and entrepreneurship courses. Through incorporating the models within the curriculum of IT innovation-based courses, the learning outcomes can extend beyond those related to the dominant paradigm to include aspects of preneurial agency that are essential to the IT creation process.

Lastly, for both novice and experienced researcher an expanded research model for grounded theory-based studies is offered. This model takes the systematic and rigorous procedures that are applied to the primary research and applies them to secondary data, the extant literature. The model also accurately shows that the point where the researcher enters the study is when they start to read for coding sensitivity. In addition, the model shows that, within grounded theory research, the researcher enters the field within the general topic and, only after the emergence of core category, do they progress to the substantive topic area. It is expected that the clear articulation of the role of the grounded literature review within the extended research model, will reduce methodological confusion for novice researchers, aiding them in applying the method to build theory. 


\subsubsection{Value and implications of the research to practitioners}

This study was motivated by a desire to provide entrepreneurs and managers within entrepreneurial firms with a better understanding of the factors impacting on the social interactions that take place when creating IT innovation. By obtaining a greater understanding of such factors it was hoped that practitioners involved in the IT innovation process may become more skilled, efficient, and effective in the activities and processes needed to create innovation.

The research found that the term "entrepreneur" was often used misleadingly and understated the role of intrapreneurs. In addition, it found that entrepreneurs ultimately may become intrapreneurs. Therefore, focusing solely on the action of the (entre) preneur or solely applying (entre) preneur centric factors to manage IT innovation is problematic. Greater benefit may be achieved through applying an abstracted view of preneurship.

The preneur does not have to be the leader as espoused by Schumpeter (1934); rather, they can act as a guide who shows the way to the collective agents. In addition, while the original idea may be unique and innovative, the process that the preneur undertakes to make it a tangible reality is a generic process. It involves a number of stages that occur in a sequence; within each stage the preneurs "undertakes" a specific set of actions, able to be expressed as a theoretical proposition. By understanding the proposition, the preneur may be better able to inform their practice in that stage of the PA process. This also implies that the each stage of the process can be taught, managed, and improved. 
Theoretical proposition 1 - The preneur will undertake actions to give initial form to the vision.

The preneur needs to act to make a tangible expression of their intangible idea. This may be a flow diagram, conceptual design, drawing, model or similar manifestation. Through developing such artefacts he/she then has a boundary object that can be shared with the collective agents and used to share and communicate the idea to them.

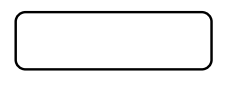

\section{Establishing}
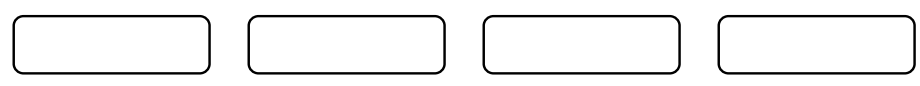

Theoretical proposition 2 - The preneur will undertake actions to establish the preneurial $b a$.

To create the IT innovation, the preneur needs to interact with collective agents, as innovation is a collective process. Agents and actors interact within social structures within which they share common objectives. Therefore, the preneur needs to establish a common social structure within which he/she can interact with collective agents and guide them in their actions to create the IT innovation.

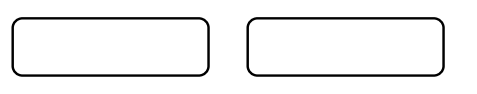

\section{Acquiring}

Theoretical proposition 3 - The preneur will undertake actions associated with articulating and sharing the vision, to attract and acquire the required resources.

For the IT-based preneur, one of the most essential resources to acquire is software development expertise. IT innovation requires software, and software requires programming codes to be developed. The preneur must have the prerequisite level of software development expertise needed to develop the innovation or be able to acquire it. 


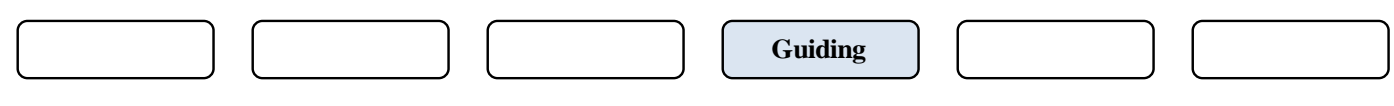

Theoretical proposition 4 - The preneur will undertake actions that show the way to the collective agents and guide their actions so they can combine resources into new combinations to make the innovation tangible.

The preneur may benefit from recognising that the collective agents are travellers in a strange land, with the strange land being the innovative idea and the interactions to make that innovation real. His/her role is to be a guide showing the way to collective actors so they may combine their collective agency in such a way to create the IT innovation.

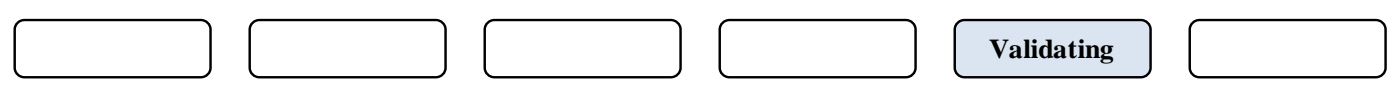

Theoretical proposition 5 - The preneur will undertake actions to demonstrate, validate, and improve the innovation in an agile and adaptive manner.

When the innovative idea becomes tangible for the first time, it is in the form of a rudimentary version. For the first time, the preneur has a working version of the idea that he/she can use to test and validate his/her design assumption. Based on his/her experiences with the beta product, he/she should then seek to improve the design.

This research shows that when acting to validate and improve the rudimentary design, the preneur should act with agility in order to move quickly and make the best use of limited resources.
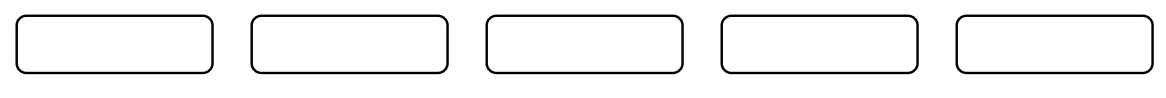

Extricating

Theoretical proposition 6 - The preneur will undertake actions "at some point" that seek to remove him/herself from direct, hands-on involvement with the innovation and its associated PA process. 
Also, at some point, the preneur's agency in the creation of a specific IT innovation will be overtaken by the collective agency of others. The preneur is then able to extricate him/her self from that specific PA process so as to be able to concentrate on his/her role as an institutional actor or to focus on his/her next entrepreneurial activity.

\subsection{Limitations of the research}

Previously within this chapter I have reflected on my use of the grounded theory method and commented on associated issues of rigour, credibility, and validity within this research study. As part of that discussion, I have acknowledged limitations and potential weakness of my research. In this section, I identify and list the real or potential limitations of this research study and its findings

Geographic generalisability - a concern might be raised with the research sample being comprised of preneurs who have links to New Zealand, and more specifically the greater Wellington region, and the consequent generalisability to other countries. There was no suggestion or indication within the research data that the preneurs ability to act preneurially and create the IT innovation was fundamentally changed by their locality. Some of the interviewees had acted preneurially both within New Zealand and internationally. I believe the PA process is not bound within a geographic context, but within the abstracted notion of structure. Further studies encompassing multiple geographic localities and cultures may be required to substantiate the applicability of the Grounded Theory of Preneurial Agency in IT Creation to other geographic regions.

Industry generalisability - because the research was conducted within a specific industry it may be perceived as not being generalisable to other industries. It is probable, even highly likely, that the PA process may be different in other industries. The most obvious difference is that many industries do not have software as a core component of their underlying technology and may be reliant on a much more diverse resource base to create an innovation. Less obvious is the freedom the preneur has to act, to change, prove, improve, and validate their 
innovation. Within this research context the preneur was found to act with agility; however, it could be reasonably assumed that, due to issues of public safety, complexity, and interrelationships, preneurs within contexts such as the pharmacology and aeronautical industries have less freedom.

Completeness - the goal of grounded theory research is to produce just a theory and not an accurate description (Glaser, 2005). The Grounded Theory of Preneurial Agency in IT Creation is just a theory and it is not an accurate description. The theory predicts and explains how preneurs act to create IT innovation; it is open to testing, reinterpretation, and use in other industries and with other types of innovation.

\subsection{Directions for future research}

Earlier in section 8.5.1, Value and implications of the research to academics, I provide a detailed discussion of the benefits of the research findings to academics. Within this section, I identify the main opportunity for future research based on the findings of this study.

This study has shown that the IT artefact is a product of both preneurial and collective agency. Such agency was hinted at by Orlikowski (1992) who sees technology use within institutions being a factor of human agency that is mediated by institutional properties and consequences. Information Technology is not only used by human agents, it is also created by human agency where the interactions are mediated within structures. In order to produce a unifying theory of IT innovation, IT innovation research needs to account for preneurial agency and the agency of collective agents that create the innovation along with the agency of the users or technology. In addition, any such theory needs to account for institutional effects at the larger institutional level and within the preneurial $b a$ as shown within the Structurational Model of Preneurship in IT Creation.

When relating the Theory of Preneurial Agency in IT Creation to the existing Theory of Structuration in Chapter 7, section 7.6, I develop a Structurational 
Model of IT Creation (see Figure 24) to explain how preneurial agency is associated with the preneurial $b a$. This model which draws upon the work of Orlikowski (1992) can in turn be extended this time to account for the transitions of preneurship. In doing so, it provides a framework to guide future research that seeks to account for the actions of both entre and intra preneurs in the creation of IT innovation.

In the later stages of the PA process - Guiding, Validating and Extricating - the preneur's preneurial agency is overtaken by the collective agency and the preneur increasingly extricates him/her self from the process to focus on his/her role as an institutional actor or to pursue the creation of another new innovation.

This additional view of the preneur as an institutional actor is depicted in Figure 28, which extends the Structurational Model of IT Creation, Chapter 7, Figure 25, to include the preneur as an institutional actor within the wider institution.

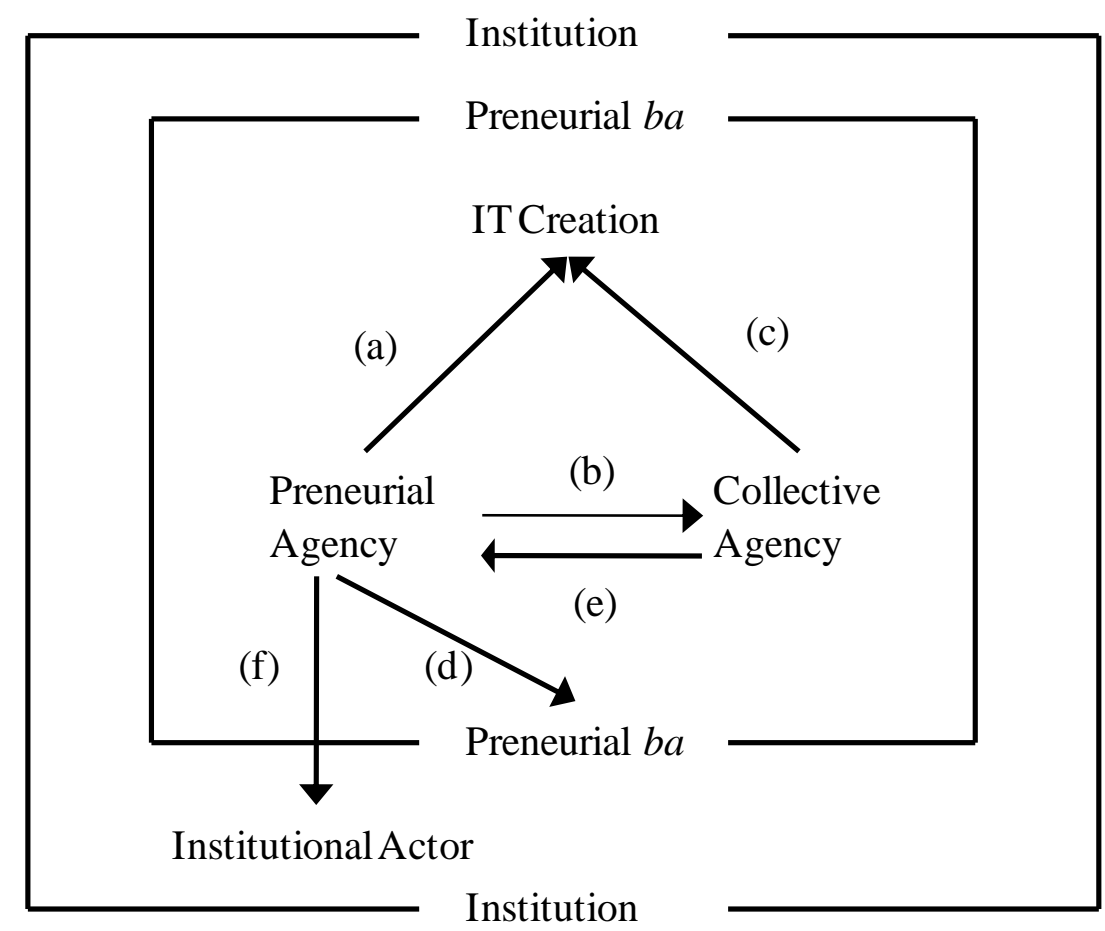

Figure 28: Structurational Model of Preneurship in IT Creation 
Figure 28, also combines and extends Figure 20 in Chapter 6, which depicts the asymmetric flow of information between the preneurial actor and collective agents. When combined together in the extended model, items (a), (b), (c), and (d) relate to how the actions of the preneurial actor and collective agents within the preneurial $b a$ lead to the creation the IT innovation.

Items (b) and (e) show how the interaction and flow of information between the preneur and collective agent is asymmetric. During the Acquiring stage of the PA process the preneur does not share all that he/she knows with the collective agents. Also, as shown in Chapter 6, section 6.2, during the Designing stage the preneur receives more information from the network relationships than he/she shares.

The addition of item (f), institutional actor, shows that as the preneur transitions through the PA process they increasingly become an institutional actor with a functional role within the wider institution, shown as the outer box in Figure 28. The preneurial $b a$ associated with the specific IT innovation is embedded within the wider institution.

The Structurational Model of Preneurship in IT Creation is an agency based view of the IT creation process; it has the potential to provide a testable framework that explains how preneurial actors and collective agents act within structures to create IT innovation.

In addition, this research suggests that IT innovation is largely a dimension of the intellectual property of the preneur and collective agents such as software developers. The IT artefact is seen as a product of intangible resources that is made tangible through software code resident within hardware and Information and Communication Networks. It may be of benefit to undertake further research to understand and measure what resource inputs and combinations are needed to create an IT innovation. 
For researchers within the field of entrepreneurship, this researcher extends the view put forward by Kirzner (1973) that at some point the entrepreneur is no longer a "pure entrepreneur", becoming an (intra) preneur and an institutional actor. This poses the question, "At what point does an entrepreneur become a preneur?" The research also suggests that the preneur's agency is overtaken by the collective agency at some point; therefore, it may be asked, "At what point does the preneur agency become overtake by collective agency?"

The research was limited in terms of both geographic locality and industry, the study provides an opportunity for replication in other contexts.

Finally, it is commonly acknowledged that the terms "entrepreneur" and “entrepreneurship" defy precise definition. Perhaps, through conducting additional research focused on the abstracted view of preneurial agency that recognises both (entre) preneurial and (intra) preneurial agency, a more precise and accepted definition may emerge.

\subsection{Chapter summary}

In this final chapter I have reflected on my journey as a researcher using the grounded theory method, the process that I went through, and the validity and credibility of my research. I show that my research and findings are rigorous, credible, and valid. The value and implications of the research to both academics and practitioners are identified. For academics, the study provides an abstracted agency-based view of (entre) preneurship that explains the actions of both (entre) and (intra) preneurs. Researchers are provided with a triality-based view of preneurship that precedes adoption and use. For practitioners, six main propositions are identified where the preneur must undertake specific actions. The limitations of the research are noted and fall into three main areas: geographic generalisability, industry generalisability, and completeness. Finally, opportunities for future research are suggested and a Structurational Model of Preneurship in IT Creation is provided as a framework to guide future research that seeks to account for the actions of both entre and intra preneurs in the creation of IT innovation. 


\subsection{Concluding statement}

Through following the Glaserian variant of the grounded theory method as recommended for use in IS-based studies a substantive theory of Preneurial Agency in IT Creation has been generated. This has been presented as a model that describes, explains and predicts how preneurial actors act and interact with collective agents to create IT innovation. While the majority of IT innovationbased research has primarily focused on issues of diffusion and use, this research departs from the dominant paradigm and explored how IT innovation is created so that it may then be used.

The Grounded Theory of Preneurial Agency in IT Creation provides an abstracted view of entrepreneurship and intrapreneurship that accounts for the actions entrepreneurs and intrapreneurs undertake to create IT innovation. This abstracted view of preneurship sees the preneur as someone who acts to establish a preneurial $b a$ where they guide the actions of collective agents to make their innovative idea a tangible reality. The view of the preneur that is provided within this study is of someone who transitions external and internal institutional boundaries to create IT innovation and once he/she has extricated him/herself from the innovation specific process become institutional actors.

It is hoped that this research and the contributions arising from it will lead to preneurs improving their practice in each stage of the Preneurial Agency process. It is also hoped that this research may contribute to the development of a Formal Theory of IT innovation, a theory that accounts for how IT-based innovation is not only used and diffused within society but also how it is created through preneurial and collective agency. 
Adams, J. S. (1976). The structural dynamics of behavior in organizational boundary roles. In Dunette, M. D. (Ed.) Handbook of industrial and organizational psychology. Chicago, Rand McNally College Publishing Company.

Ajzen, I., \& Fishbein, M. (1980). Understanding attitudes and predicting social behavior. Englewood Cliffs, N.J, Prentice-Hall.

Akerlof, G. A. (1970). The Market for "Lemons": Quality Uncertainty and the Market Mechanism. The Quarterly Journal of Economics, 84(3): pp. 488-500.

Aldrich, H., \& Herker, D. (1997). Boundary Spanning Roles and Organization Structure. Academy of Management. The Academy of Management Review, 2(2): pp. 217-230.

Aldrich, H. (2001). Who wants to be an evolutionary theorist? Remarks on the occasion of the year 2000 OMT distinguished scholarly career award presentation. Journal of Management Inquiry, 10(2): pp. 115-127.

Allard-Poesi, F. (2005). The Paradox of Sensemaking in Organizational Analysis. Organization 12(2). pp 169-196.

Alvarez, S. A. (2007). Entrepreneurial rents and the theory of the firm. Journal of Business Venturing, 22(3): pp. 427-442.

Ancona, D. G., \& Caldwell, D. F. (1988). Beyond Task and Maintenance Defining External Functions in Groups. Group \& Organization Studies, 13(4): pp. 468-494.

Ancona, D. G., \& Caldwell, D. F. (2007). Improving the Performance of New Product Teams. Research Technology Management, 50(5): pp. 37-43.

Andersen, P. R. (2008). Determining Competency for Entry to Nursing Practice: A Grounded Theory Study. A thesis submitted in fulfilment of the requirements for the Degree of Doctor of Philosophy in Nursing at the Victoria University of Wellington. New Zealand.

Antoncic, B., \& Hisrich, R. (2001). Intrapreneurship: Construct refinement and cross-cultural validation. Journal of Business Venturing, 16(5): pp. 495-527.

Antoncic, B., \& Hisrich, R. (2003). Clarifying the intrapreneurship concept. Journal of Small Business and Enterprise Development, 10(1): pp. 7-24.

Aoyama, M. (1998). Web-based agile software development. IEEE Software, 15(6): pp. 56-65. 
Archer, M. S. (1995). Realist social theory: the morphogenetic approach. New York, Cambridge University Press.

Bandura, A. (1986). Social foundations of thought and action: a social cognitive theory. Englewood Cliffs, N.J., Prentice-Hall.

Bandura, A. (1989). Human Agency in Social Cognitive Theory. The American Psychologist, 44(9): pp. 1178-1184.

Bandura, A. (1996a). Reflections on Human Agency: Part I. Constructivism in the Human Sciences, 1(2): pp. 3-12.

Bandura, A. (1996b). Reflections on Human Agency: Part II. Constructivism in the Human Sciences, 1(3/4): pp. 5-15.

Baskerville, R., \& Pries-Heje, J. (2004). Short cycle time systems development. Information Systems Journal, 14(3): pp. 237-264.

Beekhuyzen, J. (2007). Putting the Pieces of the Puzzle Together: Using Nvivo for a Literature Review. 4th QUALIT Conference - Qualitative Research in IT \& IT in Qualitative Research Wellington, New Zealand.

Brown, S. B., \& Duguid, P. (2001). Knowledge and organization: A socialpractice perspective. Organization Science, 12(2): pp. 198-213.

Brush, C. G., Duhaime, I. M., Gartner, W. B., Stewart, A. K., Jerome, A., Hitt, M. A., Alvarez, S. A., Meyer, G. D., \& Venkataraman, S. (2003). Doctoral Education in the Field of Entrepreneurship. Journal of Management, 29(3): pp.309-331.

Brunåker, S., \& Kurvinen, J. (2006). Intrapreneurship, local initiatives in organizational change processes. Leadership \& Organization Development Journal, 27(2): pp. 118-132.

Bryant, A. \& Charmaz, K. (2007a). Grounded Theory Research: Methods and Practices. In: Bryant, A. \& Charmaz, K. (Eds.). The Sage Handbook of Grounded Theory. London, Sage Publications.

Bryant, A. \& Charmaz, K. (2007b). Grounded Theory in Historical Perspective: An Epistemological Account. In: Bryant, A. \& Charmaz, K. (Eds.). The Sage Handbook of Grounded Theory. London, Sage Publications.

Burgelman, R. A. (1983). Corporate Entrepreneurship and Strategic Management: Insights from a Process Study. Management Science, 29(12): pp. 1349-1364.

Burt, R. S. (1983). Distinguishing Relational Contents. In Burt, R. S., \& Minor, M. J. (Eds.) Applied Network Analysis: A Methodological Introduction.

Beverly Hills, California, Sage Publications. 
Burt, R. S. (1992). Structural Holes: The Social Structure of Competition. Harvard University Press, Cambridge, MA.

Burt, R. S. (2005). Brokerage and Closure: An Introduction to Social Capital. Oxford University Press.

Burt, R. S. (2007). Secondhand Brokerage: Evidence on the Importance of Local Structure for Managers, Bankers, and Analysts. Academy of Management Journal, 50(1): pp. 119-148.

Carlile, P. R. (2002). A pragmatic view of knowledge and boundaries: Boundary objects in new product development. Organization Science, 13(4): pp. 442455.

Carlile, P. R., \& Rebentisch, E. S. (2003). Into the black box: The knowledge transformation cycle. Management Science, 49(9): pp. 1180-1195.

Carlile, P. R. (2004). Transferring, Translating, and Transforming: An Integrative Framework for Managing Knowledge Across Boundaries. Organization Science, 15(5): pp. 555-568.

Carter, M. (2006). Entrepreneurship and Marketing. The Oxford Handbook of Entrepreneurship. In Casson, M., Yeung, B., Basu, A., \& Wadeson, N. (Eds.). The Oxford Handbook of Entrepreneurship. Oxford, Oxford University Press.

Caruana, A., Morris, M. H., \& Vella, A. (1998). The effect of centralization and formalization on entrepreneurship in export firms. Journal of Small Business Management, 36(1): pp. 16-29.

Cassell, C., \& Symon, G. (2004). Essential Guide to Qualitative Methods in Organization Research. London, Sage Publications.

Cassis, Y., \& Minoglou, I. P. (2005). Entrepreneurship in Theory and History: State of the Art and New Perspectives. In Cassis, Y., \& Minoglou, I. P. (Eds.). Entrepreneurship in Theory and History. Palgrave MacMillan.

Casson, M. (1982). The entrepreneur: an economic theory, Oxford: Martin Robertson.

Casson, M., \& Godley, A. (2005). Entrepreneurship and Historical Explanation. In Cassis, Y., \& Minoglou, I. P. (Eds.). Entrepreneurship in Theory and History. Palgrave MacMillan.

Casson, M., Yeung, B., Basu, A., \& Wadeson, N. (2006). Introduction. In Casson, M., Yeung, B., Basu, A., \& Wadeson, N. (Eds). The Oxford Handbook of Entrepreneurship. Oxford, Oxford University Press. 
Charmaz, K. (2006). Constructing Grounded Theory: A Practical Guide Through Qualitative Analysis. London, Sage Publications Ltd.

Cheuk, B. (2008). Applying Sense-making Methodology to Design Knowledge Management Practices. International Journal of Knowledge Management, 4(3). pp. 33.43 .

Chisholm, T. A. (1987). Intrapreneurship and Bureaucracy. S.A.M. Advanced Management Journal, 52(3): pp. 36-40.

Cho, S., \& L. Mathiassen (2007). The role of industry infrastructure in telehealth innovations: a multi-level analysis of a telestroke program. European Journal of Information Systems, 16: pp. 738-750.

Chu, T-H. \& Robey, D. (2008). Explaining changes in learning and work practice following the adoption of online learning: a human agency perspective. European Journal of Information Systems, 17(1): pp. 79-98.

Chua, W. F. (1986). Radical Developments in Accounting Thought. The Accounting Review, 61: pp. 601-632.

Coleman, J. S. (1988). Social Capital in the Creation of Human Capital. The American Journal of Sociology, 94: pp. s95-s120

Cooper, R. B. \& Zmud, R. W. (1990). Information Technology Implementation Research: A Technological Diffusion Approach. Management Science, 36(2): pp.123-139.

Corbin, J., \& Strauss, A. (2008). Basics of Qualitative Research: Techniques and Procedures for Developing Grounded Theory. Thousand Oaks, CA, Sage Publications.

Courvisanos, J. (2007). The Ontology of innovation: Human agency in the pursu it of novelty. History of Economics Review, Winter: 20: pp. 41-59.

Covin, J. G., \& Morgan, P. M. (1999). Corporate entrepreneurship and the pursuit of competitive advantage. Entrepreneurship Theory and Practice, 23(47): pp. 47-63.

Creswell, J. W. (2003). Research Design: Qualitative, Quantitative, and Mixed Methods Approaches. Thousand Oaks, California, Sage Publications.

Cunningham, J. B., \& Lischeron, J. (1991). Defining Entrepreneurship. Journal of Small Business Management, 29(1): pp. 45-61.

Daft, R. L. (1978). A Dual-Core Model of Organizational Innovation. Academy of Management Journal, 21(2): pp. 193-210. 
Davis, F. D. (1986). A technology acceptance model for empirically testing new end-user information systems : theory and results. A thesis submitted in fulfilment of the requirements for the Degree of Doctor of Philosophy at Sloan School of Management, Massachusetts Institute of Technology.

Davis, F. D., Bagozzi, R. P. \& Warshaw, P. R. (1989). User Acceptance Of Computer Technology: A Comparison Of Two. Management Science 35(8): pp 982-1003.

Denzin, N. K. \& Lincoln, Y. S. (1998a). Introduction to This Volume. In: Denzin, N. K. \& Lincoln, Y. S. (Eds.). Strategies of Qualitative Inquiry. Thousand Oaks, California, Sage Publications.

Denzin, N. K. \& Lincoln, Y. S. (1998b). Entering the Field of Qualitative Research. In: Denzin, N. K. \& Lincoln, Y. S. (Eds.). Strategies of Qualitative Inquiry. Thousand Oaks, California, Sage Publications.

Dew, N., Velamuri, S. R., \& Venkataraman, S. (2004). Dispersed knowledge and an entrepreneurial theory of the firm. Journal of Business Venturing, 19(5): pp.659-679.

Dey, I. (1999). Grounding Grounded Theory: Guidelines for Qualitative Inquiry. San Diego, Academic Press.

Dictionary, S. O. E. (1973). Shorter Oxford English Dictionary: On Historical Principles C. T. Onions. Oxford, UK, Oxford University Press.

DiMaggio, P. (1988). Interest and agency in institutional theory. In: Zucker, L. G. (Ed.). Institutional patterns and organizations: culture and environment. Cambridge, MA, Ballinger Publishing Company.

Dodgson, M. (1994). Technological collaboration and innovation. In Dodgson, M. \& Rothwell, R. (Eds.) The Handbook of Industrial Innovation. Chelthenham, Edward Elgar Publishing.

Dubini, P., \& Aldrich, H. (1991). Personal and Extended Networks are Central to the Entrepreneurial Process. Journal of Business Venturing, 6(5): pp. 305-313.

Edmondson, A. C. \& Nembhard, I. M. (2009). Product Development and Learning in Project Teams: The Challenges Are the Benefits. The Journal of Product Innovation Management, 26(2). pp. 123-138.

Emirbayer, M., \& Mische, A. (1998). What is agency? The American Journal of Sociology, 103(4): pp. 962-1023.

Etemad, H. (2004). International Entrepreneurship as a Dynamic Adaptive System: Towards a Grounded Theory. Journal of International Entrepreneurship, 2(1-2): pp. 5-59. 
Fernandez, W. D., Lehmann, H., \& Underwood, A. (2002). Rigor and Relevance in Studies of IS Innovation: A Grounded Theory Methodology Approach. ECIS 2002 Proceedings. Paper 134.

Fernandez, W. D. (2003). Metateams in Major Information Technology Projects: A grounded theory of conflict, trust, communication and cost. A thesis submitted in fulfilment of the requirements for the Degree of Doctor of Philosophy at the Queensland University of Technology. Brisbane.

Fichman, M. \& Levinthal, D. A. (1991). Honeymoons and the Liability of Adolescence: A New Perspective on Duration Dependence in Social and Organizational Relationships. Academy of Management. The Academy of Management Review, 16(2): pp. 442-468.

Fichman, R. G. (2004). Going Beyond the Dominant Paradigm for Information Technology Innovation Research: Emerging Concepts and Methods. Journal of the Association for Information Systems, 5(8): pp. 314-355.

Fishbein, M., \& Ajzen, I. (1975). Belief, attitude, intention, and behavior : an introduction to theory and research. Reading, Mass, Addison-Wesley Pub. Co.

Fligstein, N. (1997). Social skill and institutional theory. The American Behavioural Scientist, 40(4): pp. 397-405.

Frederick, H. H., \& Carswell, P. J. (2001). Global Entrepreneurship Monitor New Zealand 2001. New Zealand Centre for Innovation and Entrepreneurship. Auckland.

Garud, R., Jain, S., \& Kumaraswamy, A. (2002). Institutional entrepreneurship in the sponsorship of common technological standards: The case of Sun Microsystems and Java. Academy of Management Journal, 45(1): pp. 196-214.

Garud, R., \& P. Karnøe (2003). Bricolage versus breakthrough: Distributed and embedded agency in technology entrepreneurship. Research Policy, 32(2): pp. 277-300.

Garud, R., Hardy, C., \& MaGuire, S. (2007). Institutional Entrepreneurship as Embedded Agency: An Introduction to the Special Issue. Organization Studies, 28(7): pp. 957-969.

Giddens, A. (1979). Central Problems in Social Theory: Action, Structure and Contradiction in Social Analysis. Berkeley and Los Angeles, University of California Press.

Giddens, A. (1984). The Constitution of Society: Outline of the Theory of Structuration. Berkeley and Los Angeles, University of California Press. 
Giddens, A., \& Pierson, C. (1998). Conversations with Anthony Giddens : making sense of modernity. Stanford, California, Stanford University Press.

Glaser, B., \& Strauss, A. (1967). The discovery of grounded theory; strategies for qualitative research. Chicago, Aldine Publishing Company.

Glaser, B. G. (1978). Theoretical Sensitivity: Advances in the Methodology of Grounded Theory. Mills Valley, CA, The Sociology Press.

Glaser, B. G. (1992). Emerging vs. Forcing: basics of grounded theory analysis. Mill Valley, CA, The Sociology Press.

Glaser, B. G. \& Holton, J. A. (2004). Remodelling Grounded Theory. The Grounded Theory Review: An international journal, 4(1). pp. 1-24.

Glaser, B. (2005). The grounded theory perspective III: theoretical coding. Mill Valley, CA, Sociology Press.

Glaser, B. G. (2007). Doing Formal Grounded Theory: A Proposal. Mill Valley, CA, Sociology Press.

Glaser, B. G. (2007). Doing Formal Theory. In: Bryant, A. \& Charmaz, K. (Eds.). The Sage Handbook of Grounded Theory. London, Sage Publications.

Goulding, C. (2005). Grounded theory, ethnography and phenomenology: A comparative analysis of three qualitative strategies for market research. European Journal of Marketing 39(3-4). pp. 294-308.

Gourlay, S. (2006). Conceptualizing Knowledge Creation: A Critique of Nonaka's Theory. The Journal of Management Studies, 43(7): pp.1415-1436.

Granovetter, M. S. (1973). The Strength of Weak Ties. The American Journal of Sociology, 78(6): pp. 1360-1380.

Granovetter, M. S. (1985). Economic Action and Social Structure: The Problem of Embeddedness. The American Journal of Sociology, 91(3): pp. 481-510.

Granovetter, M. S. (2005). The Impact of Social Structure on Economic Outcomes. The Journal of Economic Perspectives, 19(1): pp. 33-50.

Gregor, S. (2006). The Nature of Theory in Information Systems. MIS Quarterly, 30(3): pp. 611-642.

Guba, E. G. \& Lincoln, Y. S. (1994). Competing Paradigms in Qualitative Research. In: Denzin, N. K. \& Lincoln, Y. S. (Eds.). Handbook of Qualitative Research. Thousand Oaks, California, Sage Publications. 
Gulati, R. (1998). Alliances and networks. Strategic Management Journal, 19(4): pp. 293-317.

Gulati, R. (2007). Managing Network Resources: Alliances, Affiliations and Other Relational Assets, Oxford University Press.

Hammersley, M. (2001). On 'Systematic' reviews of research literatures: A 'narrative' response to Evans \& Benefield. British Educational Research Journal, 27(5): pp. 543-554.

Hawley, F. B. (1913). The Definition of Economics. The American Economic Review, 3(3): pp. 606-609.

Hawley, F. B. (1927). The Orientation of Economics on Enterprise. The American Economic Review, 17(3): pp. 409-428.

Hayek, F. A. (1937). Economics and Knowledge. Economica, New Series, 4(13): pp.33-54.

Hayek, F. A. (1945). The Use of Knowledge in Society. The American Economic Review, 35(4): pp. 519-530.

Hexmoor, H., Wilson, S., \& Bhattaram, S. (2006). A theoretical interorganizational trust-based security model. The Knowledge Engineering Review, 21(2): pp. 127-161.

Hildreth, P. M. \& Kimble, C. (2002). The duality of knowledge. Information Research, 8(1).

Hirschheim, R. (1992). Information Systems Epistemology. In: Gallier, R. (Ed.).An Historical Perspective. Information Systems Research. Issues, Methods and Practical Guidelines. Oxford, Blackwell Scientific Publications: 39.

Hoffman, A. J. (1999). Institutional evolution and change: Environmentalism and the U.S. chemical industry. Academy of Management Journal, 42(4): pp. 351372.

Houde, S. C. (2009). The Systematic Review of the Literature: A Tool for Evidence-Based Policy. Journal of Gerontological Nursing, 35(9): pp. 9-12.

Hunter, I. (2005). Risk, persistence and focus: a life cycle of the entrepreneur. Australian Economic History Review, 45(3): pp. 244-272.

Hunter, I. and M. Wilson (2007). Origins and opportunity: 150 years of New Zealand entrepreneurship. Journal of Management and Organization, 13(4): pp. 295-311. 
Ichijo, K., \& Nonaka, I. (2007). Introduction: Knowledge as Competitive Advantage in the Age of Increasing Globalization. In Ichijo, K., \& Nonaka, I. (Eds.). Knowledge Creation and Management: New Challenges for Managers. New York, Oxford University Press.

Ireland, R. D., Kuratko, D.F., \& Morris, M. H. (2006). A health audit for corporate entrepreneurship: innovation at all levels: part I. The Journal of Business Strategy, 27(1): pp. 10-17.

Janesick, V. J. (1998). The Dance of Qualitative Research Design: Metaphor, Methodolatry, and Meaning. In: Denzin, N. K. \& Lincoln, Y. S. (Eds.). Strategies of Qualitative Inquiry. Thousand Oaks, California, Sage Publications.

Johnson, J. D., \& Chang, H. J. (2000). Internal and external communication, boundary spanning, and innovation adoption: An over-time comparison of three explanations of internal and external innovation Communication in a New Organizational Form. The Journal of Business Communication, 37(3): pp. 238-263.

Jones, T., \& Evans, D. (2000). Conducting a systematic review. Australian Critical Care, 13(2): pp 66-71.

Jones, M. R., \& Karsten, H. (2008). Giddens's Structuration Theory and Information Systems Research. MIS Quarterly, 32(1): pp. 127-157.

Kalantaridis, C. (2004). Understanding the Entrepreneur: An Institutionalist Perspective. Aldershot, Ashgate Publishing Limited.

Katila, R. \& S. Shane (2005). When does lack of resources make new firms innovative? Academy of Management Journal, 48(5): pp. 814-829.

Kenny, M. G. (2009). The effect of academic entrepreneurship on overall faculty job satisfaction: A comparison of academic entrepreneurs and traditional professors. United States Association for Small Business and Entrepreneurship. Boca Raton: 32: pp. 1224-1255.

King, J., Gurbaxani, V., Kraemer, K., McFarlan, F., Raman, K. \& Yap, C. King, (1994). Institutional factors in information technology innovation. Information Systems Research, 5(2): pp. $139-169$.

Kirzner, I. M. (1973). Competition and Entrepreneurship. Chicago, University of Chicago Press.

Kirzner, I. M. (1997). Entrepreneurial discovery and the competitive market process: An Austrian approach. Journal of Economic Literature, 35(1): pp.6085. 
Kirzner, I. M. (2000). Entrepreneurial discovery and the law of supply and demand. Ideas on Liberty, 50(2): pp. 17-19.

Kiessling, T. S. (2004). Entrepreneurship and Innovation: Austrian School of Economics to Schumpeter to Drucker to Now. Journal of Applied Management and Entrepreneurship, 9(1): pp. 80-91.

Klein, H. K. \& Meyers, M. D. (1999). A Set of Principles for Conducting and Evaluating Interpretive Field Studies in Information Systems. MIS Quarterly, 23(Special Issue on Intensive Research 1): pp. 67-88.

Klein, G., Moon, B., \& Hoffman, R. R. (2006). Making Sense of Sensemaking 1: Alternative Perspectives. IEEE Intelligent Systems, 21(4). pp. 70-73.

Knight, F. H. (1921). Risk, Uncertainty, and Profit, Boston, MA: Hart, Schaffner \& Marx; Houghton Mifflin Company.

Kolchin, M. G., \& Hyclak, T. (1987). The Case of the Traditional Intrapreneur. S.A.M. Advanced Management Journal, 52(3): pp. 14-18.

Lane, C. (1998). Theories and issues in the study of trust. In Lane, C. \& Bachmann, R. (Eds.). Trust Within and Between Organizations. New York, Oxford University Press.

Lavie, D. (2006). The Competitive Advantage of Interconnected Firms: An Extension of the Resource-Based View. Academy of Management. The Academy of Management Review, 31(3): pp. 638-658.

Lavie, D. (2007). Alliance portfolios and firm performance: A study of value creation and appropriation in the U.S. software industry. Strategic Management Journal, 28(12): pp. 1187-1212.

Lehmann, H. (2001a). A Grounded Theory of International Information Systems. Management Science and Information Systems. A thesis submitted in fulfilment of the requirements for the Degree of Doctor of Philosophy at the University of Auckland. Auckland.

Lehmann, H. (2001b). Using Grounded Theory with Technology Cases: Distilling Critical Theory from a Multinational Information Systems Development Project. Journal of Global Information Technology Management, 4(1): pp. 4560.

Lehmann, H. (2010). The dynamics of international information systems: anatomy of a grounded theory investigation. New York; London, Springer.

Lempert, L. B. (2007). Asking Questions of the Data: Memo Writing in Grounded Theory Tradition. In: Bryant, A.\& Charmaz, K. (Eds.). The Sage Handbook of Grounded Theory. London, Sage Publications. 
Levina, N., \& Vaast, E. (2005). The Emergence of Boundary Spanning Competence in Practice: Implications for Implementation and Use of Information Systems. MIS Quarterly, 29(2): pp. 335-363.

Lings, B. \& Lundell, B. (2005). On the adaptation of Grounded Theory procedures: insights from the evolution of the $2 \mathrm{G}$ method. Information Technology \& People, 18(3): pp. 196-211.

LoBiondo-Wood, G., \& Haber, J. Eds. (1994). Nursing Research: Methods, Critical Appraisal, and Utilization. St Louis, USA, Mosby.

Lounsbury, M., \& Crumley, E. T. (2007). New Practice Creation: An Institutional Perspective on Innovation. Organization Studies, 28(7): pp. 993-1012.

Lyytinen, K., \& Rose, G. M. (2006). Information system development agility as organizational learning. European Journal of Information Systems, 15(2): pp. 183-199.

Luchsinger, V., \& Bagby, D. R. (1987). Entrepreneurship and Intrapreneurship: Behaviors, Comparisons, and Contrasts. S.A.M. Advanced Management Journal, 52(3): pp. 10-13.

Lucas Jr, H. C., Swanson, E. B., \& Zmud, R. W. (2007). Implementation, Innovation, and Related Themes over the Years in Information Systems Research. Journal of the Association for Information Systems, 8(4): pp. 206210.

Luke, B., Verreynne, M-L., \& Kearins, K. (2007). Measuring the benefits of entrepreneurship at different levels of analysis. Journal of Management and Organization, 13(4): pp. 312-330.

MacIntyre, A. (1984). The claims of "After Virtue". Analyse und Kritik, 6(1): pp. 3-7.

MaGuire, S., Hardy, C., \& Lawrence, T. B. (2004). Institutional Entrepreneurship in Emerging Fields: Hiv/Aids Treatment Advocacy In Canada. Academy of Management Journal, 47(5): pp. 657-679.

Mantzoukas, S. (2005). The inclusion of bias in reflective and reflexive research: A necessary prerequisite for securing validity. Journal of Research in Nursing, 10(3): pp. 279-295.

Markus, M. L., Saunders, S. (2007). Editor's Comments. MIS Quarterly, 31(1): 4.

Markus, M. L. (2009). Building IS Theory: Difficulties and Directions. Workshop on Theory Building. HEC Montreal, Montreal, Canada. 
Martin, P., Y. \& Turner, B. A. (1986). Grounded Theory and Organizational Research. The Journal of Applied Behavioral Science, 22(2): pp. 141-157.

Massey, A. P., \& Montoya-Weiss, M. M. (2006). Unravelling the Temporal Fabric of Knowledge Conversion: A Model of Media Selection and Use. MIS Quarterly, 30(1): pp. 99-114.

Matlay, H. (2005). Researching entrepreneurship and education: Part 1: what is entrepreneurship and does it matter? Education \& Training, 47(8/9): pp. 711724

Melville, N., \& Ramirez, R. (2008). Information technology innovation diffusion: an information requirements paradigm. Information Systems Journal, 18(3): pp. 247-273.

Metcalfe, J. S. (2006). Entrepreneurship: an Evolution. In Casson, M., Yeung, B., Basu, A., \& Wadeson, N. (Eds). The Oxford Handbook of Entrepreneurship. Oxford, Oxford University Press.

McGhee, G., Marland, G. R., \& Atkinson, J. (2007). Grounded theory research: literature reviewing and reflexivity. Journal of Advanced Nursing, 60(3): pp. 334-342.

Miller, D. (1983). The Correlates of Entrepreneurship in Three Types of Firms. Management Science, (pre-1986) 29(7): pp. 770-792.

Mises, L. (1949). Human Action: A Treatise on Economic. New Haven, Yale University Press.

Mitchell, V. L. (2006). Knowledge Integration and Information Technology Project Performance. MIS Quarterly, 30(4): pp. 919-939.

Mitchell, R., \& Nicholas, S. (2006). Knowledge creation through boundaryspanning. Knowledge Management Research \& Practice, 4(4): pp. 310-318.

Monnavarian, A., \& Ashena, M. (2009). Intrapreneurship: the role of social capital - empirical evidence and proposal of a new model of intrapreneurship and its relationship with social capital. Business Strategy Series, 10(6): pp. 383-399.

Moreno Jr, V. (1999). On the social implications of organizational reengineering A phenomenological study of individual experiences of BPR processes. Information Technology \& People, 12(4). pg. 359.

Morris, M. H., \& Paul, G. W. (1987). The Relationship Between Entrepreneurship and Marketing in Established Firms. Journal of Business Venturing, 2: pp. 247259. 
Morris, M. H., \& Trotter, D. J. (1990). Institutionalizing Entrepreneurship in a Large Company: A Case Study at AT\&T. Industrial Marketing Management, 19(2): pp. $131-139$.

Morris, M. H., \& Lewis, P. S. (1995). The determinants of entrepreneurial activity: Implications for marketing. European Journal of Marketing, 29(7): pp. 31-49.

Morris, M. H. (2001). From the Editor: The critical role of resources. Journal of Developmental Entrepreneurship, 6(2): pp. v-vii.

Morris, M. H. (2002). From the editor: The entrepreneur as a guerrilla. Journal of Developmental Entrepreneurship, 7(2): pp. v-vi.

Morris, M. H. (2003). Reflections on the advancement of the field and the JDE. Journal of Developmental Entrepreneurship, 8(2): pp. v-vi

Morse, J. M. (2009). Tussles, Tensions, and Resolutions. In: Morse, J. M., Stern, P. N., Corbin, J., Bowers, B., Charmaz, K., \& Clarke, A. E. (Eds.). Developing Grounded Theory: The Second Generation. Walnut Creek, California, Left Coast Press.

Myers, M. D. (1997). Qualitative research in information systems. MIS Quarterly, 21(2): pp. 241-242.

Nonaka, I. (1991). The Knowledge-Creating Company. Harvard Business Review, 69(6): pp. 96-104.

Nonaka, I. (1994). A dynamic theory of organizational knowledge creation. Organization Science, 5(1): pp. 14-37.

Nonaka, I., \& Takeuchi, H. (1995). The Knowledge-Creating Company: How Japanese Companies Create the Dynamics of Innovation. New York, Oxford University Press.

Nonaka, I., \& Konno, N. (1998). The concept of "ba": Building a foundation for knowledge creation. California Management Review, 40(3): pp. 40-54.

Nonaka, I., Toyama, R., \& Konno, N. (2000). SECI, ba and leadership: A unified model of dynamic knowledge creation. Long Range Planning, 33(1). pp. 5-34.

Nonaka, I., \& Toyama, R. (2003). The knowledge-creating theory revisited: knowledge creation as a synthesizing process. Knowledge Management Research \& Practice, 1(1): pp. 2-10.

Nonaka, I., \& Toyama, R. (2005). The theory of the knowledge-creating firm: subjectivity, objectivity and synthesis. Industrial and Corporate Change, 14(3): pp. 419-436. 
Nonaka, I., von Krogh, G., \& Voelpel, S. (2006). Organizational Knowledge Creation Theory: Evolutionary Paths and Future Advances. Organization Studies, 27(8): pp. 1179-1208.

Nonaka, I., \& Toyama, R. (2007). Strategic management as distributed practical wisdom (phronesis). Industrial and Corporate Change, 16(3): pp. 371-394.

Nonaka, I., \&Toyama, R. (2007). Why Do Firms Differ? The Theory of the Knowledge-Creating Firm. In: Ichijo, K. \& Nonaka, I. (Eds.). Knowledge Creation and Management: New Challenges for Managers. New York, Oxford University Press.

Nonaka, I., von Krogh, G., \& Voelpel, S. (2006). Organizational Knowledge Creation Theory: Evolutionary Paths and Future Advances. Organization Studies, 27(8): pp. 1179-1208.

Nonaka, I., \& von Krogh, G. (2009). Tacit Knowledge and Knowledge Conversion: Controversy and Advancement in Organizational Knowledge Creation Theory. Organization Science, 20(3): pp. 635-652.

Oakley, A. (2002). Popper's ontology of situated human action. Philosophy of the Social Sciences, 32(4): pp. 455-486.

Orlikowski, W. J., \& Baroudi, J. J. (1991). Studying Information Technology in Organizations: Research Approaches and Assumptions. Information Systems Research, 2(1): pp. 1-28.

Orlikowski, W. J. (1992). The Duality of Technology: Rethinking the Concept of Technology in Organizations. Organization Science, 3(3): pp. 398-427.

Orlikowski, W. J. (1993). CASE tools as organizational change: Investigating incremental and radical changes in systems development. MIS Quarterly, 17(3): pp. 309-340.

Orlikowski, W. J. (2000). Using technology and constituting structures: A practice lens for studying technology in organizations. Organization Science, 11(4): pp. 404-428.

Patton, M. Q. (2002). Qualitative Research \& Evaluation Methods. Thousand Oaks, California Sage Publications.

Pawlowski, S., \& Robey, D. (2004). Bridging User Organizations: Knowledge Brokering and The Work Of Information Technology Professionals. MIS Quarterly, 28(4): pp. 645-672.

Pender, M. (2009). The Meaning of Entrepreneurship: A Modular Concept. Journal of Industry, Competition and Trade, 9(2): pp. 77-99. 
Peteraf, M. A., \& Barney, J. B. (2003). Unravelling The Resource-Based Tangle. Managerial and Decision Economics 24(4): pp. 309-323.

Pentland, B. T. (1999). Building process theory with narrative: From description to explanation. Academy of Management. The Academy of Management Review, 24(4): pp. 711-724.

Pickard, A. J. (2007). Research methods in information. London, Facet.

Pinchot, G. (1985). Intrapreneuring. New York, Harper \& Row, Publishers.

Polanyi, M. (1966). The tacit dimension. London, Rutledge \& Kegan Paul.

Rao, H. (1998). Caveat emptor: The construction of nonprofit consumer watchdog organizations. The American Journal of Sociology, 103(4): pp. 912-961.

Reed, J. \& Procter, S. (1995). Practitioner research in context. In: Reed, J. \& Procter, S (Eds.). Practitioner research in health care: the inside story. London, Chapman and Hall.

Reynolds, E. V., \& Johnson, D. J. (1982). Liaison Emergence: Relating Theoretical Perspectives. Academy of Management. The Academy of Management Review, 7(4): pp. 551-559.

Ricketts, M. (2006). Theories of Entrepreneurship: Historical Development and Critical Assessment. In Casson, M., Yeung, B., Basu, A., \& Wadeson, N. (Eds). The Oxford Handbook of Entrepreneurship. Oxford, Oxford University Press.

Rodrigues, G. (2010). Intrapreneurship in a Fast Growing Economy: A Study of the Emirates of Dubai. The Business Review, 15(2): pp. 144-151.

Santos, F. M. \& K. M. Eisenhardt (2005). Organizational Boundaries and Theories of Organization. Organization Science, 16(5): pp. 491-508.

Sathe, V. (1985). Managing an Entrepreneurial Dilemma: Nurturing Entrepreneurship and Control in Large Corporations. Frontiers of Entrepreneurship Research: 21.

Sathe, V. (2003). Corporate Entrepreneurship: Top Managers and New Business Creation. Cambridge, Cambridge University Press.

Schindehutte, M., Morris, M. H., \& Kuratko, D.F (2000). Triggering events, corporate entrepreneurship and the marketing function. Journal of Marketing Theory and Practice, 8(2): pp. 18-30.

Schumpeter, J. A. (1934). The Theory of Economic Development, Harvard University Press, Cambridge, MA. 
Schutz, A. (1967). The phenomenology of the social world (G. Walsh \& F. Lehnert, Trans.). Evanston, IL: Northwestern University. (Original work published in 1932).

Scott, R. W. (2008). Approaching adulthood: the maturing of institutional theory. Theory and Society, 37(5): pp. 427-442.

Scott, R. W. (2010). Reflections: The Past and Future of Research on Institutions and Institutional Change. Journal of Change Management, 10(1): pp. 5-21.

Seldén, L. (2005). On Grounded Theory - with some malice. Journal of Documentation, 61(1): pp. 114-129.

Sewell, W. (1992). A Theory of Structure: Duality, Agency, and Transformation. The American Journal of Sociology, 98(1): pp. 1-29.

Shane, S. (2000). Prior knowledge and the discovery of entrepreneurial opportunities. Organization Science, 11(4): pp. 448-469.

Shane, S. (2002). Selling university technology: Patterns from MIT. Management Science, 48(1): pp. 122-137.

Shane, S. (2003). A general theory of entrepreneurship: the individualopportunity nexus Cheltenham, Edward Elgar Publishing Limited.

Shane, S., \& Cable, D. (2002). Network ties, reputation, and the financing of new ventures. Management Science, 48(3): pp. 364-381.

Shane, S., \& Venkataraman, S. (2000). The promise of entrepreneurship as a field of research. Academy of Management. The Academy of Management Review, 25(1): pp. 217-226.

School of Information Management (2009). School of Information Management: Research Degrees Handbook, Victoria University of Wellington.

Snowden, D. J. (2005). From atomism to networks in social systems. The Learning Organization, 12(6). pp. 552-562.

Strauss, A. (1987). Qualitative analysis for social scientists New York, Cambridge University Press.

Strauss, A. \& Corbin, J. (1990). Basics of Qualitative Research, Grounded Theory, Procedures and Techniques. London, Sage.

Stern, P. N. (1994). Eroding Grounded Theory. In: Morse, J. M. (Ed.). Critical issues in qualitative research methods. Thousand Oaks, California, Sage Publications. 
Stevenson, H. H. \& Jarillo, J. C. (1990). A Paradigm of Entrepreneurship:

Entrepreneurial Management. Strategic Management Journal, 11: pp. 17-27.

Swanson, E. B. (1994). Information systems innovation among organizations. Management Science, 40(9): pp. 1069-1092.

Swanson, E. B. \& Ramiller, N. (1997). The organizing vision in information systems innovation. Organization Science, 8(5): pp. 458-474.

Swanson, E. B. \& Ramiller, N. (2004). Innovating Mindfully With Information Technology. MIS Quarterly, 28(4): pp. 553-583.

Thistoll, A., Pauleen, D., \& Hooper, V. (2009). Using NVivo to Conduct a Grounded Literature Review: An Application in Innovation and Entrepreneurship Research. 4th European Conference on Entrepreneurship and Innovation. The University of Antwerp, Belgium.

Thistoll, T. \& Pauleen, D. (2010). Commercialising innovation internationally: A case study of social network and relationship management. Journal of International Entrepreneurship, 8(1). pp. 36-54.

Tsoukas, H. (1996). The Firm as a Distributed Knowledge System: A Constructionist Approach. Strategic Management Journal, (1986-1998) 17(Winter Special Issue): pp. 11-25.

Tsoukas, H. (2003). Do we really understand tacit knowledge? In Easterby-Smith, M., \& Lyles, M. A. (Eds.). The Blackwell Handbook of Organizational Learning and Knowledgement. Oxford, UK, Blackwell.

Tushman, M. L. (1977). Special Boundary Roles in the Innovation Process. Administrative Science Quarterly, 22(4): pp. 587-605.

Urquhart, C. (2001). An encounter with Grounded Theory: Tackling the Practical and Philosophical Issues. In: Trauth, E. M. (Ed). Qualitative Research in IS: Issues and Trends. Hershey P.A., Idea Group publishing.

Urquhart, C. \& Fernandez, W. (2006). Grounded Theory Method: The Researcher as Blank Slate and Other Myths. ICIS 2006 Proceedings.

Urquhart, C. (2007). The Evolving Nature of Grounded Theory Method: The Case of the Information System Discipline. In Bryant, A., \& Charmaz, K. (Eds.). The Sage Handbook of Grounded Theory. London, Sage Publications.

Urquhart, C., Lehmann, H. \& Myers, M. D. (2009). Putting the 'theory' back into grounded theory: guidelines for grounded theory studies in information systems. Information Systems Journal, Early View, June 2009. 
Van de Ven, A. H. (1993a). The development of an infrastructure for entrepreneurship. Journal of Business Venturing, 8(3): pp. 211-230.

Van de Ven, A. H. (1993b). The emergence of an industrial infrastructure for technological innovation. Journal of Comparative Economics, 17(2): pp. 338365.

Van de Ven, A. H, \& Engleman, R. M. (2004). Event- and outcome-driven explanations of entrepreneurship. Journal of Business Venturing 19(3): pp. 343-358.

Van de Ven, A. H. (2005). Running in Packs to Develop Knowledge-Intensive Technologies. MIS Quarterly, 29(2): pp. 365-377.

Velamuri, S. R. \& Venkataraman, S. (2005). Why Stakeholder And Stockholder Theories Are Not Necessarily Contradictory: A Knightian Insight. Journal of Business Ethics, 61(3): pp. 249-262.

Venkataraman, S. (2002). Stakeholder value equilibration and the entrepreneurial process. Ruffin Series in Business Ethics: pp. 45-47.

Venkatesh, V., Morris, M. G., Davis, G. B., \& Davis, F. D. (2003). User acceptance of information technology: Toward a unified view. MIS Quarterly 27(3): pp. 425-478.

Venkatesh, V., Davis, F. D., \& Morris, M. G. (2007). Dead Or Alive? The Development, Trajectory And Future Of Technology Adoption Research. Journal of the Association for Information Systems 8(4): pp. 267-286.

Wade, M., \& Hulland, J. (2004). The resource-based view and information systems research: review, extension, and suggestions for future research. MIS Quarterly 28(1): pp. 107-142.

Walsham, G. (1995). Interpretive case studies in IS research: Nature and method. European Journal of Information Systems, 4(2): pp. 74-81.

Walter, J., Lechner, C., \& Kellermanns. F. W. (2007). Knowledge transfer between and within alliance partners: Private versus collective benefits of social capital. Journal of Business Research, 60(7): pp. 678-710.

Wang, P. (2009). Popular Concepts beyond Organizations: Exploring New Dimensions of Information Technology Innovations. Journal of the Association for Information Systems, 10(1): pp. 1-30

Wastell, D. G., \& McMaster, T. (2008). Organizational dynamics of technologybased innovation: diversifying the research agenda. Journal of Information Technology, 23(2): pp. 63-70. 
Weber, R. (2003). Theoretically speaking. MIS Quarterly, 27(3): pp. iii-xii.

Williams, M. D., Dwivedi, Y. K., Lal, B., \& Schwarz, A. (2009). Contemporary trends and issues in IT adoption and diffusion research. Journal of Information Technology, 24(1): pp. 1-10.

Wright, M. \& Burrows, A. (2006). Entrepreneurship and Management Buy-outs. In Casson, M., Yeung, B., Basu, A., \& Wadeson, N. (Eds.). The Oxford Handbook of Entrepreneurship. Oxford, Oxford University Press.

Zahra, S. A. (1991). Predictors and Financial Outcomes of Corporate Entrepreneurship: An Exploratory Study. Journal of Business Venturing, 6(4): pp. 259-285.

Zmud, R. W. (1982). Diffusion of Modern Software Practices: Influence of Centralization and Formalization." Management Science, (pre-1986) 28(12): pp. 1421-431. 
APPENDICES 


\section{Appendix A - SIM Human Ethics Committee Application}

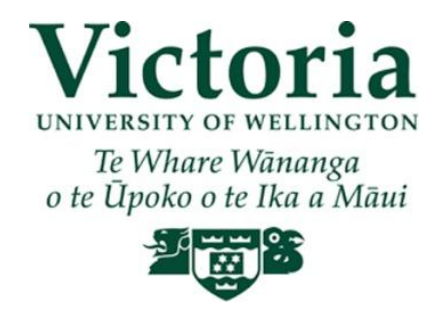

Application for Approval of Research Projects

Please email applications to your supervisor, who will then email it to a SIM HEC member for a preliminary review.

Note: The Human Ethics Committee attempts to have all applications approved within 6 working days, but a longer period may be necessary if applications require substantial revision.

1 NATURE OF PROPOSED RESEARCH:

(a) Student Research

(b) If Student Research Degree PhD Course Code INFO690

(c) Project Title: Factors Influencing Resource Acquiring Relationships Between the Entrepreneurial Actor and Network Broker:

An IT Perspective

2 INVESTIGATORS:

(a) Principal Investigator

Name Anthony (Tony) Thistoll

e-mail address tony.thistoll@vuw.ac.nz

School/Dept/Group SIM

(b) Other Researchers

Name Position - Non

(c) Supervisor (in the case of student research projects)

Dr David Pauleen

Senior Lecturer

Dr Val Hooper

Senior Lecturer

\section{DURATION OF RESEARCH}

(a) Proposed starting date for data collection - After HEC approval has been 
granted.

(Note: that NO part of the research requiring ethical approval may commence prior to approval being given)

(b)Proposed date of completion of project as a whole 31 May 2010

4 PROPOSED SOURCE/S OF FUNDING AND OTHER ETHICAL CONSIDERATIONS

(a) Sources of funding for the project

Please indicate any ethical issues or conflicts of interest that may arise because of sources of funding

e.g. restrictions on publication of results

Victoria University of Wellington Postgraduate Scholarship for $\mathrm{PhD}$ Study

(b) Is any professional code of ethics to be followed

$\mathbf{N}$

If yes, name

(c) Is ethical approval required from any other body

$\mathbf{N}$

If yes, name and indicate when/if approval will be given

\section{DETAILS OF PROJECT}

Briefly Outline:

(a) The objectives of the project

1. To determine the factors that drive, enable and inhibit resource acquiring relationships between Information Technology (IT) entrepreneurs / entrepreneurial managers within entrepreneurial firms and network brokers.

2. To identify any similarities, differences and complementarities between the parties in regards to the identified drivers, enablers and inhibitors

3. To identify any similarities, differences and complementarities between non technology based innovation compared with 
Information Technology based innovation in regards to the identified drivers, enablers and inhibitors

(b) Method of data collection

Participants will be asked a series of questions through the use of semistructured interviews. These interviews will be recorded and transcribed by the researcher. Each transcription will be forwarded to the respective interviewee for their confirmation.

(c) The benefits and scientific value of the project

It is hoped that through this research, Information Technology entrepreneurs might become more skilled, efficient and effective in their management of resource acquiring relationships and contribute to the success of future technology based innovation efforts i.e. through providing guidelines, tip sheet.

(d) Characteristics of the participants

The sample will be split into two streams: Stream A associated with nontechnology based innovation and Stream B associated with Information Technology based innovation. This will allow for any noticeable differences between the two to be identified and isolate any drivers, enabler and inhibitors specific to IT innovation.

Within the sample streams, there will be two main types of people interviewed, entrepreneurs/entrepreneurial managers within entrepreneurial firms; and network brokers who broker resource acquiring relationships.

Participants within the study will be at middle to senior management level, and given the focus on entrepreneurial managers, participants may include Chief Executives and/or company founders. Exact details of participants will not be known until the research study progresses and is complete.

(e) Method of recruitment

To allow for the possibility to incorporate an analysis of the relationship dyad and to cater for a split sample between non-technology based innovation and IT based innovation, theoretical sampling will be used. Theoretical sampling is where data is collected from people that are best suited to understanding the research problem and research question and will maximise the opportunity to develop concepts. Research will continue until theoretical saturation is achieved. 
To allow for theoretical saturation to be achieved, the two sample streams will be researched in groups of 10 participant interviews, which hopefully include 5 entrepreneurial actor and 5 broker interviews associated with 5 resource acquiring relationships. It is expected that a minimum of 40 interviews will be required.

Emphasis will be placed on ICT organisations where the innovation is primarily based around the IT artefact and where the firm needs to acquire external resource to enable the innovation, for example:

\section{(names removed to protect confidentiality)}

Participants and resource acquiring relationships researched will range from those undertaken within small enterprises to large corporations. Participants will be asked to provide referrals to an entrepreneurial manager or broker who they may have dealt with.

(f) Payments that are to be made/expenses to be reimbursed to participants

None

(g) Other assistance (e.g. meals, transport) that is to be given to participants

None

(h) Any special hazards and/or inconvenience (including deception) that participants will encounter

None

(i) State whether consent is for: (Please indicate as many as it applies)

(i) the collection of data $\mathbf{Y}$

(ii) attribution of opinions or information $\mathbf{N}$

(iii) release of data to others $\mathbf{N}$

(iv) use for a conference report or a publication $\mathbf{Y}$

(v) use for some particular purpose (specify) $\mathbf{Y}$

Transfer of learning to students through lectures and course content

Attach a copy of any questionnaire or interview schedule to the application

(j) How is informed consent to be obtained (see paragraphs 4.31(g), 5.2, 5.5 and 5.61 of the Guidelines) 
(i) the research is strictly anonymous, an information sheet is supplied and informed consent is implied by voluntary participation in filling out a questionnaire for example (include a copy of the information sheet)

\section{$\mathbf{N}$}

(ii) the research is not anonymous but is confidential and informed consent will be obtained through a signed consent form (include a copy of the consent form and information sheet)

\section{Y}

(iii) the research is neither anonymous nor confidential and informed consent will be obtained through a signed consent form (include a copy of the consent form and information sheet)

\section{$\mathbf{N}$}

(iv) informed consent will be obtained by some other method (please specify and provide details)

\section{$\mathbf{N}$}

With the exception of anonymous research as in (i), if it is proposed that written consent will not be obtained, please explain why

(k)If the research will not be conducted on a strictly anonymous basis state how issues of confidentiality of participants are to be ensured if this is intended. (See paragraph 4.3.1(e) of the Guidelines). (e.g. who will listen to tapes, see questionnaires or have access to data). Please ensure that you distinguish clearly between anonymity and confidentiality. Indicate which of these are applicable.

(i) access to the research data will be restricted to the investigator

(ii) access to the research data will be restricted to the investigator and their supervisor (student research)

\section{Y}

(iii) all opinions and data will be reported in aggregated form in such a way that individual persons or organisations are not identifiable

\section{Y}

(iv) Other (please specify)

(1) Procedure for the storage of, access to and disposal of data, both during and at the conclusion of the research. (see section 7 of the guidelines). Indicate which are applicable: 
(i) all written material (questionnaires, interview notes, etc) will be kept in a locked file and access is restricted to the investigator

Y

(ii) all electronic information will be kept in a password-protected file and access will be restricted to the investigator

\section{$\mathbf{Y}$}

(iii) all questionnaires, interview notes and similar materials will be destroyed:

(a) at the conclusion of the research

$\mathbf{N}$

$\underline{\underline{\text { or }}}$ (b) 5 years after the conclusion of the research

$\mathbf{Y}$

(iv) any audio or video recordings will be returned to participants and/or electronically wiped Y

(v) other procedures (please specify):

If data and material are not to be destroyed please indicate why and the procedures envisaged for ongoing storage and security

(m)Feedback procedures (See section 8 of the Guidelines). You should indicate whether feedback will be provided to participants and in what form. If feedback will not be given, indicate the reasons why.

A summary of the research findings will be made available to participants for their information, where they have indicated they wish to receive a copy.

(n)Reporting and publication of results. Please indicate which of the following are appropriate. The proposed form of publications should be indicated on the information sheet and/or consent form.

(i) publication in academic or professional journals Y

(ii) dissemination at academic or professional conferences Y

(iii) deposit of the research paper or thesis in the University Library (student research)

Y

(iv) a case study used for teaching purposes

(v) other (please specify)

Transfer of learning to students through lectures and course content 
Signature of investigators as listed on page 1 (including supervisors) and Chair of SIM HEC.

NB: All investigators and the Chair of SIM HEC must sign the form, then send it to the SIM HEC administrator for filing once the electronic application has been approved.

Date

Date.

Date

Supervisors:

Date

Date

Chair of SIM HEC:

Date 


\section{Appendix B - SIM Human Ethics Committee Approval}

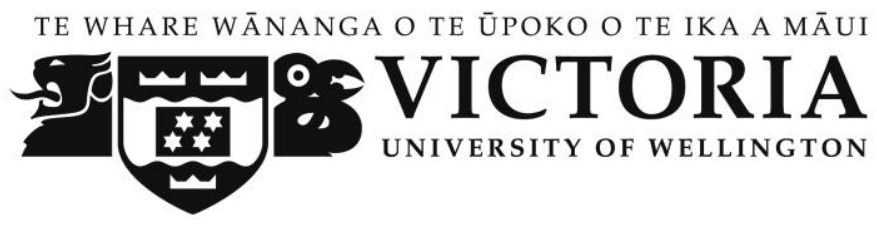

\section{SIM HUMAN ETHICS COMMITTEE}

Comments on Application for Human Ethics Approval

\section{Date: $20 / 11 / 2008$}

Re: Factors Influencing Resource Acquiring Relationships Between the

\section{Entrepreneurial Actor and Network Broker: An IT Perspective}

Principal Researcher: Tony Thistoll

Supervisor (student research): David Pauleen, Val Hooper

Ref No: \#16196

Your HEC application has been reviewed and the Committee's decision is the following:

\section{Application accepted.}

Human Ethics Approval valid until: (Date: as in application or no more than 3 years) Thank you for the amendments you have made to your HEC application. These meet the committee's required changes. On behalf of the HEC Chair I am authorised to inform you that you may now proceed with your application. You may begin your data collection immediately but please note that a hard copy of your application signed by both you and your supervisor (or other researchers involved for staff applications) is required within one month before approval can be recorded. This should be submitted to me at: EA121, School of Information Management, Kelburn Parade, Kelburn Campus.

Tiso Ross

HEC Administrator

SIM Human Ethics Committee. 


\section{Appendix C - Doctoral Research Information Sheet (entering the field)}

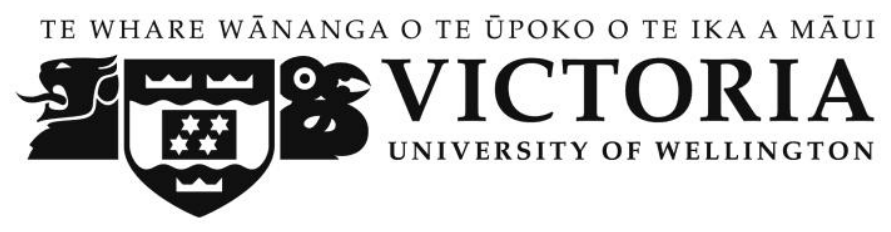

\section{Doctoral Research Information Sheet Factors Influencing Resource Acquiring Relationships Between the Entrepreneurial Actor and Network Broker: An IT Perspective}

This doctoral research is being conducted by Mr Tony Thistoll a $\mathrm{PhD}$ student at the School of Information Management, Victoria University, Wellington, New Zealand. Focus for this research is on how entrepreneurial managers/firms seek out and leverage resources they do not have or even know about in order to bring their innovation to market. One particular relationship that has been found to be extremely powerful and critical to the success of such resource acquiring activities is the relationship between the entrepreneur/entrepreneurial managers and network brokers. The broker is often seen as a conduit, a pipe, through which previously unseen resources may flow.

This doctoral research seeks to determine the factors that drive, enable and inhibit resource acquiring relationships between entrepreneurs/entrepreneurial managers within entrepreneurial firms and network brokers. The expected 40 plus participants in the study are being split into two streams, stream A associated with non-technology based innovation and stream B associated with Information Technology based innovation. This will allow for any noticeable differences between the two to be identified and isolate any drivers, enablers and inhibitors specific to IT innovation. It is hoped that though gaining a better understanding of the factors impacting on these relationships, entrepreneurs and managers within entrepreneurial firms may be become more skilled, efficient and effective in their management of resource acquiring relationships, and contribute to the success of future innovation efforts.

The interview will be recorded and take approximately 1 hour. All interview notes, recordings and transcripts will be kept in confidence and destroyed within 5 years of the 
conclusion of the doctoral research. You will be offered the opportunity to verify your interview transcript for accuracy. No information that you provide will be attributed to you or your organisation, and neither you nor your organisations will be identifiable in any way. You will be asked to confirm that you have authority to participate / or have obtained approval from an appropriately authorised manager to participate in this study.

You may withdraw from this research within a four week period from the date of the interview without having to give reason. Any information obtained up to this date of withdrawal will be excluded from the study and destroyed. It is envisaged that research findings will be published in articles and conference papers and the finished thesis will be available on the internet through the Victoria University Library. A summary of research findings will also be made available to participants. Approval for this research has been given by the Human Ethics Committee of Victoria University of Wellington. Should you have any questions about the study please feel free to contact, either:

Tony Thistoll (Researcher)

Easterfield Bldg, Kelburn Pde,

Wellington, New Zealand

Phone +64 21446270

Email: tony.thistoll@ vuw.ac.nz
Dr Val Hooper (Supervisor)

Easterfield Bldg, Kelburn Pde, Wellington New Zealand

Phone +64 44635020

Email: val.hooper@vuw.ac.nz 


\section{Appendix D - Doctoral Research Information Sheet (Substantive Topic)}

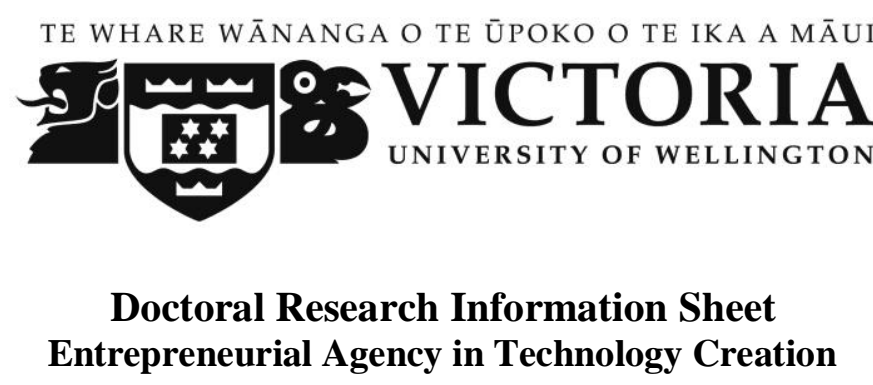

This doctoral research is being conducted by Mr Tony Thistoll a $\mathrm{PhD}$ student at the School of Information Management, Victoria University, Wellington, New Zealand. The research problem emanates from the practitioner community where single individuals or entrepreneurs endeavouring to bring an Information and Communication Technology (ICT) based innovation into being and widespread use realise that they cannot do so by themselves. How these entrepreneurial actors go about securing and using the resources they need, in order to act upon the entrepreneurial opportunity and achieve their aim, is at the core of the phenomena being investigated.

The entrepreneur though his/her actions or agency, as it is commonly referred to, are located in and participate in, social structures such as personal social networks and firms. In these social structures they interact with other people in order to secure and combine the resources required to bring their entrepreneurial vision into being. These interactions are a specific focus of the research study. By gaining a better understanding of the factors impacting on the social interactions, it is hoped that entrepreneurs and managers within entrepreneurial firms may be become more skilled, efficient and effective in their activities and processes needed to bring technology creations into being.

The interview will be recorded and take approximately 1 hour. All interview notes, recordings and transcripts will be kept in confidence and destroyed within 5 years of the conclusion of the doctoral research. You will be offered the opportunity to verify your interview transcript for accuracy. No information that you provide will be attributed to you or your organisation, and neither you nor your organisations will be identifiable in any way. You will be asked to confirm that you have authority to participate / or have obtained approval from an appropriately authorised manager to participate in this study. 
You may withdraw from this research within a four week period from the date of the interview without having to give reason. Any information obtained up to this date of withdrawal will be excluded from the study and destroyed. It is envisaged that research findings will be published in articles and conference papers and the finished thesis will be available on the internet through the Victoria University Library. A summary of research findings will also be made available to participants. Approval for this research has been given by the Human Ethics Committee of Victoria University of Wellington. Should you have any questions about the study please feel free to contact, either:

Tony Thistoll (Researcher)

Easterfield Bldg, Kelburn Parade,

Wellington, New Zealand

Phone +64 21446270

Email: tony.thistoll@ vuw.ac.nz
Dr Val Hooper (Supervisor)

Easterfield Bldg, Kelburn Parade,

Wellington New Zealand

Phone +64 44635020

Email: val.hooper@vuw.ac.nz 


\section{Appendix E - Doctoral Research Consent \& Signoff Form}

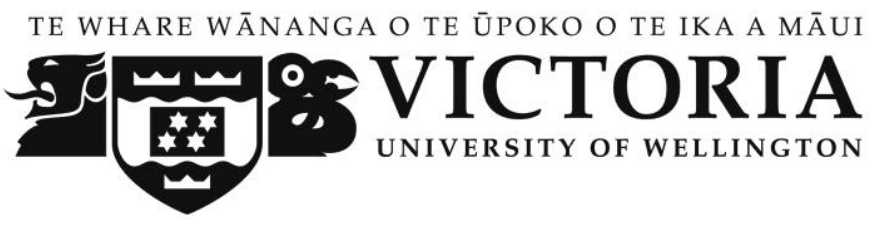

\section{Doctoral Research Consent \& Signoff Form}

\section{Entrepreneurial Agency in Technology Creation}

I have been given an Information Sheet about this doctoral research and understood the explanation of this research. I have had the opportunity to ask questions and have them answered to my satisfaction.

I understand that my participation will involve a semi-structured interview of approximately 60 minutes in length.

I grant permission for the interview to be recorded on the understanding that I shall be sent a copy of the transcription for confirmation of the accuracy of the transcribed data.

I understand that I may withdraw from this research within 4 weeks from the date of the interview without having to give reasons. Any information obtained up to the date of withdrawal will be excluded from the study and destroyed.

I understand that any transcripts and interview notes resulting from the interview will be kept confidential to the researcher, transcriber and research supervisors.

I understand that any information or opinions I provide will be kept confidential and reported only in an aggregated/non-attributable form and neither myself nor my organisation will be identifiable in any way.

I have authority to participate / or I have obtained and can provide approval from an appropriately authorised manager for my participation in this Doctorial research study

I understand that all interview notes, audio recordings and similar materials will be kept in confidence and destroyed within 5 years from the conclusion of this doctoral research.

I understand that the data I provide may be used for academic purposes as identified below:

(i) Publication in academic or professional journals

(ii) Dissemination at academic or professional conferences

(iii) Transfer of learning to students through lectures and course content

(iv) Deposit of the thesis in the University Library 
$\square \quad$ I would like to receive a summary of the key findings of this research when it is completed

$\square \quad$ On that basis I agree to take part in this doctoral research.

Name:

Signed:

Date:

SCHOOL OF INFORMATION MANAGEMENT FACULTY OF COMMERCE AND ADMINISTRATION 


\section{Appendix F - Interview Guide and Schedule}

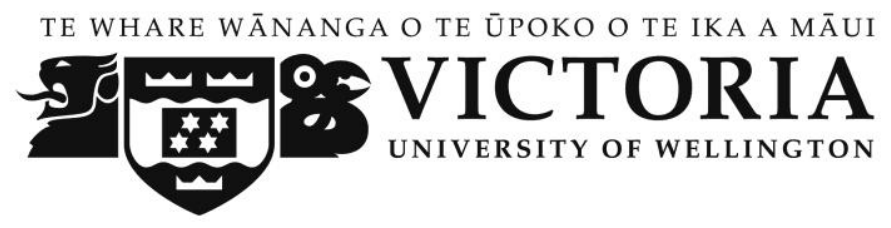

Interview Guide and Schedule

Factors Influencing Resource Acquiring Relationships Between the Entrepreneurial Actor and Network Broker: An IT Perspective

\section{General Introduction}

Thank you for agreeing to participate in my doctoral Research Study. As stated within the information sheet, this research seeks to determine the factors that drive, enable and inhibit resource acquiring relationships between entrepreneurs / entrepreneurial managers within entrepreneurial firms and network brokers. Questions will be framed in such a way as to ask you how you made sense of issues that you experienced, what perceptions and / or beliefs you held at that time and later upon reflection. I would be grateful if following the interview you could provide an introduction to an entrepreneurial manager or broker who you may have dealt with.

The interview will be recorded. The recording will be transcribed as soon possible after this meeting, and a copy sent to you for your review and comment. Please feel free to ask for the recording to be turned off at any time during the interview.

I shall start recording now if that's alright?

\section{Interview questions:}

1. Innovation \& Context

- Can you tell me about the innovation?

- How would you describe what your organisation does?

- What problem does the innovation solve?

- How did your involvement with the innovation come about and what role did you play?

2. Resources

- What resources were available to you and the firm in order to bring the innovation to market?

- What resources were needed in order to bring the innovation to market?

- What strategies did you put place in order to seek out and acquire the resources required? (If not you, what strategies did the organisation put in place?)

3. Drivers 
- How did the relationship (and/or relationships...specific to interview...) come about?

- What were you trying to achieve from the relationship?

- What do you think the other party was trying to achieve?

4. Relationship

- How did the relationship have a positive influence on the innovation?

- What were the nuances of the relationship that you had to come to terms with?

- How did you come to understand / make-sense of these nuances?

- Were there any particular techniques, skills or experiences you used?

- What were your personal feelings and beliefs regarding the opportunity / relationship?

- Was there anything strange or unique with the relationship?

- How did this come about?

$\circ$ How was it managed - attended to?

- How did the relationship end up impacting on you over time - both positively and negatively?

- How did the relationship end up impacting on the innovation over time - both positively and negatively?

- From your viewpoint/understanding how did the relationship end up impacting on the other party over time - both positively and negatively?

- Was there a need to end the relationship? If so, why do you think it needed to come to an end?

5. Enablers

- What type of things helped the relationship to become established?

- What type of things helped the relationship grow?

- What type of things helped the relationship to end (if it did)?

6. Inhibitors / Barriers

- Can you describe any barriers that you experienced in establishing the relationship?

- How were they resolved or come to be accepted?

- Can you describe any barriers that you know of that the other party experienced in establishing the relationship

- Can you describe any barriers that you experienced in maintaining the relationship?

- How were they resolved or come to be accepted?

- Can you describe any barriers that you know of that the other party experienced in establishing - maintaining the relationship

- Can you describe any barriers that you experienced in terminating the relationship (if this was the case)?

- How were they resolved or come to be accepted?

- Can you describe any barriers that you know of that the other party experienced in terminating the relationship 
7. Reflection

- As time passed, how did your perceptions and understanding of the relationship (and/or ...specific to interview...) change over time?

- On reflection is there anything you would have done differently?

- Has your approach changed based on your experiences?

○ How?

- Again on reflection, did you get what you wanted out of the relationship?

○ Did the other party get what they wanted?

8. Innovation

- What you went through and experienced, was that normal? Do you think it would be the same in other firms? Industries? Product innovations?

\section{Wrap-up}

At the conclusion of the interview, the participant will be asked if they have any further comments they would like to make or information they would like to discuss.

The participant will be asked to consider who else may be appropriate to interview for the doctoral research and a request made for a referral to be made.

They will be thanked for their time and asked if they are available for any follow-up enquiries. 


\section{Appendix G - Article summary form template}

\section{File Reference :}

\begin{tabular}{|l|l|}
\hline Purpose & \\
\hline Target Audience & \\
\hline Claims & \\
\hline Achievement & \\
\hline Originality / Value & \\
\hline Relevancy to my & \\
Research & \\
\hline Primary Topic & \\
\hline Secondary Topic & \\
\hline Additional Key Words & \\
\hline Theoretical Approach & \\
\hline Epistemology & \\
\hline Methodology & \\
\hline Type of Research & \\
\hline Sample Size & \\
\hline Industry Researched & \\
\hline Place of Research & \\
\hline $\begin{array}{l}\text { Questionnaire Survey } \\
\text { attached }\end{array}$ & \\
\hline Model Provided & \\
\hline Model Tested & \\
\hline Variables & \\
\hline
\end{tabular}

\section{Definitions}

\section{Key Points}

For Follow-up

\section{My Comments / Observations}




\title{
Appendix H - Abridged articles summary example
}

\author{
File Reference : $\quad$ (Van de Ven 2005)
}

Van de Ven, A. H. (2005). "RUNNING IN PACKS TO DEVELOP KNOWLEDGE-INTENSIVE TECHNOLOGIES." MIS Quarterly 29(2): 13.

\begin{tabular}{|c|c|}
\hline Purpose & $\begin{array}{l}\text { Expand the commercialisation debate to include the need for collective } \\
\text { actions and the political savvy needed to manage these relationships }\end{array}$ \\
\hline Target Audience & Scholars and Practitioners \\
\hline Claims & $\begin{array}{l}\text { To succeed, firms are advised to focus on building their distinctive } \\
\text { competencies, outsource the rest, and become nodes in value chain } \\
\text { networks. This shifts the level of competition from between individual } \\
\text { firms to between networks of firms. In these networks, individual firms } \\
\text { or entrepreneurs seldom have the resources, power, or legitimacy to } \\
\text { produce change alone. }\end{array}$ \\
\hline Achievement & $\begin{array}{l}\text { Technological innovation is fundamentally a collective action process of } \\
\text { building an infrastructure that reduces the time, costs, and risks for each } \\
\text { participating member. Knowledge-intensive technologies seldom } \\
\text { provide sufficient proprietary benefits for sustainable competitive } \\
\text { advantage to individual organizations; instead, they provide collective } \\
\text { benefits for cooperative advantage. Developing and commercializing } \\
\text { these new products and services require resources that are beyond the } \\
\text { capabilities of any one firm. }\end{array}$ \\
\hline Originality / Value & Seminal \\
\hline $\begin{array}{l}\text { Relevancy to my } \\
\text { Research }\end{array}$ & Highly Relevant \\
\hline Primary Topic & Entrepreneurship \\
\hline Secondary Topic & Knowledge management, infrastructure, networks. \\
\hline \multicolumn{2}{|l|}{ Additional Key Words } \\
\hline Theoretical Approach & industrial infrastructure \\
\hline Epistemology & Interpretivist \\
\hline Methodology & Qualitative \\
\hline Type of Research & Research Essay \\
\hline Sample Size & N/A \\
\hline Industry Researched & N/A \\
\hline Place of Research & N/A \\
\hline $\begin{array}{l}\text { Questionnaire Survey } \\
\text { attached }\end{array}$ & No \\
\hline Model Provided & Yes \\
\hline Model Tested & No \\
\hline Variables & $\begin{array}{l}\text { Expand the commercialisation debate to include the need for collective } \\
\text { actions and the political savvy needed to manage these relationships }\end{array}$ \\
\hline
\end{tabular}

\section{Definitions}

Knowledge - intensive Services include all economic activities whose output (1) is not a product or construction, (2) is generally consumed at the time it is produced, and (3) provides added value in forms (such as convenience, amusement, timeliness, comfort, or health) that are essentially intangible concerns of its purchaser" (Quinn 1992, pp. 5-6). "The common element of services is the predominance of managing intellect-rather than managing physical things-in creating their value-added."

Technology itself is gaining a new meaning. Initially viewed as a physical artifact, the definition of technology is broadening to include the body of knowledge that is embodied in the design or architecture of the artifact (Layton 1986) 


\section{Key Points}

The knowledge and information necessary for developing and commercializing an innovation transcends the borders of individual firms, industries, and countries (p.366),

Knowledge-intensive services have become the dominant form of work in the industrialized world. Quinn et al. (1997) report that three-fourths of all economic activity is based on managing intellectual activities and the interface to their service outputs.

As a result, knowledge-intensive technologies have no nationality (Murtha et al. 2001). Such global distribution of knowledge and work has been made possible by (1) information technologies that enable division, distribution, and coordination of work across national boundaries, (2) the lowering of institutional trade barriers across countries adopting policies of economic liberalization, and (3) global diffusion of competencies to do the same work. (p.366).

This knowledge is socially constructed, meaning that it is an evolving product of human interactions and understandings at the time and place the artifact was created (Bijker et al. 1987). In this sense, a technical artifact represents a time capsule of the body of knowledge, institutions, and social constructions instantiated in the artifact at the time of its construction.

Quinn et al. (1997, pp. 228-229) point out that this competition takes place not among individual firms, but rather among "spider's webs" of organizations, which are competing work design networks consisting of firms that have specialized knowledge and are geographically dispersed yet need to interact often and in depth

For Follow-up

(Layton 1986) - Obtained

Bijker, W. E., Hughes, T. P., and Pinch, T. (Eds.). The Social Construction of Technological Systems: New Directions in the Sociology and History of Technology, MIT Press, Cambridge, MA, 1987.

\section{My Comments / Observations}

This article has the potential to become the core theory or the foundation for my research. The running in packs analogy makes me wonder about who is the pack leader? Is that the systems integrator or the community owners?

Need to follow-up on who cites the article - have found one Cho and Mathaissen (2007).

My master research focused on the management of network ties between external to the venture one aspect I had no specifically commented on or identified was political savvy it was there but not made explicit. The management of the rolodex was an example.

Article starts to answer - what IS Entrepreneurship is 


\section{Appendix I - Conceptual codes from reading for coding sensitivity}

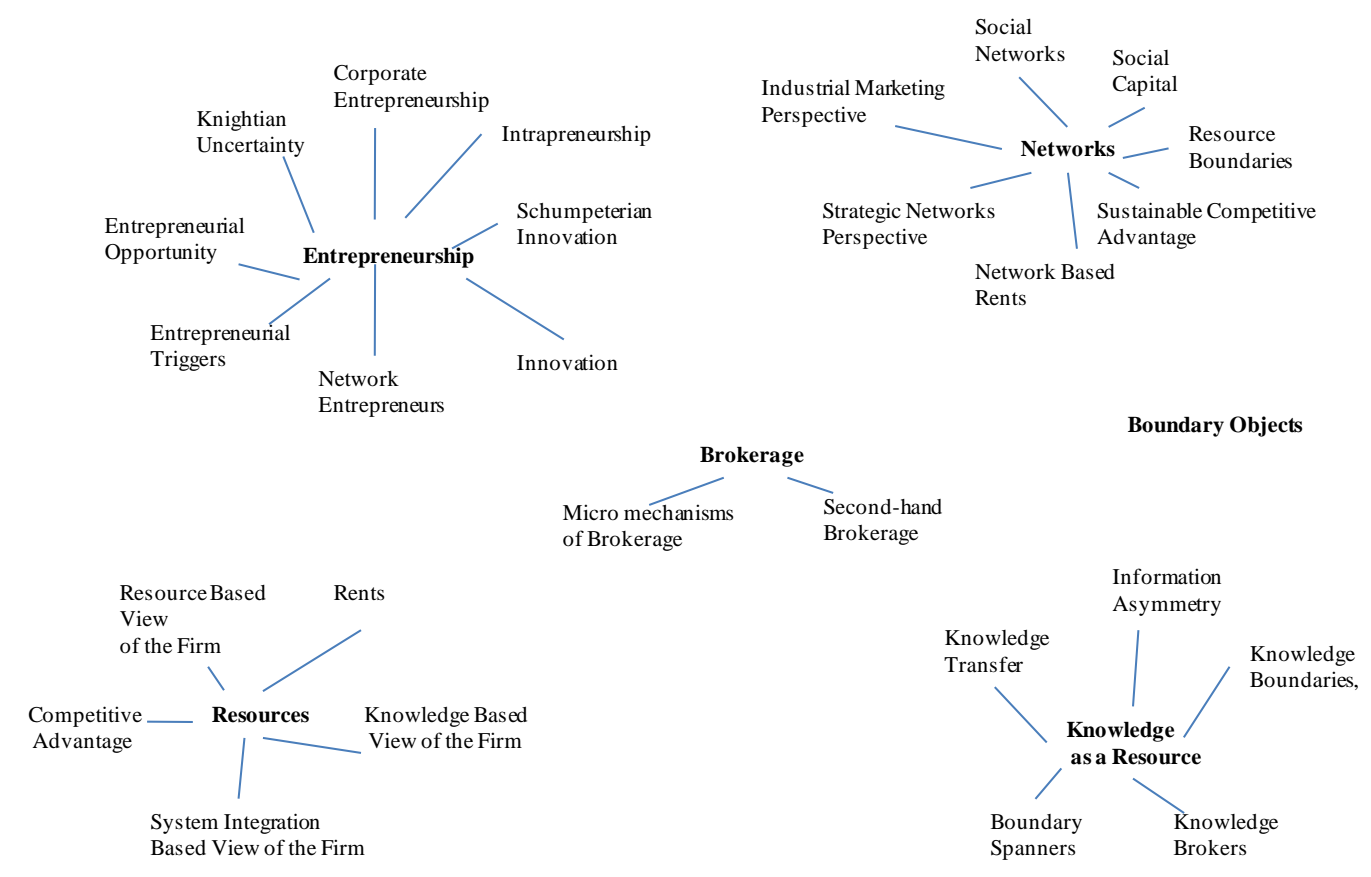




\section{Appendix J- Example of memos made during coding}

\section{Example 1 - Clear distinction - two business people and five developers}

Participant makes a very clear distinction between the commercial business people and the five developers. They are seen to be very different!

\section{Example 2 - Connecting into a central hub}

The participant is placing high importance on the ability to have a direct connection into a central hub (name removed). They see that by having this one central connection they can have access to a multitude of end relationships.

This is similar to the concepts in the (name removed) interview with a client service engagement manager provides an access point to the collective learning and networks that (name removed) have available to it throughout the world.

This is also similar to the interview (I-10) where they are providing a product innovation that can link multiple parties together and provides interconnection system to connect disparate learning management systems. I am just recalling a personal conversation at the end of the that interview, interviewee (I-10) where the participant and I were talking about network and interconnection issues and the participant said how good it was to talk to somebody that got it. By this I think he is meaning that he was feeling alone in pushing something that not many people got they could not see how it all came together and interconnected connected. This is similar to some of the concepts being discussed in the spiderweb analogy where business partners cannot see how the spiders Web is formed which the entrepreneurs and boundary spanner seem to be able to do. Is this a key differentiator?

\section{Example 3 - Continue to guide - read direct}

While the entrepreneurial agent makes reference to them staying involved in an innovation in order to guide it, this can also be seen as them staying involved in order to direct activities.

\section{Example 4 - Designer - key theoretical code (question mark)}

The entrepreneurial agent is primarily the designer of the master solution, is that their key role and skill set?

As I analyse the data during this phase, I am drawn to the possibility of the entrepreneurial action being the designer and director. These two aspects are heavily present in the first two stages it will be interesting to see if they come through in the next stages. 


\section{Example 5 - Focusing}

The entrepreneurial agent does not have the time and resources to chase every rainbow. They must focus and priorities their resources including their own "mind space"

\section{Example 6 - Is interconnecting a key characteristic of IT Innovation}

Is interconnecting a key characteristic of what makes IT innovation different. There are numerous references occurring within the data to show how IT innovation is layered (i.e. the ISO model) but it also must be connected to things both of the software and at the hardware layer.

Just like a Van de Ven says technology companies run in pacts and that no company exist solely by itself, and the work of people like Gulati and Lavie is heavily focused on alliances technology alliances, these alliances work at the technology layer i.e. Bluetooth and the blue tooth stack, in the last couple of days I have looked at the home networking stack associated with things like LCD TVs. IT innovation must interconnect within a stack. This also means there must be demarcation points.

\section{Example 7 - Key concept reinforcement - it is about being the visionary and then directing the resources}

This participant is reiterating a key point may by other as I have picked up on. In that they are primarily responsible for setting the vision and directing the resources to make it happen

Others have contributed and added their contribution

Delivering on the entrepreneurial vision is not something that the entrepreneurial agent does alone, they need others to contribute and add to what they are doing.

This could be like the whole Web 2.0 thing. Where the power is to harness the community and captures some of their input along the way

\section{Example 8 - Trapped - unknown - uncertain end point}

This entrepreneur did not have a clear idea as to long it is going to take to develop and commercialise his innovation. As indicated by this participant, the endpoint keeps on moving out, with the goal being to sell the business was substantial profit the entrepreneur can be seen to be locked into the venture until this point is reached. This participant also talks about his vision of a successful innovation is when he exits and sells it for lots of money. These are really interesting points how does the entrepreneur exit, what is that process and who helps them. This is a potential aspect for further follow-up? 